\title{
MOMENTS OF TRANSITION
}

\author{
by \\ Aviv Sarner \\ Bachelor of Architectural Science (Honours), Ryerson University, 2014
}

\author{
A design thesis project \\ presented to Ryerson University \\ in partial fulfillment of the \\ requirements for the degree of \\ Master of Architecture \\ in the program of
}

Architecture

Toronto, Ontario, Canada, 2016

(c) Aviv Sarner, 2016 
ii MOMENTS OF TRANSITION 


\section{AUTHOR'S DECLARATION}

I hereby declare that I am the sole author of this thesis. This is a true copy of the thesis, including any required final revisions, as accepted by my examiners.

I authorize Ryerson University to lend this thesis to other institutions or individuals for the purpose of scholarly research.

I further authorize Ryerson University to reproduce this thesis by photocopying or by other means, in total or in part, at the request of other institutions or individuals for the purpose of scholarly research.

I understand that my thesis may be made electronically available to the public. 
iv I MOMENTS OF TRANSITION 


\section{ACKNOWLEDGEMENTS}

In preparing this thesis, I have been fortunate to have received the encouragement and guidance of my professors, friends, family and colleagues, all of whom deserve my gratitude.

I would like to particularly thank Masha Etkind for her invaluable help as my thesis supervisor. Throughout the entire process, she was generous with her time, patience, guidance and insight. She helped shape the way I think today and the future architect I will become. I greatly appreciated her devotion and for pushing me out of my comfort zone, making me think differently from the way I normally do. Masha is a true role model for me and I feel lucky to have been able to be guided by her.

I would also like to thank George Kapelos for his support and counsel. He always made himself available, helping me expand my thinking in order to take my thesis further and in a better direction. George was an important source of positive energy and reinforced my desire to succeed with this thesis and beyond.

Both Masha and George have guided me since my initial undergraduate years -- George from my first year and Masha from my second. They both have been such a significant part of my journey. I cannot thank them enough and will always cherish the memory of their involvement in my studies.

In addition, I would like to thank those closest to me - my husband Itzik; my parents Galya and Robert and my siblings Etye and Shani and my brother-in-law Tzahi - for their patience and understanding over the past seven years. This thesis would not have been possible without them. I will forever be thankful for their incredible devotion. They often gave up things due to my studies and pushed me to achieve my goal. It's no exaggeration to say I would never have succeeded without their love and support. 
vi MOMENTS OF TRANSITION 
This thesis is dedicated to my late grandmother, Frances Sarner. She always encouraged me to pursue my dreams and to push myself to the ultimate limits. It was her wish to see me graduate as an architect.

This is for you, Grandma. 
viii MOMENTS OF TRANSITION 


\section{ABSTRACT}

Transitional moment conditions exist almost everywhere around us, and are an effective device in defining a place. It is through enhancing these thresholds, and defining a clearer, vivid environment that creates places from spaces, that facilitates variety through visual clarity, hierarchy, and synthesis necessary at the urban and architectural levels. This thesis will argue that creating an engaging and fulfilling environment architecturally and on an urban level, is highly dependent on the successful threshold conditions in various degrees of complexity. 


\section{TABLE OF CONTENTS}

Author's Declaration iii

Acknowledgements $\quad \mathrm{V}$

Abstract ix

Table of Contents $x$

List of Figures $\quad$ xii

01 Prologue

Design + Research methodology 1

02 Urban Space: Morphology

Solid/void relationship in $20^{\text {th }}$ century urban form 4

2.1 Power of the void 8

$2.2 \quad$ Nolli's city plan 11

$\begin{array}{lll}2.3 & \text { Soft space / Hard space } & 12 \\ 2.4 & \text { Hierarchy of spaces and urban sequence } & 11\end{array}$

03 Space and Place

Space

3.1 Defining space 16

32 Space defining elements 19

$\begin{array}{ll}3.2 & \text { Space defining elements }\end{array}$

$\begin{array}{lll}3.3 & \text { The experience of space } & 21\end{array}$

3.4 Spatial awareness and conceptual space

Place

$\begin{array}{ll}3.5 & 22\end{array}$

3.6 Sense of place 24

3.7 Genius loci 25

$\begin{array}{lll}3.8 & \text { The experience of place } & 25\end{array}$

$\begin{array}{lll}3.9 & \text { Psychogeography } & 27\end{array}$

$\begin{array}{lll}3.10 & \text { From space to place } & 27\end{array}$

$\begin{array}{lll}3.11 & \text { Perception of space } & 30\end{array}$

$\begin{array}{lll}3.12 & \text { Movement and Spatial sequencing } & 31\end{array}$

04 Thresholds, Transition + Liminality

$4.1 \quad$ Defining thresholds 35

$\begin{array}{lll}4.2 & \text { A ritual } & 37\end{array}$

$\begin{array}{lll}4.3 & \text { Threshold roles } & 41\end{array}$

4.4 Transitional moments typology and precedents 42

- The triumphal passage 42

- Urban thresholds 44

- Intermediate passage: Interior to exterior 45

- Building as a threshold 46

- Perception of space 48

- Acknowledging the transition 50 
- Bridging the new and old 52

- Sensorial transitions 53

4.5 The sensual explored in transitions 54

4.6 A choreographed sequence 59

4.7 The process of transition 60

4.8 Transitions typology study and Design explorations 62

- Acknowledging the transition 64

- Perception of space 66

- Mikveh as a tool in exploring transitions 68

- Space defining elements 70

- Spatial sequencing method: thresholds variance 71

\section{Transformation and Water}

$5.1 \quad$ Cleansing, the roots of personal hygiene and bathing 76

- Bathing, a sequence, a daily a ritual 79

- Thermae: programmatic requirements 82

5.2 Water, science and the connection to body mind and soul 85

5.3 Sacred and profane - water as a means to attaining 87

spiritual and religious purity

- Immersion in water as part of a spiritual experience 88

5.5 The thermae as the new contemporary temple for the 90 body

\section{Urban Design Considerations}

6.1 Transformative experiences as amenities inserted within the 96 city's network

6.2 The thermae to be placed at the centre of civic life 98

6.3 Spirituality as a step towards health in the city 99

6.4 Premise for a site 103

6.5 Site selection criteria; the case for the post-industrial city 104

\section{Final Design Project: A Thermae}

7.1 Site existing conditions 112

7.2 Design Assumptions 116

$\begin{array}{lll}7.3 & \text { Path to 'another place': strategies } & 117\end{array}$

$\begin{array}{ll}7.4 & 119\end{array}$

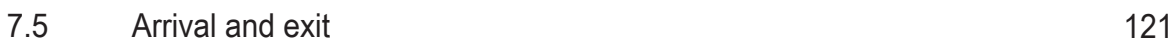

$\begin{array}{lll}7.6 & \text { Thermae; A sequence } & 126\end{array}$

08 Conclusion 145

09 References 146

10 Appendix

A The Thermae: case studies 150

B Immersion in religion; Christianity, Judaism 157 


\section{LIST OF FIGURES}

\section{PROLOGUE}

FIGURE 1.1 Entry threshold into Gallery of Micro-Hutong / standardarchitecture

Gallery of Micro-Hutong / standardarchitecture - 3. Retrieved September 15, 2016, from Archdaily, http://www.archdaily.com/775045/micro-hutong-standardarchitecture/5617890fe58ece 9 4b8000218-micro-hutong-standardarchitecture-photo

\section{URBAN SPACE: MORPHOLOGY}

FIGURE 2.1 Modernism's ideals affecting typical urban systems leading to inconsistent urban fabrics. Reprinted from Les Villes et les Formes: Sur I'Urbanisme Durable (p. 253), by Salat, S., Labbé, F., \& Nowacki, C., 2011 Paris: Hermann. Copyright 2011 by CSTB.

FIGURE 2.2 Comparison between Parma's 1830 dense urban fabric vs. Brasilia 1960 fractured urban fabrics.

Reprinted from Les Villes et les Formes: Sur I'Urbanisme Durable (p. 42), by Salat, S., Labbé, F., \& Nowacki, C., 2011 Paris: Hermann. Copyright 2011 by CSTB.

FIGURE 2.3 1925 Plan Voisin, Le Corbusier.

Reproduced from Le Corbusier by 'Architecture Theory.Net', 2014. <http://www.medienarchitektur. at/architekturtheorie/le_corbusier/2011_corbusier_links_de.shtml\#fu_contemporary>. Copyright 2014 by Architecture Theory.Net.

FIGURE 2.4 Le Corbusier's 1945 Saint-Die in France juxtaposed with the plan of Parma in Emilia. Reprinted from Collage City (p. 27,62), by C. Rowe and F. Koetter, 1984 Cambridge, MA. Copyright 1984 by the MIT Press. Reprinted with permission.

FIGURE 2.5 Symbols of modernism; Contemporary city, Le Corbusier.

Reprinted from Finding Lost Space (p. 6), by R. Trancik, 1986 New York, NY: Van Nostrand Reinhold Company. Copyright 1986 by Van Nostrand Reinhold Company.

FIGURE 2.6 Symbols of modernism; Modernism's ultimate symbol of failure, pruitt igoe housing, St. Louis, MI, 1950; later demolished in 1972.

Reprinted from Les Villes et les Formes: Sur I'Urbanisme Durable (p. 77), by Salat, S., Labbé, F., \& Nowacki, C., 2011 Paris: Hermann. Copyright 2011 by CSTB.

FIGURE 2.7 Nolli's 1748 city plan of Rome conveying its innate patterns of public and private space and their relationship in relation to the urban whole.

Reprinted from Les Villes et les Formes: Sur I'Urbanisme Durable (p. 12), by Salat, S., Labbé, F., \& Nowacki, C., 2011 Paris: Hermann. Copyright 2011 by CSTB. Reprinted with permission.

FIGURE 2.8 Rome's solid and void relationship. Piazza Novona outlined in relation to the city's fabric. Reprinted from Les Villes et les Formes: Sur I'Urbanisme Durable (p. 105), by Salat, S., Labbé, F., \& Nowacki, C., 2011 Paris: Hermann. Copyright 2011 by CSTB.

FIGURE 2.9 Piazza Novona as an easily identifiable "figural" element in the city. Surrounding buildings act as a "ground" into which the element has been carved away.

Reprinted from 'View of the Piazza Navona, Rome' in Wikimedia Commons, n.d., Retrieved November 14, 2015, from https://commons.wikimedia.org/wiki/File:View_of_the_Piazza_ Navona,_Rome_LACMA_49.17.3.jpg.

FIGURE 2.10 The variance in compositions and hierarchies of Rome's urban fabric. The monumental Piazza Novona; Via del Giubbonari and its complex and winding medieval blocks; Via del Corso and its radial and straight blocks.

Reprinted from Les Villes et les Formes: Sur I'Urbanisme Durable (p. 105), by Salat, S., Labbé, F., \& Nowacki, C., 2011 Paris: Hermann. Copyright 2011 by CSTB. 
FIGURE 2.11 Illustrating Nolli's solid and void relationship and it's inverse of Rome's city plan where white symbolized public space carved out of the urban mass. Churches were considered by Nolli part of the public space network of the city adding to the distinct and identifiable character of Rome's urban fabric.

Reprinted from Les Villes et les Formes: Sur I'Urbanisme Durable (p. 32), by Salat, S., Labbé, F., \& Nowacki, C., 2011 Paris: Hermann. Copyright 2011 by CSTB.

FIGURE 2.12 Illustrating the contrast between Le Corbusier's Unite in Marseilles and Vasari's Uffizi buildings in Florence.

Reprinted from Collage City (p. 68), by C. Rowe and F. Koetter, 1984 Cambridge, MA. Copyright 1984 by The MIT Press.

FIGURE 2.13 Votive church plaza in Vienna. Camillo Sitte, 1909. Plaza infill in re-defining and enclosing forecourt to the church.

Reprinted from City Planning According to Artistic Principles, by C. Sitte, 1965 Michigan: Random House. Copyright 1889 public domain.

FIGURE 2.14 Analysis of typological \& morphological elements that create urban squares, London 1979 Rob Krier.

Reprinted from Urban Space (p. 33), by R. Krier, 1979 New York, NY: Rizzoli International Publications. Copyright 1979 Academy Editions London.

FIGURE 2.15 Camillo Sitte, Study of the success of Medieval Plazas in relation to the evolution of the city. Reprinted from City Planning According to Artistic Principles (p. 12), by C. Sitte, 1965 Michigan: Random House. Copyright 1889 public domain.

\section{SPACE AND PLACE}

FIGURE 3.1 Marcel Duchamp's Nude Descending a Staircase, 1912. Early 20th example of the nonfigurative articulation of space.

Reprinted from Nude Descending a Staircase, No. 2 in Wikipedia, n.d., Retrieved October 28, 2015, from https://en.wikipedia.org/wiki/Nude_Descending_a_Staircase,_No._2.

FIGURE 3.2 Modernism and space definition through Mies Van der Rohe's Barcelona Pavilion. Reprinted from Archdaily by Kroll, A. (2011, February 8). AD classics: Barcelona pavilion / Mies van der Rohe. Retrieved December 03, 2015, from http://www.archdaily.com/109135/ad-classicsbarcelona-pavilion-mies-van-der-rohe.

FIGURE 3.3 Space defining elements, implicit to explicit space.

Readapted from Elements of Architecture: from form to place (p.101), by p. Von Meiss, 1990. London, EN: Routledge. Copyright 1991 Chapman \& Hall.

FIGURE 3.4 Stonehenge, 2600 BC. A prehistoric example of space demarcation.

Reprinted from Stonehenge in Wikipedia, n.d., Retrieved November 14, 2015, from https:// en.wikipedia.org/wiki/Stonehenge.

FIGURE 3.5 The Naked City cover page, an architecture of situations.

Reprinted from the 'Naked City', by S. Sadler, 1999. Cambridge, MA: MIT press. copyright 1991 Sadler.

FIGURE 3.5 Space, place, thresholds and their relationship. By author.

FIGURE 3.7 Spatial experience as a function of time and movement. By author. 
FIGURE 3.9 Tschumi's space and event, specifically outlining inner block behaviour.

Reprinted from the 'Manhattan Transcripts', by B. Tschumi, 1981 London, EN: Academy Editions.

Copyright 1994 Bernard Tschumi and Academy Editions.

\section{THRESHOLDS, TRANSITIONS, LIMINALITY}

FIGURE 4.1 Threshold moment. Museum of Art and Archaeology of the Côa Valley.

Reprinted from Museum of art and archaeology of the Côa valley / Camilo Rebelo by Archdaily. Retrieved March 02, 2016, from http://www.archdaily.com/52866/museum-of-art-andarchaeology-of-the-coa-valley-camilo-rebelo.

FIGURE 4.2 Janus, known in Greek mythology as god of gates and doors.

Reprinted from Janus - god of gates and doors. (2011). Retrieved September 11, 2016, from http:// www.crystalinks.com/janus.html.

FIGURE 4.3 Stages of transition according to Van Gennep.

By author.

FIGURE 4.4 Acropolis as a threshold of transitional state from profane to sacred. Left; spatial continuum bounded by carful placed space defining elements; Processional immersion within the Acropolis.

Reprinted from 'Threshold Spaces: Transitions in Architecture. Analysis and Design Tools' (p. 22-23), by Boettger Till, 2014. Copyright 2014 by Birkhäuser.

FIGURE 4.5 Acropolis, plan. Once passed through initial colonnade threshold, views on each part of the Acropolis are strategically designed to provoke curiosity, establish hierarchy and create spatial cohesion.

Reprinted from Les Villes et les Formes: Sur l'Urbanisme Durable (p. 31), by Salat, S., Labbé, F., \& Nowacki, C., 2011 Paris: Hermann. Copyright 2011 by CSTB.

FIGURE 4.6 Arch of Constantine, symbolic announcement of victory and a better world on the other side. Reprinted from Marc Antonio Architects. (2011). Retrieved January 18, 2016, from marcantonioarchitects.com/natural-laws-of-architecture-the-elevation/.

FIGURE 4.7 Arch de Triumph, Paris. threshold as an object in space, becoming a definer of space. thousandwonders.net/Arc.de.Triomphe.original.543.jpgv.

FIGURE 4.8 View through entrance gate. Old city Carcasonne in France.

Reprinted from Stock images of gates through time - the entrance gate of the old city... Csp0105855 - search stock photos, pictures, photographs, and photo Clipart. Retrieved January 28, 2016, from http://www.canstockphoto.com/gates-through-time-0105855.html.

FIGURE 4.9 Murou Art Forest, Japan. Thresholds defining and framing space.

Reprinted from 'The remote and extravagant Murou Art Forest' by Delis, K. (2015, June 4). Retrieved March 11, 2016, from https://taiken.co/single/the-remote-and-extravagant-murou-art-forest.

FIGURE 4.10 Threshold framing space and becoming part of its environment. Reprinted from Pintrest. Retrieved March 11, 2016, from https://www.pinterest.com/ pin/214413632229371341/.

FIGURE 4.11 Typical example of a Japanese Torii gate. Usually marking the transition from profane to sacred.

Reprinted from Foundation, S. A. (2016). Surfing in Japan tsunami. Retrieved March 28, 2016, from http://coastalcare.org/sections/features/japan-tsunami/page/12/.

FIGURE 4.12 Entry threshold of chapel in Valleaceron / S.M.A.O.; a careful mediator between exterior to interior. 
Chapel in Valleaceron / S.M.A.O. by A. rights. (2009, April 30). Retrieved March 28, 2016, from http:// www.archdaily.com/20945/chapel-in-villeaceron-smao.

FIGURE 4.13 Postopolis, Storefront for Art and Architecture. dynamic interior to exterior threshold condition. Reprinted from POSTOPOLIS (2007, January 6). Retrieved March 25, 2016, from http://inhabitat. com/postopolis-thursday-may-31/postopolis-event-in-nyc-postopolis-storefront-for-art-andarchitecture-inhabitat-bldgblog-city-of-sound-subtopia-architecture-blogger-conference-2/.

FIGURE 4.14 Underground descend leading to an axial route as part of Libskinds's Jewish museum transitional spaces.

Reprinted from Jewish museum Berlin. (1999). Retrieved November 28, 2016, from http://libeskind. com/work/jewish-museum-berlin/.

FIGURE 4.15 Void as an indispensable design strategy Libskind uses in addressing loss throughout the museum's journey.

Reprinted from Jewish museum Berlin. (1999). Retrieved November 28, 2016, from http://libeskind. com/work/jewish-museum-berlin/.

FIGURE 4.16 Plan of Libeskind Jewish Museum. Labyrinth where each transitional space becomes an experience of its own.

Reprinted from Jewish museum Berlin. (1999). Retrieved November 28, 2016, from http://libeskind. com/work/jewish-museum-berlin/.

FIGURE 4.17 Complete loss of spatial orientation and perception of space as one walks through the memorial. Achieved through scale, proportion, change in elevation, and openings. Reprinted from How Long is Now? by Ponto, J. (2010, May 10). Retrieved November 20, 2016, from Jodie ponto Photo Blog, http://jodieponto.com/photoblog/2010/05/04/how-long-is-now/.

FIGURE 4.18 Contrast between the seemingly understandable grid of the memorial when first approaching it vs the actual mass and dimension of it from an aerial view and going through it.

Reprinted from Memorial to the murdered Jews of Europe. (2007). Retrieved November 24, 2015, from Dori Stories, http://www.dori-stories.com/places/ger/Berlin/slides/Memorial\%20to\%20 the\%20Murdered\%20Jews\%20of\%20Europe.html.

FIGURE 4.19 Arrival and departure threshold space. Each is preparing for what's ahead. Use of visibility, light and shadow, and proportion to enhance this experience.

Reprinted from Safdie architects - Ben Gurion Airport. (2016, April 13). Retrieved November 22, 2016, from http://www.msafdie.com/\#/projects/bengurionairport.

FIGURE 4.20 Section outlining Arrival and departure threshold space.

Reprinted from Safdie architects - Ben Gurion Airport. (2016, April 13). Retrieved November 22, 2016, from http://www.msafdie.com/\#/projects/bengurionairport.

FIGURE 4.21 The experience achieved through the movement in space are further enhanced by the proportion, change in elevation, light and shadow enriched though the repetitive formal ceiling matching the movement through space.

Reprinted from Safdie architects - Ben Gurion Airport. (2016, April 13). Retrieved November 22, 2016, from http://www.msafdie.com/\#/projects/bengurionairport.

FIGURE 4.22 Original concept sketch of Great Court by Marianne McKenna and Great Court looking East. Mediating the old and new.

Reprinted from KPMB architects. (2006, December 4). Retrieved November 27, 2015, from http:// www.kpmb.com/index.asp?navid=30\&fid $1=11 \&$ fid $2=13$.

FIGURE 4.23 Therme Vals, complete sensory experience.

Reprinted from The Therme Vals / Peter Zumthor by A. rights for Archdaily. (2009, February 11). Retrieved December 04, 2015, from http://www.archdaily.com/13358/the-therme-vals.

FIGURE 4.24 Therme Vals, sketch by Zumthor. 
Reprinted from The Therme Vals / Peter Zumthor by A. rights for Archdaily. (2009, February 11). Retrieved December 04, 2015, from http://www.archdaily.com/13358/the-therme-vals.

FIGURE 4.25 Zumthor's Bruder Klaus Field Chapel. Hollowed blackened cavity and charred walls. Reprinted from Bruder Klaus field chapel / Peter Zumthor by Sveiven, M. (2011, January 26) for Archdaily Retrieved March 11, 2016. http://www.archdaily.com/106352/bruder-klaus-field-chapelpeter-zumthor.

FIGURE 4.26 Model of Diller and Scofidio's Slow House illustrating section cuts through it. Reprinted from Diller Scofidio + Renfro, Slow House. (1981). Retrieved February 02, 2015. http:// www.dsrny.com/projects/slow-house.

FIGURE 4.27 Threshold sequence phases compared to a plot's phases By author.

FIGURE 4.28 Transitions typology study. By author.

FIGURE 4.29 Transitions typology precedent study. Collage complied by author noted architect's website .

FIGURE 4.30 Experimenting with acknowledging the transition. By author.

FIGURE 4.31 Experimenting with perception of space. By author.

FIGURE 4.32 Mikveh stages. By author.

FIGURE 4.33 Mikveh material section, stages of a threshold. By author.

FIGURE 4.34 Model of Mikveh, design exploration of transitional sequencing. By author.

FIGURE 4.35- Arrival; Entrance; Changing rooms; Water immersion; Foyer, pre exit; Exit

4.40 By author.

FIGURE 4.41 Space defining elements; initial design exploration. By author.

FIGURE 4.42 Transitional moments abstracted. By author.

FIGURE 4.43 Sequencing variances in transition types. By author.

\section{TRANSFORMATION AND WATER}

FIGURE 5.1 The Great Bath of Mohenjo-daro, perspective and aerial view. Reprinted fromBBC. (2011, June 1). Primary history - Indus valley - technology and jobs. Retrieved January 17, 2016, from BBC, http://www.bbc.co.uk/schools/primaryhistory/indus_valley/ technology_and_jobs/.

FIGURE 5.2 Mohero-Daro city center map showing bathing even then as the center of civic life. 
FIGURE 5.3 Sophisticated infrastructure of Mohenjo-Daro, covered drain in the street leading to the Great Bath.

Reprinted fromBBC. (2011, June 1). Primary history - Indus valley - technology and jobs. Retrieved January 17, 2016, from BBC, http://www.bbc.co.uk/schools/primaryhistory/indus_valley/ technology_and_jobs/.

FIGURE 5.4 Egyptian princess in her Bath, wall painting in tomb in Thebes.

Reprinted from Ancient Bible History under Bath / washing. (2013, September 29). Retrieved February 19, 2016. http://ancientbiblehistory.com/1/category/bath\%20washingef8bc56c7b/1. html.

FIGURE 5.5 Roman bath design sequence logic diagram.

Reprinted from 'Baths and Bathing in Classical Antiquity' by Yegül, F., Yegul, F. K., \& Yeg, F. (1996). Cambridge, MA, United States: The MIT Press.

FIGURE 5.6 Thermae's diagrametical sequence of space.

By author.

FIGURE 5.7 12th century Romanesque Mikveh in Besalú, Spain, 36 steps lead one down to the mikveh from street level.

Reprinted from Besalú in Circa 1150 Mikveh. (2012). Retrieved March 29, 2016. http://www. redjuderias.org/google/google_maps_print/cronologia-besalu-en.html.

FIGURE 5.8 Physical damage caused by prolonged sitting. Reprinted from The health hazards of sitting. Washington Post by Berkowitz, B., \& Clark, P. (2014, January 20). Retrieved from https://www.washingtonpost.com/apps/g/page/national/the-healthhazards-of-sitting/750/ .

\section{URBAN DESIGN CONSIDERATIONS}

FIGURE 6.1 Light well, underground cave. Vietnam's Phong Nha-Ke Bang National Park .

darianworden. (2013, July 10). Head First. Retrieved June 15, 2016, from http://www. headfirstadventures.com/category/history-adventures/page/3/

FIGURE 6.2 The city and its immediate surroundings in a continuous state of transition, constantly changing.

By author.

FIGURE 6.3 Schematic; A positive transformation in one's health (measured through spiritual, physical and mental aspects) will lead to happiness and in turn will make for better cities to live in. By author.

FIGURE 6.4 Life in the city should be sustained by numerous transformational experiences continuously contributing to the happiness/quality of life of its citizen's daily life. By author.

FIGURE 6.5 The new meaning of spirituality in the 21st century.

Reprinted from the National Post Organized religion on the decline? Growing number of Canadians 'spiritual but not religious' by Carlson, K. B. (2012, December 22). Retrieved from http://news. nationalpost.com/holy-post/organized-religion-on-the-decline-growing-number-of-canadiansspiritual-but-not-religious.

FIGURE 6.6 View of passage in Derinkuyu, a total underground city.

Reprinted from Cappadocia Underground Cities, Derinkuyu. Retrieved March 12, 2016, http:// www.turkeyculturaltour.com/tr/turkiye/4/cappadocia-naturel-wonders/underground-cities-incappadocia-turkey.html. 
FIGURE 6.7 Underground Streetcar Tunnel.

Reprinted from Dupont circle Dc underground tunnels: Washington DC, Dupont underground map explores abandoned trolley station underneath Dupont circle, historical images courtesy of the Dupont underground. Retrieved June 12, 2016, from Sukirgenk, http://sukirgenk.dvrlists.com/ dupont-circle-dc-underground-tunnels.html.

FIGURE 6.8 Section of Derinkuyu, a total underground city.

Reprinted from Cappadocia Underground Cities, Derinkuyu. Retrieved March 12, 2016, http:// www.turkeyculturaltour.com/tr/turkiye/4/cappadocia-naturel-wonders/underground-cities-incappadocia-turkey.html.

FIGURE 6.9 Lower Queen station. Post industrial carved out void within the Toronto's infrastructure. Reprinted from BlogTO, A guide to "secret" tunnels in Toronto by Bateman, C. (2016, September 11). Retrieved March 12, 2016. http://www.blogto.com/city/2014/01/a_guide_to_secret_tunnels_ in_toronto/.

FIGURE 6.10 Post industrial site options, all potential below grade voids/cavities.

106-107 By author.

FIGURE 6.11 Proposals for abandoned Paris Metro Stations reborn as Nightclubs and Public Pools. Reprinted from Autopia, Catching up with Star Trek IV's true hero: The unkind punk on the bus by Barry, K. (2014, February 20). Retrieved March 12, 2016. https://www.wired.com/2014/02/parissubway-remodels/.

FIGURE 6.12 Proposal for New York's Lowline, a subterranean park piping sunlight underground. Reprinted from New Atlas, New York's Lowline subterranean park pipes sunlight underground by by Robarts, S. (2014, November 26). Retrieved July 12, 2016. http://newatlas.com/lowlineunderground-park/34949/.

FIGURE 6.13 Below grade Parking survey in Toronto's downtown core with future speculation of many becoming obsolete.

By author.

FIGURE 6.14 Toronto's TTC stations as post industrial sites potentially becoming partially obsolete. By author.

FIGURE 6.15 Toronto's PATH system and its connection with the subway system, creating am underground cavity network of its own.

By author.

FIGURE 6.16 Analysis of potential future post industrial underground voids within the downtown urban core as part of the city's below grade urban fabric.

By author.

\section{FINAL DESIGN PROJECT: A THERMAE}

FIGURE 7.1 Queen St. elevation, looking north and looking at Eaton Centre on West and from street and BOM on the east.

By author.

FIGURE 7.2 Site plan, illustrating TTC street entrances.

By author.

FIGURE 7.3 Queen platform level illustrating accessible entrances.

By author.

FIGURE 7.4 Queen platform level illustrating entry points from street. 
FIGURE 7.5 Photo survey of entrance sequence to Queen street, north west corner entrance.

FIGURE 7.6 Photo survey of entrance sequence Queen street, north east corner entrance.

By author.

FIGURE 7.7 Site section, illustrating existing conditions.

By author.

FIGURE 7.8 Site section, illustrating proposed conditions.

By author.

FIGURE 7.9 Photo survey of the abandoned Lower Queen site conditions.

Reprinted from BlogTO, A guide to "secret" tunnels in Toronto by Bateman, C. (2016, September 11). Retrieved March 12, 2016. http://www.blogto.com/city/2014/01/a_guide_to_secret_tunnels_ in_toronto/.

FIGURE 7.10 Separation, transition and incorporation as stages incorporated in the path to the underground. Exploring how variance in passage length has an effect on the overall experience.

By author.

FIGURE 7.11 Variance in approaches in path to below .By author.

FIGURE 7.12 Framing a threshold. Transition from dark to light space, light is further enhanced by walking in the dark.

Diagram by author.

FIGURE 7.13 'The path to below' exploration through reward and denial strategies (1) expansion and contraction of form (2) gradients in a transition - temperature material (3) light aperture location can have a great effect on whole experience.

By author.

FIGURE 7.14 Schematic sketch, contraction and expansion as a guiding design principle.

By author.

FIGURE 7.15 Thermae Site plan, illustrating proposed arrival and exit locations as well as outline of lower queen station below grade.

By author.

FIGURE 7.16 Design of arrival and exit sequence. Contraction at arrival and Expansion at exit. By author.

FIGURE 7.17 Arrival and exit illustration of sequence path at platform and underpass levels. Arrival with a focus on nonlinearity, contraction and loss of orientation and exit as being more linear and reinforcing expansion upwards.

By author.

FIGURE 7.18 Diagram of descend down into the thermae.

By author.

FIGURE 7.19 Arrival sequence renderings. (1) initial threshold descend down. (2) last ray of light before full incorporation.

By author.

FIGURE 7.20 Exit sequence renderings. (1) ascend upwards. (2) ray of light before the actual incorporation with the external environment hunting of the culmination of the journey.

By author. 
FIGURE 7.21 Labeled plan of arrival to and exit path from the thermae.

By author.

FIGURE 7.22 Guiding design concept gradient in intensity of personal experience.

By author.

FIGURE 7.23 Initial schematic sketch of spatial relationships.

By author.

FIGURE 7.24 Schematic illustration of journey through thermae.

By author.

FIGURE 7.25 Spatial elements as a function of intensity of personal experience.

By author.

FIGURE 7.26 Initial schematic section of spatial requirements and relationships.

By author.

FIGURE 7.27 Program elements relationships, based on Roman bath sequence of space.

By author.

FIGURE 7.28 Layers of personal experience linked to program space, its meaning and archtiectural expresion

By author.

FIGURE 7.29 Labeled thermae plan.

By author.

FIGURES 7.30 Renders of beginning of journey at arrival zone.

By author.

FIGURES 7.31 Renders of the start of the journey, the transitional space leading up to the appadarium. By author.

FIGURES 7.32 Renders of ice and steam room and the transition leading up to them. By author.

FIGURES 7.33 Render of waters and transition leaving extreme temperature rooms and framing view into the waters.

By author.

FIGURES 7.34 Renders of hydrotherapy and corps rooms. By author.

FIGURES 7.35 Renders of pre exit transition and exit ramp. By author.

FIGURES 7.36 Split section.

FIGURES 7.37 Temperature and artificial environment as a measure and inttegral part of the journey. 
FIGURES 7.41 Section along waters.

By author.

FIGURES 7.42 Cross section study of spatial relationships.

By author.

FIGURES 7.43 Experiential section.

By author.

\section{APPENDIX}

FIGURE 10.1 Baths of Caracalla, restored perspective, sections and facades.

Reprinted from Bath and Bathing in Classical Antiquity, by Fikret, Y. (1992). The MIT Press

Copyright 1992 by MIT Press.

FIGURE 10.2 Stabian Baths, Pompeii. overlay spatial analysis

Readapted from Bath and Bathing in Classical Antiquity, by Fikret, Y. (1992). The MIT Press.

Copyright 1992 by MIT Press.

FIGURE 10.3 Typical Roman bath house layout

Reprinted from Roman Baths. (2011). Retrieved March 11, 2016, from http://http://www.crystalinks. com/romebaths.html.

FIGURE 10.4 Thermal Baths, Aquae Sulis, Bath, overlay spatial analysis.

Readapted from Bath and Bathing in Classical Antiquity, by Fikret, Y. (1992). The MIT Press.

Copyright 1992 by MIT Press.

FIGURE 10.5 Image of what bathing could have been like in the Great Bath Hall in early years and what it looks like today.

Reprinted from Bath. (2016, May 24). Roman bathing complex. Retrieved March 7, 2016, from Bath, http://www.romanbaths.co.uk/roman-bathing-complex.

FIGURE 10.6 Cross-shaped fonts in early Christian baptisteries located in Avdat, and Mamshit/Mampsis Reprinted from Stone study 4. Retrieved March 29, 2016, from Stones of the Bible, http://www.sstudies.0catch.com/Stones/Stone\%20Study\%204.htm.

FIGURE 10.7 Battistero Paleocristian, early Christian baptistery which was located under Milan's Duomo. Octagonal baptismal font was surrounded with radiating apses, and traces of the canals that used to feed it with water.

Reprinted from Hayes, H. (2005). Early Christian baptistery - Milan, Italy. Retrieved March 12, 2016, from Sacred Destinations, http://www.sacred-destinations.com/italy/milan-baptistery.

FIGURE 10.8 Ortigia, Sicily Mikveh, dates from the 6th century A.D.

Reprinted from Timeline. (2012). Retrieved May 14, 2016, from Network of Jewish Quarters in Spain

- Routes of Sefarad, http://www.redjuderias.org/google/google_maps_print/cronologia-ac-en. html.

FIGURE 10.9 Underground mikve connected to water cistern.

Destinations, S. (2005). Photo of worms synagogue: Mikveh (1186). Retrieved May 14, 2016, from Sacred Destinations, http://www.sacred-destinations.com/germany/worms-synagogue/photos/ xti_4588pl. 
xxii | MOMENTS OF TRANSITION 


\section{PROLOGUE}

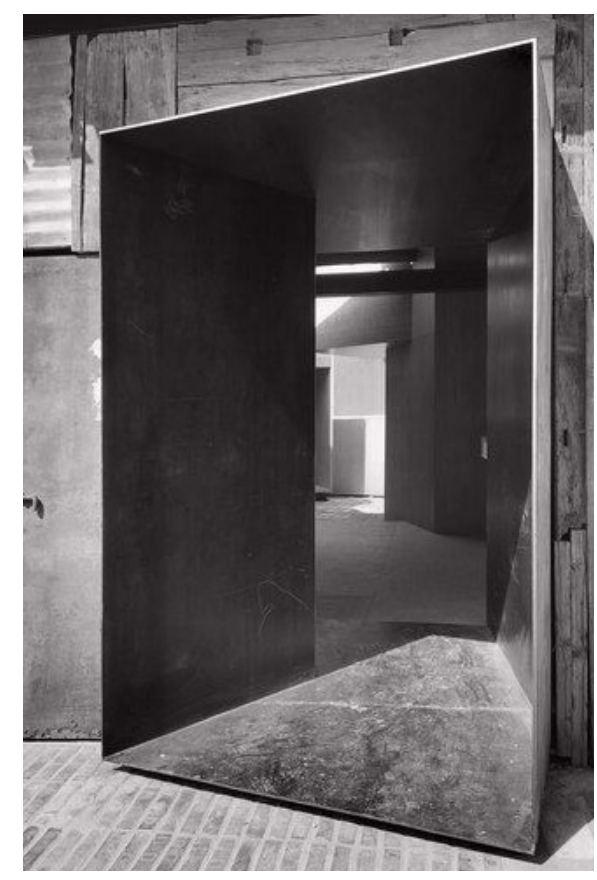

Figure 1.1 (top):

Entry threshold into

Gallery of Micro-Hutong

/ standardarchitecture
Architecture helps shape and constrain behaviour, in both positive and negative ways. Forming much of our environment, architecture's impact on people is at once physical, psychological and emotional. Our built and urban settings are made up of fragments of spaces, functions, buildings, that are connected and put together to make a whole. The fragments of this whole are no less important than its connectors, its transitional moments, perhaps even more. These transitions manifest themselves where a space becomes another; they hold a two-fold almost paradoxical aspect to their being.

Transition or thresholds spaces are everywhere around us. They play a critical role in our everyday experiences through the built environment. They become crucial in our reading of it, as they help us make clear separations. They are the crucial connecting ligaments, the bloodlines to the system, which lets the system breathe, function and feel. These transitional moments can be inspiring, or alternatively uninspiring and depressing, and at times unnoticeable as we walk through them. The inspiring ones have the power to shape our experiences through them and act as a prologue to what is coming. 
These transitions and the experience through them can only be understood firsthand. They are subjective due to the inability to control what one experiences through them, yet that is their beauty. The transition one goes through from point A to B will always vary. The art is how to successfully ensure this happens. These transition and thresholds become crucial in creating an atmosphere, helping define a place. During the state of transition, of being in-between one place and the next, it is the movement and temporality that become vital in the experience.

\section{Design + Research methodology}

In exploring a wide range of transitions, I began my investigation on an urban level. I explored how space is created at the scale of the city, the importance of hierarchy of spaces governed by urban threshold moments, edge conditions and an examination of solid and void relationships within the city form, and then applying these on a more specific architectural context. This helped me better understand the concepts of space and place and the transition from space to place, perception of space and finally examining isolated threshold conditions through an architectural lens.

I continued this investigation and categorized transitional moments and spatial boundaries in architecture into groupings of what they are as a whole and as special pieces creating a flow. This categorization and definition allowed me to better understand the power and role different transitions have in facilitating flows or, alternatively, creating conscious disruptions in architecture. I further narrowed down this process and focused on rituals and transitions as crucial devices in facilitating the spiritual and subconscious reading of this type of architecture.

I explored this through a series of design explorations, both specific and general to the topic of transitions. One of the later design explorations was centred on an examination of the design of a mikveh (a Jewish ritual bath) as a religious building-type that possessed ideas of transition and ritual from sacred to pro- 
fane through immersion in water. This design exploration helped me in expressing an architectural language which speaks of the transitional process one embarks on in this context through water involving a physical, spiritual and meaningful transition.

This design exploration led me to introduce water as a vessel for physical and spiritual transformation, one that has been understood since ancient times. My exploration of water and an immersion in it as a "tool" for transformation called for further analysis of these roots. The major monotheistic religions -Christianity, Islam and Judaism -- all share a universal tradition of immersion in water to remove physical and spiritual impurities to become pure and divine. This led me to a survey of various cultures and monotheistic religions, and their rituals of bathing and immersion that were historically part of a ceremonial and ritualistic process.

The final design exploration takes the mikveh or historic bathhouse and looks to revitalize this ancient tradition of spiritual and physical purity and transformation, in the form of a modernized thermae that involves a transformative experience in water transcending the physical and spiritual. Ultimately, I was seeking to argue that reaching a truly engaging and fulfilling environment that transcends a transformative experience is highly dependent on the successful implementation of its threshold and transitional conditions. 
\begin{tabular}{l|l}
4 & MOMENTS OF TRANSITION
\end{tabular} 


\section{URBAN SPACE: MORPHOLOGY Solid/void relationship in 20th century urban form}

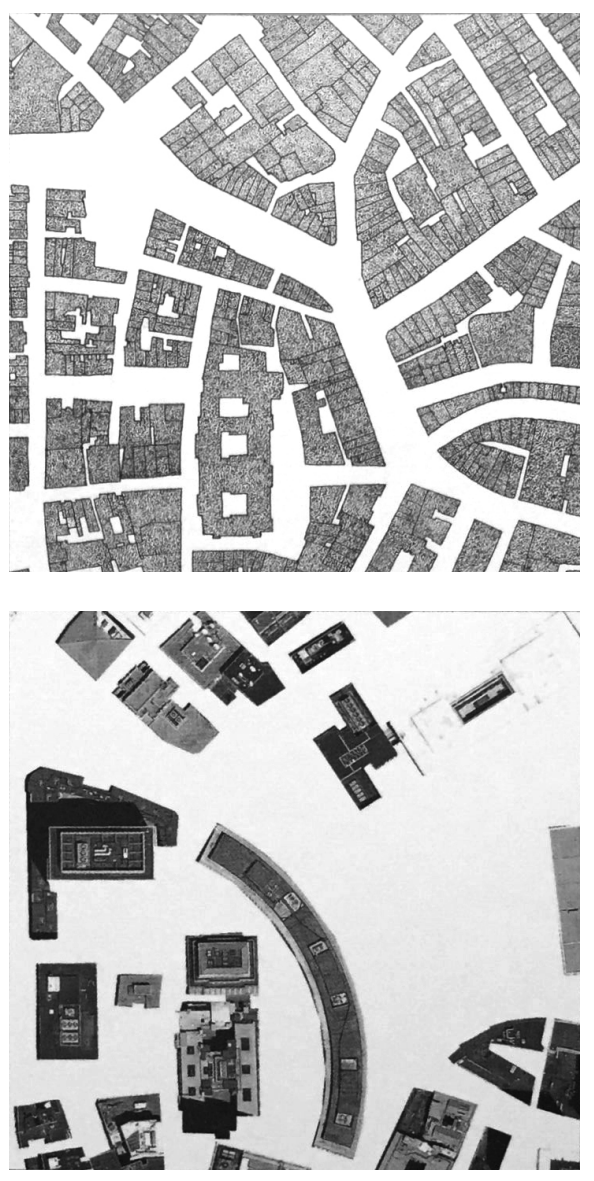

\subsection{Power of the void}

Twentieth century space is closely related to an almost universal acceptance of the functionalist program of architecture; an architecture that was primarily focused on pure forms, and unbounded, democratic space (Trancik, 1986, p. 20). 'Tabula rasa' and 'clean slate' were terms often used as a way of describing the prevailing attitudes of the functionalist movement. Regionalism and identity were almost completely ignored in the height of modernism. The International Style, as its name implies, suggested that buildings in widely different locations could have much in common. It attempted to create a universal language of architecture. The triumph of these architectural moments in history led to an architecture of highly segregating urban conditions and spaces (see Figure 2.1, 2.2). The aftermath of these ideals of free flowing space and pure architecture have since evolved into our present situation, creating incomplete and fractioned figure ground scenarios. Individual buildings isolated next to parking lots surrounded by highways is one of many examples of this approach.

In his book, Genius Loci, Christian Norberg Scholz describes 
the danger of a fractured or interrupted environment resulting in a scattered assembly of units. He says that streets and squares in the traditional sense are no longer found, breaking the distinct figure-ground relationship that used to exist. This condition interrupts the continuity of the landscape, making it hard for buildings to form clusters or groups. This discontinuity does not necessarily mean a lack of order, yet it will probably lack in its ability to convey a sense of place (Norberg-Schulz, 1980, p. 189)

Other than their architectural vision, the 1920s Avant Garde's agenda was centred on a social idealism based on a concern for the masses. Despite their concern for people, the architectural result usually lacked and ignored problems of social interaction, and unit-to-whole relationships. With his utopian visions, Le Corbusier, in his Plan Voisin (1925) (see Figure 2.3), La Ville Radieuse (1924) and his master plan for Algiers (1932), made an intentional departure from the tight block patterns of existing urban areas and public spaces for pedestrians. Unit-to-whole relationships also lacked a formal addressing, and this usually led to a greater emphasis on the building at the expense of the space around it (Trancik, 1986, pp. 10-11). A conscious refusal to connect spaces in an additive manner instead of a preference towards a spatial continuum highly defined the world of modern architects of the time (Boettger, 2014, p. 32).

A quick look at both Le Corbusier's Saint-Dié in France (1945) juxtaposed with the plan of Parma in Emilia (see Figure 2.4) reveals the ultimate failure of the modernist treatment of architectural "objects". In their book Collage City, Colin Rowe and Fred Koetter describe this as the 'the crisis of the object' where buildings were seen as objects, sealed off from the public, and scattered around in meaningless futurist grid-scapes. Rowe and Koetter discuss the failures of modern architecture proposals, saying it was due to the "retarded conception of science and... reluctant recognition of poetics" (Row \& Koetter, 1984, p. 3). They continually dismiss the 'continuous void' of

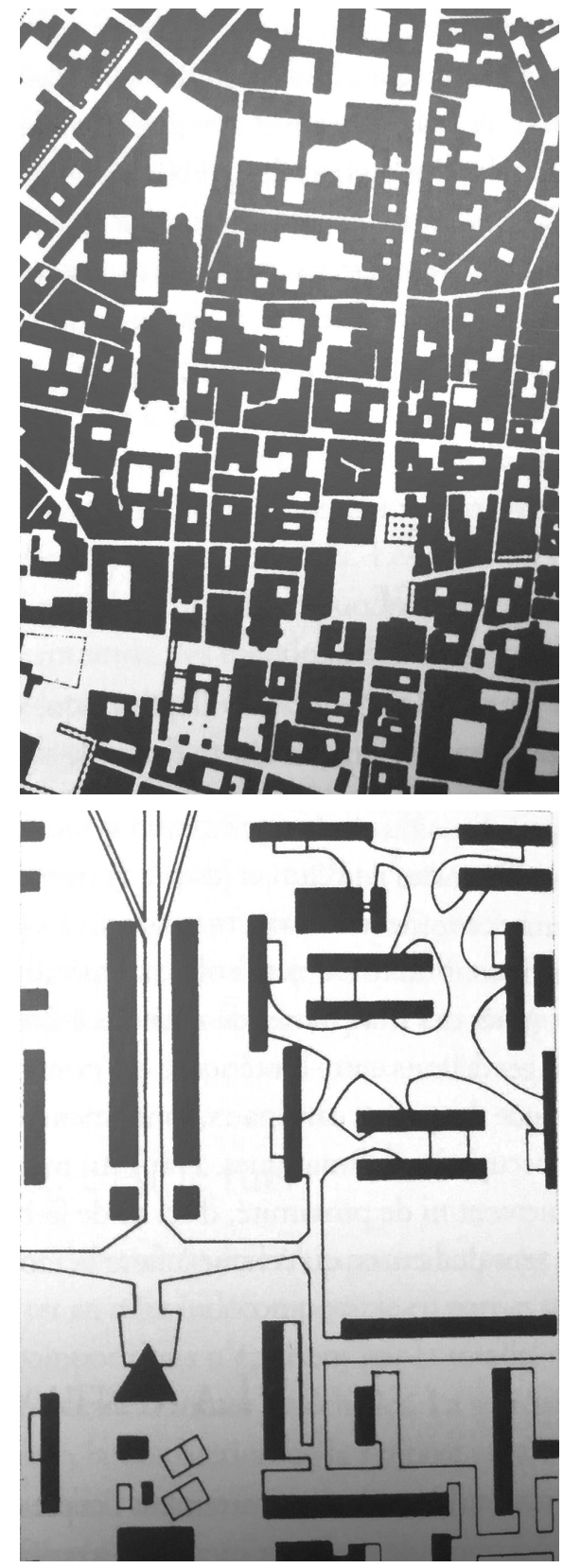

Figure 2.1 (page 5)

1980. Modernism's ideals affecting typical urban systems leading to inconsistent urban fabrics. Boston's city centre (top) in 1929 and the same site (below) fractured in
Figure 2.2 (top): Comparison between Parma's 1830 dense urban fabric vs. Brasilia 1960 fractured urban fabrics. 


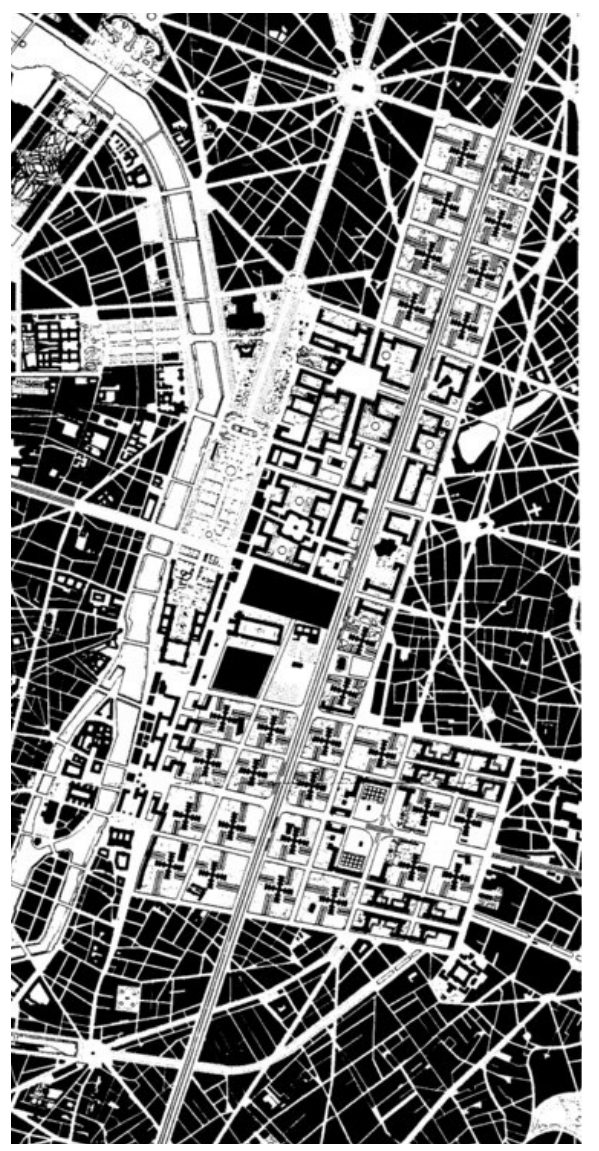

Figure 2.3 (top): 1922- Figure 2.4 (below): Le 1925 Plan Voisin, Le Corbusier's 1945 SaintCorbusier Die in France juxtaposed with the plan of Parma in Emilia. the modernist tendency to place 'towers in parks' and treat their buildings as objects. They place high importance on the speculative pleasure a city walker has creating his narrative to the formulated spaces through solid and void which allows for a more connected experience to be had, rather than allowing free reign to meander across every open space in the city. Despite this, the modernist view of buildings is not completely disregarded by Row and Koetter, and the idea of buildings acting as both space occupiers and space definers is essential to them (Row \& Koetter, 1984, pp. 61-66).

The 1950s represented a shift in the way of thinking brought by a group of second generation European Modernists - Team 10, Alison and Peter Smithson, and Aldo Van Eyck all attempting to redefine the underlying principles and current problems of urban space. Humanism became a key word for modernism's failure in place definition to account for human needs and activities in space (Trancik, 1986, p. 34). There are many architects who dealt with this; one in particular, associated with the Rationalism movement headed by Aldo Rossi and the Krier brothers, developed a reconstructed functionalism in an attempt to revive classism and traditional notions of urban design looking at historic models for inspiration (Trancik, 1986, pp. 35-37).

In his book Complexity and Contradiction in Architecture, Robert Venturi in the mid-1960s set the stage for the Post Modern movement, addressing the absence of context and open space
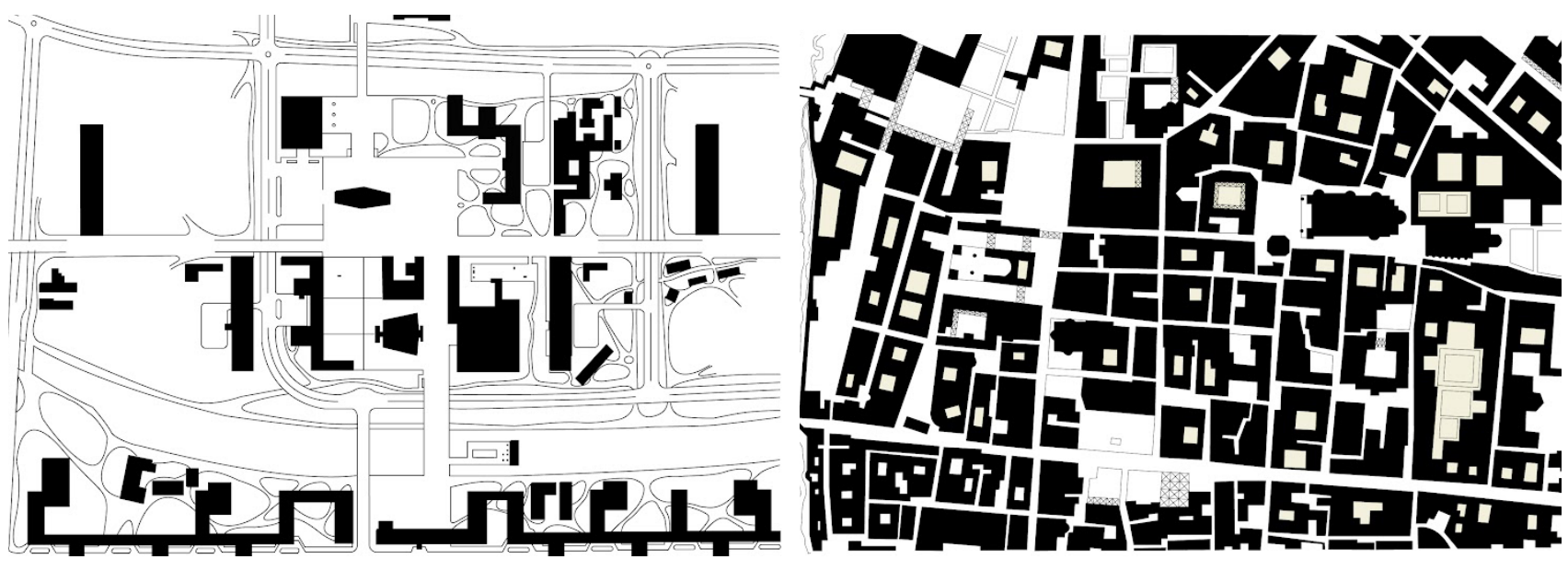
in modern architecture and urbanism, saying that an architecture of complexity and contradiction has special obligation towards the whole; "it must embody the difficult unity of inclusion rather than the easy unity of exclusion, more is not less." (Venturi, 2002, p. 16). Venturi also reinterpreted the modernist phrase 'less is more,' first coined by Mies van der Rohe, to read 'less is bore,' emphasizing that everyday ordinary space should not be stripped of its cultural meaning (Venturi, 2002, pp. 16-17).

Christian Norberg Schulz talks of the situation post-World War II where places were subjected to profound changes, where the qualities that traditionally distinguished human settlements were corrupted or lost. Nodes, paths and districts lost their identity, and the town as a whole its imageability. Kevin Lynch in his book The Image of the City (1960) further developed this and speaks of a man's need to recognize and pattern their surroundings, which draws deep roots from the withdrawal of past experiences. In building this image of the city - "The environment suggests distinctions and relations, and the observer - with great adaptability and in the light of his own purposes - selects, organizes, and endows with meaning what he sees." (Lynch, 1960, p. 6).

During the latter part of the 1900s, architects were recognizing the importance of context, space and place, and urban pattern for the continuation of the city, and its forms. Ultimately, modernism's symbolic failure in history was marked by the demolition of Pruitt-Igoe in 1972 (Trancik, 1986, pp. 13-15).

\section{$2.2 \quad$ Nolli's City Plan}

Nolli's 1748 city plan of Rome (see Figure 2.7) stands as an iconographic plan, presenting the city's "innate character" (Tice, 2005-2016). This map evokes and yields an intuitive feel for it vividly reveals topographic and spatial structure of the city. The Nolli map provides an immediate understanding of the city's urban form through the graphic method of rendering solids as
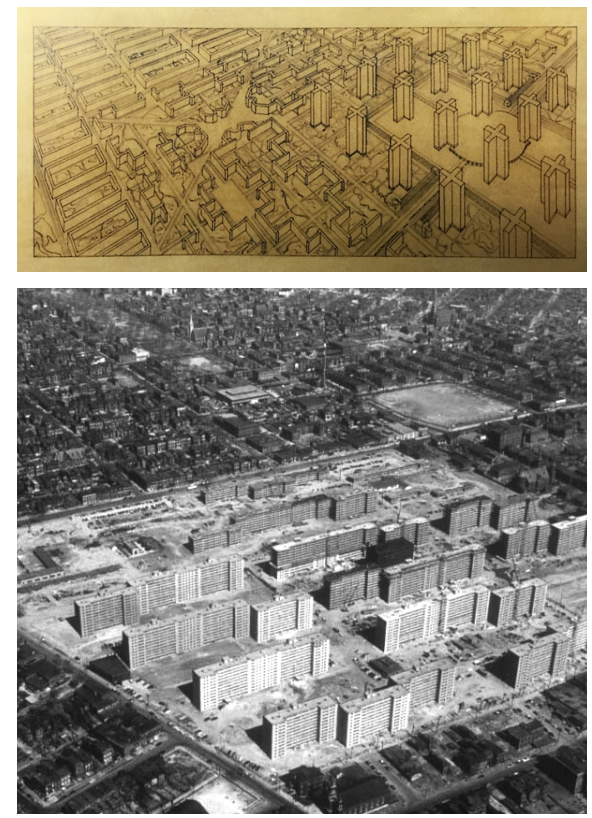

.

(n)

(1)

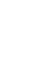

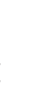

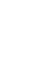


Figure 2.7 (below):

Nolli's 1748 city plan

of of Rome conveying

its innate patterns of

public and private space

and their relationship

in relation to the urban

whole. dark gray and rendering voids as white or light shades of gray to represent vegetation, paving patterns. The city in this sense is seen as a massive block which has been carved away to create outdoor rooms and a public environment. The dark and light patterns of the city reveal the way public space was conceived within the city, which is no less important than the buildings themselves (Tice, 2005-2016).

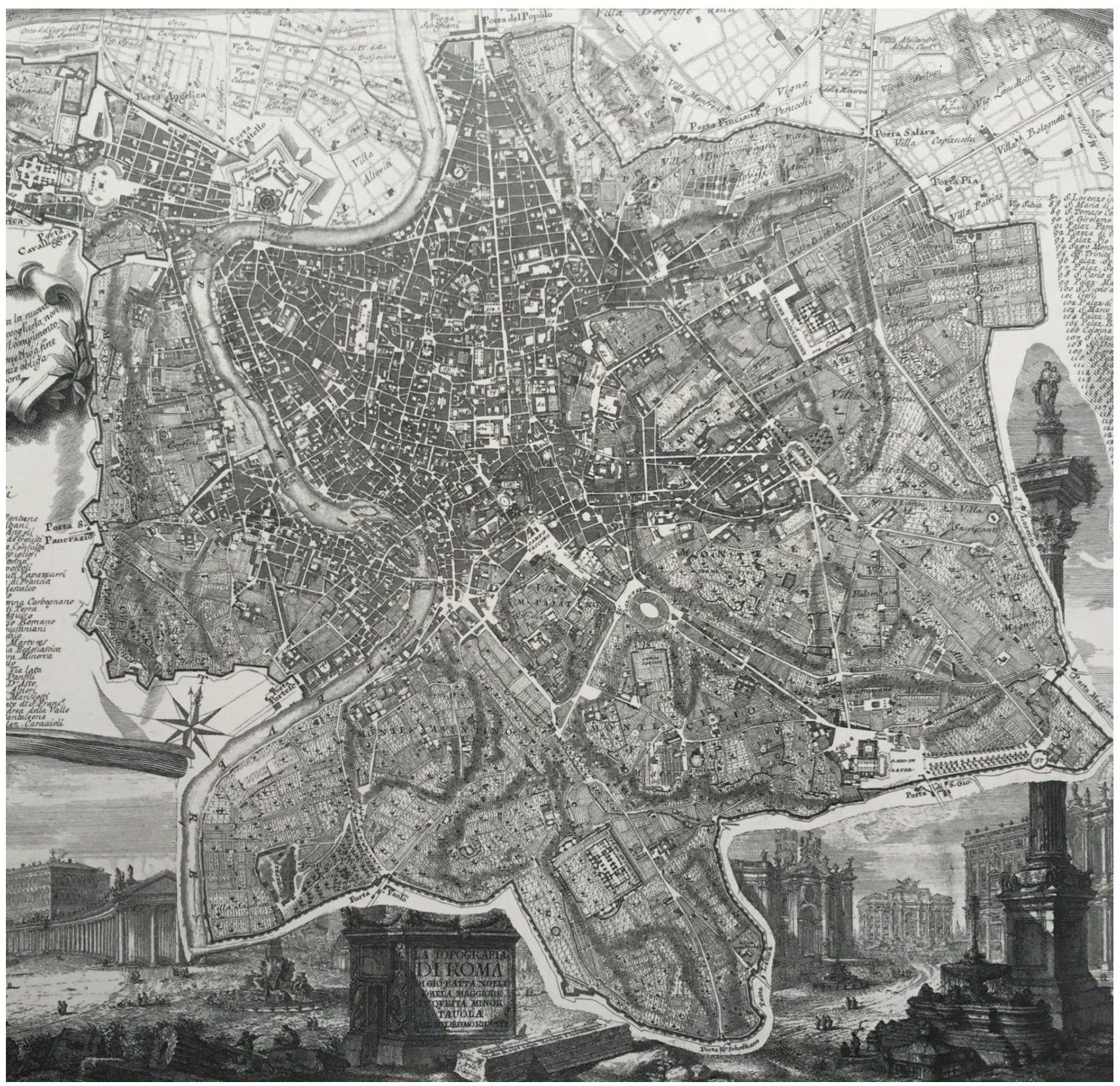




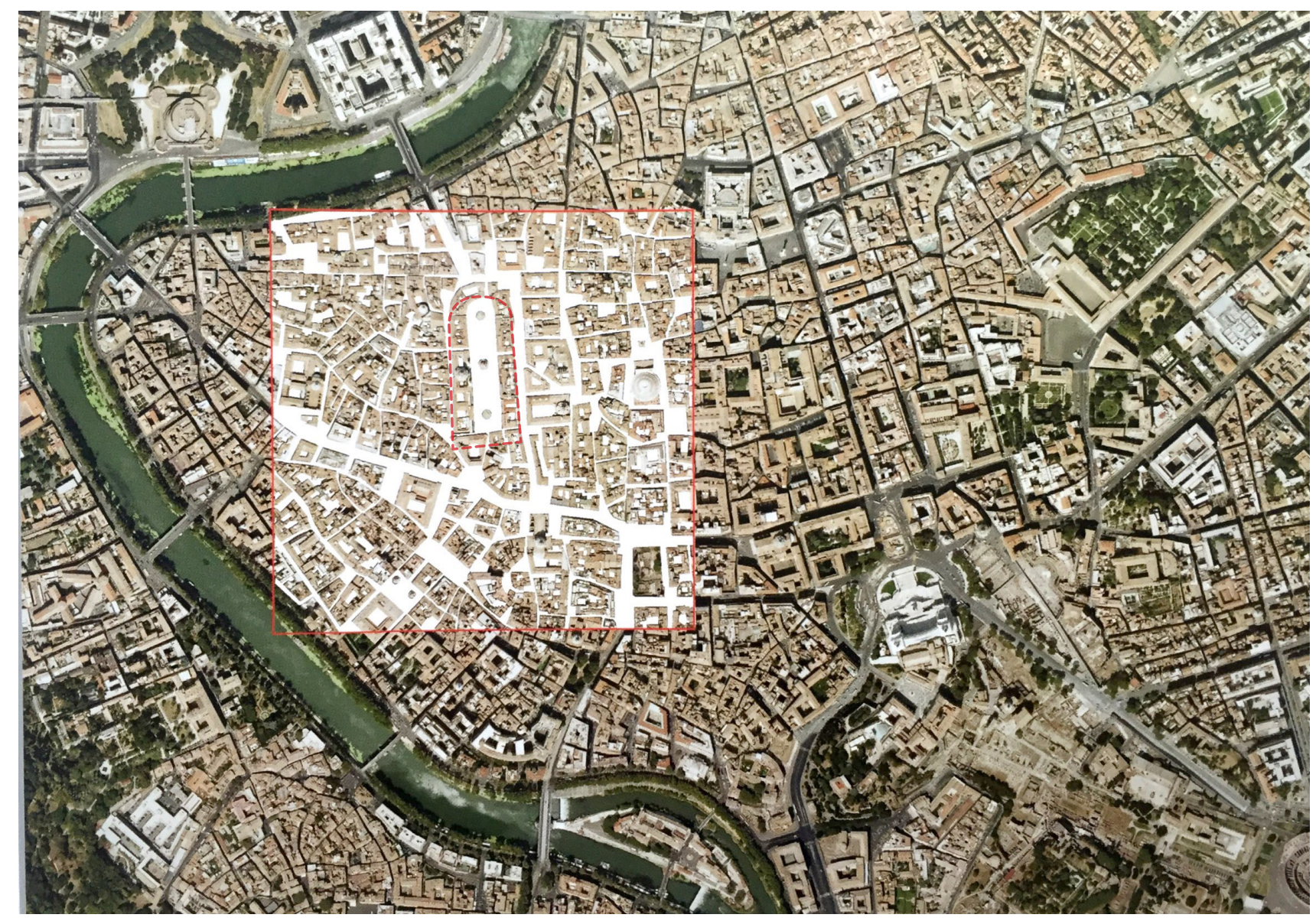

The map conveys Nolli's deep understanding of the city's patterns of private and public buildings, and furthermore, their relationships in relation to the urban whole. It affirms principles of contextual design throughout the city of Rome. This builds on the notion of the building not as an isolated event, an object, but one that has a context and is deeply embedded in the fabric of its city. The dialectical relationship between buildings and their context - a two-way street consisting of outside and inside and buildings and places - are features which Norberg Schultz refers to in affirming his genius loci in Rome. These constantly appearing contrasts, thresholds in a way, suggest the dynamic interplay between solid and void, their importance in creating a place (Tice, 2005-2016). The evolution of the city, its buildings and its spatial structure, is not a static object. It is a dynamic

Figure 2.8 (top): Rome's solid and void relationship. Piazza Novona outlined in relation to the city's fabric. 


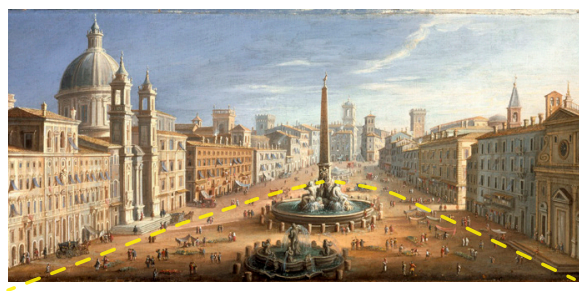

Figure 2.9 (top): Piazza Novona as an easily identifiable "figural" element in the city. Surrounding buildings act as a "ground" into which the element has been carved away.

Figure 2.10(bottom): The variance in compositions and hierarchies of Rome's urban fabric. From left to right, the monumental Piazza Novona; Via del Giubbonari and its complex and winding medieval blocks; Via del Corso and its radial and straight blocks. interplay of competing urban and human pressures, needs and desires.

The public or semi-public spaces have a distinct and identifiable character in Rome, and Nolli knew to recognize that. For that reason, a church interior and palace courtyard or public urban space were all seen as carved out space and voids (see Figure 2.7). Nolli believed churches, due to their public access, acted as support spaces just as piazzas did in sustaining public social life. Piazza Novona, (see Figure 2.9, 2.10), for example, is identified as a figural element in the city. Its surrounding buildings act as the ground on which the element has been placed or, better yet, carved away from. In contrast, the modern city reverses this conceptual reading so that a building is always seen as an active figural object while space is imagined (if at all) as a kind of recessive, formless container that provides the setting for the object (Trancik, 1986, pp. 7-9).

\subsection{Soft space/Hard space}

Roger Trancik closely inspects the typological patterns that facilitate the relationships of solid and void and hard and soft from an urban perspective. In its most basic definition, hard space is bound by walls. It can be translated into a three-dimensional frame that defines the edges of a space, a two- dimensional pattern which refers to the treatment and articulation of the ground plane, materials, texture and composition, and objects
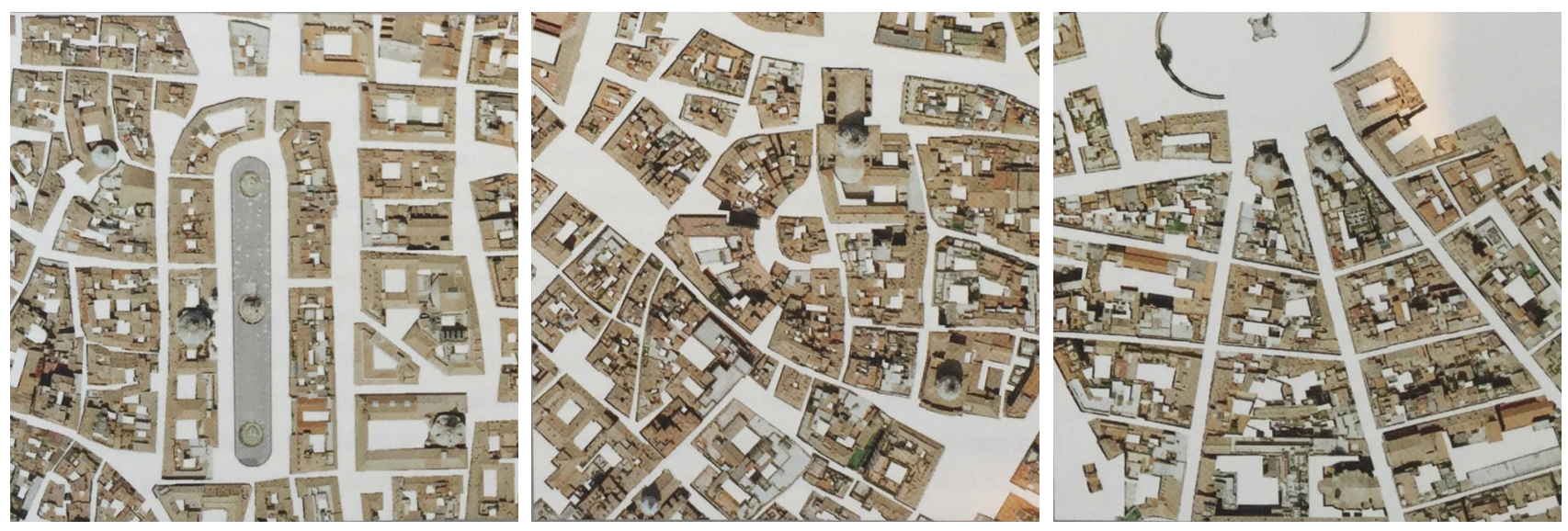
in space, which are elements such as sculptures, water features, and trees providing accents and focal points. The soft spaces mainly refer to the natural environment inside and outside the city (Trancik, 1986, p. 61).

Interestingly, in the interplay between soft and hard spaces within the city, "as Venturi pointed out over 20 years ago, the problem is not the lack of open space in the city, but its openness" (Trancik, 1986, p. 61). This space is often too open to be perceived as space, and is many times located away from the pulse of urban life. This argument is very much illustrated by contrasting Le Corbusier's 1947 Unité in Marseilles with the sublime colonnades of Vasari's 1581 Uffizi buildings in Florence (see Figure 2.12).

Other relationships relating to soft and hard scape typologies are discussed by Trancik and include public monuments, urban blocks, and directional or edge- defining buildings. Urban voids typically include entry foyers, inner block voids, networks of streets and squares, parks and gardens and linear open space systems. He says that design of the object must always be considered in conjunction with structuring the void, so that building and space can coexist (Trancik, 1986, pp. 97-110).

Piazza del Campo in Sienna derives much of its strength as a space from the contrast between the dense mass of surrounding buildings and the open piazza. The configuration of streets also reinforces the shape of the square itself. Despite being an open soft space in definition, the classic urban space has characteristics of and acts almost like a closed space resulting from the enclosed feeling achieved by the dense mass around it.

Camillo Sitte in his book City Planning According to Artistic Principles (1889) wrote of the importance of an artistic quality in urban space. He argued for the beauty and positive visual and psychological effects of enclosed space in cities and the careful

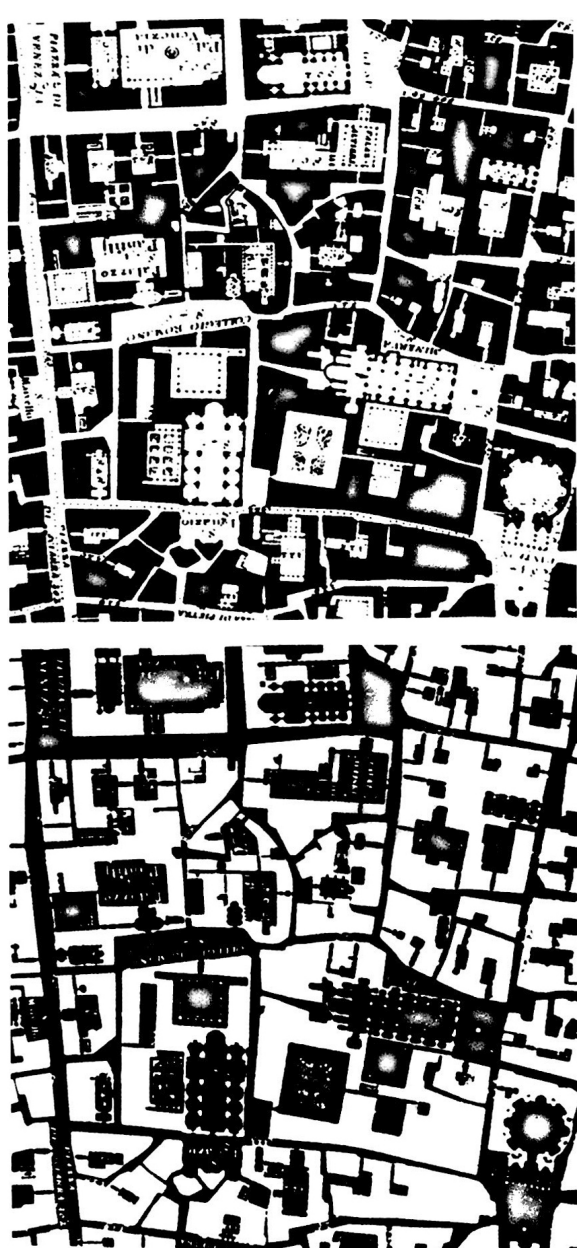

Figure 2.11 (top): Illustrating Nolli's solid and void relationship and it's inverse of Rome's

city plan where white symbolized public space carved out of the urban mass. Churches were considered by Nolli part of the public space network of the city adding to the distinct and identifiable character of Rome's urban fabric. 
Figure 2.12 (below):

Illustrating the contrast between Le Corbusier's Unite in Marseilles and Vasari's Uffizi buildings in Florence, plan and perspective. placement of objects in space. In the Votive church plaza in Vienna (see Figure 2.13), he proposed extensive infill to enclose and redefine the forecourt to the church, defining the public space and the church as its object (Sitte, 1889, pp. 281-284). This was reaffirmed half a decade later by Norberg Schulz when remarking that "the distinctive quality of any manmade space is enclosure" (Norberg-Schulz, 1980, pp. 56-57).

\subsection{Hierarchy of spaces, Urban Sequence}

Every city has its particular morphological setup which transforms over time. Solid and void relationships or figureground plans best illustrate this relationship and help intuitively understand urban hierarchies. In his book, Urban Conservation
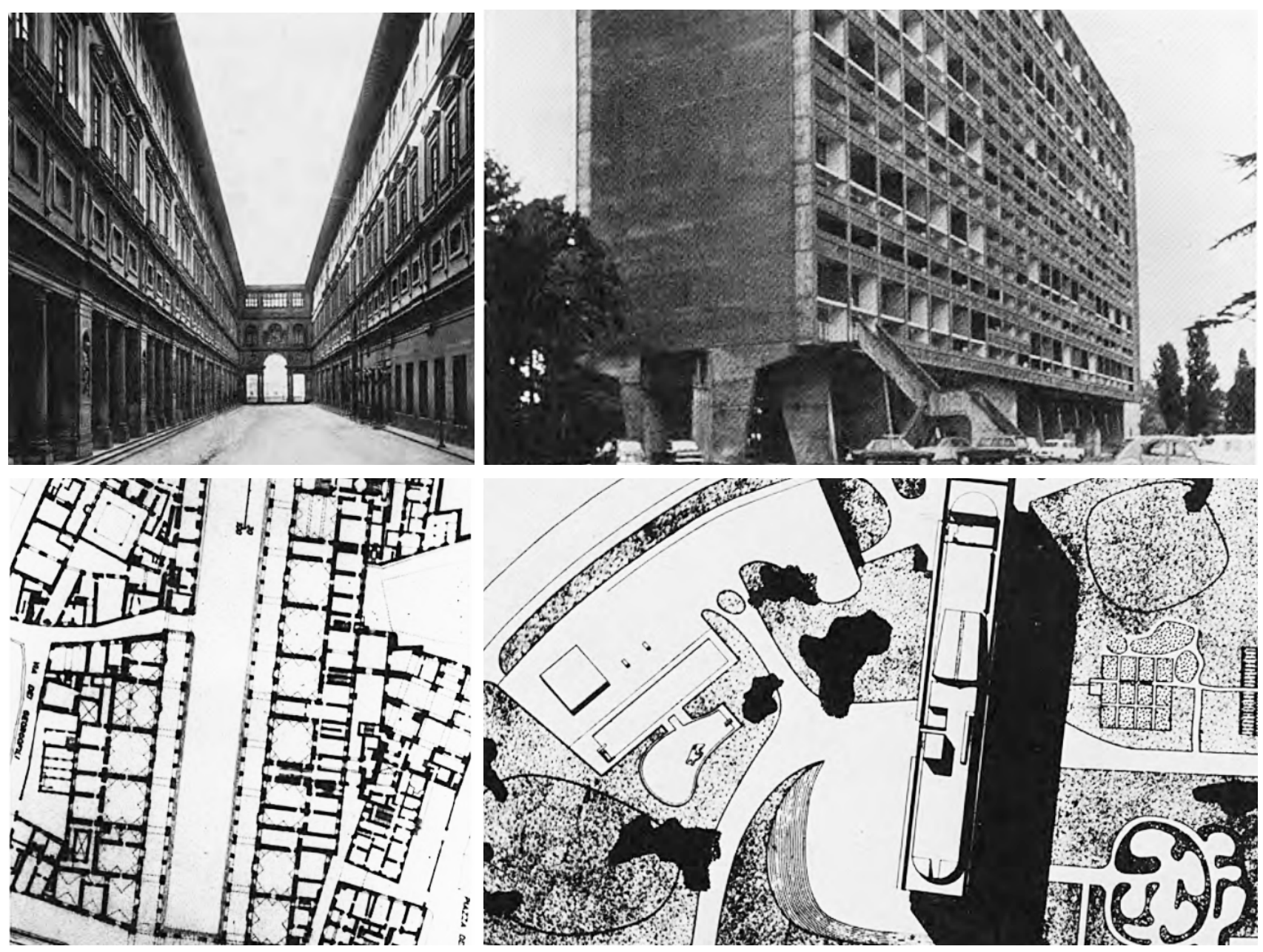
(1999), Nahoum Cohen observes how historic centres came to be. He inspects how cities were all made up of a web of buildings and streets from different periods and cultures creating particular urban strata. Cohen writes mainly of ways to properly preserve and carry on this morphology which he explains is closely related to proper hierarchal division. He speaks of four successive phases which have led to proper urban formation, all perceived in different scales but that also work as a whole.

These are 1) urban web - giving a general view, a non-specific view of a city or settlement's main axes, principal streets or roads and distinct parts. 2) the district - narrowing down on units within a web, which begin to distinguish differences of features and internal qualities yet still merge with one another. These differences become the formative nuclei which help establish local features and become an "uninterrupted accumulation of similarly featured groups. (Cohen, 1999). 3) the block - a further narrowing down leads to the block which becomes a comprehensible and intentional formation of smaller physical units. This then leads to the 4) division of the block - which becomes the smallest cell within this. Needs, neighborhood relationship and mutual agreement dictate its arrangement. Often the shape and form of these blocks tend to take similar dimensions and their logic of placement is determined by street, ventilation and lighting considerations. Thinkers like Nahoum Cohen, Kevin Lynch and Aldo Rossi have all tried to come up with the elements that make cities, that are important in maintaining healthy and successive relationships as Cohen explains, legible and comprehensible as Lynch discusses or of having an impact on people's collective memories as Rossi states. All share and proclaim the importance of urban hierarchy as part of creating a synced whole.

Reaching the topic of this thesis was triggered in part by my interest in this hierarchal relationship. This relationship is observed on an urban as well as on an architectural level. Figure-ground diagrams so clearly illustrate the sequence of

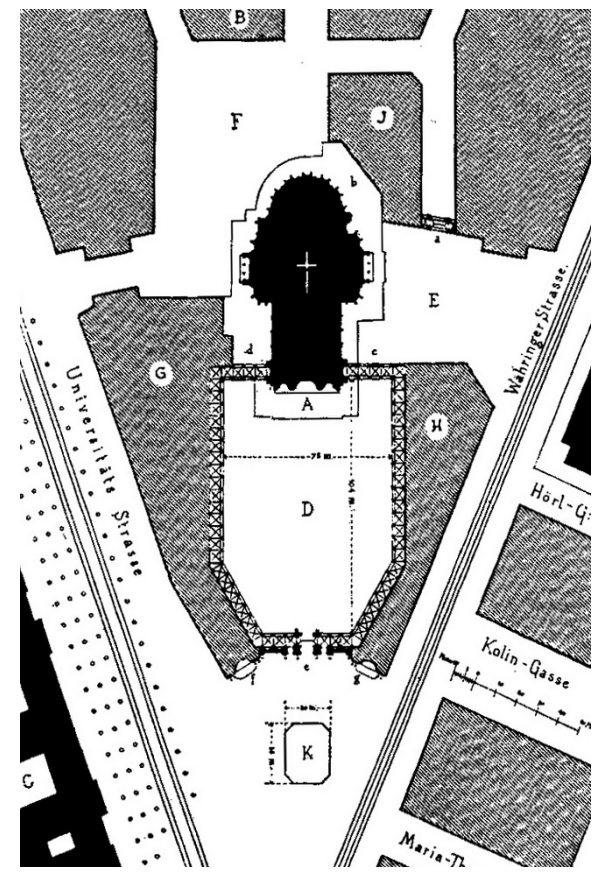

Figure 2.13 (top): Votive church plaza in Vienna. Camillo Sitte, 1909. Plaza infill in re-defining and enclosing forecourt to the church. 

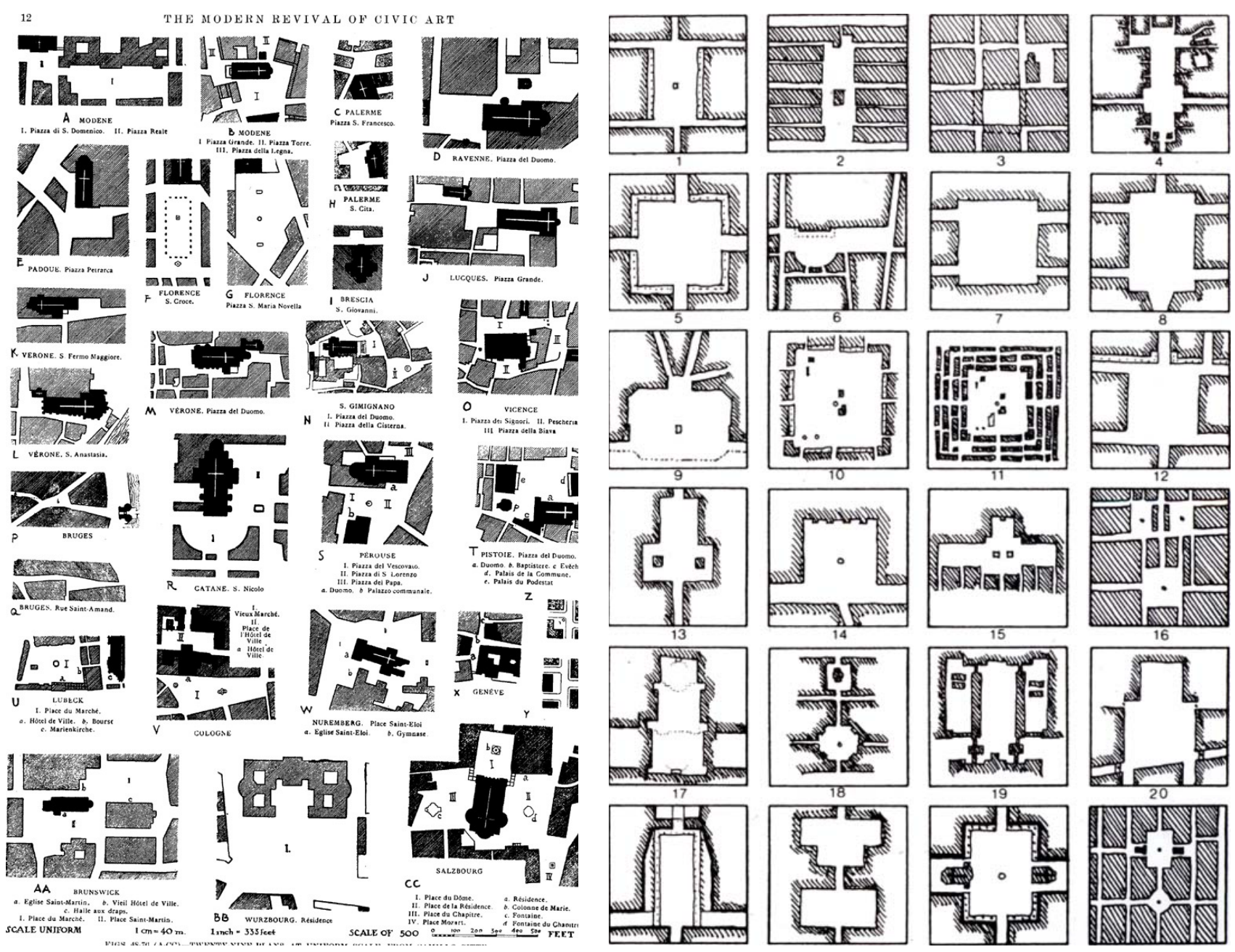

Figure 2.14 (top left):

Analysis of typological \& morphological elements that create urban

squares, London 1979 Rob Krier.

Figure 2.15 (top right): Camillo Sitte, Study of the success of Medieval Plazas in relation to the evolution of the city. spaces, from alley to street to plaza, speaking of their hierarchy and importance from a city perspective. Conversely, architecture observes similar relationships where an entrance path will usually lead to the foyer which will then lead to a living room. Architecture relies on these relationships to sustain a whole and maintain a sequence, to astonish yet remain familiar, to build up to something. "I search for surprise in my architecture." Oscar Niemeyer said of his work, "A work of art should cause the emotion of newness." (Oscar Niemeyer). 
16 MOMENTS OF TRANSITION 


\section{SPACE AND PLACE}

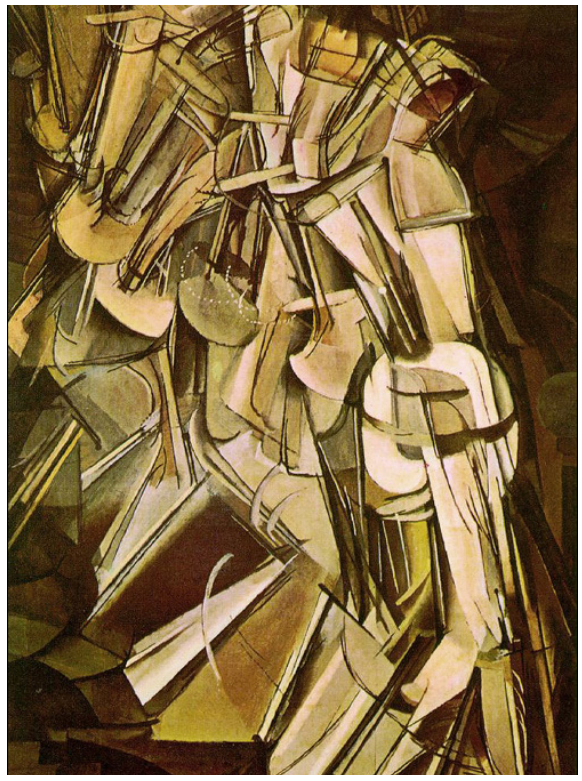

Figure 3.1 (top): :

Marcel Duchamp's Nude Descending a Staircase, 1912. Early 20th example of the nonfigurative articulation of space.
"Architecture is the thoughtful making of space. It is the creating of spaces that evoke a feeling of appropriate use." (Louis I. Kahn)

\subsection{Defining space}

Space is one of the most fundamental elements in the architect's arsenal and has long been a topic of interest in philosophy and social sciences. Perhaps its seemingly straightforward meaning makes it the complex entity that it is. We are surrounded by space and matter, and when comparing the two, space is far more flexible and ambiguous. Architects and non-architects use the concept on a regular basis. In fact, it is constantly found in our vocabulary to describe physical, temporal, scientific, imaginary, technological and hypothetical spaces.

It is the relativity of the term that becomes the definition of a space - the gap between two walls or the gap between the floor and ceiling. This gap becomes the subject space; it is the hollow that allows to contain. Space is defined as "the amount of an area, room, surface, etc. that is empty or available for use" or "an empty area between things" (Space, 2015). Its simple definition implies that the void is governed by its mass, yet it is 
the mass the is its retainer. Plato defines it as the container of things, an envelope encompassing everything around us "within the limits of the sky" (Plato). He therefore defines it as a hollow that is filled up internally, seeing it as the tangible and graspable part of the finite world. He believed nothing would occur without space, is it the bed for interactions (Fisher, 2015).

Theories of space were hardly discussed by ancient theoreticians in architecture. It was mostly the physical and formal elements that occupied them. In the early 19th century, space became a topic of debate with respect to architecture due to various causes to do with religion's declining central role and the industrial revolution.Architects of the time like Gottfried Semper and Viollet-le-Duc were defining space through an architectural lens. Semper proposed that the first impulse of architecture was enclosure. It is the wall as an architectural element that makes the enclosed space visible.

Avant garde movements in the early 20th century took the discussion further, arguing for the non-figurative articulation of space. Cubism for instance is known for its abandonment of traditional perspective practices developed at the time of the Renaissance, and on to the changing experience of space, movement and time in the modern world (Sigfried, 1967, p. 434). Architecture in that period was becoming the art of space, and less about its building methods or materials. Later, the Modern movement was categorized by "sequences of linked, interpenetrating space, by open spaces, spatial sequences that, on preceding through them, open up even new perspectives and that undergo constant changes." (Joedicke, 1985, p. 168). Mies van der Rohe's Barcelona Pavilion (see Figure 3.1) clearly illustrated the essence of Modernism's detachment of history's constraints, understood as the subject's free movement in space and the conscious rejection of the historical massiveness of materiality. By separating structure from space- defining elements, van der Rohe could enhance and create freedom and spatial sequence. The spatial experience of the pavilion relies on

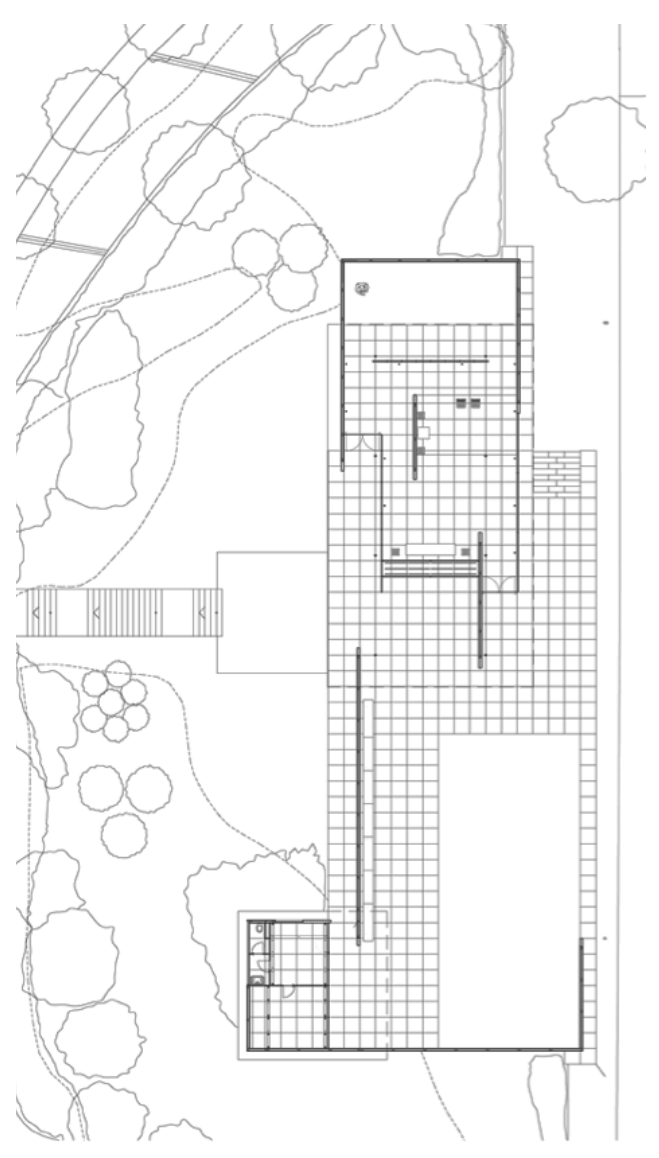

Figure 3.2 (top): : Modernism and space definition through Mies van der Rohe's Barcelona Pavilion. 
Figure 3.3 (below): Space defining elements, implicit to explicit space the mindful alternation between closed and open areas.

\subsection{Space defining elements}

Pierre von Meiss calls architecture the "art of the hollow" (Meiss, 1990, p. 101). It is the essence of an architect's ability to create the void which acts as a container. He says that a work of architecture only considered from its exterior "ceases to be architecture, it becomes a stage set." (Meiss, 1990, p. 101).

In the context of our everyday lives, space is constantly being defined, re-defined, and rearranged. It usually stands as a reference to something else, the space that the table takes in reference to the room it is in. In its basic sense, it is the relationships that occur between objects and create planes that constitute a space. In the context of a physical space, there are certain cues that allow to it be perceived as a space -- for example, a cubical room is constituted from six planes. However, what happens when a room is an irregular shape within an irregular shape, the defining elements of space become more complex. Apart from physical characteristics that help recognize a space literally, spaces are constantly being redefined by codes, rules, meanings and emotions.
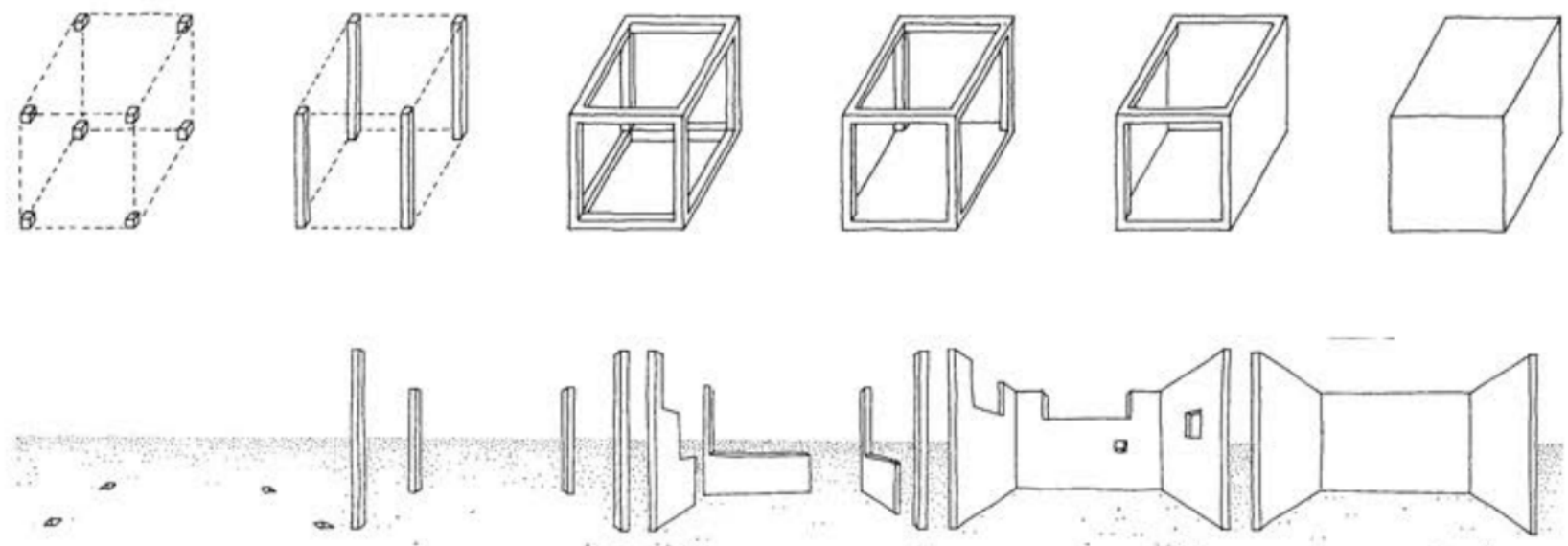

implicit
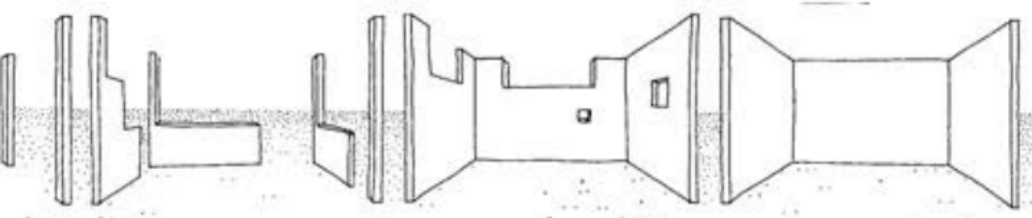

explicit 

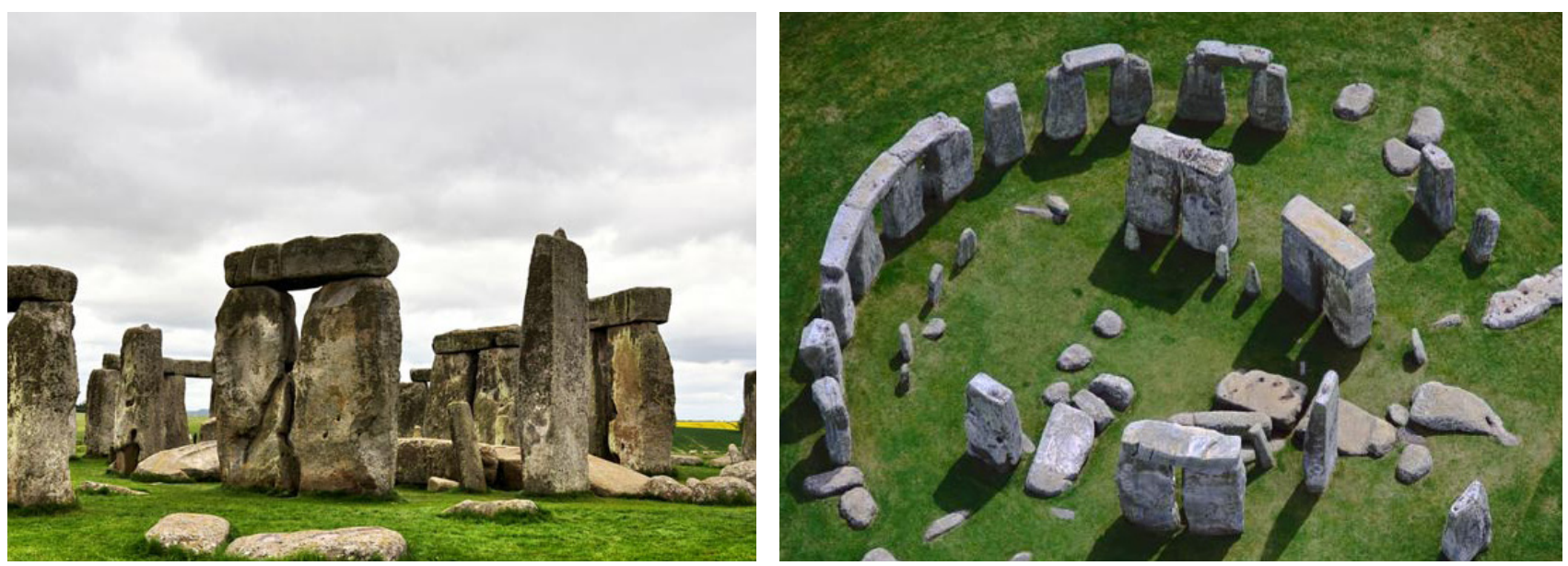

\subsection{The experience of space}

Architects's most basic education starts from walls, floors, windows etc. Yet it is the resulting space that drives the architectural experience. Spatial experience relies on multiple factors constructing it. It is sculpted by what is already composed, what is not and our mental and conceptual undersetting of it. Architects sculpt a space, and their working palette are its boundaries and shapers.

In his book The Production of Space (1974), Henry Lefebvre searches for a dialogue between mental space and real space. Space in his eyes is not only a container for social and cultural activities, but it is produced by these activities. He says that space is always being produced and in a state of becoming, therefore constantly reproducing itself. He argues that there are three aspects to spatial existence:

- Perceived space which is the physical space

- Representations of space relates to conceived mental space which is space that is controlled by us, we consciously produce it and inhibit it. Lefebvre states that "[c]onceptualized space, the space of scientists, planners, urbanists, technocratic sub-dividers and 
scientific bent -- all of whom identify what is lived and what is perceived with what is conceived." (Lefebvre, 1991, p. 38)

- Representational spaces then become social space directly influenced by our social experiences and constantly changing as we live our lives. The temporal ever-changing aspect to our experiences through space, is directly linked to our imagination, dreams and the way spaces gets re-appropriated according to our lived experiences. Lefebvre says that "Space as directly lived through its associated images and symbols." (Lefebvre, 1991, pp. 38-39).

In his discussion of space, it is clear Lefebvre makes a distinction between the physical status quo of space and its more complex, mental and emotional level. Space is experienced on multiple conceptualized levels. His most interesting argument is that spaces are constantly being reproduced, and re-appropriated. Space is constantly in a state of becoming, it is always being built - both metaphorically and physically - consciously and subconsciously (Lefebvre, 1991).

\subsection{Spatial awareness and conceptual space Martin}

Heidegger said that space was neither a property of the mind nor extant prior to one's being in the world. He said that space does not exist without one's being in it. In fact, they are intertwined. Buildings, in his eyes, do not build 'pure' spaces; it is the act of dwelling, inhabiting it that achieves this. He said "space is in essence that for which room has been made, that which is let into its bounds" (Heidegger, 1971, p. 152) can only happen for a specific place, or person. Space to him is unmeasurable and non-quantifiable. Here he introduces something new to the architectural discourse of space, where space is no longer a scientific entity. It becomes abstract, there is a mental and conceptual realization of what the space becomes and can become once dwelled in. Heidegger brings forth an interesting discussion, one which promotes high spatial awareness and 
consciousness despite the seeming simplicity of a physical boundary. He remarks that space becomes a place when something has been made room for, meaning it has a boundary. Despite this boundary, space should be recognized not as one that has boundaries but the point from which space starts to be presenced. He sums this up and says "[a] boundary is not that at which something stops but, as the Greeks recognized, the boundary is that from which something begins its presencing. That is why the concept is that of horismos, that is, the horizon, the boundary" (Heidegger, 1971). Heidegger was promoting the beginning of a school of thought that saw space as being unmeasurable and non-quantifiable.

\subsection{Defining place}

From space to place, architects are masters of shaping space but are also responsible for making them places. I believe that the carefully thoughtful transformation of a site - from space to place - is and should be the essence of what architecture is about. Space is usually understood as an abstract area, not fully defined. Place is part of this space, it is the part that comes in direct contact with the world, human life, physical space, memories, experiences, historical considerations and cultural associations of a site and behavioral patterns related to local culture, etc. Therefore, a place has the power of encompassing meaning, identity and a subjectivity to it. Place in this sense is highly related to the human activity which goes on in a space. "Space changes with the movement of the sun" but place "changes with the movement of human beings." (Meiss, 1990, p. 135).

Edward Casey described that in early Greek philosophy place first emerged as 'topos'. Greek philosophers saw it as a form of ontological ground; a place was inseparable from being or existing, to be is to exist in a place. Casey says that this idea of place was repressed in most Western philosophy into a more rational definition of an abstract location within spatial coordinates. This can be associated with scientific discoveries 
and the belief in rationality. Enlightenment and modernity made space an abstract concept yet it was a primary one. However place was seen as a secondary outcome (Casey, 2013).

Martin Heidegger in the 20th century revived the ontology of place. He said that a space's pure purpose and existence stem from the location it is in. It is the place that establishes connections between spaces. As his model of architecture was centered on human experience, the importance of dwelling in the creation of a place was so important in his eyes. It is the architect's goals to transform a place, through activating the potential content of an environment to a place of dwelling (Heidegger, 1971, p. 55). He said that architecture was not enough since he believed architects were too concerned with aesthetic priorities and not enough with the priorities of people who make and inhabit places for themselves. The word architecture to him was part of the problem. He suggested dwelling as an alternative. He said:

Bridges and hangars, stadiums and power stations are buildings but not dwellings; railway stations and highways, dams and market halls are built, but they are not dwelling places. Even so, these buildings are in the domain of our $d w e l l i n g$. That domain extends over these buildings and yet is not limited to the dwelling place. The truck driver is at home on the highway... today's houses may even be well planned, easy to keep, attractively cheap, open to air, light and sun, but do the houses in themselves hold any guarantee that dwelling occur in them? (Heidegger,1971, pp. 145-146)

This quote echoes his idea of dwelling, as not being necessarily the meaning of the word, but the feeling of home. One can occupy a building on a daily basis but others will not necessarily feel that as they come to that building. Heidegger also makes a distinction "...between space and place, where 'spaces' gain authority not from 'space' appreciated mathematically but 'place' appreciated through human experience." (Heidegger, 1971, p. 154). Therefore, he means that places are understood through use and experience. He speaks of the origin of a bridge, and imagining what was on a site before it was built. The moment where the bridge builder chose the spot for the bridge was crucial for Heidegger as it represented the moment where 
dwelling was to become inscribed as a place through the act of building. To construct something on a site therefore creates the initial identification for a place which is adopted by others and is absorbed into their understanding (Heidegger, 1971).

\subsection{Sense of place}

Spirit of a place was coined by Norberg Schulz to describe identity and sense of place. People and humanity as a social phenomenon have always strived to feel a sense of belonging and attachment to a place, to make it their own. Place begins to be defined by the experiences that take place through its being. Culturally, a public place acquires its sense of place and identity through shared events that take place there. Despite its temporality, a place has an identity, a DNA.

Sense of place could also be regarded as constantly being in the state of becoming. This is very much related to a place's continuous state of change affected by its temporal environment. However, places are also very much identified by what doesn't change. Character and identity are seen as more stable aspects of creating this. Sense of place could be misunderstood as a nostalgic ideology rather than understanding the innate nature of a place being highly affected by its history and memory, yet also being strongly affected by the daily changing environment.

Sense of place also translates in people striving to feel a part of something. It is linked to a desire to assimilate, a process where we relate to our environment through appearance and behavior. We are governed by a chameleon-like urge to blend in with our surroundings, to camouflage ourselves. Neil Leach speaks of this process as a mechanism of defense. It is people's way of feeling at home, finding a place in the world. People constitute their identities in part through their built realities. Nothing is alienating forever, even when arriving at a new place. We adapt to it very quickly until it doesn't seem new anymore. Humans are dominated with the compulsion to familiarize themselves with the unfamiliar. That is why, according to Leach, home is 
a floating concept, which shifts from place to place. We are in a constant process of adaptation to our built environment. Therefore, place in a way is a floating concept according to him, continuously changing (Leach, 2006, pp. 4-10).

\subsection{Genius loci}

Norberg-Schulz initially sought to investigate the psychology of architecture, yet the Latin term, 'genius loci' became the heart of his discussion. The Roman mythology describes each place as protected by a divinity or a super natural being. The Romans believed each place had its own spirit, only expressed in that particular location. In his book Genius Loci: Towards a Phenomenology of Architecture, Norberg-Schulz explored this divinity aspect of a place, the character of places and their meaning for people. Genius Loci is defined by him as a sense people have of a place, perceived by all the physical and symbolic values in nature and the human environment. He therefore sees genius loci as being comprised of four main components:

- Nature, earth's topography, this is the basic connection for people to the land

- Natural conditions, mainly the cosmological light conditions - this relates to a temporal aspect and sequential notion of nature. Continuous light change and vegetation change according to seasons.

- Buildings - relatively stable in comparison to the natural condition

- Symbolic meanings in the cultural landscape (NorbergSchulz, 1980)

The difficulty with genius loci and sense of place are their subjectivity. For example, in his analysis of place, Lynch chose to ignore meaning and genius loci and focused on structure and identity.

\subsection{The experience of place}

People require a stable system of places in which to develop 
themselves, their social lives and their culture. These needs give manmade space an emotional content - a presence that is more than physical. Martin Heidegger said that "a boundary is not that at which something stops. The boundary is that from which something begins its presencing" (Heidegger, 1971, p. 154). Therefore, our environments are made up of a whole which is divided into sections forming our places. A large degree of its success is the spatial continuity and separation between these places in making this whole its transitions. Architecture must respond to and enhance environmental identity and sense of place through them. According to Norberg Schulz:

A place is space which has a distinct character. Since ancient times, the genius loci, or spirit of place, has been recognized as the concrete reality man has to face and come to terms with in his daily life. Architecture means to visualize the genius loci and the task of the architect is to create meaningful places where he helps man to dwell. (Norberg-Schulz, 1980)

It is not simply about manipulating form to make space but to create place through a synthesis of the components of the total environment, including the social. It is the synthesis of the physical and cultural context fused by the psychological and historic conditions that create the ultimate experience of a place. As discussed earlier in this section, our experiences through places are in a constant state of change. We are constantly making new ones, imbedding our identifies through them.

In describing the experience of places through the city, Kevin Lynch in his book 'The image of the City' says that "Nothing is experienced by itself, but always in relation to its surrounding, the sequence of events leading up to it, the memory of past experiences" (Lynch, 1960, p. 1). He is addressing the notion that society will always form associations with some part of the city - these become images - that are then soaked in memories and meaning. This image of the city is a composite of all of our senses in reading the city. Our perception of the city will usually be fragmented since our routes and feelings can never be fully controlled. This composite of images is part of a city's way of 


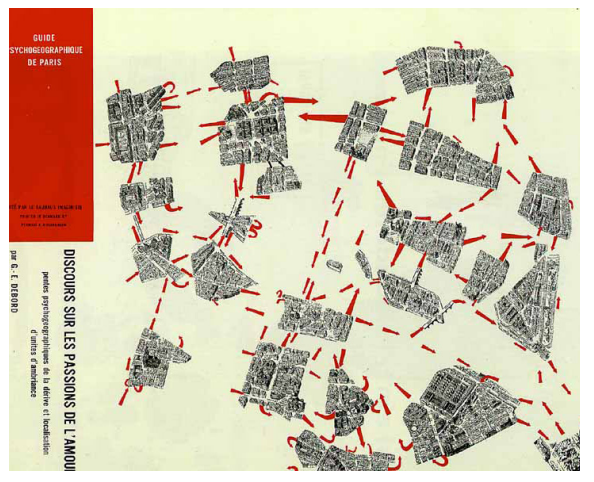

Figure 3.3 (top): The

Naked City cover, an architecture of situations. becoming a 'legible city', one whose districts and landmarks or pathways are easily identifiable and are easily grouped into an overall pattern.

\subsection{Psychogeography}

Toward the end of the modernist period, Guy Debord was critiquing the alienating conditions of everyday life. He along with the Situationist movement were concerned with the false consciousness consumer culture was producing - the diversion of the spectacle. They discussed spaces as becoming uninvigorating and predictable. Interested mostly in the degrading of social space, the Situationists developed a method called psychogeography which was involved with experimentation enabling new possibilities for experiencing everyday aspects of life. They believed cities were born out of interferences of meshing situations, and through aimless, random urban exploration guided by an emotional awareness, an exotic and exciting ambiance evolves. In essence, their view of spaces consisted of the constant re-appropriation of situations to constitute the exciting, creative and spontaneous space affecting the overall mental experience of it (Sadler, 1999, p. 28). In the Naked City (see Figure 3.3), the Situationists cut up a map of Paris in different areas that are experienced by some people as distinct units. These units were visualized by spreading them out and mentally associated the 'felt' distances by the red arrows. They believed in the concept of dériver, which meant to let people drift or float, and discover their own version of the city and create their own atmosphere.

\subsection{From space to place}

It is the discussion of a space to place that ultimately is most engaging. Fascinating is the human capability to turn the seemingly 'nothingness' of space into a place full of meanings, associations, a product of imagination and character. In explaining this transition from space to place, Heidegger cites the example of a bridge. A bridge is not only a thing; its being in the world has great impact on people's immediate experiences. 
Without it, people would not be able to walk or drive much further. The bridge essentially changes people's everyday lives. Its significance derives from its physicality and the influence it has on people. This space only became a place when the bridge was put on it to form a connection between two points. The bridge is the built formation and the physical environment that becomes the reference of a place. Our consciousness also associates this bridge with this place and as a place of transition between two points, affected by cultures of either end (Heidegger, 1971).

"If in abstract, physical terms, space is a bounded or purposeful void with the potential of physically linking things, it only becomes place when it is given a contextual meaning derived from cultural or regional context" (Trancik, 1986, p. 112). While space can be categorized based on its physical qualities, it is place that is unique, taking the character of its surrounding. This character is comprised by both the tangible and intangible cultural associations, memories and human use over time. It is not simply about manipulating form to make space. Creating place entails a synthesis of the components of a total environment, including the social. In his manifesto for team 10, Aldo Van Eyck said, "Whatever space and time mean, place and occasion mean more. For space in the image of man is place; articulate the in between... Space experience, I repeat, it's the reward of place experience" (Trancik, 1986, p. 114). On this topic, Casey refers to human experience beginning with space and time and only then becomes a place. Space and time are universal but place is particular.

Architecture must enhance environmental identity and sense of place to encompass its totality, as identified by Norberg Schulz who said,

A place is space which has a distinct character. Since ancient times, the genius loci, or spirit of place, has been recognized as the concrete reality man has to face and come to terms with in his daily life. Architecture means to visualize the genius loci and the task of the architect is to create meaningful places where he 


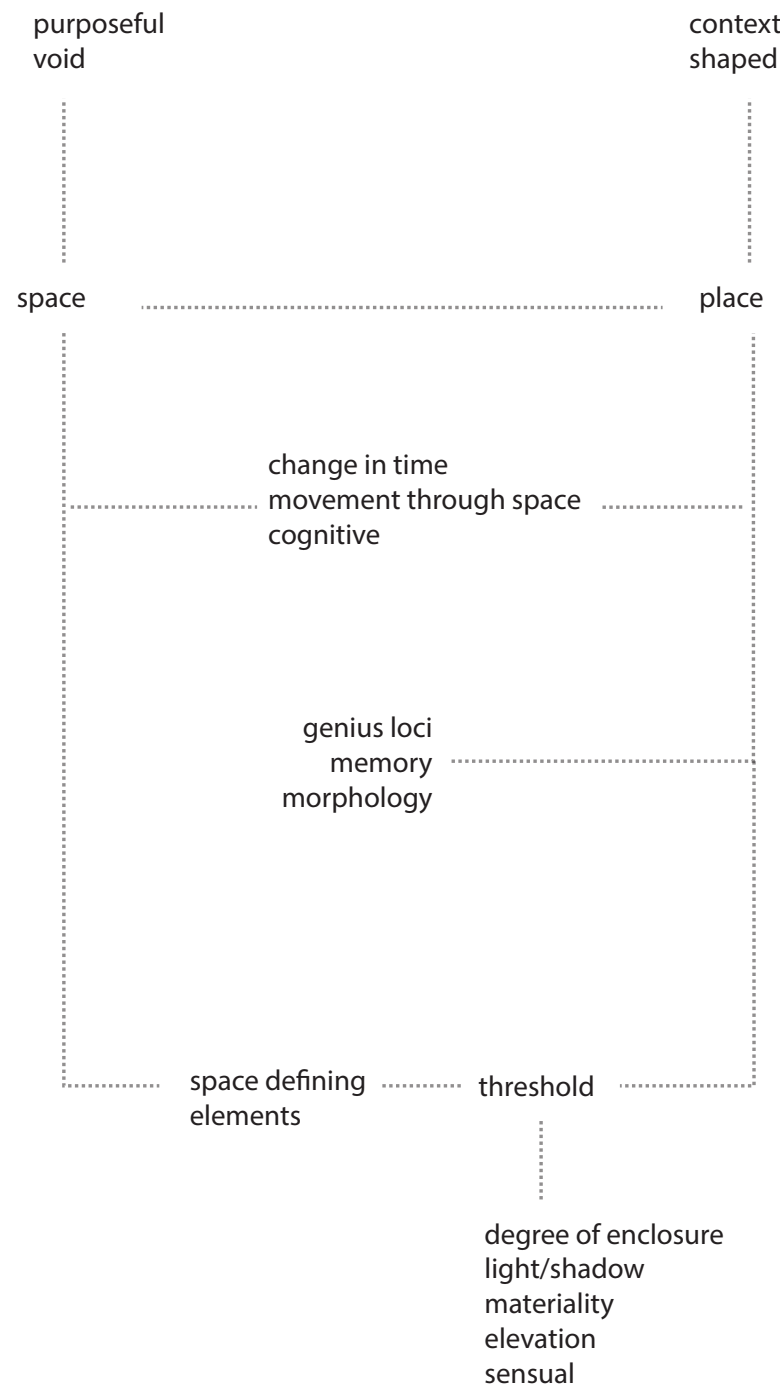

helps man to dwell. (1980, p. 5)

Figure 3.6 (top): Space, place, thresholds and their relationship. contextual meaning by events 
political, economic and social realities.

Space is a bounded purposeful void with the potential of physically linking things. It only becomes place when it is given a contextual meaning derived from a cultural or regional context. It is the medium of urban experience providing the sequence between public, semi-public and private domains. For this sequence to work, it is the articulation and differentiation of solids and voids that make up the fabric of the city and establish the physical sequence and visual orientation between places.

The becoming of place is highly complex. However, this thesis is arguing that a main component of its facilitation are threshold conditions, transitions through space that ultimately create a narrative, a structured journey in becoming aware, accustomed or familiar with an environment, its cultural associations, its built network, whether it be a building or a city.

\subsection{Perception of space}

On a basic level, space is created through the perception of space-defining elements and their inter-relationship. Space is experience with a constant reference to its temporal aspect. As we move through space, our physical location changes, but also our perception of space is constantly being re-evaluated adjusting itself to the changing environment. The temporal aspect of movement through space is constantly being built on the memory of what was just experienced and the anticipation of what is ahead.

How do humans perceive spaces through their experiences, what is their perception of the space intentioned? "Perception occurs via the senses, to which, according to [Aristotle's] classical subdivision, sight, hearing smell, taste and touch belong" (Aristotle). Along with basic orientation which helps facilitate perception of a person's position in space, humans have an inert ability to perceive their environment and orient themselves in space. Movement through space is a crucial property for 


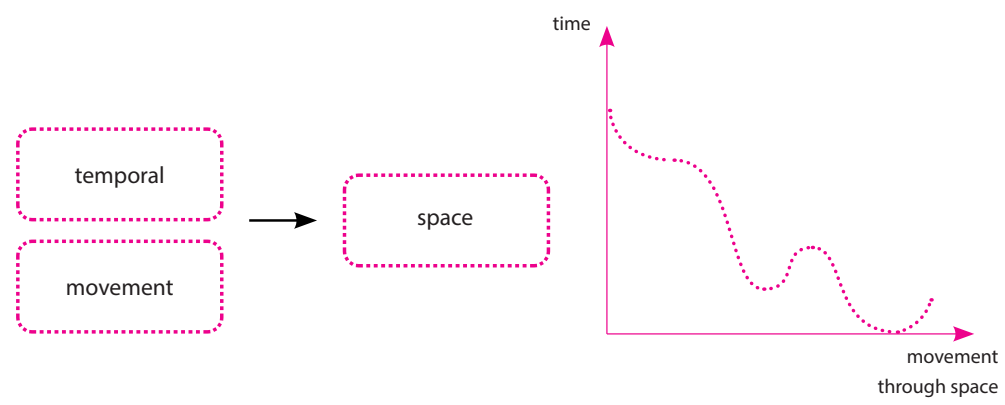

comprehending a space. In the course of movement through space, sensory organs are activated in a consciously selective manner in trying to gain a clear perception of the complexity of space. Space can only be fully absorbed and understood by motion through it. The temporal is also a big contributor to the perceivable process. It is highly dependent on the order by which a space was perceived. Succession and sequence are key in relation to movement through space in time. Therefore, our perception of a space is highly related to our experience through a space, the way our senses are triggered, the sequence, and its temporality (Boettger, 2014, p. 17).

\subsection{Movement and Spatial sequencing}

On a literal level, our movement through space occurs through space-defining elements. Degree of enclosure very much shape our perception of a space. It will control specific qualities of light to enter, affords us views out and into other spaces and controls what we experience and perceive. "There is an art of relationship just as there is an art of architecture" (Cullen, 1995, p. 7). In his book, Townscape, Gordon Cullen translates the experience of a sequence through space into a series of images (see Figure 3.7) arguing that the urban environment is not experienced statically but through a dynamic and temporal experience, constantly unfolding. The perception of place and the image of a place relate to the mental understanding of the physical, and the relationship between object and movement, as well as the event

Figure 3.7 (top): Spatial of arriving at or leaving city or building rooms (Cullen, 1995).

experience as a function of time and movement.

In his equates physical form to a stage set, attempting to 

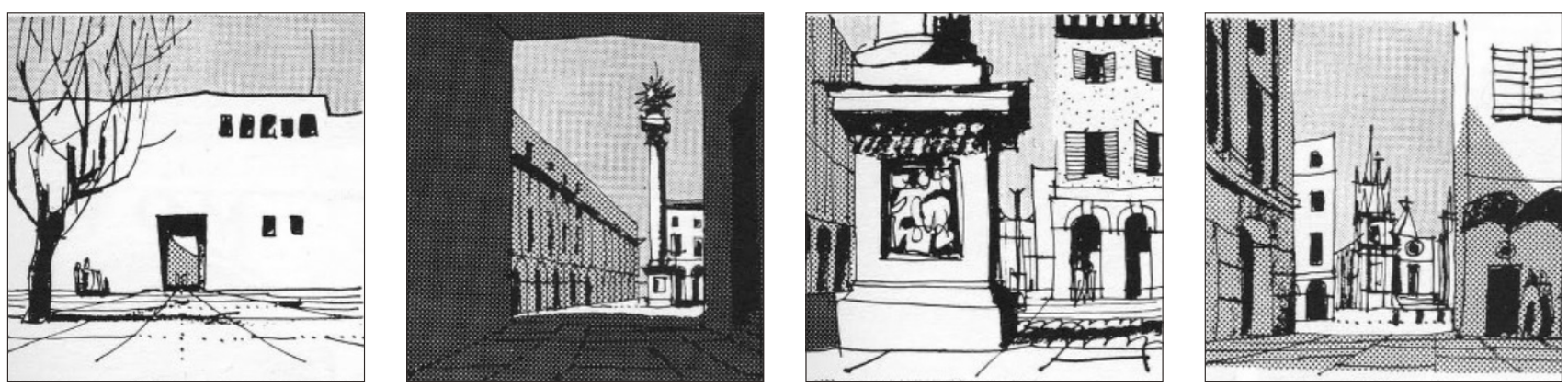

describe the complex relationship between spaces and their uses, between type and program. His intention is to invoke a sequence and movement through space (see Figure 3.9) that relates to the different functions a space can take upon itself through a succession of frames (Tschumi , 1981).

He believes space is a social product and reacts to movement through it as a procession. It is about the inventible intervention of bodies into a controlled order of architecture. Derrida says that what happens to us through architecture both constructs and instructs us. We are engaged with architecture but we also become its subject. What happens to us, the event, is the making of space. Therefore, he relates it to an architecture of events. It is easy to forget the architecture we inhabit is not an object to us at all. It has history and its heritage gives us intimacy. Architecture must have meaning, present it, and signify it (Tschumi, 1981).
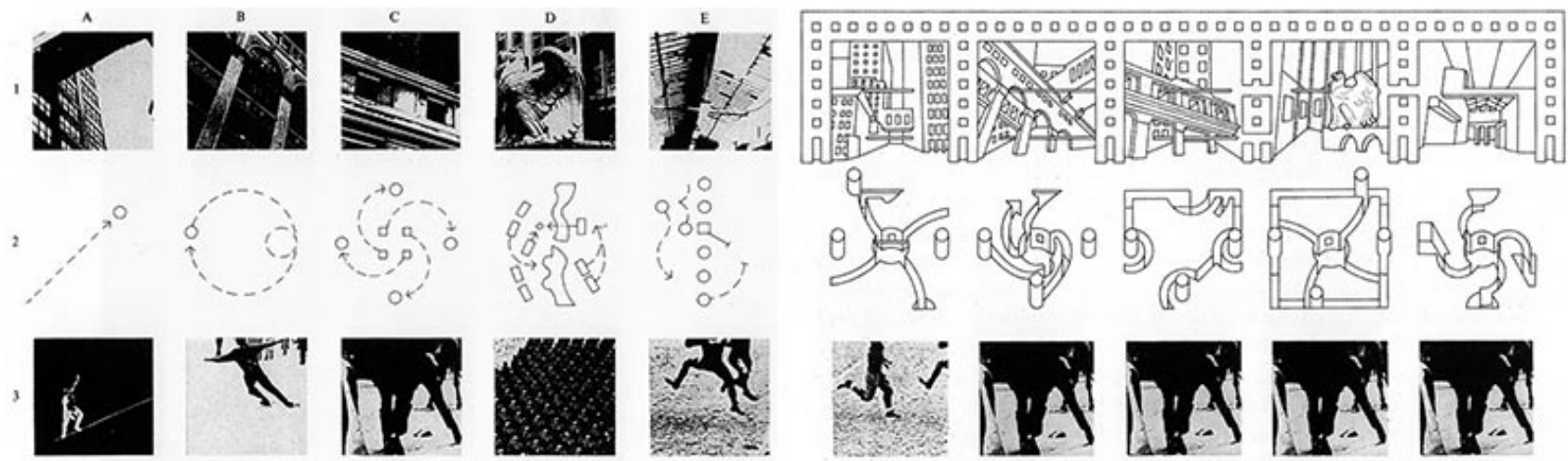

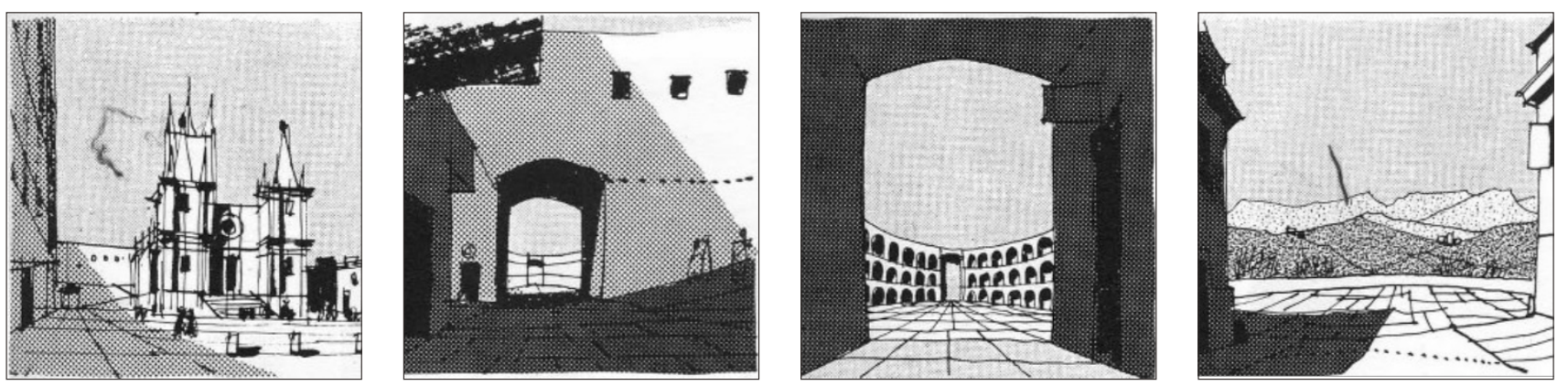
34 MOMENTS OF TRANSITION 


\section{THRESHOLDS, TRANSITIONS, LIMINALITY}

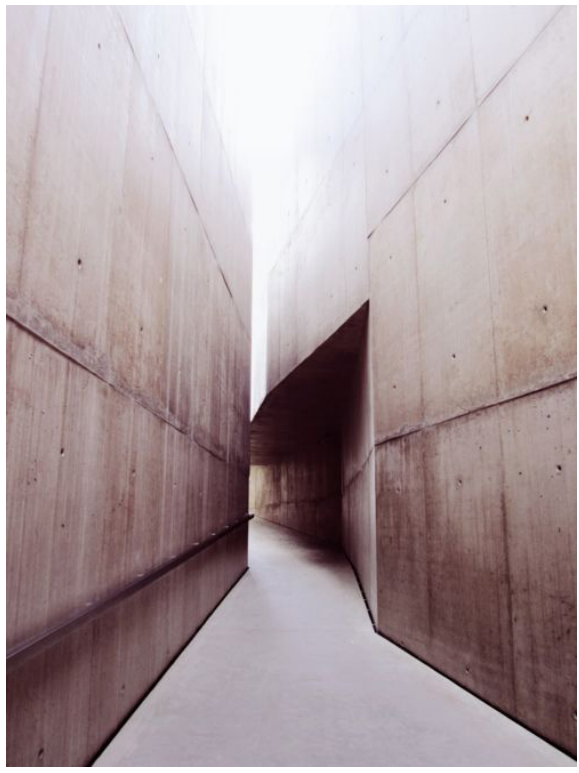

Figure 4.1 (top):

Threshold moment.

Museum of Art and

Archaeology of the Côa

Valley
The character of a man-made place is to a high extent determined by its degree of openness. The solidity or transparency of the boundaries make the space appear isolated or as part of a more comprehensive totality. We here return to the insideoutside relationship which constitutes the very essence of architecture. (NorbergSchulz, 1980, p. 63)

\subsection{Defining thresholds}

Spatial boundaries are crossed on a daily basis through movement. Architecture is based largely on these transitions. Liminality, transitional and the in-between are all words that can be used to describe these moments. Thresholds, in essence, provide a pause from spatial fluidity. They can be seen as both an interruption and a device in intensifying an experience. In Latin, liminal (root of limin) means threshold, and its meaning is "relating to a sensory threshold" or "of, relating to, or being an intermediate state, phase, or condition: in-between, transitional." (Liminal, 2015). Therefore, liminal refers to an intermediate state.

Literally the root of the word limen, liminal or threshold are defined as the region which marks a boundary, the sill of a door separating two rooms or a sidewalk from the road. They are literally the limit of a portion of land from the rest of the universe, creating the 
interior and exterior conditions, a separation from point $A$ to $B$. Society benefits from these limits, creating comprehensible places in order to situate them within the world. Thresholds, in this sense, produce a relationship between two places that are dependent on one another creating differentiation and transition at the same time (Meiss, Elements of Architecture: from Form to Place, 1990, p. 148).

In the architectural sense, once abstracted, thresholds facilitate a flow, a narrative to a work. Interruption and continuity, boundary and crossing, separation and connection all become part of a greater experience. Thresholds control the permeability of a limit, governing spatial continuity or discontinuity, physically and visually. Thresholds have the potential of marking much more than their literal meaning, as space definers or indicators that proclaim the nature of the places they give access to or which they represent. They represent the preface to the perception of an architectural space, helping determine the tone, building up an emotional response and delineating what's ahead. Thresholds are part of a sequence relating to the past, present and future. This in-between zone is defined by Fred Koetter as "the realm of conscious and unconscious speculation and questioning - the zone where things concrete and ideas are intermingled, taken apart and reassembled - where memory, values, and intentions collide." (Koetter, 1980, p. 69). A space that is intentionally ambiguous by definition relies on its temporality and lies between fixed constants.

This thesis is arguing that thresholds are the essence of an architect's joy. The quality of a project's transitions in many ways determine its success. The act of separating, connecting and building commonalities through creating transitions is what ensures a work will flow both spatially and cognitively. Thresholds often become a work of art in architecture. Through the conscious choreographing of a sequence of spaces, architects have the ability to move people and evoke meaning beyond a single space's true reason for being. 


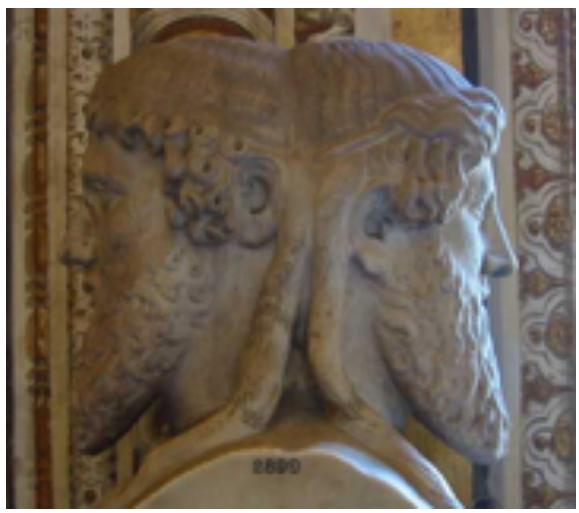

Figure 4.2 (top):

Janus, known in Greek mythology as god of gates and doors.

\section{<trans> as a prefix}

Transformation and transition are words that utilize the prefix of trans and have a direct association with the in-between or liminal. According to the Oxford English Dictionary the etymology of $<$ trans $>$ is derived from Latin and was first used in 1612. <Tra> and <trans> usually refers to 'across, to or on the farther side of, beyond, over' and is used in adjectives, nouns and verbs that have a similar association. <trans $>$ ition; <trans $>$ formation; $<$ trans> cend; <trans>fusion (Oxford University Press, 2016).

\subsection{A ritual}

Thresholds can be can be traced back to Greek mythology specifically to Janus, the god of gates and doors, of beginnings and transitions, endings and time (see Figure 4.2). Pictured as a two-faced god, he consists of both the future and past. The idea of a liminal deity also exists in other mythologies, (including Chinese, Hindu, Korean) and speaks of the importance of these symbolic and physical thresholds. Symbolism attributed to the transition from one state to another often takes on a spiritual association. These could include embarking on a long trip, the transition from childhood to manhood, adulthood to parenthood, etc. (Janus, 2015).

The dictionary definition of liminality is influenced by threshold rituals. The Oxford English Dictionary associates the term's first appearance to psychology in 2884 AD, but further developed by Arnold Van Gennep in his publication, The Rites of Passage (1909) Gennep describes the analogy between various rituals and spaces in different cultures. He differentiates between the profane (secular) and the sacred (religious).

He says the process of transition from one to the other will always occur through an intermediate stage, a journey of preparation, guidelines and rules. He adds:

"So great is the incompatibility between the profane and the sacred worlds that man cannot pass from one to the other without going through an intermediate stage." (Van Gennep, 1961, p. 1). 
He also makes the analogy of life as a series of stages and passages from one to the next -- giving birth, puberty, marriage, parenthood and death. Different cultures attribute these transitional moments to the transition from the sacred to profane, regulated by society and given utmost importance. The essence of the ceremonial regulated transitions is done to heighten the importance of transition from one defined state to the next (Van Gennep, 1961, p. 16). Van Gennep also interprets transitions as having three main stages (see Figure 4.3):

- Rites of separation, referring to the beginning of something and leaving the old behind, breaking free and its metaphorical death.

- Rites of transition, this refers to the actual act of passing between stages, the start of feeling change, and special dislocation.

- Rites of incorporation, the process of taking upon a new being by incorporation into the new stage. Interestingly, Van Gennep speaks of rites of passage as an important part of the social fabric, as they help validate changes of one's status spiritually and in reality. He says:

"A rite of spatial passage has become a rite of spiritual passage." (Van Gennep, 1961, p. 40).

The Acropolis is a fundamental historical precedent and significant in understanding thresholds and the transition from sacred to profane as a meaningful journey through space. The design of the spaces in between breaks the autocracy of it as a mass and creates a new whole (Boettger, 2014, p. 22). "The path through this exterior space allows for a 'step
Figure 4.3 (top): Stages of transition according to Van Gennep.
Figure 4.4 (opposite page, bottom; from left to right):

Acropolis as a threshold of transitional state from profane to sacred. Left; spatial continuum bounded by carful placed space defining elements; Processional immersion within the

Figure 4.5 (opposite page, top): Acropolis, plan. Once passed through initial colonnade threshold, views on each part of the Acropolis are strategically designed to provoke curiosity, establish hierarchy and create spatial cohesion. Acropolis. 


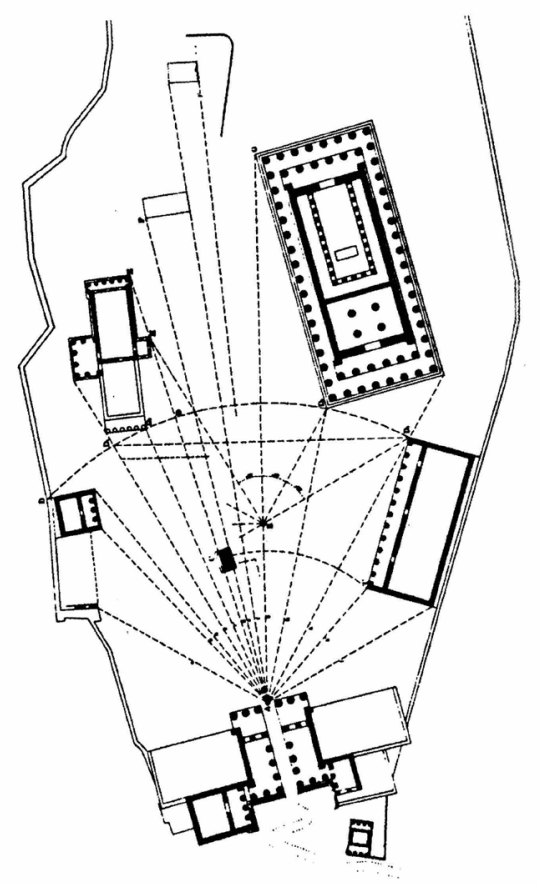

by step' immersion and facilitates an exceptional architectural experience." (Boettger, 2014, pp. 22-24). The separate temples together become intentional space-defining elements - creating a purposeful void - that form a planned interconnected exterior space. The Propylaea also becomes a formal gateway mediating between the inside and outside, framing the exterior space, the elevation change upwards also provides an extended path for experiencing the change in conditions. The Propylaea uses several devices to acknowledge the physical transition from inside to outside - to formally enter the spatial continuum of the Acropolis, one must go through the Propylaea first. The transition is comprised of a staggered height colonnade which pulls the visitor into the space, fully separating the profane in this process, immersing and incorporating into the sacred. Propylaea creates an ambiguous space of transition and procession into the Acropolis and by doing so, leading to a full immersion. Separation, transition and incorporation as discussed by Van Gennep become clear in describing the processional immersion within the Acropolis (see Figure 4.4, 4.5) (Boettger, 2014, pp. 22-24).

The whole experience from the approach to the Acropolis is something that is staged from the moment someone approaches it from below. Through an effective play of visual
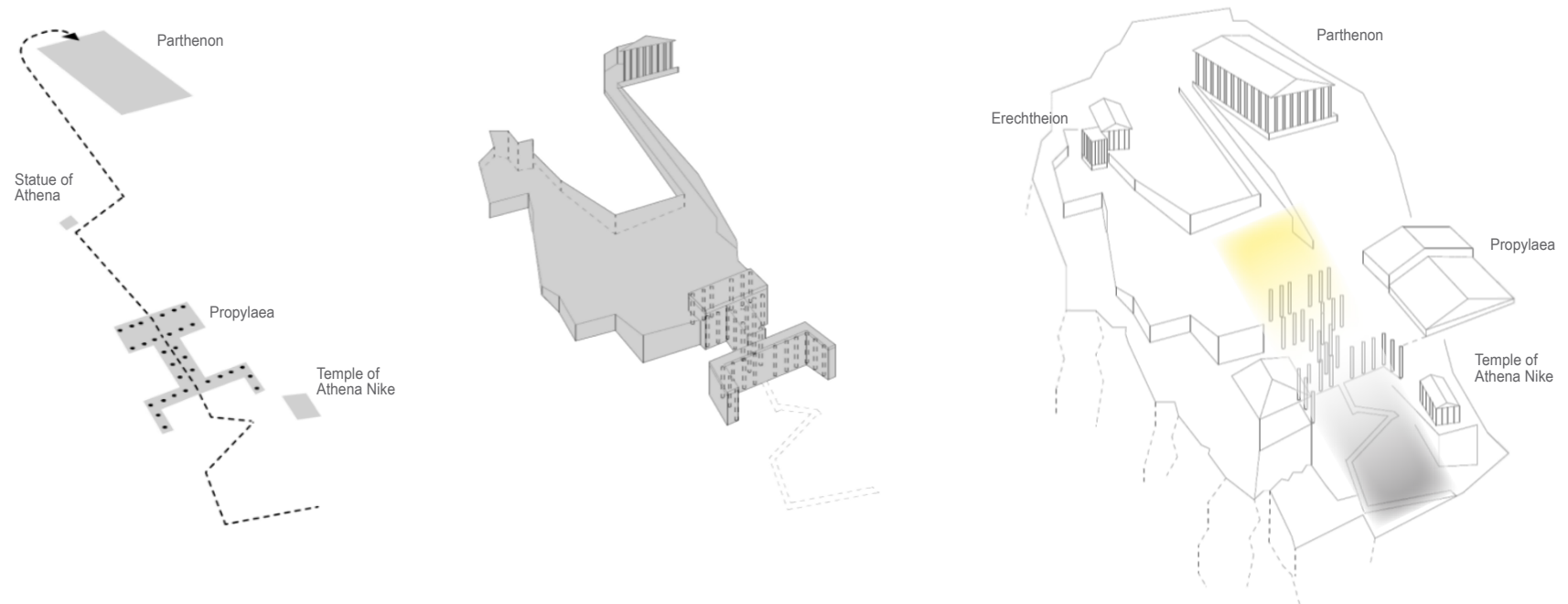
perception, visitors seeing the temples from the distance get the impression that the buildings are all of a similar size despite that not being the case. The perspective makes the Parthenon seem secondary and smaller, making the Erechtesion similar in size when in reality it is the smallest of the structures. The Temple Athena Nike becomes the focal point. Moving upward along the mountain becomes part of a processional path, passing through different benchmarks as part of the process. There are many elements that carefully heighten, anticipate and prepare the sacred way upwards. These include the interconnected exterior space, the derivative void, the journey upwards through layers of elevation change, and the formal and informal gateways. This sequence becomes part of the experience emphasizing the unhasty approach away from the profane (see Figure 4.4, Figure 4.5).

Victor Turner's essay Betwixt and Between: The Liminal Period in Rites of Passage published in The Forest of Symbols is, in a way, a more contemporary interpretation of Van Gennep's theory on Liminality. Published in 1967, Turner expanded on Van Gennep's theory transcending not into anthropology but into other fields. Similarly, he applies a threefold structure that occurs in society to assure hierarchies and healthy separations from one state to another and calls them pre-liminal, liminal, and post-liminal (W. Turner, 1967). He speaks specifically of the enormous potential these stages can possess due to their ambiguity in that they can have an impact on people psychologically, emotionally and physically, positively and negatively. He says:

\footnotetext{
What is interesting about liminal phenomena for our present purposes is the blend they offer of lowliness and sacredness, of homogeneity and comradeship. We are presented, in such rites, with a 'moment in and out of time,' however fleetingly, some recognition (in symbol if not always in language) of a generalized social bond that has ceased to be and has simultaneously yet to be fragmented into a multiplicity of structural ties (W. Turner, 1967, p. 69).
} 


\subsection{Threshold Roles}

In his book Elements of Architecture, Pierre von Meiss discusses three roles of thresholds:

- Utilitarian role - as the functional role of a threshold, a passage for a door, light and ventilation for a window.

- Protective role - as a controlled passageway which is carefully selected. The degree of view and exposure depends on physical and social conditions. Social practices many times govern the extent of protection according to the cultural characteristics of people and the building's program. They are perceived differently in various cultures. For example, window and entry devices are not the same in Islamic countries as in the west. Many times social conations and specific behaviour are the sign of the threshold.

- Semantic role - architectural elements or objects make the passage and transition more meaningful, give it a character and identity. Historically this is many times linked to the existence of ritual. Initial forms of god worship are often linked to a preparation, the worship is linked to a place, and threshold is created as a means for this preparation. In his book Thinking Architecture, Peter Zumpthor makes note of a door handle he remembers from childhood and its sensual importance until this day as part of the whole experience. The door handle is cited here to show how every bit contributes to an experience. These threshold conditions are only amplified when the orchestration of sensual qualities are brought to life (Zumthor, Thinking Architecture , 2010). 


\subsection{Transitional moments typology and precedents}

"In such societies every change in a person's life involves actions and reactions between sacred and proface-actions and reactions to be regulated and guarded so that society as a whole will suffer no discomfort or injury. Transitions from group to group and from one social situation to the next are looked on as implicit in the very fact of existence, so that a man's life comes to be made up of a succession of stages with similar ends and beginnings: birth, social puberty, marriage, fatherhood, advancement to a higher class, occupational specialization, and death. For every one of these events there are ceremonies whose essential purpose is to enable the individual to pass from one defined position to another which is equally well defined."(Van Gennep, 1961, p. 3).

Threshold and transition conditions are found everywhere around us. They frame our daily experiences through both interior and urban spaces. Arguably, they are what make an experience through space more exciting and surprising or, on the contrary, ordinary and mundane. Thresholds are an important part in telling a story. They create tension, mystery and anticipation in an architectural work. Without them, there would be no architectural fluidity, no connection. They are a preparation for what's to come and an indispensable portion of our experience. Roughly, threshold conditions can be categorized into the urban context condition and an interior to exterior condition.

\section{- The triumphal passage}

Triumphal thresholds are ones we are all familiar with, possibly the easiest in understanding the added meaning man has attempted to give them from early on in history. They are usually associated with some sort of historic or significant event and their reason for being is memory. These type of thresholds demarcate space, their threshold becomes a space of its own, at times even a landmark. Usually, a part of our urban or external environment these thresholds become spatial objects of their own, and we refer to them appropriately as they start to define the space around it (Figure 4.6-4.8).
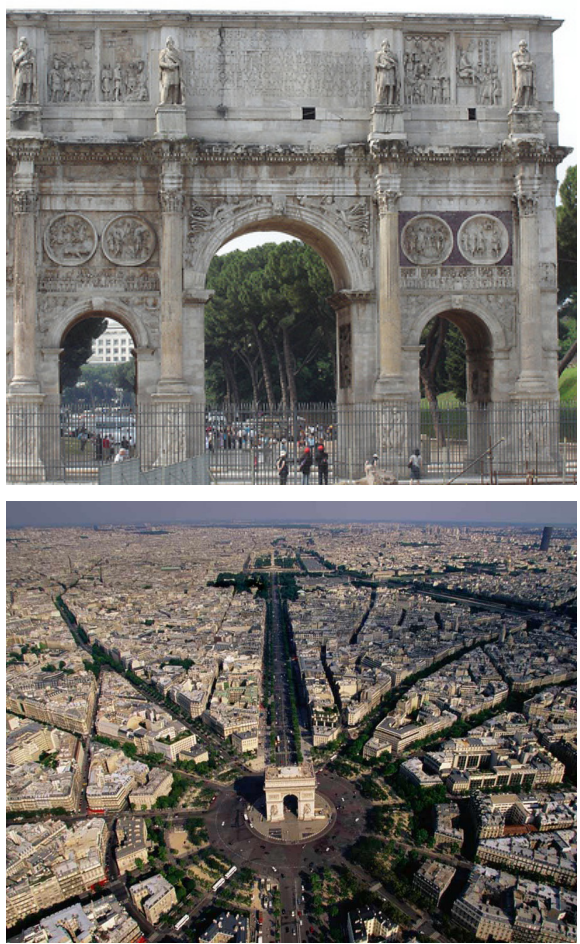

Figure 4.6 (top page): Arch of Constantine, symbolic announcement of victory and a better world on the other side.

Figure 4.7 (middle page): Arch de Triumph, Paris. threshold as an object in space, becoming a definer of space.

Figure 4.8 (right): View through entrance gate. Old city Carcasonne in France. 


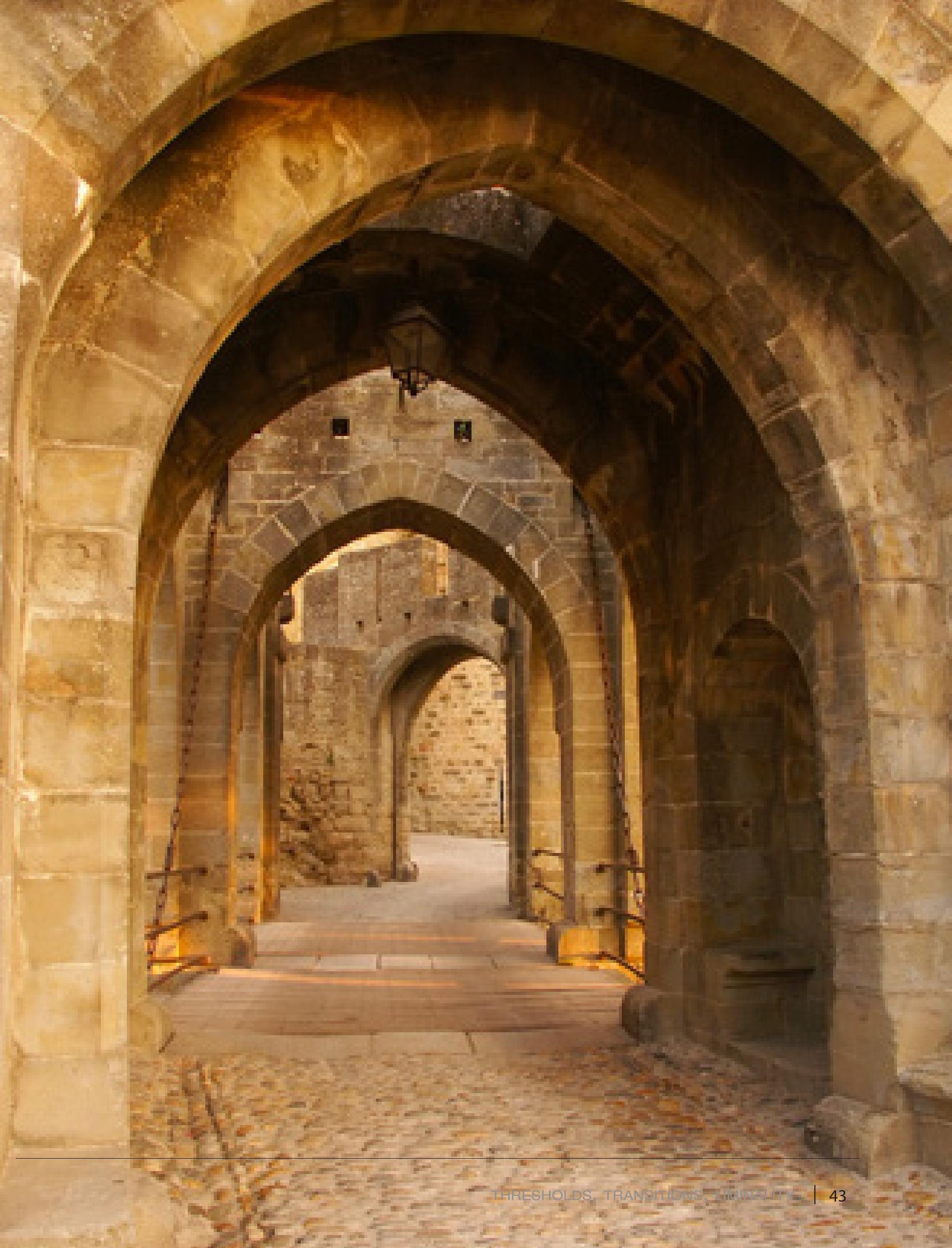




\section{Urban thresholds}

Our urban environment is full of conditions where buildings create unplanned and planned transition/in-between spaces which become part of a greater temporal experience depending on the route of travel. Contrasts of solid and voids are perhaps the best tools. The urban environment facilitates in carving out its negative and positive spaces, which become devices in sustaining urban threshold conditions. The threshold is the mediator between the solid and the void. In a sense, it acts as a 'coulisse' of an urban theatre in framing the two. Urban thresholds happen in various urban scales, from residential to public areas, from a park to a street. The transition, for example, can be the complete contrast between a narrow alley to an open piazza that adds to the richness of the whole experience. In a way, these type of thresholds become somewhat of a loose definition. At times they are even suggestive to their occupant without imposing a specific action, leaving it up to the visitor to choose their journey through the given environment. These type of thresholds become aids in the better defining a spatial environment, as Cullen and Tschumi graphically suggested (see chapter 3). As discussed space is a function of time and movement in it, so is threshold, perhaps even more. Movement is indispensable to it as it is the sequence within it that will determines one's experience. A threshold becomes a product of the approach to it, the transition within it, and how it frames what's ahead.

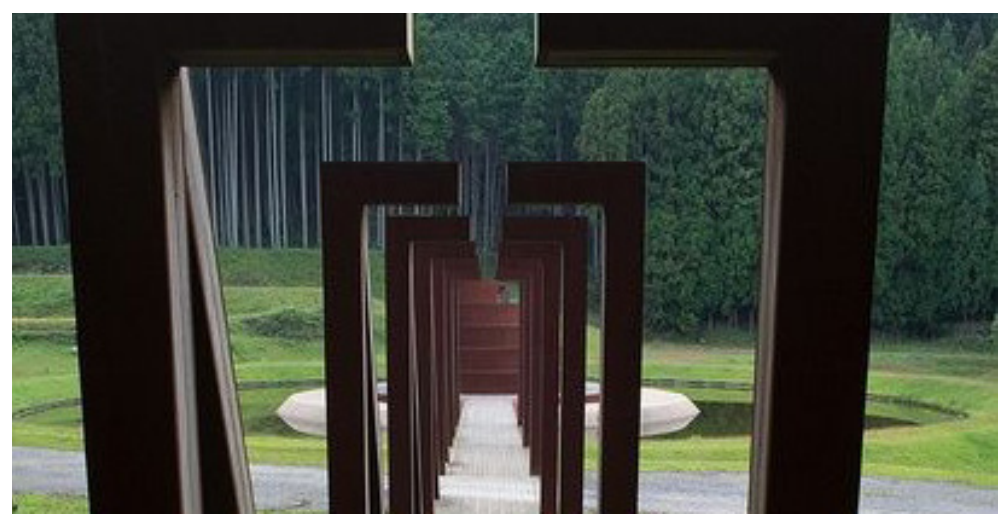

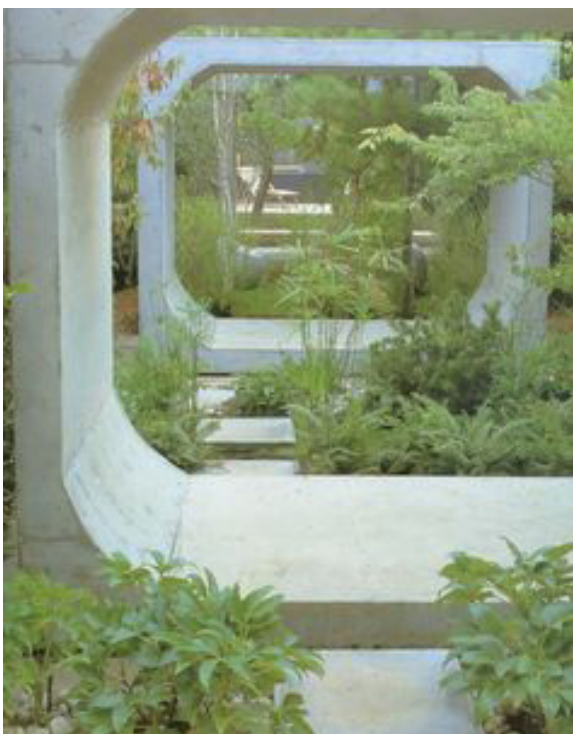

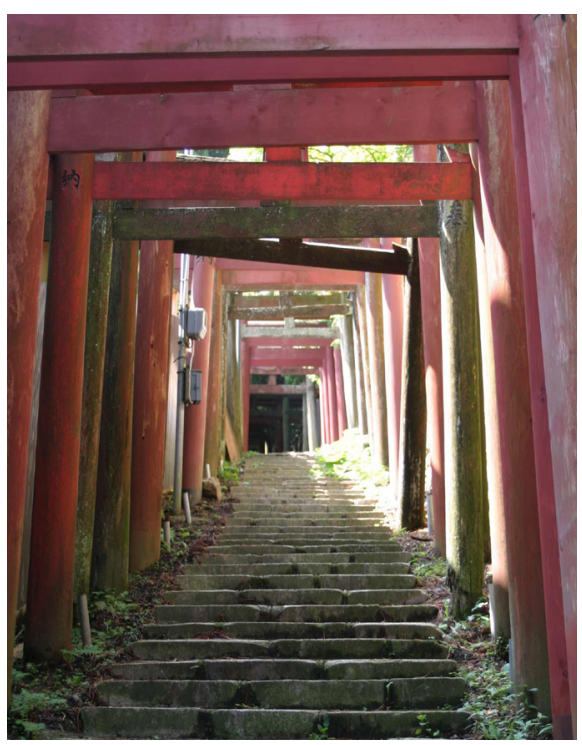

Figure 4.9 (left): Murou Art Forest, Japan. Thresholds defining and framing space.

Figure 4.10 (top): Threshold framing space and becoming part of its environment.
Figure 4.11 (above): Typical example of a Japanese Torii gate. Usually marking the transition from profane to sacred. 


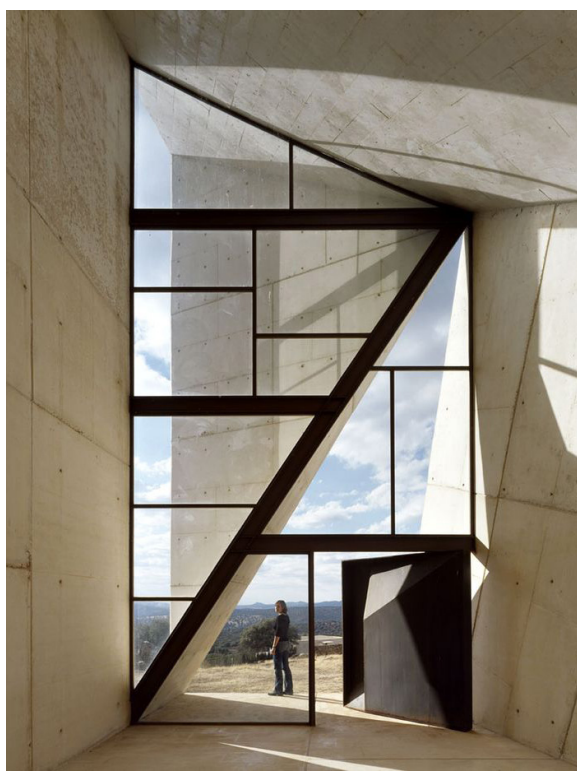

Figure 4.12 (top):

Entry threshold of

chapel in Valleaceron /

S.M.A.O.; a careful medi-

ator between exterior to

interior.

Figure 4.13 (below):

Postopolis, Storefront for

Art and Architecture. dy-

namic interior to exterior

threshold condition.

\section{Intermediate passage: Interior to exterior conditions}

Threshold, with respect to the built environment, refers to something as simple as a door, or conversely to something as elaborate as a stairwell, corridor or grand lobby. At times, threshold conditions become blurred as they mesh with other spaces fusing a flexible definition of what a threshold is. The relationship between the built form and its immediate external environment is also a threshold, despite there being a main threshold, namely the front door. Porosity can occur on different fronts.

The following precedents attempt to look at thresholds from different perspectives and themes. Despite their being an overlap of multiple themes for each precedent, I have chosen to locate precedents where they fit most appropriately to the category (yet could still be relevant to others).
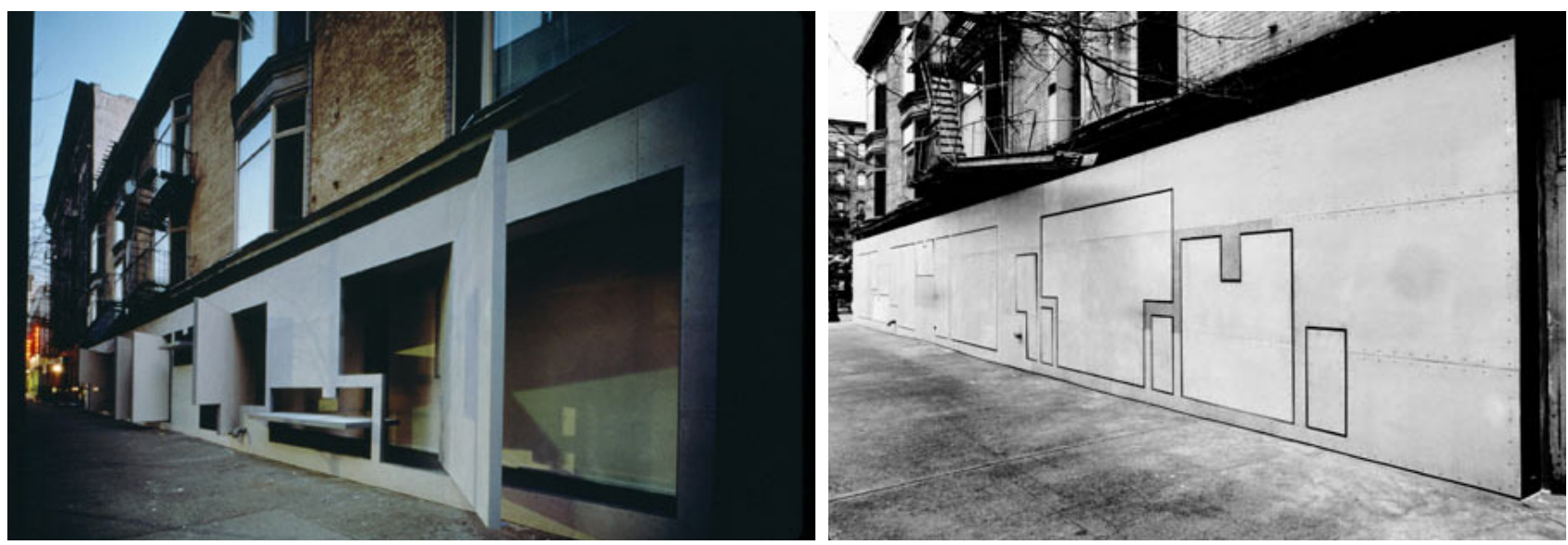


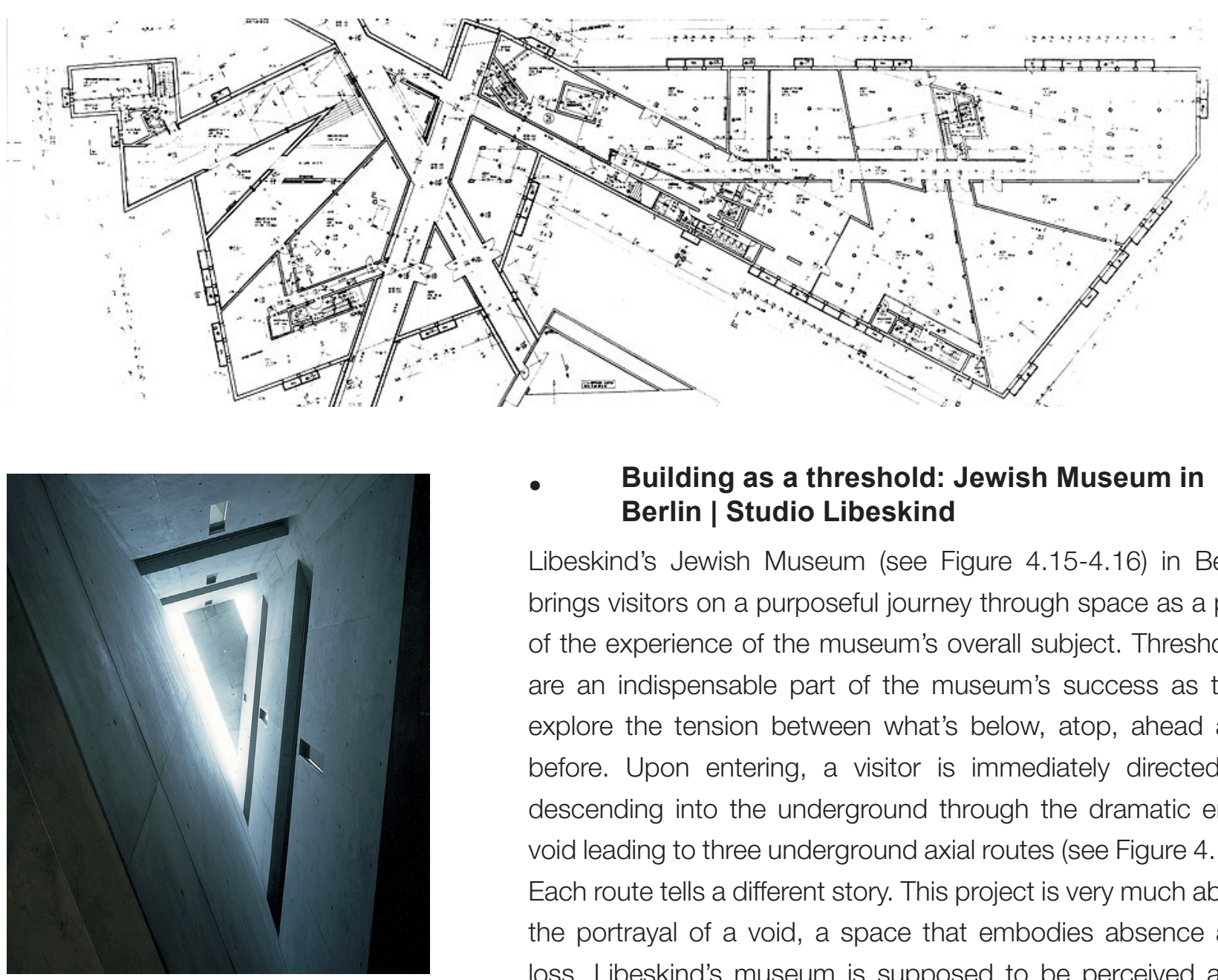

- $\quad$ Building as a threshold: Jewish Museum in Berlin | Studio Libeskind

Libeskind's Jewish Museum (see Figure 4.15-4.16) in Berlin brings visitors on a purposeful journey through space as a part of the experience of the museum's overall subject. Thresholds are an indispensable part of the museum's success as they explore the tension between what's below, atop, ahead and before. Upon entering, a visitor is immediately directed to descending into the underground through the dramatic entry void leading to three underground axial routes (see Figure 4.14). Each route tells a different story. This project is very much about the portrayal of a void, a space that embodies absence and loss. Libeskind's museum is supposed to be perceived as a whole experience and not solely by its individual rooms. It is the anticipation of wandering through thresholds between spaces that feeds a sense of curiosity and sets the mood of what is to come, and the memory of what was just experienced (Kroll, 2010).

Figure 4.14 (opposite page): Underground descend leading to an axial route as part of Libskinds's Jewish museum transitional spaces.

Figure 4.15 (above): Void as an indispensable design strategy
Libskind uses in addressing loss throughout the museum's journey.

Figure 4.16 (top): Plan of Libeskind Jewish Museum. Labyrinth where each transitional space becomes an experience of its own. 


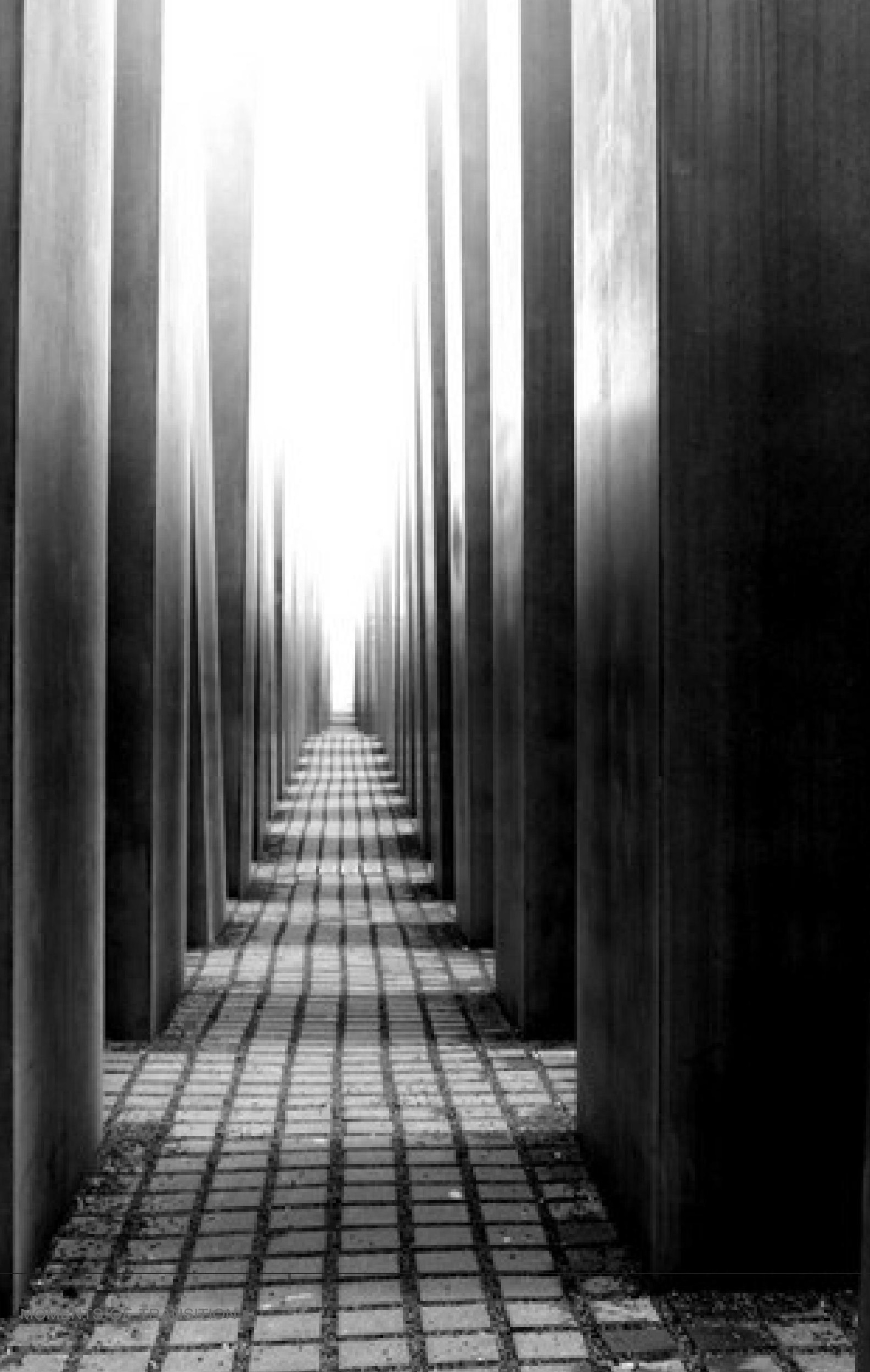



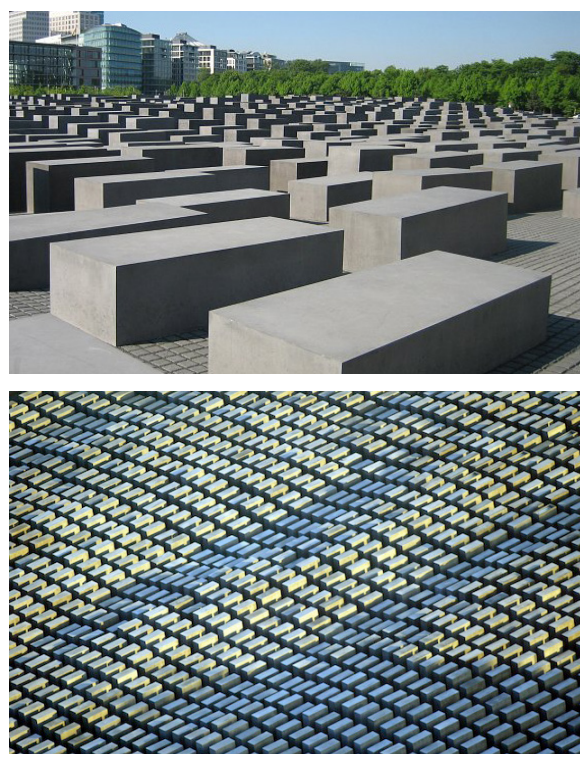

Figure 4.17 (left):

Complete loss of spatial orientation and perception of space as one walks through the memorial. Achieved through scale, proportion, change in elevation, and openings.

Figure 4.18 (top): Contrast between the seemingly understandable grid of the memorial when first approaching it vs the actual mass and dimension of it from an aerial view and going through it.
- Perception of space: Memorial to the Murdered Jews of Europe | Peter Eisenman

The Berlin Memorial to the Murdered Jews of Europe is an example I look at often for its formal simplicity yet complex architectural experience I associate with it (see Figure 4.17). This is a vivid example of non-direct preservation of artifacts yet a creation of a multifaceted experience which touches the consciousness and unconsciousness of a user through enhancing and altering the perception of space. "[T]his monument has no goal, no end, no working one's way in or out," Eisenman says. "The duration of an individual's experience of it grants no further understanding, since understanding is impossible" (Sion, 2015, p. 70).

Consisting of a $19,000 \mathrm{sq} \mathrm{m}$ site with 2,711 concrete slabs arranged in a grid pattern on a sloping field, this memorial touches on a multisensory experience that engages not only sight but the whole body. It is both overwhelming yet stimulating as you can seemingly see what lies ahead of you when you start the journey through it. Yet when one enters the narrow paths where one can only walk alone, planes become confusingly sloped and sight lines are reduced or diminished. Concrete slabs vary in height throughout one's journey proportionally changing one's experience through space at all times. Eisenman speaks of how such a seemingly rational grid when it becomes too big and scales are blown out of proportion in relation to its original purpose lose their connection with the human reason (see Figure 4.18). The constant changing environment of a user also changes the amount of light and shadow penetrating, enhancing the feeling of loss and confusion (Eisenman, 2005). I see this work as important in understanding how manipulation of space and its perception through the exaggeration of scale, proportion, and planes can achieve an evocative architectural experience relating to the senses. An example of historical events which are intended to be understood through an experience, both physical and sensorial. 

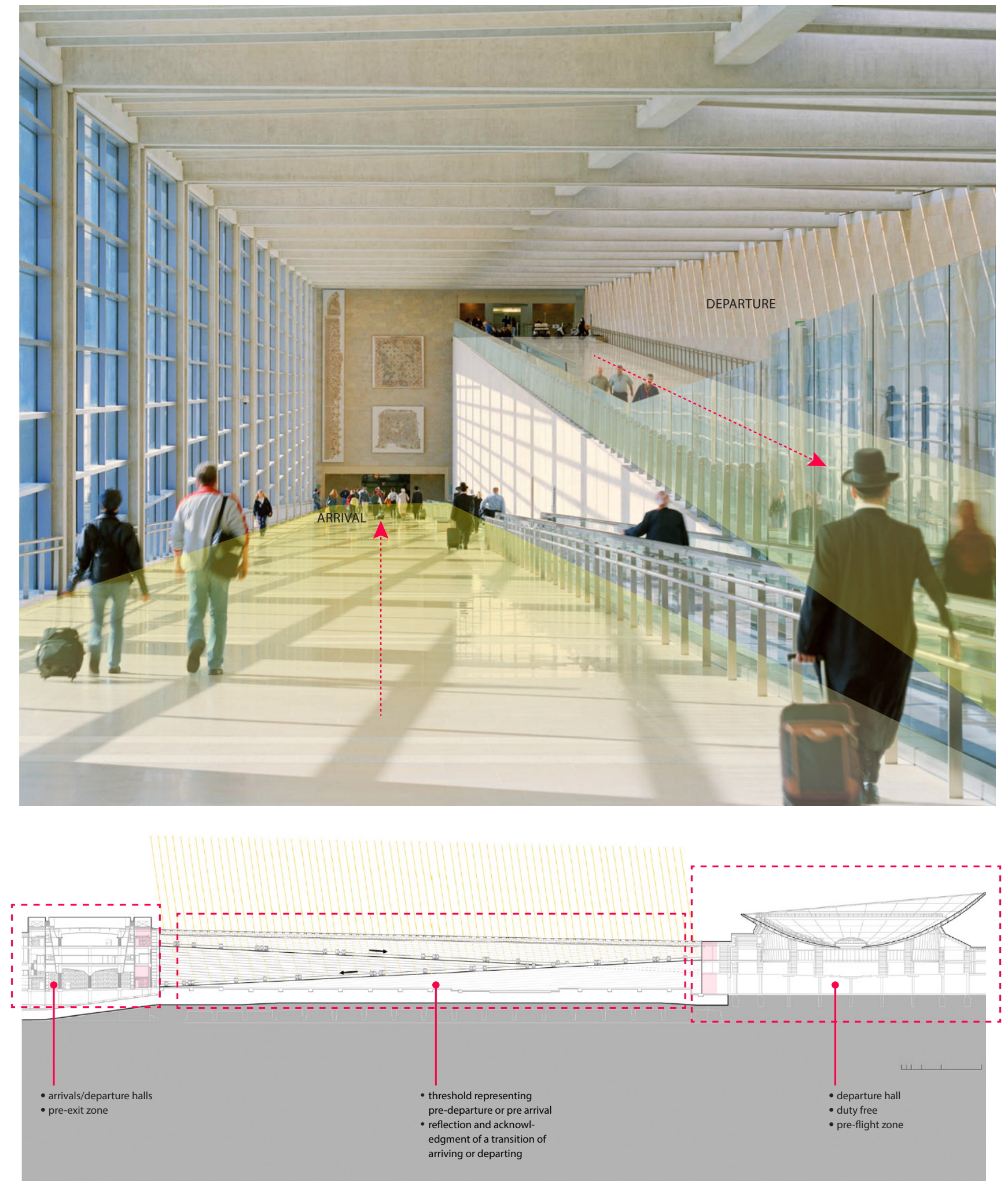

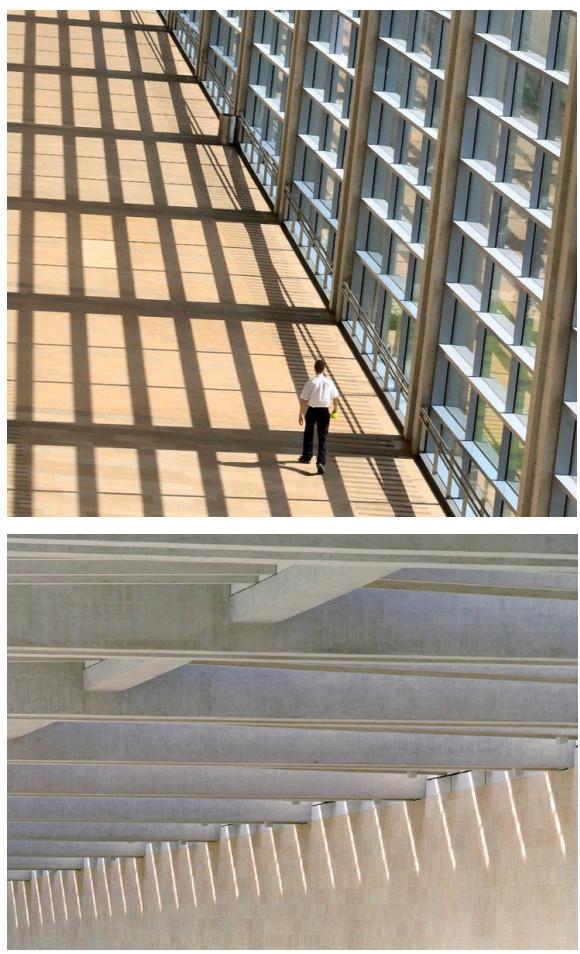

Figure 4.19 (opposite page, top left):

Arrival and departure threshold space. Each is preparing for what's ahead. Use of visibility, light and shadow, and proportion to enhance this experience.

Figure 4.20 (opposite page, bottom left): Section outlining Arrival and departure threshold space.
Figure 4.21 (top): The experience achieved through the movement in space are further enhanced by the in elevation, light and shadow enriched though the repetitive formal ceiling matching the movement through space. proportion, change

\section{Acknowledging the transition: Ben Gurion International Airport | Safdie Architects}

The arrival and departure hall was designed as a transitional space that seeks for user acknowledgement as he/she is going through it. The proportions of spaces that make this experience greater back this up. Each space is approached from passport control, smaller corridors spaces, this space calls out transition (see Figure 4.19). Being a triple height space, the approach to arrival or departure are done from two ends of the hall, each with a higher or lower vantage point of the other. Interestingly, both directions are of downward movement. As one progresses down to arrival or departure, there is a difference of visual awareness of the other's route.

The experience achieved through the movement in space is further enhanced by the proportion, change in elevation, light and shadow enriched though the repetitive formal ceiling matching the movement through space. Both routes begin and end with a single height entrance or exit node at the start and end of the space compared with the heightened feeling of this space. These help in preparing the user of the transition from the end of trip to back-to-life, or from the embarking on a journey and leaving everyday life (see Figure 4.21). Having personally gone through this space many times while arriving in and departing from Israel, this space doesn't cease to amaze me in its transitional aspect, as there is something about its length, seeing the other side, the reflection of light and shadow, that makes me anticipate and acknowledge an end or a beginning for what I have experienced or what is to come. 


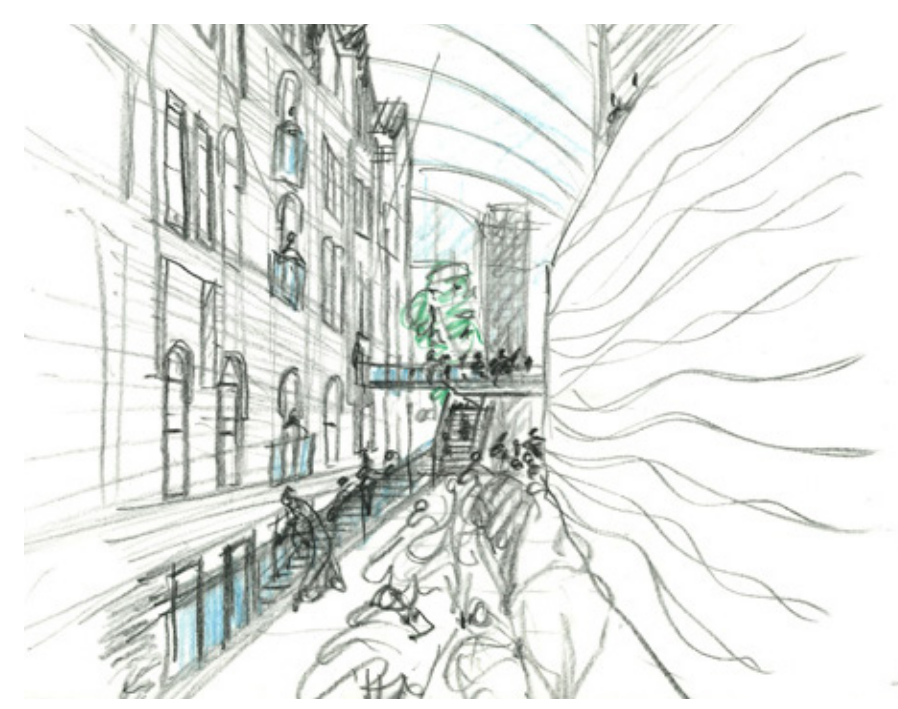

RCM calcert Hal n. 10.02

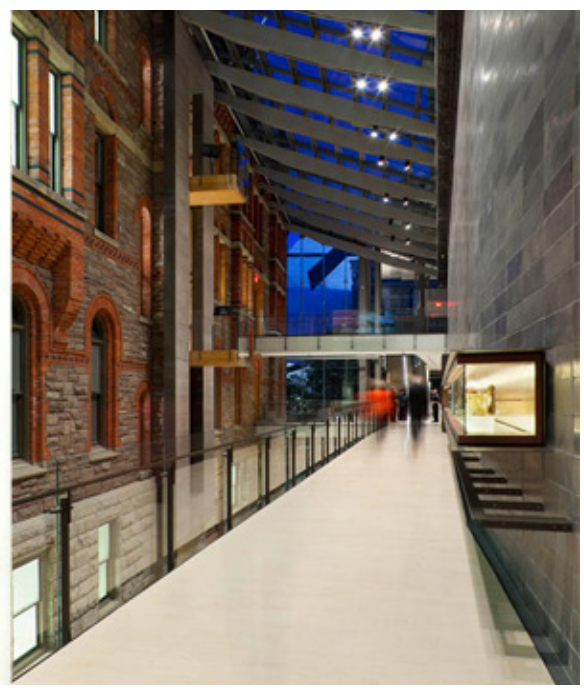

\section{- Bridging the new and old: Royal Conservatory | KPMB}

Old and new. Past present and future. Heritage and conservation of past built forms with the combination of the new demands a proper mitigation of what is existing vs what is new. Transitional moments within these kind of buildings need to be properly resolved, either through a complete rejection or an acknowledgment of the existing. I believe the experience of these types of space first and foremost, even before their function, should convey the succession of time, and is a technique for dealing with it. Entry begins with an ascent upwards without seeing the existing building but going through a series of stairwells, coat check, WC and corridors until you reach a four-story space (see Figure 4.22), the great court as a transitional space before reaching the lobby and the concert hall. This space stands as an in-between zone, mediating between the past existing building and the new concert hall. This zone is intentionally left as a four-story height space, and users are able to look down and up to fully appreciate and acknowledge the tension and difference between the two.

Figure 4.22 (top): Original concept sketch of Great Court by Marianne McKenna and Great Court looking East. Mediating the old and new. 


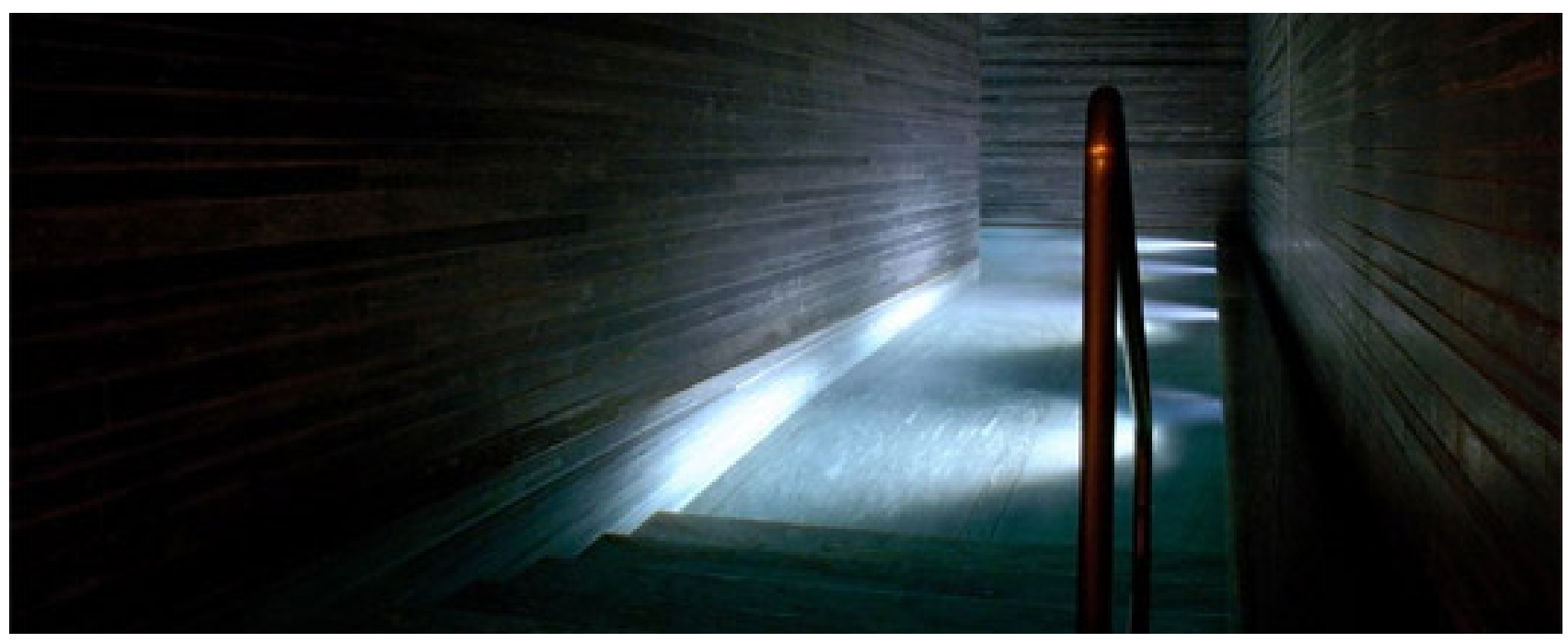

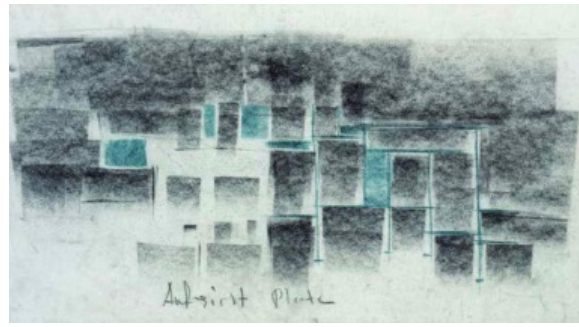

Figure 4.23 (top):

Therme Vals, complete sensory experience.

Figure 4.24 (bottom): Therme Vals, sketch by Zumthor

\section{Sensorial transitions: The Therme Vals I Peter Zumthor}

"Mountain, stone, water - building in the stone, building with the stone, into the mountain, building out of the mountain, being inside the mountain - how can the implications and the sensuality of the association of these words be interpreted, architecturally?" (Zumthor, 2009)

The importance of the sensory aspect of every architectural experience is of outmost importance for Zumthor. Materiality to him can help people recall places and create thought-evoking sensual qualities. Built over the only thermal springs in its area in Switzerland, Therme Vales aims to achieve a complete sensory experience for its users. Formally creating a cave-like structure partially buried into the hillside, Therme Vals is built from a local quarried stone, layered on top of each other in slabs. The progression through space is carefully articulated to enhance private, informal and public spaces within the complex. Light and shadow, open and closed spaces, the mystic qualities of stone in enhancing light reflection on the water, the steam in the air, and acoustical qualities are all aspects that enhance the sensuous experience of this project (see Figure 4.23). This work was important in understanding the significance of positioning materials in certain ways, orchestrating them in a way that is highly evocative. To Zumthor, this creates a presence and life in his buildings (The Therme Vals / Peter Zumthor, 2009). 


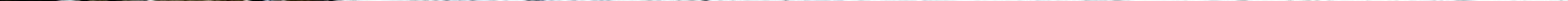




\subsection{The sensual explored in transitions}

"The hands want to see, the eyes want to caress" - Johann Wolfgang von Goethe

So far, my writing has been mainly focused on the categorization, identification and explanation of transitions in architecture. As discussed, our day-to-day experiences and literal transitions through space can be influenced by many factors, which we as architects sometimes have no control over. Inner feelings, mood or psychological state all have an influence on the way one experiences a space, or doesn't because of this. On the other hand, at times it is the architect's intended choices of design that can affect a whole experience thoroughly. Transitional spaces can be mundane or alternatively inspiring, evocative and almost 'speak' out to its occupiers.

In his book The Eyes of the Skin, Juhani Pallasmaa addresses the importance of the sensorial and phenomenological dimension of a human experience through architecture. Pallasmaa is concerned with the dominance of vision and the suppression of the other senses in the way architecture is taught and viewed. He calls it a 'short circuit' in light of the significance of the other senses in our experiences and understanding of the word

Figure 4.25 (left): Zumthor's Bruder Klaus Field Chapel. Hollowed blackened cavity and charred walls. (Pallasmaa, 2012, p. 6). The title of his book, The Eyes of the Skin, is a direct statement of Pallasmaa's critique and where he later explains that our skin actually is able to distinguish a number of colours. He also brings medical evidence confirming 
touch as being the "parent of our eyes, ears, nose, and mouth" (Pallasmaa, 2012, p. 12). He says, "Life-enhancing architecture has to address all the senses simultaneously, and help to fuse our image of self with the experience of the world." (Pallasmaa, 2012, p. 12)

Interestingly, Pallasmaa is referring to everyday architecture in his discussion and criticizes it for its lack of epistemology of the senses. He argues this causes architecture and cities to become inhumane and therefore neglecting the importance and centrality of the human body in understanding the built world. (Pallasmaa, 2012, p. 21). "Modernist design at large housed the intellect and the eye," he says, "but it has left out the body and the other senses, as well as our memories, imagination and dreams." (Pallasmaa, 2012, p. 22). He explains that we were not always dominated by vision and cites different examples of past cultures where smell, taste and touch had a collective importance in collective and personal cultures.

The importance of a sensory experience is not understated enough to him. He believes this involves an experience where the human body is in its conscious centre where it is the one truly experiencing the city and the built environment. To him, the smallest details become part of a sensorial experience - our legs, for instance, measure the length of an arcade, our body will feel this and will sense the size of recesses and feel the mass of a cathedral door. These are all seemingly tiny details of a whole, yet essential in one's experience of the world, of a place, and of architecture. Pallasmaa believes that "sensory experiences become integrated through the body, or rather, in the very constitution of the body and the human mode of being." (Pallasmaa, 2012, p. 44). It is our body then which is in constant movement and in continuous interaction with the environment and the world. Experiencing architecture will always occur in relation to something else. "It is not an isolated and self-sufficient artifact." (Pallasmaa, 2012, p. 44), as described earlier in this thesis. 
An architectural experience will always be measured primarily through the eye, ear, nose, skin, tongue, skeleton and muscle. Pallasmaa refers to James J. Gibson who looked at how it is not only vision or the classic five senses that measure an experience but actually five sensory systems that utilize at least 12 senses as assumed by the Stirnerian philosophy (Pallasmaa, 2012, p. 45). These five systems are better known as the visual system, auditory system, taste-smell system, basic orienting system and the haptic system and are further explained by Gibson.

Senses in architecture have also been widely discussed by Peter Zumthor and has been the topic of his discussions and books. He said "we perceive atmosphere through our emotional sensibility - a form of perception that works incredibly quickly, and which we humans evidently need to help us survive." (Zumthor, 2003, p. 13).

The first interaction or impression one will have with a building can often be misleading, he says. This is the power of our immediate emotional and intuitional response which is comparable to the power of music to draw you in on the first note.

Similar to Pallasmaa, he says that beauty on one hand is in the eye of the beholder yet at the same time is highly dependent on one's psychological, emotions and mood on a certain day and at a certain hour. On the other hand, he explains that the beauty in architecture is a simple alignment or placement of form. The creation of space can arouse and change our emotions, our moods, our feelings, positively or negatively. This to him is the 'magic of the real world.' He acknowledges that feelings generated when seeing a work of architecture, or even art, are highly related to personal sensitivities but he strives to find some measure in deciphering what arouses these sensitivities.

1. The Body of Architecture - Materiality and its effect and presence in an architectural masterpiece. The tectonics and combination of different materials to create a space

2. Material Capabilities - The combination of materials and 
their properties and the way they react or rely on one another. "Material is endless. Take a stone, you can saw it, grind it, drill it, drill into it, split it or polish it - it will become a different thing each time." (Zumthor, 2003, p. 25). Materials offer so many opportunities of light reflection, texture, visibility and presence.

3. The Sound of Space - Interior space will collect, amplify and transmit sound but that has to do with the particular shape of each space and the materiality.

4. The Temperature of a Space - Atmospheres are highly reliant on the temperature that a building or space possesses. Some materials can help in this, by extracting heat or warmth. "Temperature in this sense is physical but presumably psychological too. It's in what I see, what I feel, what I touch even with my feet." (Zumthor, 2003, p. 35)

5. Surrounding Objects - Zumthor comments on the arrangement of objects that people keep around them. Here he wondered if the architect's job is to merely design the "receptacles to house objects?" (Zumthor, 2003, p. 37). In a way, this is the future of the spaces architects design, the way people inhabit them and make them their own.

6. Between Composure and Seduction - Architecture and movement. Architecture is both a spatial and temporal art. Zumthor speaks of the importance of, on one hand, inducing a sense of freedom of movement for people without direct guidance, a casual stroll by means of seducing people, arousing their curiosity. He gives the example of hospital corridors, and how they are all about directing people where to go as quickly as possible, but some buildings allow this "gentle art of seduction." (Zumthor, 2003, p. 43), He says this is one of the great powers of being an architect. He speaks of Thermal Vals as an example of spaces where his intention was for people to feel as they were drawn in, as if they wanted to stay, and not just pass through. Allowing people to guide 
their experience through space. "Direction, seduction, letting go, granting freedom." (Zumthor, 2003, p. 43). He says that he admires works of cinema for their ability to draw you in. He tries to make his architecture that way. He speaks of the synthesis of elements that make this happen, "Guidance, preparation, stimulation, the pleasant surprise, relaxation." (Zumthor, 2003, p. 45).

7. Tension between Interior and Exterior - thresholds, crossings

8. Levels of Intimacy - Proximity and distance, scale and proportion of the building relative to a human and alternatively the proportion to things that are smaller than humans. The details. Size of a thick door vs a thin one. A thick wall vs a medium thickness.

9. The Light on Things - Light and shadow. Temporal aspects of it. How certain walls will sparkle, have a different depth. Choose materials that emphasize this.

\subsection{A choreographed sequence: Slow House | Diller and Scofidio}

As accurately noted by Le Corbusier, "an architecture must be walked through and traversed..." (Le Corbusier, 1999, p. 45). Architecture and experience can only be truly judged by walking through it, the act of moving through it. The accumulation of the succession of spaces make the experience whole. The transitional state is directly linked to movement in a temporary timeframe. Wolfgang Meisnheimer calls thresholds "tools for architectural choreography" (Boettger, 2014, p. 10). He identifies the dual role they have -- connecting and separating. Through the process of dissecting and putting back together into combinations and meanings, a journey, a story through space occurs, and the architect is its narrator and choreographer.

Slow House by Diller and Scofidio began as a proposal for a 


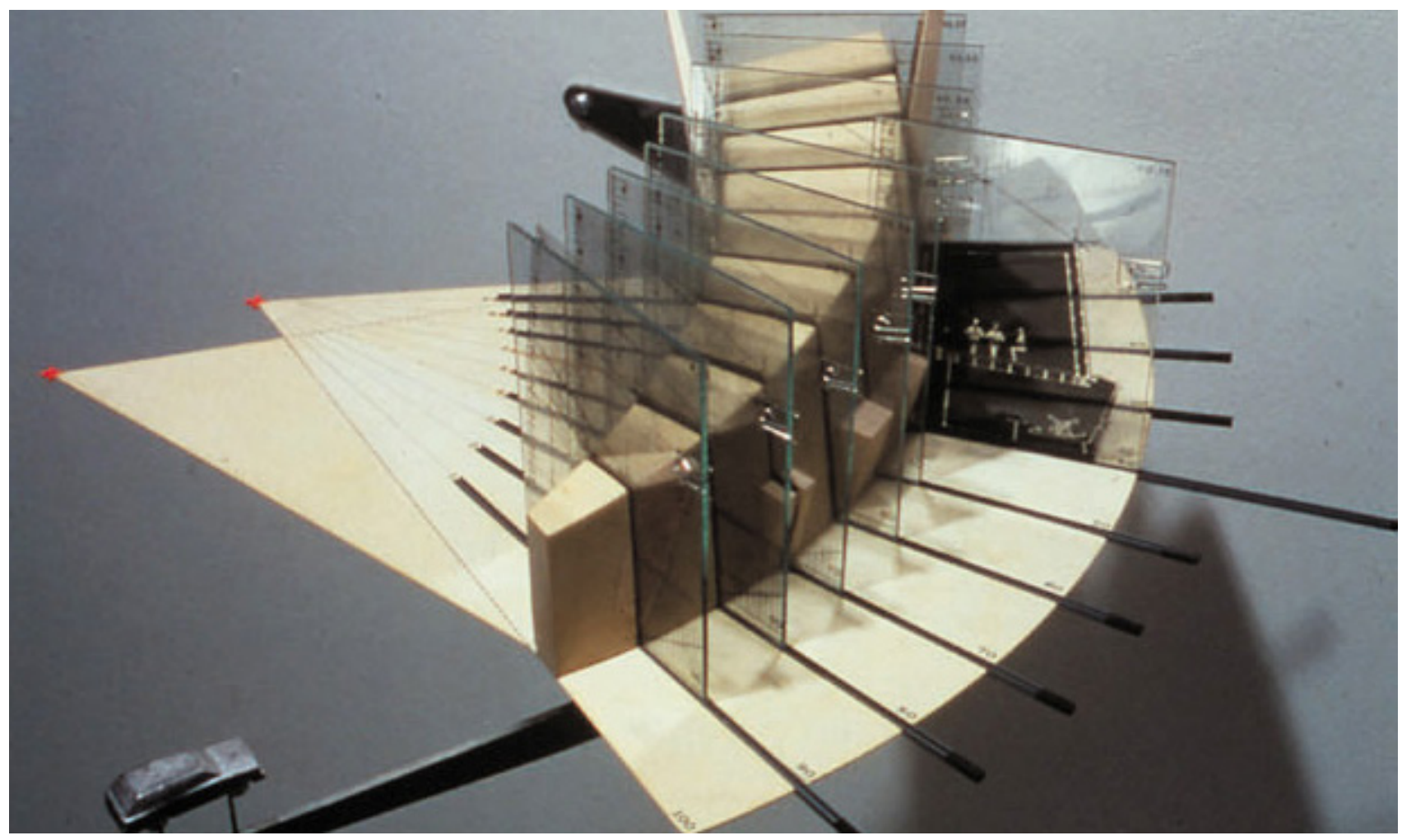

vacation house in Long Island. Movement and the sequence through space were the driving force for this proposal. The movement through the house is designed to gradually deliver the user from the front door to the window view. However, in

Figure 4.26 (top): Model of Diller and Scofidio's Slow House illustrating section cuts through it.

doing so, Dillar and Scofidio began thinking of the trajectory journey through the house as a series of moments one has to pass through until reaching the window. Their model (see Figure 4.26) sliced through, illustrates the change in settings through the progression of its program.

\subsection{The process of transition}

How do we move in the state of inbetweeness, the passage, transition, and threshold can prepare us for a spatial experience with a deeper meaning into the associated architecture. "Threshold spaces should be used as perceptual and cognitive architectural access to immersion in architectural experiences" 
Figure 4.27 (top right): Threshold sequence phases compared to a plot's phases

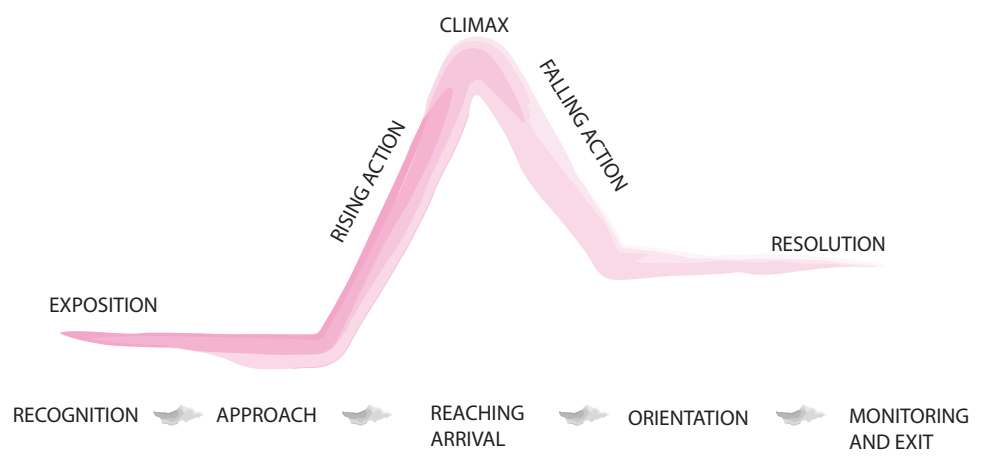

(Baudrillard \& Nouvel, 2002 , p. 61), and their design will determine the character and atmosphere found there.

'Threshold space' used in architecture by Ilka and Andreas Ruby to describe the experience of space is highly dependent on sequence. In his book "Threshold Space," Till Boettger quotes them, "[t]he entrance [...] is becoming a less spatial element and more a complex spatial sequence. We do not enter at a particular point, it is a process in space and time. So the threshold is no longer linear but a 'threshold space' that can be both in front and behind the façade." (Boettger, 2014, p. 48). Threshold space is strongly determined not only by tension biding counterbalances but also by the sequence in which a space is experienced.

Like a structured play, a threshold can have a sequence which creates a story, through anticipation and tension. This sequence can be divided into phases (see Figure 4.27). 


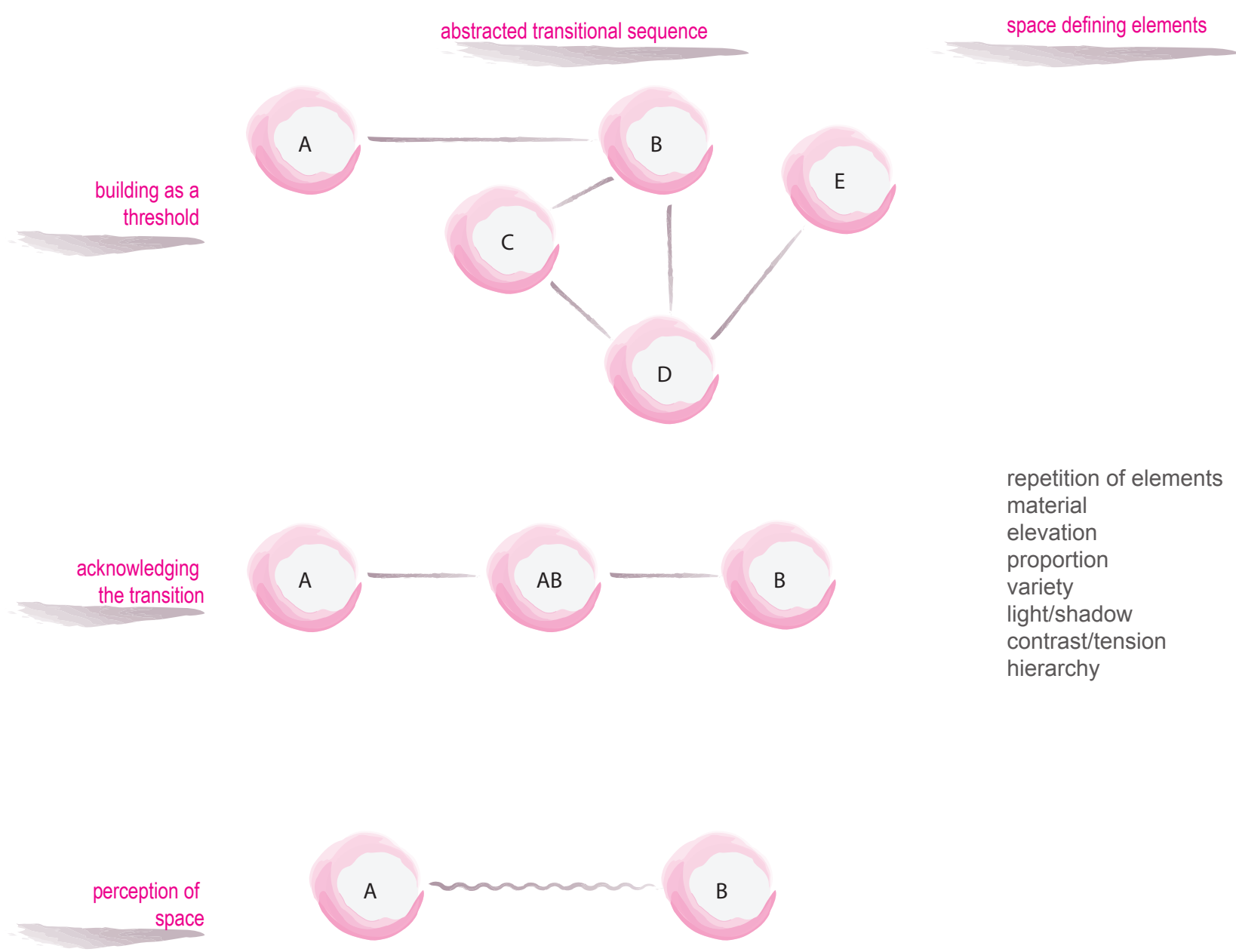

\subsection{Transitions typology study and Design explorations}

In exploring the transition typology in Section 4.4, I have chosen to look at three of the categories in greater detail -- buildings as a threshold, acknowledging the transition and perception of space. This involved implementing a precedent matrix and looking at other project examples having similar criteria (see Figure 4.28, 4.29). Further investigation involved making study models within each category. Every model was carried out with careful understanding of its respective category and attempting to let its defining elements have the power to convey formally and emotionally certain outcomes. Diagrammatically, each model had the intention of looking at an A to B scenario.

Figure 4.28 (opposite page): Transitions typology precedent study.

Figure 4.29 (top): Transitions typology study. 
building as a threshold

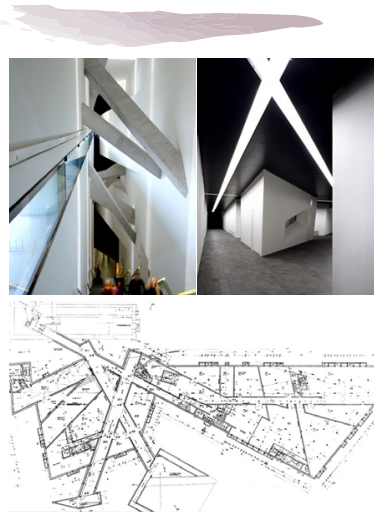

Jewish Museum Berlin I Studio Libeskind

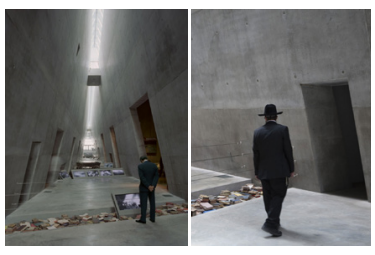

Yad Vashem I Safdie Architects
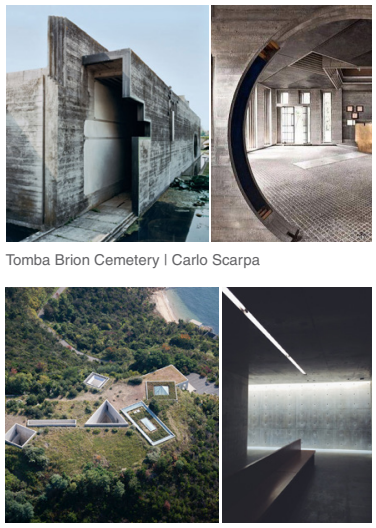

Chichu Art Museum I Tadao Ando

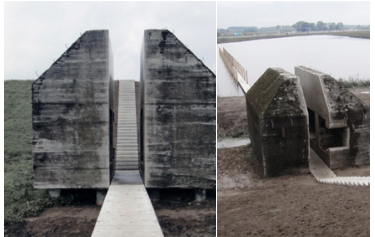

Bunker 599 | RAAAF + Atelier Lyon

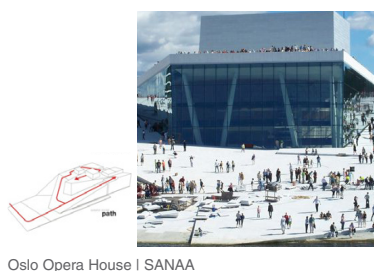

Acknowledging the

Transition
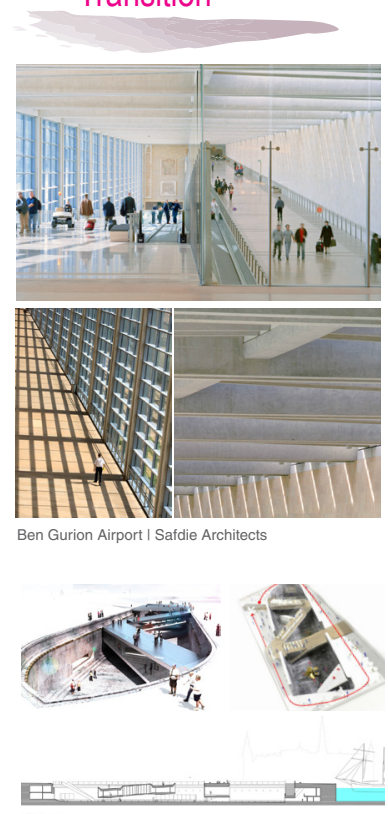

Danish National Maritime Museum I BIG

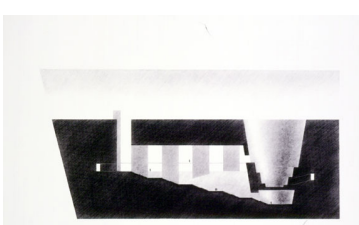

Theatre in the Rock I Tadao Ando

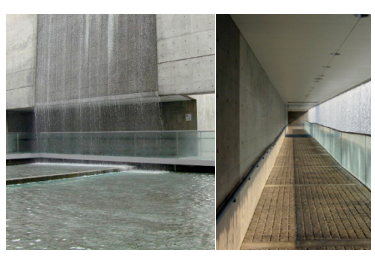

Sayamaike Museum I Tadao Ando

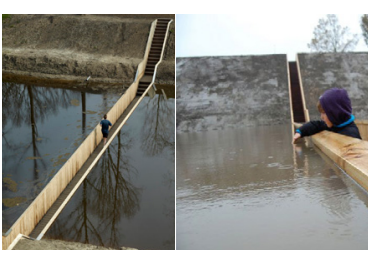

Moses Bridge | RO\&AD Architecten

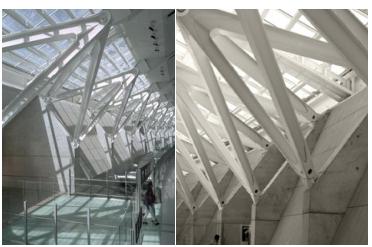

Toronto's Terminal 1 | Safdie Architects
Perception of Space /

Sensorial Transitions
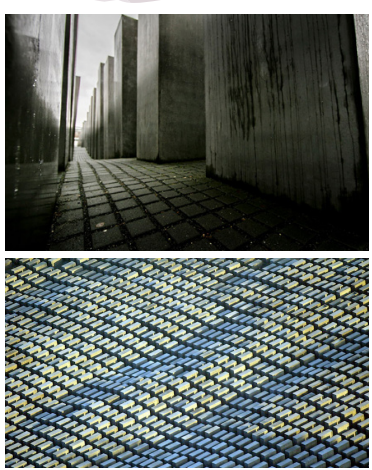

Nemorit Eisenman

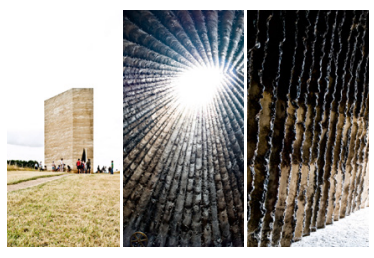

Bruder Klaus Field Chapel I Peter Zumthor

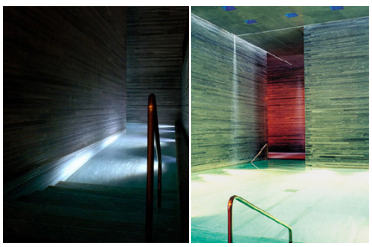

Therme Vals I Peter Zumthor

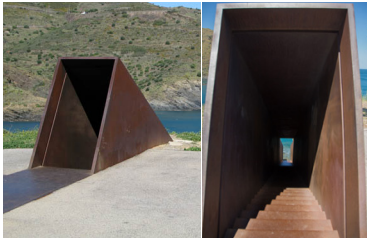

Hommage to Walter Benjamin I Dani Karavan

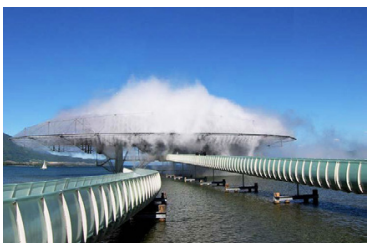

Blur I Diller and Scofidio

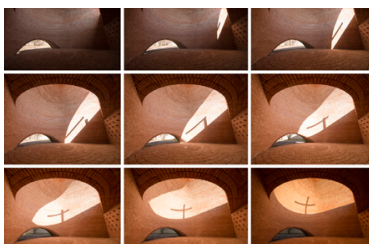



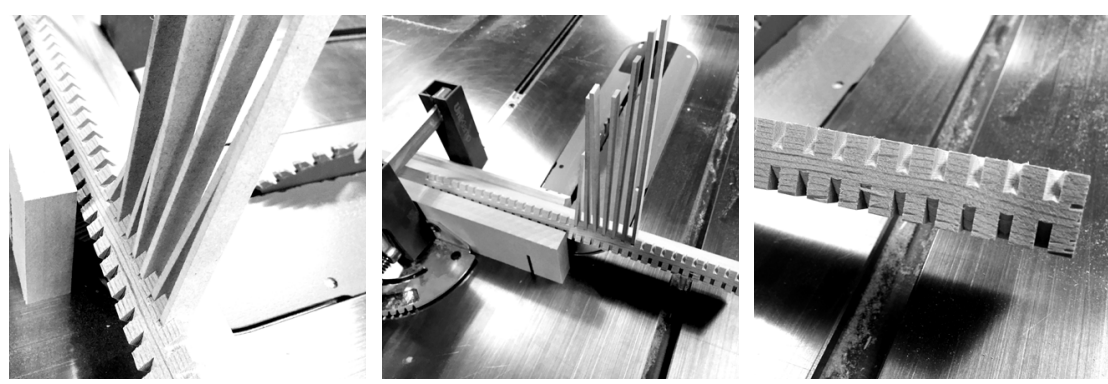

\section{- $\quad$ Acknowledging the transition}

Inspired immensely by the Ben Gurion airport transition where one acknowledges the change he is going though. I began exploring different ways 'acknowledging the transition' could specifically occur and be amplified through architecture. Here, I chose to signify this through repetition of architectural elements which create a two-way passage system potentially implying two routes to be taken. The two-way passage is supported by a system of beams forming two routes affording limited to no visibility of the other side as one goes through it. Beams are parametrically varied in size and are to be placed in different angles to create a variance of light and shadow experience as one proceeds through this passage. Tension between visible, semi-visible to no visibility at all is of great importance here. Architecture relies on these tensions to surprise and attract people to it.
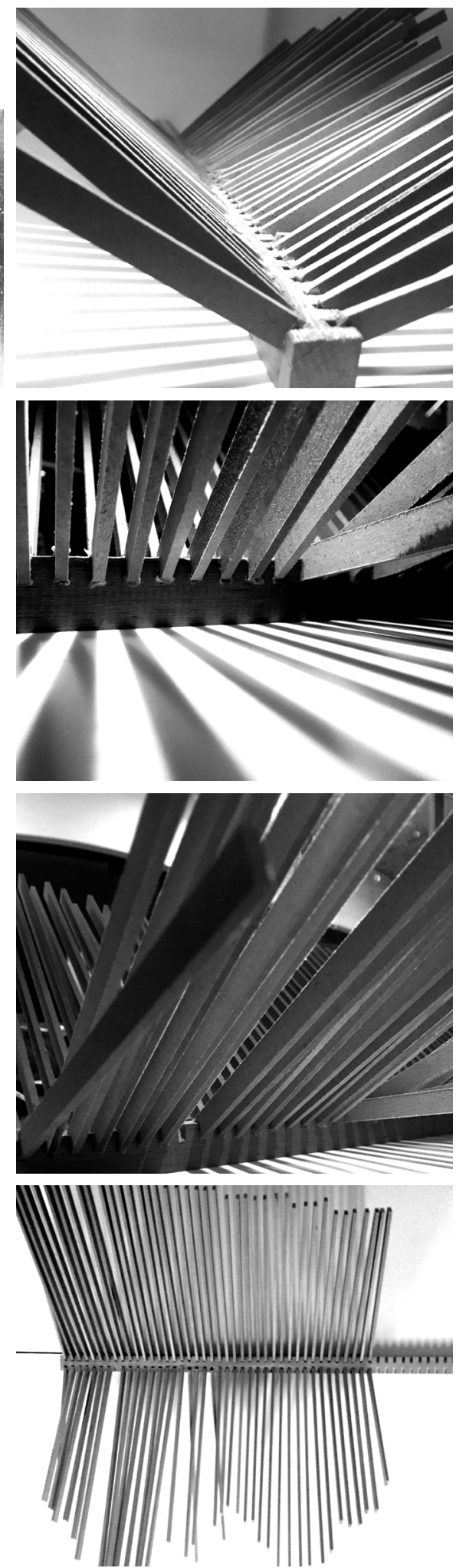

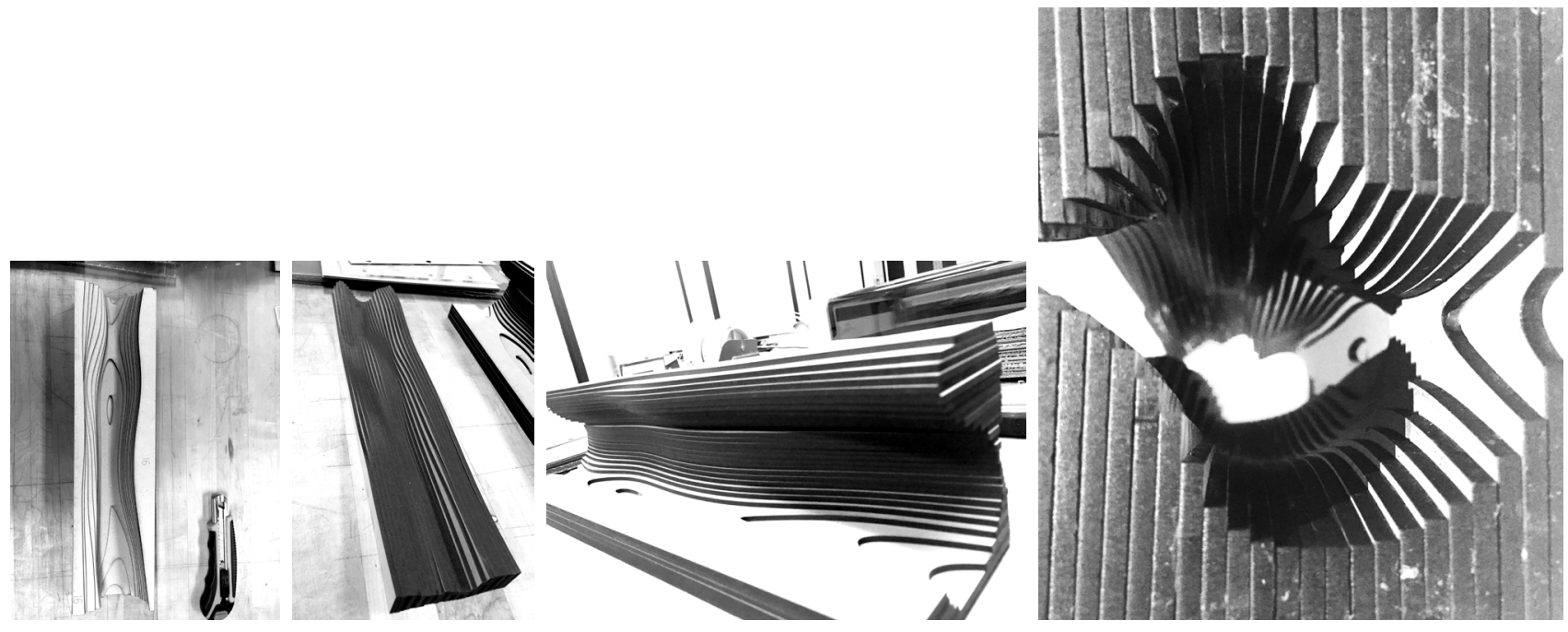

\section{- $\quad$ Perception of space}

The architectural experience achieved in Eisenman's Holocaust Memorial is highly dependant on the skewing of the perception of space as one progresses through it's transitions. In a way, the transitions themselves become the subject space and the architectural experience is reliant on their affect on its users. In this design exploration I attempted to explore the perception of space quality that can add immensely to a transition. This passage is designed with the premise of a constantly changing environment, on all sides; floor, walls and ceiling. The design attempts to blur the lines of what is floor, what is wall and what is ceiling, it relies on the merging of elements and the mystery of wondering what is what. Void and views to the outside environment were carefully thought of as a constantly changing experience as one progresses through this passage. What's outside is constantly being re-framed through the undulating and form and change in position.
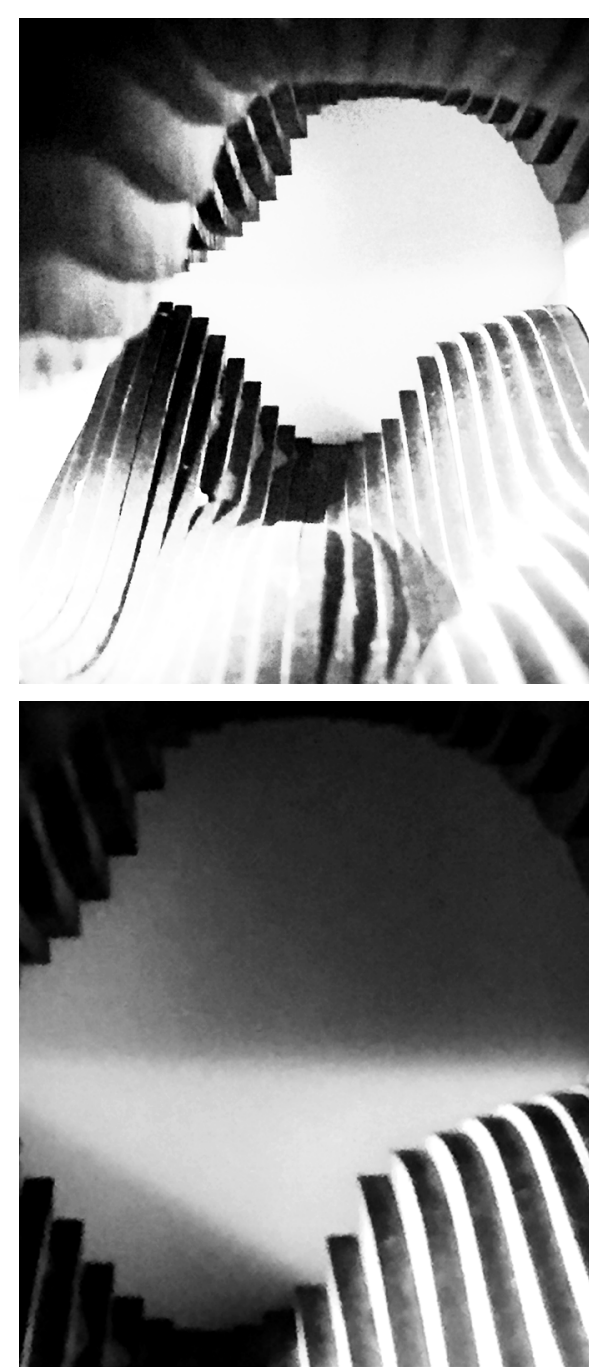


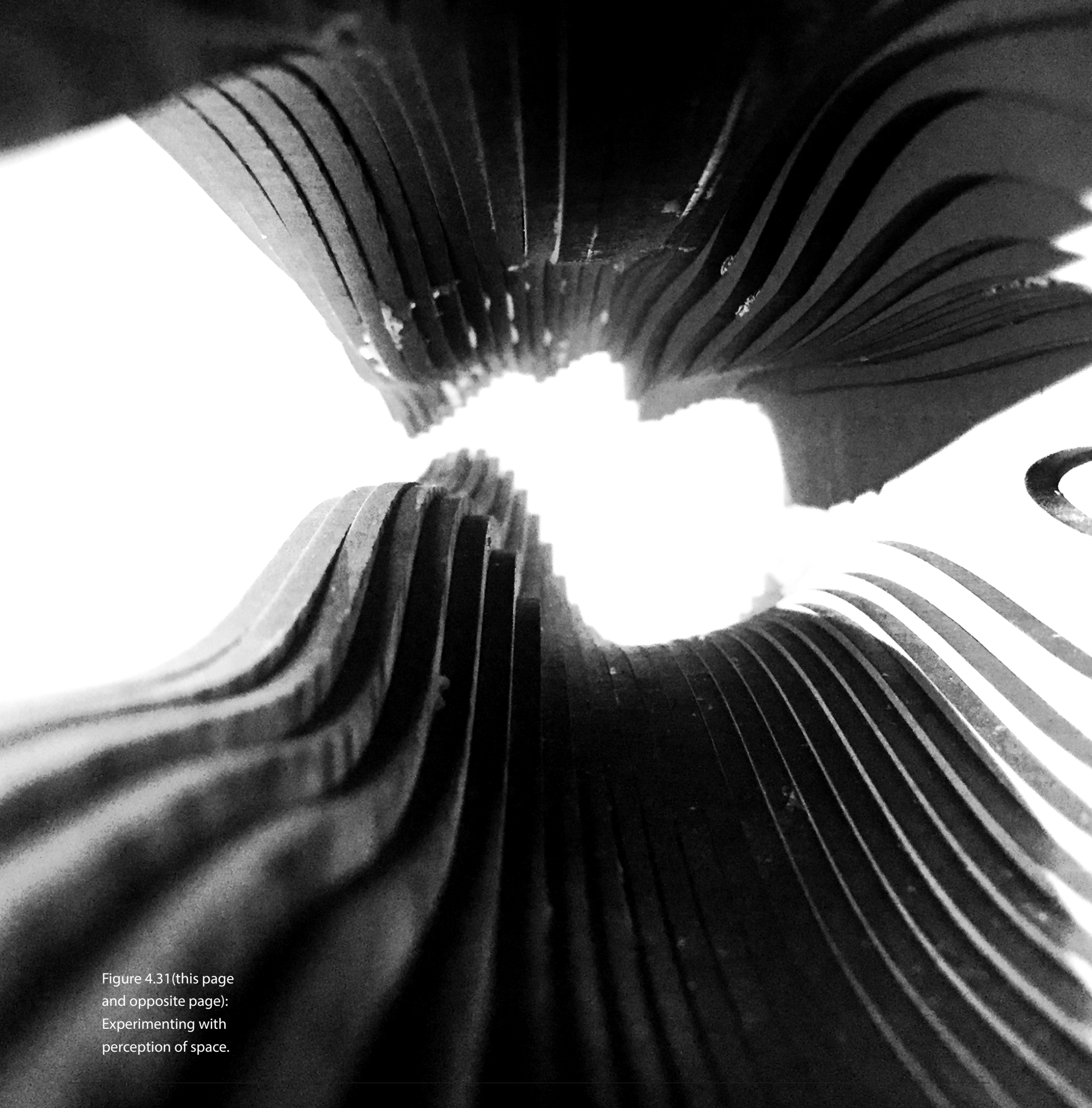



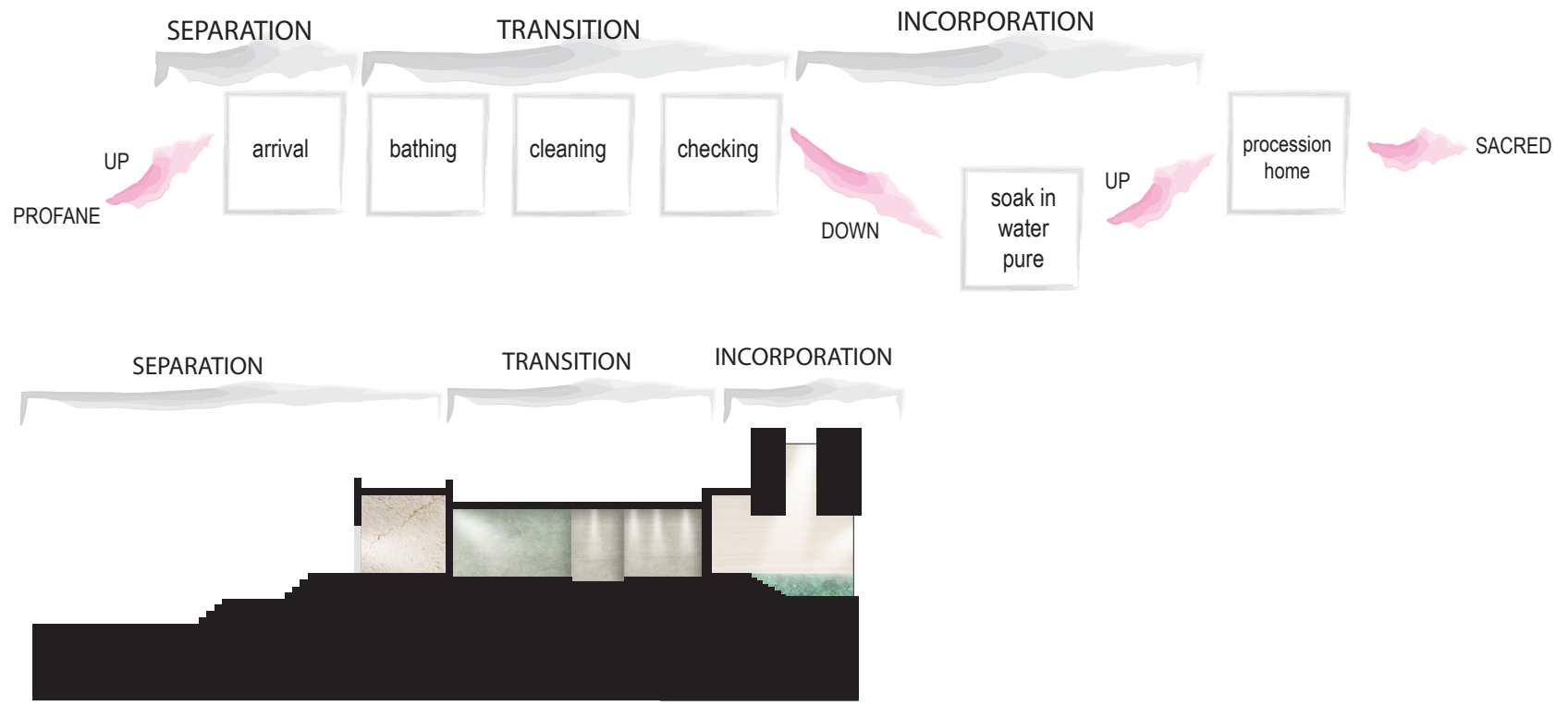

- $\quad$ Mikveh as a tool in exploring transitions

As a preliminary study of thresholds and transitions, I have chosen to look at the religious structure of the mikveh. A mikveh could be compared to a spa, yet it has religious rituals associated with Judaism. I have chosen to explore the mikveh as a building that defines transitions from space to space. The whole process of going through the mikveh is to enter in a profane state and become sacred through soaking in water.

Figure 4.32 (top left): Mikveh stages.

Figure 4.33 (middle left): Mikveh material section, stages of a threshold.
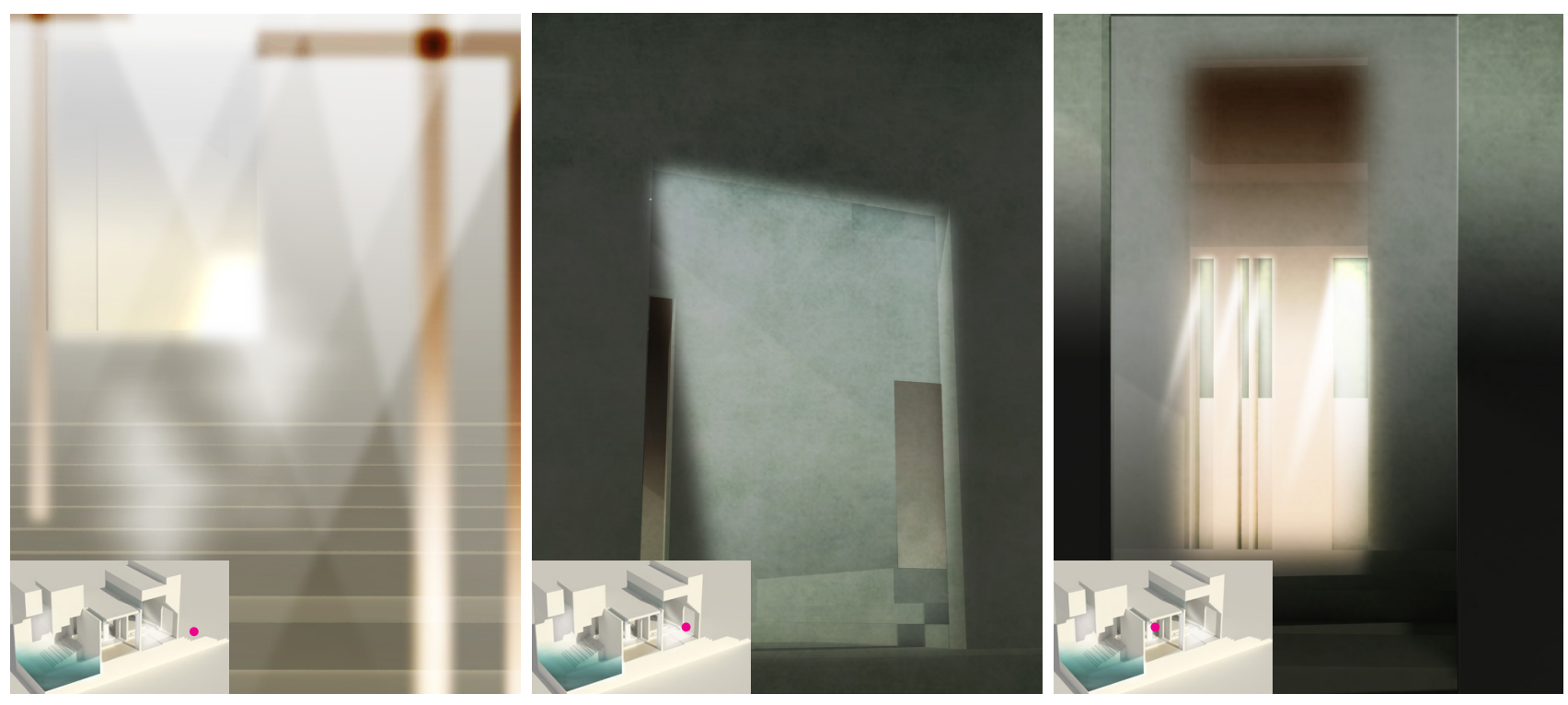


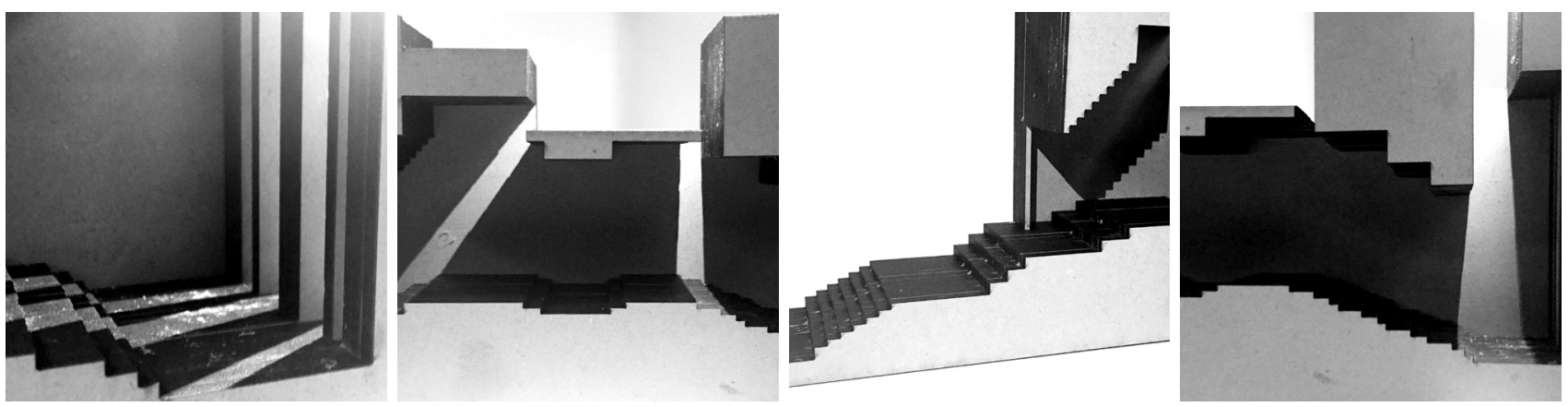

Figure 4.34 (this page): Model of Mikveh, design exploration of transitional sequencing.

Figure 4.35- 4.40 (bottom opposite and current page, Left to right):

Figure 4.35: Arrival

Figure 4.36: Entrance

Figure 4.37: Changing rooms

Figure 4.38: Water immersion Figure 4.39: Foyer, pre exit

Figure 4.40: Exit
The idea behind a mikveh is that one enters with the purpose of coming out differently, as in spiritually more enlightened. The process of preparation for the act of immersing oneself in water is part of this transition. I believe that the full mikveh experience is highly dependent on the transitional spaces, separating each symbolic act from another.

In attempting designing, I undetook understanding of the stages one has to go through -- from the procession from everyday life to the culmination of purity (see Figure 4.32) to a spatial translation of this precession (see Figure 4.35-4.40).
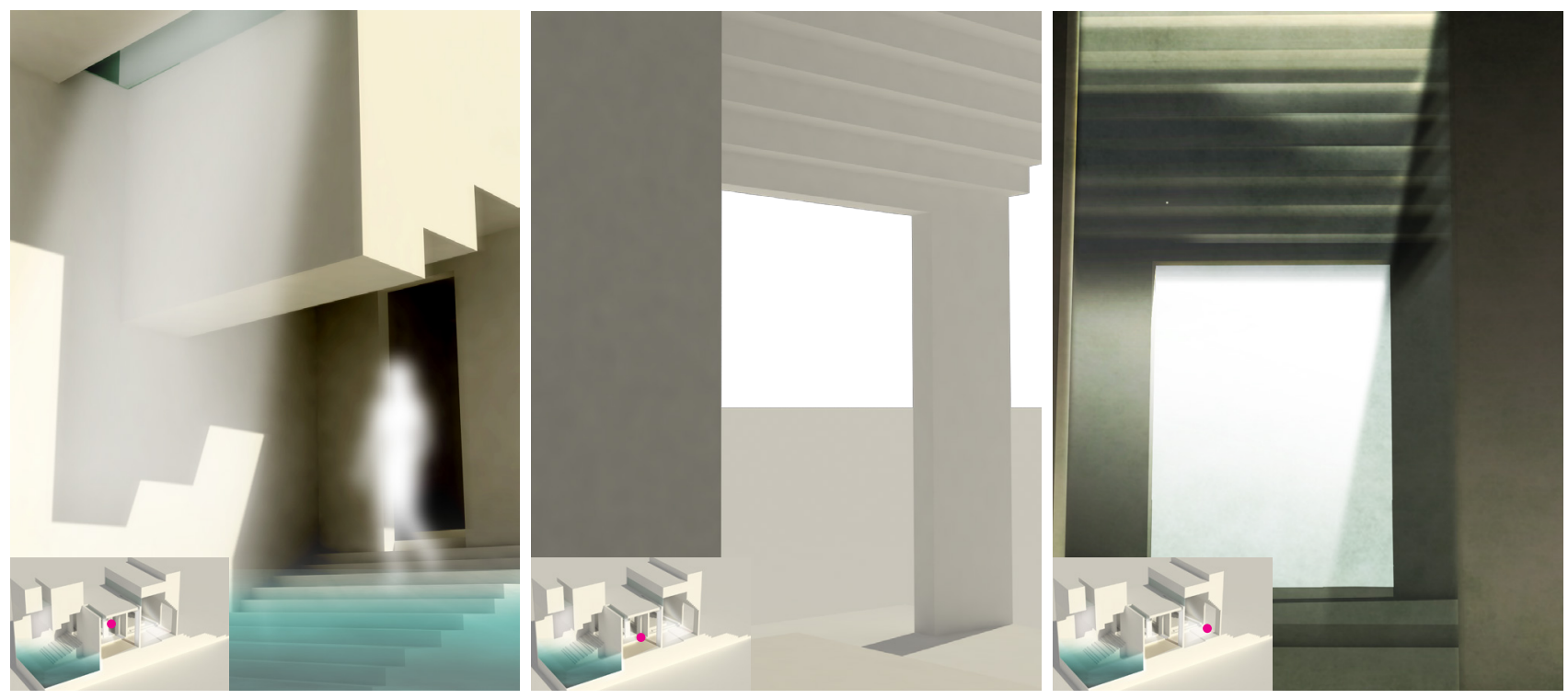


\section{- $\quad$ Space defining elements}

This following design explorations relate to the creation of transitional conditions in various settings. These explorations will address different theoretical hypotheses while addressing topics including the creation of space and its various conditions, from space to place through a contextual approach, transitional moments in architecture enhanced through movement in space and sequencing methodology. Through these design explorations, I intend to develop the necessary techniques to help in approaching the final design project.

This initial design exploration was implemented to better understand the most basic space-defining element and the perception of space through small vignette models. This exploration allowed for a greater understanding of spatial definition and association through the creation of basic spacedefining elements and altering their parameters. Perception of space is highly governed by one's vantage point. Arrival, exit and mid-journey experiences are all aspects that must be taken into consideration when analyzing the interplay between spacedefining elements and the user.

Space-defining elements have the power to evoke psychological and even cultural reactions among people. A series of experimentations was done exploring different parameters pertaining to degree of enclosure including wall length, wall height, wall angle, curvature, wall width, enclosure, proportion and scale in relation to another wall (see Figure 4.41). These various states had seemingly simplistic decisions on placement, edge conditions or materials, our perception and feelings at any given point in relation to formal gesture at that moment.
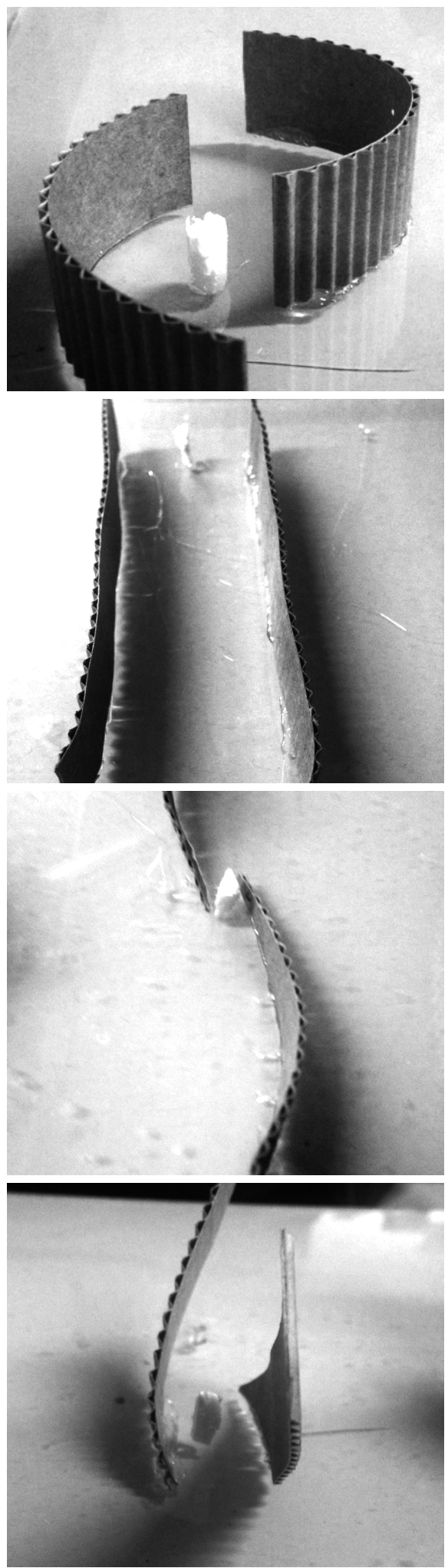


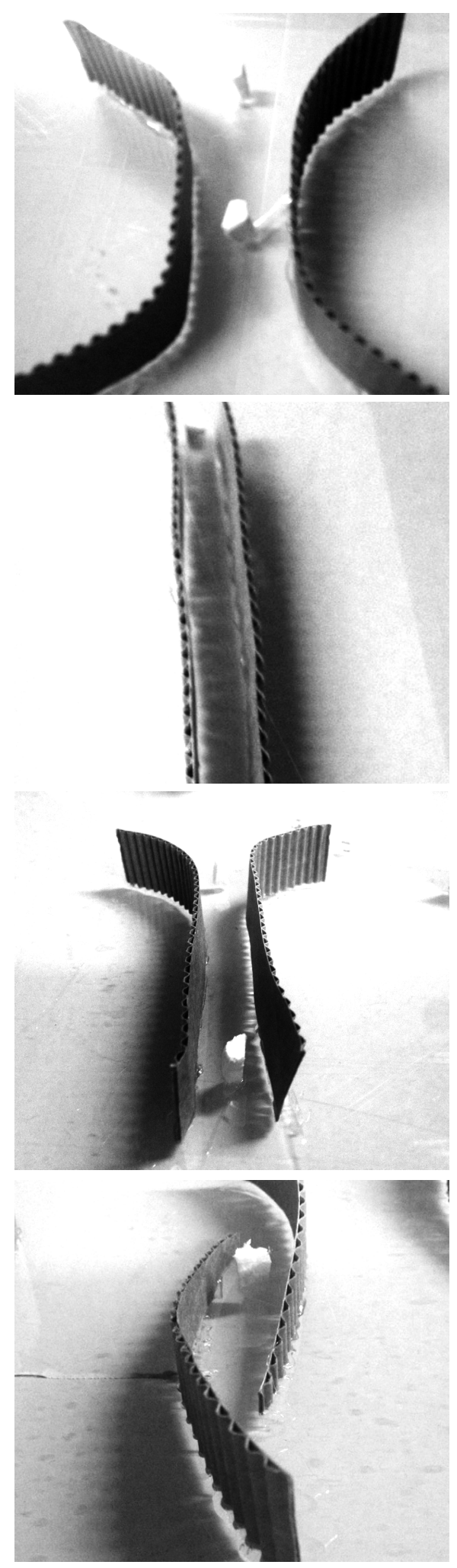

\section{- $\quad$ Spatial sequencing method: threshold} variance

This design exploration was centered around understanding one's vantage point and experience when moving through space. Utilizing a sequencing technique, I have chosen to look at one's movement from several perspectives and $3 d$ testings. One's experience when looking at an artifact vs going through it is highly subjective and can be perceived as two opposites. Feelings pre-arrival and on exiting can also differ and be strongly influenced by the quality and success of the architect's intervention.

Transition spaces have exactly this power in conveying an effective experience affected by its temporality and successful implementation of its stages. Successful transitions can offer an individual a meaningful and evocative experience preparing him/her for the next to come. Despite there being external parameters affecting an individual's experience through space, it is architecture that is the architect's tool and what he/she can control. Therefore, careful, detailed choice of materiality, proportion, scale, etc. can have great influence on its success. For the purpose of this exploration, I have chosen to create a threshold which looks at a single A to B journey testing how proportion, scale and form can have an effect as one goes through a space (see Figure 4.43).

- Form - form can have significant influence on the experience through space by way of parameters such as degree of openness, visibility or opaqueness through a threshold. How does this affect a vague and a harsh threshold and how does it affect our perception of space?

- Scale and distance - how long does the threshold last? How long do the stages within last? Is it only the moment when we walk in the door? What happens when we stretch or blur the threshold? Do our spaces have intermittent spaces where the threshold 
continues? Are they where we get adjusted to a new space? Variances in distance or scale of walls and between them can affect our emotional or physical presence and feeling within a space. For example, a tight space with little width between walls will usually create a claustrophobic, uninviting feeling not to stay for long, and therefore encouraging movement. In contrast, a wider, taller space will be more inviting and encourage people to linger more, chat and enjoy the space.

- Materiality - Unquestionably, materiality has an enormous effect on the quality of a space, especially with transitional spaces. Materiality can help define a threshold, distinguish it from the language used in the rest of a building. On the contrary, what happens when there isn't any change? Does it mean we carry the outside inside? Materiality can have a large impact on our perception of space through pattern or variation. Materiality is not solely affected by sight. It also affects our understanding of different material quality and their smell, texture, or acoustical properties. In his seminal work, the Eyes of the Skin, Pallasmaa says that sight, despite letting us literally see, in a way is what actually separates us from what we are looking at as it is our other senses that let us engage with the object itself. He says, "the nostrils awake a forgotten image and fall into a vivid dream. The nose makes the eyes to remember." (Pallasmaa, 2012). Zumthor in Thinking Architecture said that "(...) while the tactile space separates the observer from the objects, the visual space separates the objects

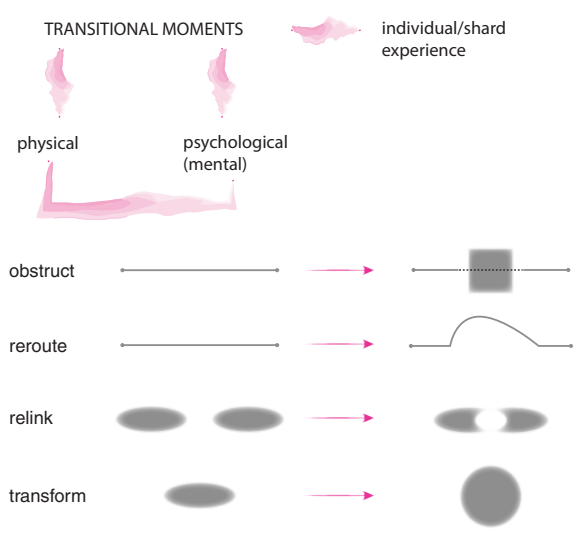

Figure 4.41 (page 70-71): Space defining elements; initial design exploration.

Figure 4.42 (top): Transitional moments abstracted.

Figure 4.43 (opposite page): Sequencing variances in transition types. 


\section{TRANSFORMATION AND WATER}

Water as a vessel in attaining spiritual and physical transformation has been used since early civilization. The act of immersion, bathing, washing oneself has held a special universal role in various traditions, religions and civilizations. In essence, the act of immersion in water as a transformative experience shares comparable values throughout these cultures and traditions. The underlying notion that has survived to this day is that water is associated with holiness, purity and supernatural qualities. Yet, each maintains a level of redefinition of its degree of cleanliness and purity.

The following section will attempt to survey water from different perspectives having to do with:

1. Cleansing -- historic survey of bathing and water as a means to attaining hygiene

2. Water, science and the connection to body, mind and soul

3. Sacred and profane -- water as a means to attaining spiritual and religious purity

4. The spa/thermae as the new contemporary temple for the body 
3000-2000 B.C prehistoric times

- sea and rivers were the purest form of bathing.

- Communities and society formation in the ancient world, was based on public bath

- cleanliness as a moral virtue, method to attaining purity and wholeness.

\section{Indus Valley Civilization | Great Bath} of Mohenjo-Daro

- sophisticated infrastructure made of straight streets and large public buildings and meeting places as well as a well though water and sewage system

- it was assumed that ceremonial and spiritual quality was associated with the presence of such scale of bath.
1500 B.C | Egypt

-Washing, bathing and putting on cosmetics were highly important rituals

- cleansing as a means to getting closer to the god.

500-300 B.C. | Mesopotamia

- These 'showers' become rituals - servants would pour cold water from jugs over people's heads in private quarters, reserved for the wealthy.

\section{B.C Ancient Greek}

- Public bathing facilities start becoming a wide spread phenomenon - pioneers of showers out of need to find appropriate bathing facilities for men to bathe after their exercises.

\subsection{Cleansing, the roots of personal hygiene and bathing}

Personal hygiene is directly linked to survival, which is every organism's inert biological and basic quest. Premature decay and internal and external poisoning are all aspects that organisms and humans specifically try to protect their bodies from, done largely through cleansing. Hygiene and cleansing also have a related psychological impact which has to do with the way one perceives one's body, one's image of oneself and the way one acts.

Grooming and hygiene in early human societies were governed only by biology. As man progressed, sensorial experiences, smell, touch, textures, and tastes started to govern cleansing patterns. On one hand, cleansing is a highly mechanical physical process. Yet at its roots during the late Neolithic period, it was highly related to the spiritual aspect of cleansing. The human psyche started to develop an invisible moral dimension to this process that has survived until today - cleanliness as a moral virtue.

From early on in various civilizations, cleansing and hygiene 
6th century A.D Dark ages and Byzantine period

- Decline and fall of the Roman empire, Christianity taking a much more centralized role. - Catholic Church - much more opinionated yet vague position on bathing. Rejected Roman values yet careful about totally rejecting bathing.

- Devillike and pagan associations were being made to bathing.

- Church against luxury and obsession with body and soul that bathing possessed, and was more about frugality and self denial.

\section{7th century A.D Dark ages and} Byzantine period

- Bath houses still existed, despite disapproval from the Catholic Church and remained the social centres that they once were.

- Some bathhouses gained a reputation for being similar to brothels, where people could engage in sexual acts. 14th century A.D (1340-1350 A.D), The Black Plague

- The Black Plague changed popular European view regarding bathhouses - Doctors believed that open pores opened by heat of the water would allow more illness to enter their body, impurities from the water

- impression that complete filth and dirt could block disease.

- Church's views began penetrating and making more sense due to this as places of sin. - From this point on, bathing as a communal act became scarce leading to the disappearance of the public bath house. People bathed privately according to their wealth level, if at all. 18th century A.D, The Age of Enlightenment.

The importance of bathing and hygiene as a measure of better health and serving medical purposes began to reappear.

- England, 1767 - the mechanical shower as we now it today was first invented

- The idea of water as a therapeutic and hygienic device also began during this time and the term hydrotherapy was conceived describing therapies which water could cure - Different health conditions were being recognized and appropriate baths were recommended.

\section{9th century A.D,}

- Cleanliness seen as part of culture, ad ideals associated with good health and gentility became prominent.

- Soap, plumbing and tubs manufacturing became a huge business and municipal water systems were being constructed.

- England,1829 - first public modern baths began to open in

- From this point in history on, the importance and stress over personal hygiene as a means to achieving purity and cleansing entered society norm.

were regarded as a method to attaining purity and wholeness. And in turn purifying oneself was usually most closely related to washing, most commonly in water. "....inner (and outer) bodily 'cleansing' is ultimately connected to the more profound principle of 'wholesomeness' within the general system of homeostasis that balances and sustains all bodily function" (Smith, 2007, p. 9). Bathing, apart from having a functional and hygienic role, was a "personal regeneration and a deeply rooted social and cultural habit" (Fikret, 1992, p. 1).

During prehistoric times, (3000-2000 B.C.) the sea and rivers were the purest form of a bath. Communities and society formation in the ancient world was based on the public bath as the main way to wash oneself as people didn't have access to private bathing facilities. It was also regarded as one of the main public social places and a way of interacting with people.

One of the earliest examples of a public bath is the Great Bath of Mohenjo-Daro located (see Figure 5.1) in the Indus Valley, in what today is known as Pakistan. It dates back to the Indus Valley Civilization, one of the three oldest human 
civilizations. (Raymond Allchin, 2016) The great bath was only one part of the sophisticated infrastructure of Mohenjo-Daro. Its infrastructure was made of straight streets and large public buildings and meeting places as well as a sophisticated water and sewage system reinforcing the importance of water to city life. The city center, the citadel, provided vital services such as a school, granary, assembly hall, temple, a canal and city walls for protection (see Figure 5.2). The great bath occupied a central position in the northern half of the citadel. (Upinder, 2008). Studies suggest that ceremonial and spiritual quality was associated with the presence of such a scale of bath. Most scholars agree that the bath was used for special religious functions, where water was used to purify and renew the wellbeing of bathers. Found next to the ruins of the Great Bath were bathing stones that experts believe were used to scrub with, cups for ritual and oils as artifacts. The bathing facility was sunken in the ground and respected the users' privacy, and its plan indicates small rooms on all sides of the bath where people could change clothes. The actual bath measured approximately 12 meters north-south and 7 meters wide, with a maximum depth of 2.4 meters (Kenoyer, 1996).

Washing, bathing and putting on cosmetics were highly important rituals regarded by the ancient Egyptians (circa 1500 B.C), especially due to the importance they placed on the afterlife. They believed cleansing gave them a means of getting closer to the gods. Burial rituals were directly related to hygiene, makeup and the clothing one wore as a means and preparation for the gateway to the afterlife. 'Showers' were used as a means for cleansing and for religious reasons in Egypt and Mesopotamia during 500-300 B.C. and were reserved for the wealthy. These 'showers' became rituals where servants would pour cold water from jugs over people's heads in private quarters. Egyptians used baths (Bushak, 2015).

Although showers were used by the Egyptians, these only involved water pouring from jugs. The Greeks were the first to

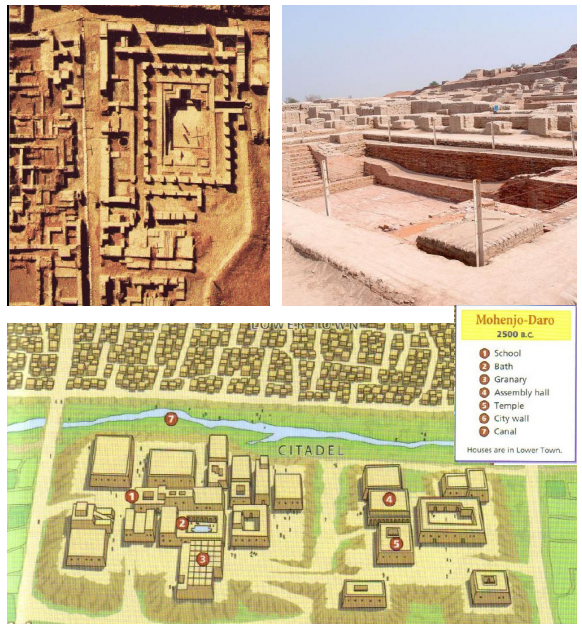

Figure 5.1 (top): The Great Bath of Mohenjo-daro, perspective and aerial view

Figure 5.2 (top middle): Mohero-Daro city center map showing bathing even then as the center of civic life 


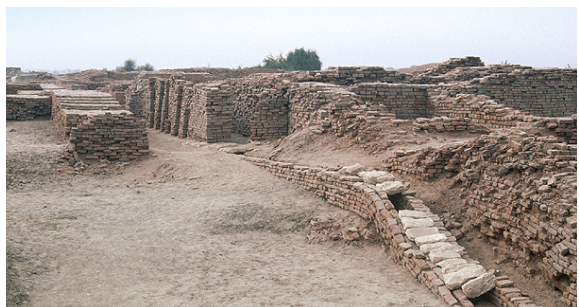

Figure 5.3 (bottom): Sophisticated infrastructure of Mohenjo-Daro, covered drain in the street leading to the Great Bath. make public bathing facilities a widespread phenomenon but it was the Romans who made this phenomenon central to their civic life. The Greeks were the ones to create showers closest to what we would consider the modern shower. This most likely happened out of need to find appropriate bathing facilities for men to bathe after their exercises in the Gymnasiums which were places for sports- training and public games. The showers devised by the Greeks involved complex indoor plumbing and sewage systems which could facilitate the high volume of water going through pipes in and out of rooms (Bushak, 2015).

Bathing was however perfected during the Roman era. They took it to the next level and made bathing their cultural and civic hub. Bathing was done in what later became the bathhouses which were developed into complexes offering bathing options as well as other activities involved around it (Bushak, 2015). Socially, bathhouses represented inclusivity rather than exclusivity for their vast appeal to the masses ignoring sex, wealth or colour, they were "the epitome of democratic ideals and institutions," (Fikret, 1992, p. 2).

\section{- $\quad$ Bathing, a sequence, a daily ritual}

At its bare minimum, bathing involved a traditional order of usage which included a sequence of cold, tepid and hot rooms which are known as frigidarium, tepidarium and Caldarium. However, this sequence was usually much more elaborate and involved various programs. Bathing becamea daily activity for the Romans, so much so that their daily structure reserved the afternoon and evening for leisure and spending this time at a roman bath. This became an unquestionable part of the Roman national life and identity (Fikret, 1992, p. 4). Bathing became both a physical and psychologically satisfying experience, an awakening of all the senses through soaking in different temperature waters, marble surfaces, steam atmosphere, the echoes of sounds, aroma of oil and intimacy of massages. Bathing was believed to be a source for "the creation of the feeling of relaxation, comfort, well-being, and happiness. Bathing cleansed physical as well 
as moral stains." (Fikret, 1992, p. 5) This idea of bathing as a vessel to attaining a light, optimistic feeling from a place of pain and worry became a culturally shared belief. (Fikret, 1992, p. 5). Bathing during the Roman times, like the Greek, usually involved physical exercise as a means of staying healthy and fit. "the feelings of regeneration and rebirth of the body achieved through exercise and bathing acted as an effective tonic for the mind, too." Therefore, "bathing, from its earliest history, was considered as a serious therapeutic measure and received full support and authority from ancient medicine". To this end, Greek and Roman doctors prescribed a strict and detailed bathing regiment for staying healthy. The nudity and warmth of the baths often encouraged friendship and intimacy, as one was sharing a sensorial experience with others (Fikret, 1992, p. 5).

Public bathing usually involved olive oil rubs, gym workouts, scraping the sweat, dirt and oil from the skin and then soaking in waters and getting a massage - all having a common goal of mental or physical cleansing. Massage was a central ritual to the process of bathing as a means of sensual pleasure but also as means of therapy for stiff or sore muscles, disease curing and improvement of blood circulation. Other than providing bathing, bath houses became full recreational centres providing other programs such as medical treatment, shaving, hair grooming, food and wine, reading, entertainment, gardens, assembly halls, gyms and later also sex. The bath house was to become a place people would come to be for hours or days (Heise, 2007). Bathing, despite being an experience in itself, was usually a prelude and preparation for a dinner or party, "it can be seen as a stage in leisurely sequence of expectations in the Roman day."

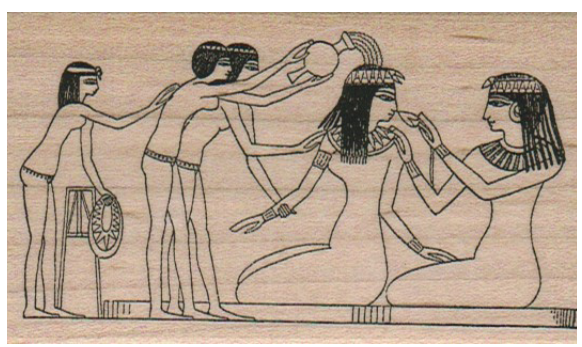
(Fikret, 1992, p. 5).

Charles Cameron, 18th century expert on Roman baths, commented on the synthesis of programs which the baths evoked and said,

Figure 5.4 (top): Egyptian princess in her Bath, wall painting in tomb in Thebes. 
"the temples were confined to religious rites and ceremonies; the theatres, amphitheatres, basilicas, etc. had each their distinct and separate province assigned to them; but in the baths all these seem to have been united. Besides the amazing number of chambers, and other necessary accommodation for the purposes of bathing, they were furnished with spacious Halls and Porticos for walking, which Exedrae and Seats for the meetings of the Philosophers. The most complete libraries in the city were transported thither, and the people, in the great space they in clothed, were treated with theatrical entertainments, as well as she shews of the gladiators." (Cameron, 1775, p. ii).

Roman baths were architectural masterpieces as they had a central role in the development of Roman building technology. Bathhouses often involved elaborate and curvilinear forms, vaults and domes. The bathhouse stood as a platform for testing new ideas for its utilitarian role as less conservative, traditional forms of religious architecture, like the temple, and was instrumental in "bringing more widespread acceptance of new ideas and revolutionary style into the realm of architectural acceptance." (Fikret, 1992, p. 2). Architecturally, Roman bath complexes were huge, and were a way of making a statement. In contrast to rather modest and small homes, bath houses were elaborately designed, involving decorated vaults, walls and floors polychrome marble veneer, fountains, sculptures, mosaics and ornamentation. Larger baths even had statues to gods. In general, there were two basic planning principles, symmetrical and asymmetrical. The categorization evidently is a much more complex one which has to do with regional variation of partial symmetrical or partial axial schemes. The asymmetrical baths tended to be the medium size baths, often the result of difficult and restricted sites, or low budgets (as with Baths of Pompeii, see appendix, Figure 7.5). With the symmetrical plans (such as the baths of Caracalla and Trajan), its rooms and halls usually were a mirror image of each other on a main axis. Symmetrical baths are typically categorized as larger complexes, more elaborate, called the "imperial thermae". They were planned by the big architects of the time, and reflected ambitious planning. They were a true reflection of the Romans's ability to create a "total artificial environment, much like a miniature city." (Fikret, 1992, p. 3). 


\section{- $\quad$ Thermae: programmatic requirements}

The process of bathing was usually built around three main bathing rooms:

- The calidarium - hot room, with an artificially heated hot water pool

- Benefits: Hot water is known for being first stimulating and making body temperature higher and bringing body circulation outward and being a source of relaxation and dissolving for muscles and blood vessels. It therefore encourages sweat, opens pores capillaries and penetrates skin or muscles deeply. Hot water immersion is not recommended however as a result of extreme body temperature or eventual dehydration.

- The tepidarium - warm room had a medium body temperature or a bit cooler with a tepid temperature pool.

- Benefits: Warm, body temperature water is mainly known for being harmonizing and balancing, regaining, creating appetite and stimulating digestion or digestive organs.

- The frigidarium - cool room, coolest temperature of the three rooms. It was unheated and had a cold-water pool. Being unheated allowed for larger pools than the other two types.

- Benefits: Cooler temperature water - around 10-16 C is known for soothing heat and can invigorate, contracts blood vessels and blood circulation and closing pores.

- The cold water's role in the Romans's water immersion rituals became invigorating for their skin, closing up pores that were open in the warm and hot waters. Cold water can also stimulate digestion and metabolism, giving a sense of hunger and it helps with sports injuries in reducing swelling or inflammation. Cold water immersion is not meant to be a lengthy one, no more than $4-5$ minutes.

- Contrary to hot water, which relaxes, disperses blood circulation toward the body's exterior, cold water stimulates, consolidates and shunts blood circulation inwards toward the core and internal organs.
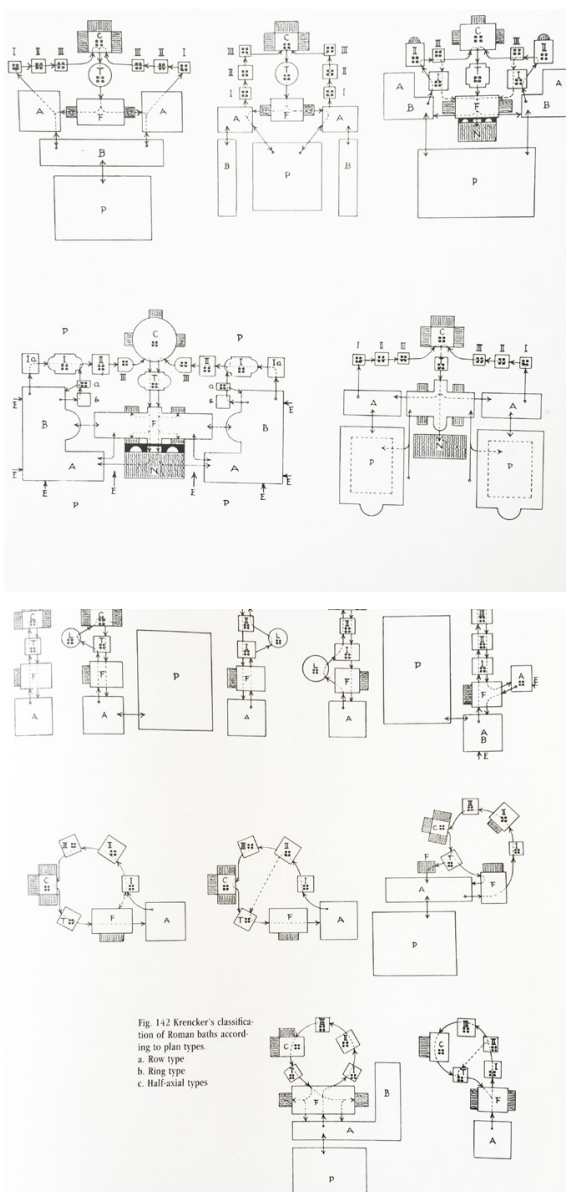

Figure 5.5 (top): Fikret's Roman bath design sequence logic diagrams. 


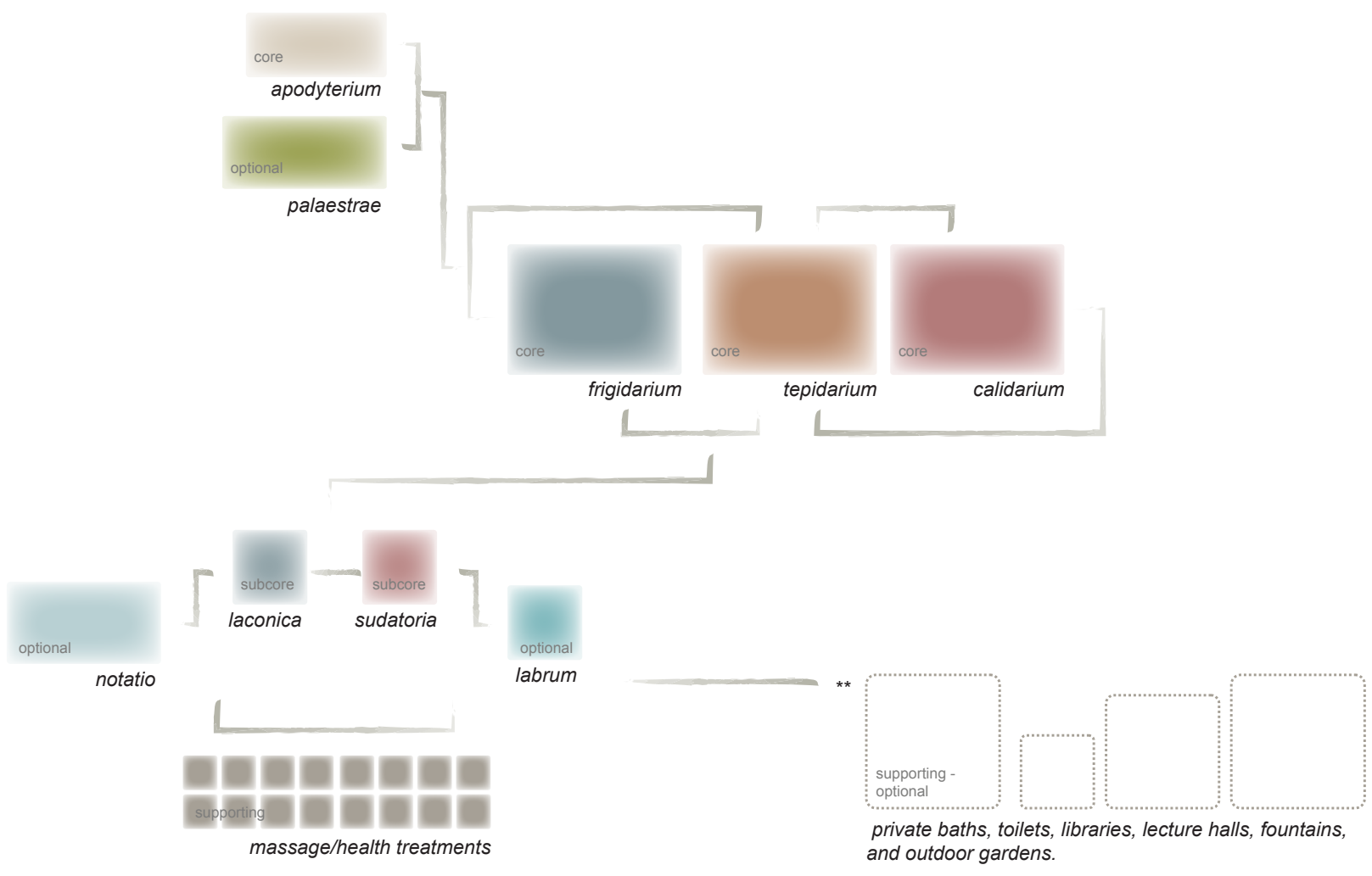

- Other supporting spaces included:

- The apodyterium - changing rooms

- The palaestrae - exercise rooms

- The notatio - open-air swimming pool

- The labrum - hot plunge bath

- The laconica and sudatoria - intense heat dry and wet sweating-rooms (dry and wet sauna)

- Rooms for massage and other health treatments

Figure 5.6 (top): Thermae's diagrametical sequence of Typically, order of usage would involve beginning with the changing rooms or apodyterium where one would leave one's clothes with one's servant and change into a robe. It was recommended to work up a sweat before entering the pools, therefore using the exercise rooms or palaestrae. After a workout, the servant would apply oil on a bather's body as a pre-bathing process. Despite not mandatory, usually the process through waters began with the cold room frigidarium 
and only then finish and recuperate with the tepidarium - warm room and then with the hottest of them the calidarium - hot room. After this, the servant would scrape the oil off the skin. Then, the same process would be repeated in reverse order finishing off with the frigidarium.

Contrasting between warm and cold temperatures sounds trivial today yet it was revolutionary for its time. The premise for using it involved a light tissue workout and giving them stimulation with no extreme stress and sensation without movement. The Romans pioneered what is today known as therapeutic contrasting which involves the immersion and continuous alternation between immersion in hot and cold waters. Scientific and psychological benefits are numerous, including reduced muscle aches, injury recovery, tension reduction, relief from strain-related injuries. (Ingraham, 2015)

The idea behind alternating between hot and cold is to gain the blood stabilizing effect of hot water and on the other hand gain from the effect of cold water on circulation directing freshly circulated blood into internal organs and body core. Interchanging water or room temperatures became a technique to greatly increase circulation, healing and regeneration.

In a way, bath houses were a sort of temple of the body, where rituals of body-related practices would make for a more wholesome body, mind and soul connectivity, therefore making one purer - a world created and dedicated to the cultivation of the body and by extension the mind. Similar to the church, where people would go to on a regular basis, the bath house became the ideal Roman way of urban life, providing a proper environment, much like a city club or community centre. In 33 B.C., Rome had 170 small bath houses according to the Agrippa's census. By the fifth century AD, this number had grown to 856 (Fikret, 1992, p. 30). This astonishing amount alone speaks of the popularity the bath house as a public building had during these times and their potential influence on 
the culture. They were fully pubic, open daily for use by the masses and owned and operated by the city or state in which they were in located (Fikret, 1992, p. 128).

\section{Thermae and Balneae}

The Romans distinguished between a Thermae and Balneae and the primary difference was the ownership and scale. A Balneae was associated with a small bathing establishment, usually privately- owned and fitting within city lots. Thermae were owned by the state or city and were usually whole complexes occupying large areas, sometimes even an open space, or a few city blocks. Thermae etymology has Latin and Greek roots. In Latin, it refers to thermal and goes back to mineral and curative waters. The Greek influence comes from the word thermai (myetymology, 2016) and the name is directly derives from the pre-historic town of Thermae where residents were called "Asclipians", associated with the god of medicine -- "Asclipios (Thermal springs in Europe, 2016)

\subsection{Water, science and the connection to body mind and soul}

Water is essential to human survival, both spiritually and physically. It creates and maintains the evolution of life. It is well known that all major civilizations began their development near a source of water, usually freshwater. Comprising $70 \%$ of the earth's surface, water is a mineral which moves in a continuous cycle of evaporation, transpiration, condensation and precipitation. It can be found in three basic states -- solid, liquid and ice (mist as a fourth in-between state). Interestingly, water is the only substance that can exist in nature in these conditions. It is a medium that sustains metamorphosis, change, building and recycling, nourishment, information transfer and energy exchange (Bartholomew, 2010, pp. 1-18).

In many ways, water symbolizes both life and death. It sustains life, brings with it memory of the past yet the seeds of the future. "Water mediates between life and death, between being and not 
being, and between health and sickness, yet we have allowed water to spread illness and disease" (Bartholomew, 2010, pp. 1-18). On one hand, it is healing and life-enhancing, yet when it is degraded and polluted, water can carry disease that is deadly. The fact that water is necessary for survival makes it a key part of culture. In her poem Still Water Meditation, Caroline Way illustrates humans's common heritage is carried though the medium of water; She says, "we are all one - water is the epitome of holism". (Bartholomew, 2010, pp. 1-18).

In her book, The Spiritual Life of Water: Its Power and Purpose, Alick Bartholomew discusses the mitigation necessary between the scientific and real properties of water vs. the more spiritual and emotional associations people have with water. She quotes Johann Wolfgang von Goethe, a poet, philosopher and scientist during the years bridging pre- and post-enlightenment thinking. His outlook included both a scientific and spiritual understanding of water. It was both rational and traditional and an understanding that water is inseparable from a holistic view on life. He called this "holistic" science as opposed to "reductionist" science. "Goethe understood that all life is one, closely interconnected and interrelated, and that water - sustainer of life - is the very symbol of holism". He referred to water as "the grounds for all being" (Bartholomew, 2010, p. 4). Victor Schauberger, an Austrian water expert, had a similar view to Goethe and said that water was a product of subtle energies that created our planet and made it a living substance. He wrote,

"In every drop of water swells a deity, whom we all serve; there also dwells life, the soul of the 'first' substance - water - whose boundaries and banks are the capillaries that guide and it and in which it circulates" (Bartholomew, 2010, p. 18).

Bartholomew also speaks of the sheer undeniable pleasure most people take in going to the ocean. Its vastness, texture, sound and smell arouses joy and inspiration. Water makes man feel his size in comparison to the universe. Its differentiation from any other compound or substance makes water unique, and is the most favorable environment for life. Bartholomew says that this 
begs the question of water as being an exception to evolution by natural selection. She believes that water's properties and its role in ecosystems places it at the heart of all ecosystems. She included the mysterious quality of water dating back to water deemed as sacred by our ancestors. She calls it the "medium of consciousness", "the ground of all being" and the "primal substance" (Bartholomew, 2010, p. 5).

Religious association with water usually relates to freshwater found in natural sources containing thermal benefits like springs or rivers. The underlying notion is that water cleanses and washes away impurities or pollutants, literal or spiritual. Water has spiritual, medicinal and physical cleansing associations. The strength of water as a force - both as a symbol of transformative purity and a primary building block of life able to build or destroy manifests itself in different ways in religions.

\subsection{Sacred and profane - water as a means to attaining spiritual and religious purity}

Discussion of bathing or immersion in water would not be complete without mentioning the religious and spiritual aspects that have been associated with it for thousands of years. How is it that throughout time, in most cultures and religions water has remained known for purifying?

The three great monotheistic religions (see appendix) all have a universal tradition of some sort of immersion in water - Christian baptism, the Jewish mikveh and the Muslim ablutions. Other religions such as Hinduism, Baha'i and Shintoism practice similar purifying rites. The idea is that water acts as a vessel of transformation has been understood since early history; one that removes physical and spiritual impurities in order to become pure and divine. In fact, these traditions predated scientific theories which proved disease and germs need to be removed by cleansing. (Bushak, 2015). 


\section{- Immersion in water as part of a spiritual experience}

Water used in a purifying ritualistic way began from the beginning of the rise of civilizations in the ancient Near East. In Babylonia, water was an important part of rituals in the cult of Enki, according to the Tablets of Maklu. In Egypt, the Book of the Dead, an ancient text used by Egyptian for funerals (1550 B.C.), has a part about the baptism of newborns which is meant to purify them from imperfections in the womb. This was done with the Nile River's cold water, which was believed to have regenerative powers. In Egypt, the Book of Going Forth by Day (17) contains a treatise on the baptism of newborn children, which is performed to purify them of blemishes acquired in the womb. The Osiris myth, an ancient and influential story in Egyptian Mythology, describes baptizing rituals with the Nile River's waters on the dead. The Egyptians were strong believers in the afterlife and they supposed this ritual promised an afterlife and got rid of any profanity people acquired in their previous life. In the book of John, baptism of the dead was also mentioned to be practiced by the Mandaeans, which were most likely from southern Mesopotamia (Meslin, 2005).

The Greeks also had a similar view on immersion and they associated it with immortality as was found on Cretan funeral tablets. They believed baths with some Gods could lead to immortality. Some of their religious rites could even lead to removal of sins. Initiation rites to different cults, like the Eleusinian mysteries, involved bathing in the sea, leading to a physical purification and followed by a sacrifice of a pig. In most mythical cases, immersion was part of a preface to a whole process of rite, or initiation receiving approval of the Gods (Meslin, 2005).

Hellenistic philosophy held a similar speculation as the Egyptians where divine water had a transformative power. Regeneration through water was developed by Egyptian cults. Because of its natural qualities, water is of high significance in all world religions: it is often associated as being the residence of gods, 
ghosts and other powers; it is often even admired as a holy force. In many religious and mythological narrations about the genesis of world, water symbolizes the state of creation or even the basic source for all beings. The world's origin is the sea, which creates the other cosmological elements (e-collection, 2008). As a source of all life, water is considered to constitute a life-generating principle of order. On the other hand, water is considered to be a power of destructive chaos, which destroys the world catastrophically as the flood, and threatens life. Seas and oceans are viewed as menacing homesteads of the evil. In both Judaism and Christianity, water is a symbol of the origin of creation. Water is a hierophany (i.e. a physical manifestation of the holy or sacred). It can represent a creative force of life or a destructive force of death (UNESCO, 2006).

Water cleans the body, and by extension, purifies it. These two main qualities confer a highly symbolic -- even sacred -- status to water. Water is therefore a key element in ceremonies and religious rites. Not only does water wash away external signs of dirtiness, it also -- in many cultures -- erases spiritual difficulties. Through contact with or immersion in water, believers can cleanse themselves of wrong-doing, or simply rid themselves of signs of the secular world, and prepare themselves to enter the religious and spiritual realm.

This contact with water can occur in various ways, depending on the culture and the objective: in Christianity, for example, immersion in water is seen as a symbolic rebirth wherein the believer is cleansed of all sins through the power of Jesus (who is called 'the living water' in the Bible). Cleansing is one of the most important properties of water in religious practices, and ablutions before prayer, weddings, or other ceremonies is common across the world. However, other cultures view water differently: in Hinduism, water is used to cleanse, in fact all water is sacred, and holy places are usually located on the banks of rivers, which are viewed as particularly sacred. It is believed that those who bathe in the Ganges River -- the most sacred of rivers 
-- and those who leave some part of themselves on the left bank will reach paradise before being reincarnated (Plantinga, 2007).

From the earliest times, healing cults have been associated with water sources. Evidence exists of religious worship at numerous springs in western Europe during the Neolithic period and the Bronze Age. Linked to water's purifying element is the belief in its intrinsic healing and protecting properties. Used in blessing ceremonies and naming ceremonies, water is sprinkled around an abode, for instance, to protect the household from evil. The healing properties of water are sometimes thought to be an inherent supernatural power of water itself. At one time, some Christians hung an amulet filled with holy water at the entrance to their house to prevent evil spirits from entering.

Washing in sacred waters is said to provide healing from ills ranging from arthritis to blindness, and pilgrims travel the world over to immerse themselves in these waters. This is the case of Lourdes, in France, where millions of people every year gather to bathe in or collect some of the water from a local hot springs that is said to have healing properties. Over the decades, hundreds of miracles have been reported, 67 of which have been officially recognized by the Roman Catholic Church. The healing properties of water are also professed by practitioners of hydrotherapy, a treatment of disease through the use of water, such as baths and compresses

\subsection{The thermae as the new contemporary temple for the body}

It was ultimately the regulation of home showers, industrialization and health regulations that changed the social public bathing culture. The 18th century brought clear medical and hygienic facts that bathing and washing leads to better health and less germs. Water used as a therapeutic measure (hydrotherapy) started to gain recognition. However, it was ultimately the invention of the first mechanical shower in the late 18th century (1767) in England that brought forth the idea of bathing as being 
accessible to individual households on a daily basis. Showering from an upper basin above one's head was a revolutionary innovation compared to the normal bath that required great amounts of water to pour on one self. The spread of showers was promoted by industrialization and later strict sanitary and hygiene regulations indicating that simply washing would remove disease.

Yet modernized versions of bath houses still existed in the 19th century as proper piping and water sewer systems weren't yet properly developed to sustain showers in home. Interestingly, in the mid-1800s reliable plumbing was finally being developed, a concept the Roman and Greek understood so long ago for their bath houses. Despite these advances, showers were still considered a luxury and were only installed in the houses of the rich. It was only in the early 20th century that showers became a normalized element of a home, starting in the USA. Not surprisingly, the addition of the shower to the home has made bathing a much more private affair that usually occurs on a daily basis. For some, it can be several times a day. (van Tubergen \& van der Linden, 2001).

Today, showering or bathing is almost taken for granted and its health and hygienic benefits are widely understood. Social public bathing has not become completely obsolete and is now more of a luxurious affair and social affair. The late 20th century saw a need for restructuring of the way bath houses were to be marketed and seen by society.

With bathing becoming a regular daily activity, there was less of a need for bathing facilities, therefore less of a focus on the body and its grooming. The technological revolution and white collar worker has ushered in an age where prolonged sitting is a necessity degrading health and physical state. Until the industrial revolution the average worker would not be sitting, working was done standing up. Today many of our habits abuse our bodies, especially the highly sedentary lifestyle such as sitting while 
working on the computer, watching TV, driving etc. Research at the American Mayo Clinic shows a link between prolonged sitting and serious medical conditions -- heart disease, over productive pancreas, colon cancer, muscle degeneration, strained neck, sore shoulders, and spine and disk damage (see Figure 5.8) (Berkowitz \& Patterson , 2014).

Concrete medical evidence of these dangers has served to underline the importance of physical activity and exercise and with it the cultivation of not only body but mind and soul. This had led to a surge in interest in fitness activities and spurred the proliferation of gym facilities, spas, hydrotherapy and halo-therapy, especially among young urbanites. The ancient

Figure 5.7 (below): 12th century Romanesque Mikveh in Besalú, Spain, 36 steps lead one down to the mikveh from street level.

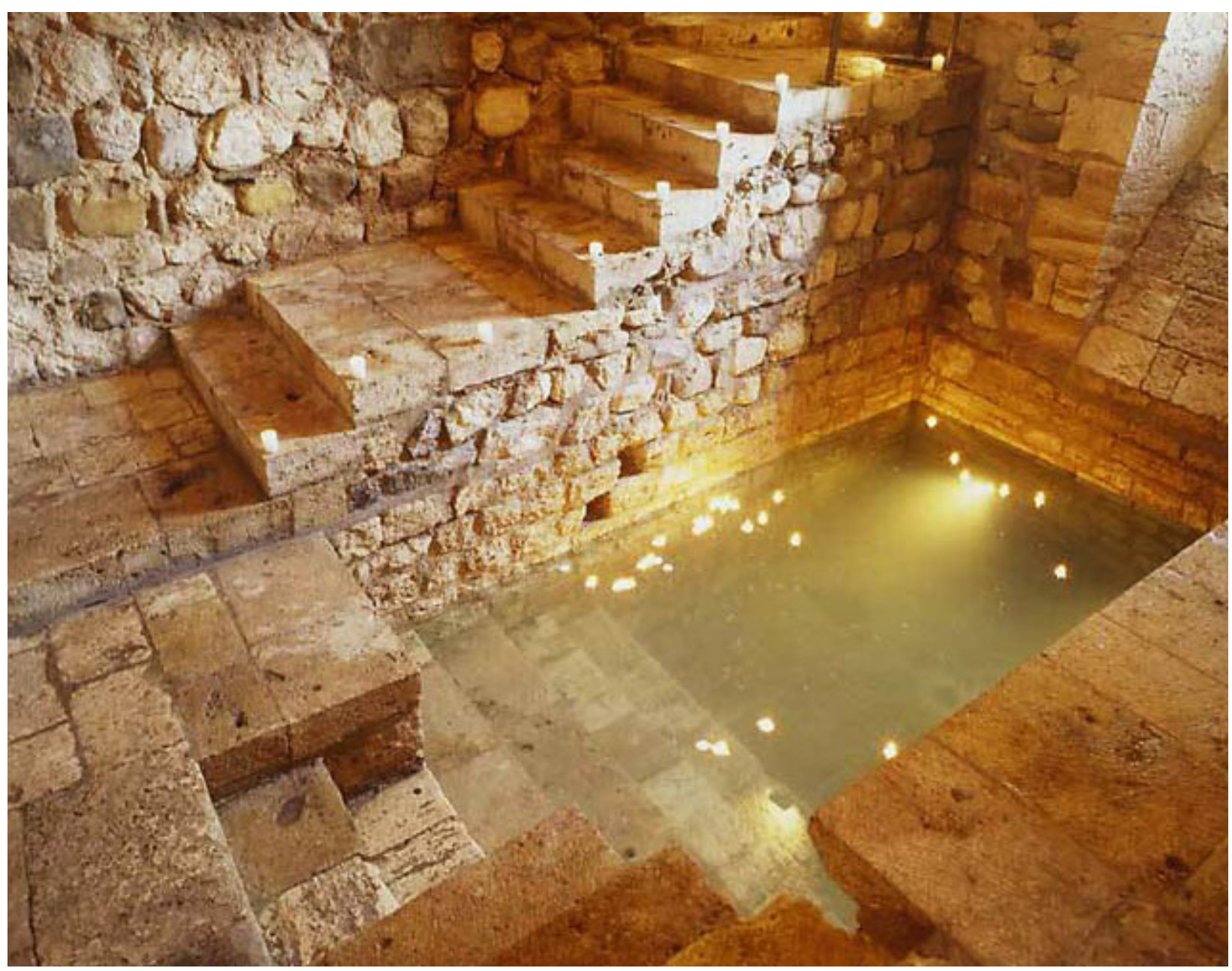




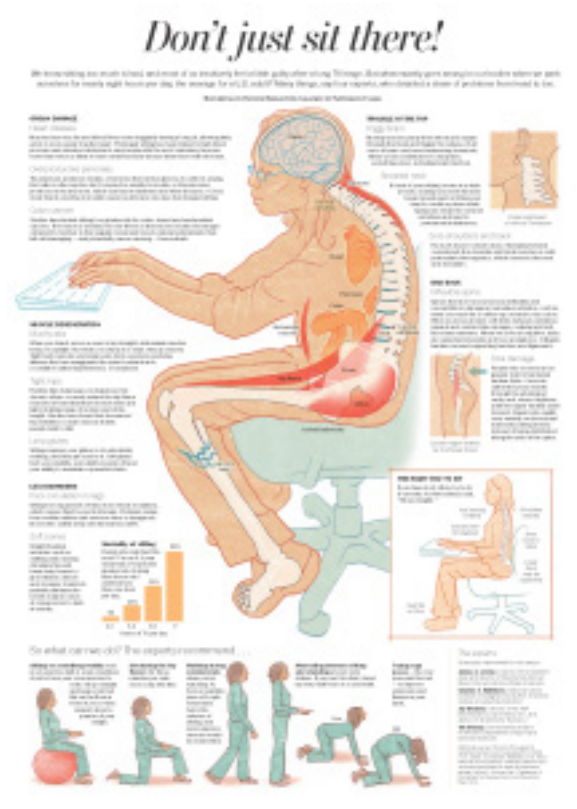

Figure 5.8 (top): Physical damage caused by prolonged sitting. pedigrees of spas has become more mainstream and an increased appreciation and re-discovery of the Greek and Roman bath house, the Russian banya, Japanese onsen bathing, the Turkish hammam or the Finnish sauna. Spas have become almost like contemporary temples as people today avoid traditional houses of worship and look for alternative ways for spiritual connection. Spas become temples of wellness that can help the transforming of a person's mind, body and soul. Susie Ellis president of SpaFinder Wellness and has been in the spa industry for 40 years says, "Spas can be inspirational places where l've seen many people have transformational experiences. With people not going as much to church, spas are a natural place to have some of these experiences". (Alene, 2013)

Mayra Rivera, an assistant theology professor at Harvard Divinity School, says that rituals such as fasting and cleansing have been around since ancient times in shaping the body and to "attune it with the divine and experience of a spiritual connection." She mentions that "an increased emphasis on the body as a way to enrich the self is part of a broader cultural trend in our times. Caring for and especially improving the self are seen as salvific." (Alene, 2013). 
94 MOMENTS OF TRANSITION 


\section{URBAN DESIGN COSIDERATIONS}

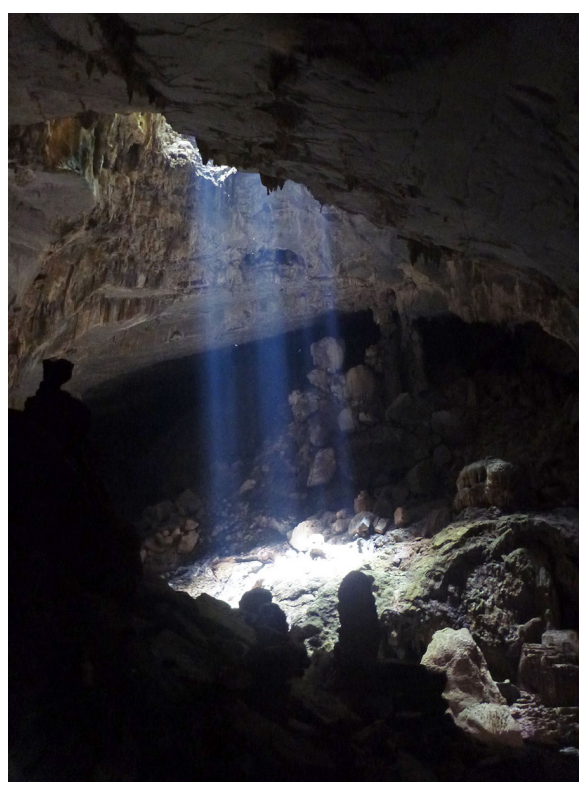

Figure 6.1 (top): Light well, underground cave. Vietnam's Phong Nha-Ke Bang National Park.
At its core leading up in the previous chapters, this thesis is focused on the research of transitional moments and transformational experiences in architecture. Chapter 2 dealt with looking at how in essence, architecture echoes urban environments in their formations, finding commonalities, and facilitating the flow between its spaces. In fact, it is the argument of this thesis, that without appropriate flow to this system, architecture will remain yet meaningless and uninspiring. As future architects, I believe we should constantly be thinking of this flow and sustaining it, from an architectural and urban level.

From a general urban overview, my research attempted to be increasingly specific - starting from the urban macro level into then looking at actual transitions in architecture. The series of design explorations (chapter 4.8) attempted to address different kinds of transitions types. In exploring a building type that sustains transitions, I began looking at designing a mikveh. In doing so, I became more drawn to water's role in a transformative experience and began exploring how this could work hand in hand in a more elaborated final design project. For this, I decided to undertake the design of a contemporary thermae. In doing 


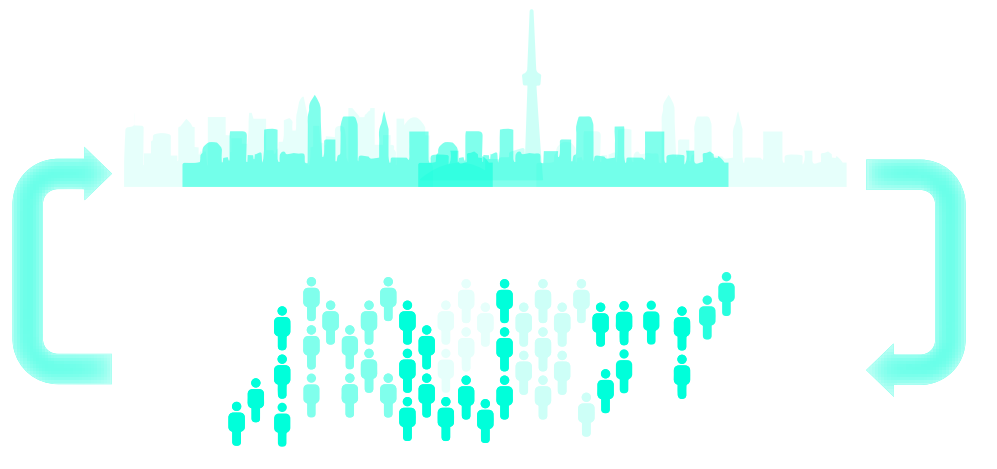

so, I approached the thermae through a contemporary lens as a transitional space that in essence facilitates a transformative experience, both physically and spiritually (similar to the sacred/ religious premise of exploring the mikveh).

\subsection{Transformative experiences as amenities inserted within the city's network}

On the larger macro scope, the thermae as a transitional space can be examined as both physically and metaphorically crucial to the success of cities. It is a place that helps make people feel better in their daily lives and constantly acknowledge the importance of healthy lifestyles. In his book, The Architecture of Happiness, Alain de Botton (2006) speaks of the continuous give-and-take cycle that exists in our environment and cities. The quality of life, the success and happiness of its citizens can ultimately generate further good on the rest of a city. Happiness, as de Betton explains, is very much a product of one's environment and is directly influenced by the quality of architecture that exists within it. The proposed thermae becomes a place which contributes to better spiritual and physical health which will directly contribute to people's happiness and satisfaction. This will have an influence on how they come back to the city -- happier citizens will lead to better citizens wanting to make a positive difference.

People's quality of life is also very much affected by the availability and variety of its given amenities. The thermae then becomes one of these amenities. A society's success is no longer solely
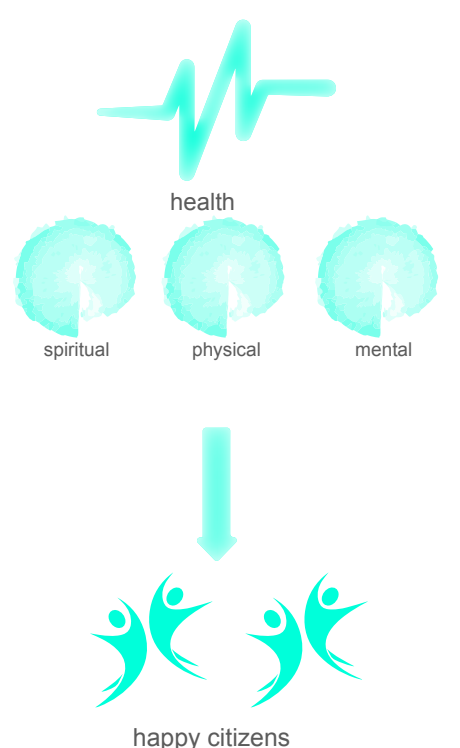

happy citizens

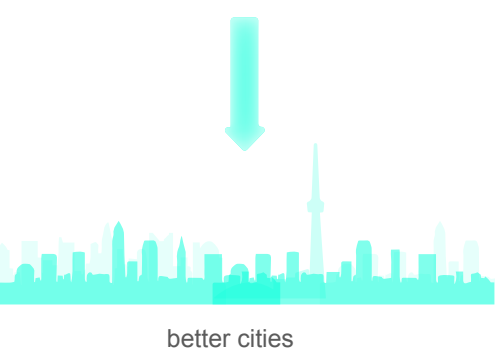

Figure 6.2 (top left): The city and its immediate surroundings in a continuous state of transition, constantly changing.

Figure 6.3 (top): Schematic; A positive transformation in one's health (measured through spiritual, physical and mental aspects) will lead to happiness and in turn will make for better cities to live

in

Figure 6.4 (opposite page): Life in the city should be sustained by numerous transformational experiences continuously contributing to the happiness/quality of life of its citizen's daily life. 
related to traditional economic measures. Today, policy makers understand that success is measured in a variety of ways and is highly related to the subjective levels of wellbeing of a society. The article Understanding the Pursuit of Happiness in Ten Major Cities demonstrates this and acknowledges the pursuit of happiness is linked directly to key health, wealth and social considerations. Yet it argues that design conditions are most associated with the continuous improvement of happiness for residents of 10 different cities which were studied in a survey. "Happiness is linked to whether people feel their cities successfully provide amenities that improve their quality of life" (Leyden, Goldberg, \& Michelbach, 2011).

In the context of this thesis, I think this works on two levels:

I. I believe that as architects we must acknowledge the role we have in constantly inspiring and enriching people's lives through design.

II. Happy people care more, act more and do more for the places they live in. If citizens are happy, then it creates a constant cycle which renews itself and positively contributes to the greater whole. 


\subsection{The thermae to be placed at the centre of civic life}

Transformative experiences inserted within the city's network are important to maintaining this. The thermae as a place of spiritual, mental and physical transformation, is one example of a city's amenity that can do this. In a sense, a place where one goes in and comes out different and then inserted back into the city transformed through this transformative experience which is ultimately meant to inspire, rejuvenate and make citizens healthier. Our daily lives should be surrounded by architecture that does this, by spaces that do this.

In fact, this thermae becomes a transitional space that becomes crucial to the success of the city flow, for making people come back to city life rejuvenated. Ringing the importance of placing these thermaes exactly where they once were located in the centre of civic life, and arguing this is not solely for social reasons but for healthy and happy citizens that are constantly transformed through their spiritual soul but through their bodies as they experience architecture that arouses transitional experiences. The thermae being one of them.

Interestingly, the city itself is in a constant state of transition, changing, growing, rebuilding; it is exactly these dualities and extremes of city life where I intend for this thermae to be located. Where there is the most amount of stress there is hope and there is need. In this sense, it can be argued that a thermae would be most effective in a downtown site - one which is constantly in transition and changing, for the transformation to be the most extreme.

In doing so, I have chosen to focus on the thermae from a spiritual, cultural and medicinal perspective as a cross-cultural and timeless transformational facility promoting wellbeing. As discussed, water is brought into this equation as an ancient vessel in cultivating this spiritual and physical transformative 
experience. Endless distractions due to technology and the fast-paced day to day reality have resulted in people seeking a spiritual connection allowing for a temporal detachment, a pause from the constant reality. With this global fascination and preaching for the body, urbanites are seeking these places.

\subsection{Spirituality as a step towards health in the city}

The city is a system in a constant state of transition, forever changing, growing and adapting. One of its roles as a complex organism is to serve its citizens in the most suitable way to sustain their growth and success. Functionality and efficiency are of course of great concern. Arguably just as important are aspects that architects of the future will have an effect on directly through design.

Movement through the city is usually experienced as a hierarchal system, highly efficient and allows to create moments of inspiration and awe for the public. This system is shaped by the solid and void arrangements which in a sense are what begins to create its formal and informal thresholds. As a city system, voids are comprised of mostly public spaces which are meant to sustain day-to-day interaction, inspiration, happiness, spirituality and in doing so, better health. In his 1748 Nolli plan, Nolli's voids were mainly churches, but today a void is a much looser definition both conceptually and graphically and can be seen as perhaps a café, a gym, a library, or conceivably a thermae. Despite its ancient roots, the thermae is highly relevant to contemporary society as a public amenity. The proposed thermae, in a way, is a contemporary illustration of how a subterranean void can become part of the solid and void relationship of the greater system of the city in providing accessible spiritual experiences and eventually leading to healthier and happier citizens.

Physical health is influenced by many factors, one of them being spiritual health as proven in the last decade by various medical studies. A survey done in 2012, by the National Post 

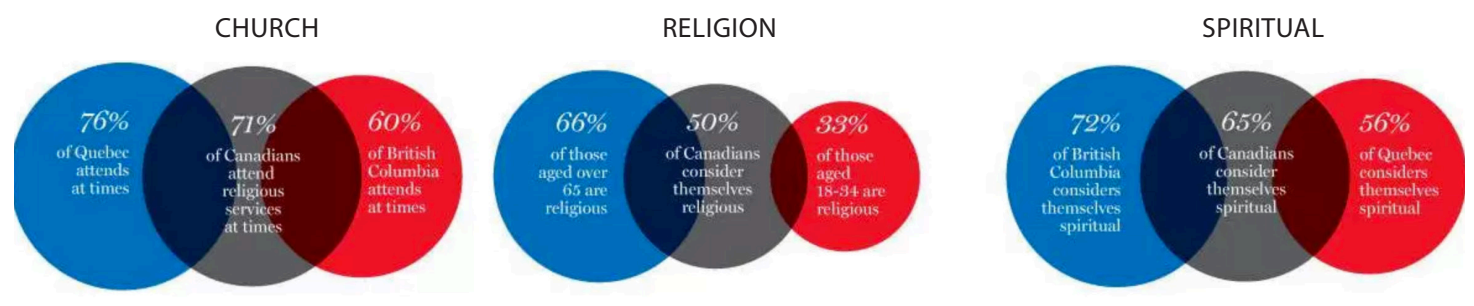

(Blaze Carlson, 2012) clearly pointed out the growing number of people who consider themselves spiritual vs, ones who consider themselves associated with religion. Blaze Carlson explains in the article that these are times where "church attendance rates are dipping, when most Canadians say they do not consider religion important and when claiming "no religion" is a more common answer than ever before". Furthermore, the article points out that two-thirds of Canadians consider themselves spiritual while only half say they are religious. While many say they do not believe in God, the fear of death or other lifethreatening events lead many to seek a spiritual connection.

Sacred spaces known as churches and temples, used for thousands of years, have provided meaning to cities and contributed to the health, wellbeing, and quality of life of its citizens. Religious gathering spaces such as churches and temples have become less and less popular, creating a need for other community-related sacred spaces for people to assemble and answer their spiritual yearning. The beauty of spirituality is that it does not necessarily categorize a space according to religion, or cultural values.

Spirituality in the 21st century, in the form of this thermae, is calling for an accessible and open-to-all spaces. A space for the cultivation of the body, where one has the possibility to connect, Figure 6.5 (top): The new meaning of spirituality in the 21st century. re-establish, and be one with oneself before returning to the city a more nourished citizen. 



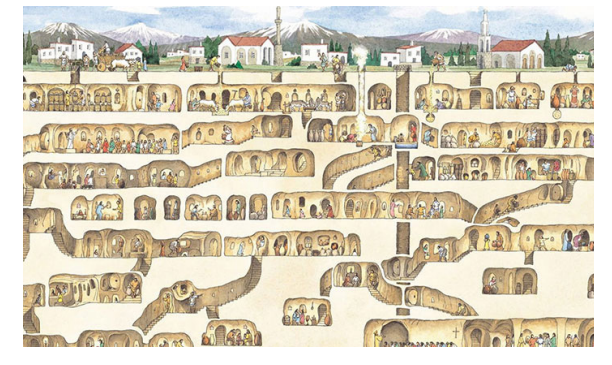

Figure 6.7 (opposite): Underground Streetcar Tunnel

Figure 6.8 (top): Section of Derinkuyu, a total underground city.

\subsection{Premise for a site}

The journey to descend and ascend was one that I was interested in pursuing very early in my design explorations. The underground, in a way, makes the prominence of transitions even greater for the contrast it provides between above and below grade conditions. The threshold between the above and below grades state can also have associations with the border between sacred and profane, known and unknown through the descent down into the earth.

Subterranean architecture often evokes a feeling of mystery, of the unknown and has a play of seen and unseen. Historically, going underground presented itself as a means to finding ultimate protection and removal. Many precedents in history such as tunnels, caves, homes, places of worship and even mikvehs (see precedents in appendix, section 8) were buried underground to provide protection. Even looking at WWI and WWII where bunkers came into use, they became ways of providing shelter from bombings and usually consisted of narrow spaces which were purely concerned with maximum survival. Yet the sense of stability was not lost as the bunkers usually gave the perception of being concealed, as a camouflage effect. Light and shadow in the context of war became extremely important in signifying seen and unseen. Light usually referring to closer to grade and absence of natural light to maximum security. In this context, there is a sense going toward a subterranean condition employs a sense of protection, of a womb-like condition and associates soil with fragility and energetic power coming from it.

It is clear that the notion of the subterranean is one that employs mystery and seclusion arguably to its best potential in providing ultimate strength and contrast between stages of the transitional moments of this thermae. The descent and ascent as part of this process become crucial in its success, in part of the arrival and exit sequence of procession through its to the actual thermae. 


\subsection{Site selection criteria; the case for the post- industrial city}

In selecting an appropriate site for architectural exploration, I set several parameters that allowed narrowing down the site search.

1. Establishing a connection to a subterranean condition, reinforcing the 'other place' as a 'place for transformation'.

i. Sustains and enhances transitions.

ii. This other place will become a prototype for a 'timeout place' in the city. A contrast from the intensity of contemporary urban pressure, speed and extreme expectations

iii. Urban pressure $>>$ results in abused mind, abused body

- Lack of personal space and the space to truly connect to your spiritual side and self-awareness.

2. Parking lots, abandoned theaters, $T \mathrm{TC}$ transit network, PATH

i. The grounds for selecting a site of this nature was one that was centred on the understanding that the not-so-distant future is calling for less reliance on the automobile, faster and more efficient public infrastructure, and less available land.

ii. Forgotten and abandoned space, that was once the vibrant bloodlines of the city will be unutilized in 30 years due to new technologies which replace old infrastructure.

3. Inside the city's 'hustle and bustle' as reference to importance of accessibility, visibility, and necessity vs. luxury.

i. Utilize contrast and growth of the city centre to my advantage as where there is a greater amount of stress and hustle, there is more opportunity to insert 


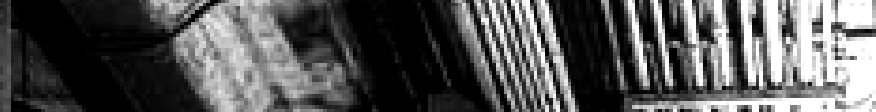
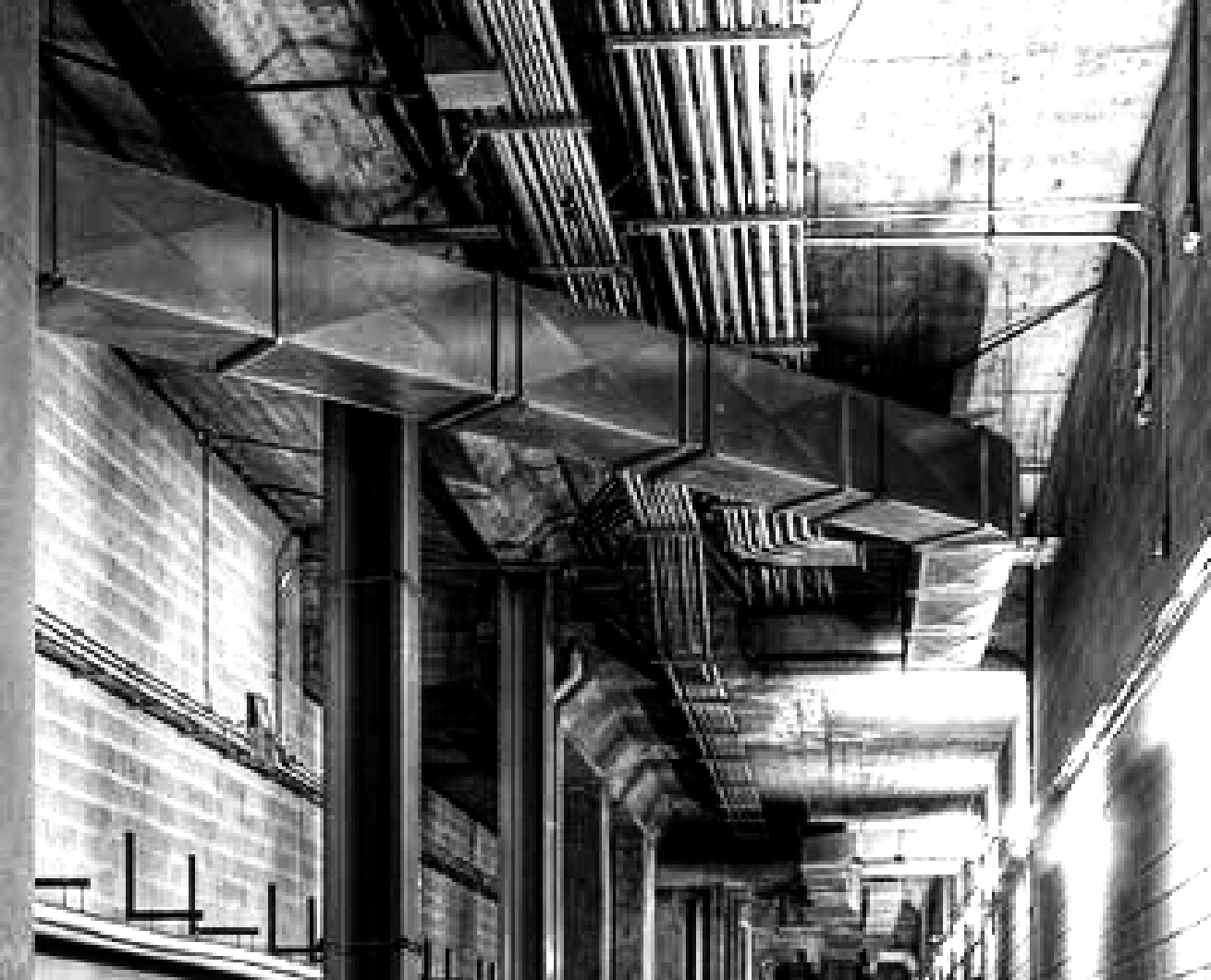

12

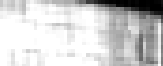

.

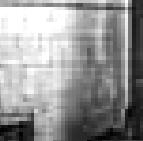

\section{E.}
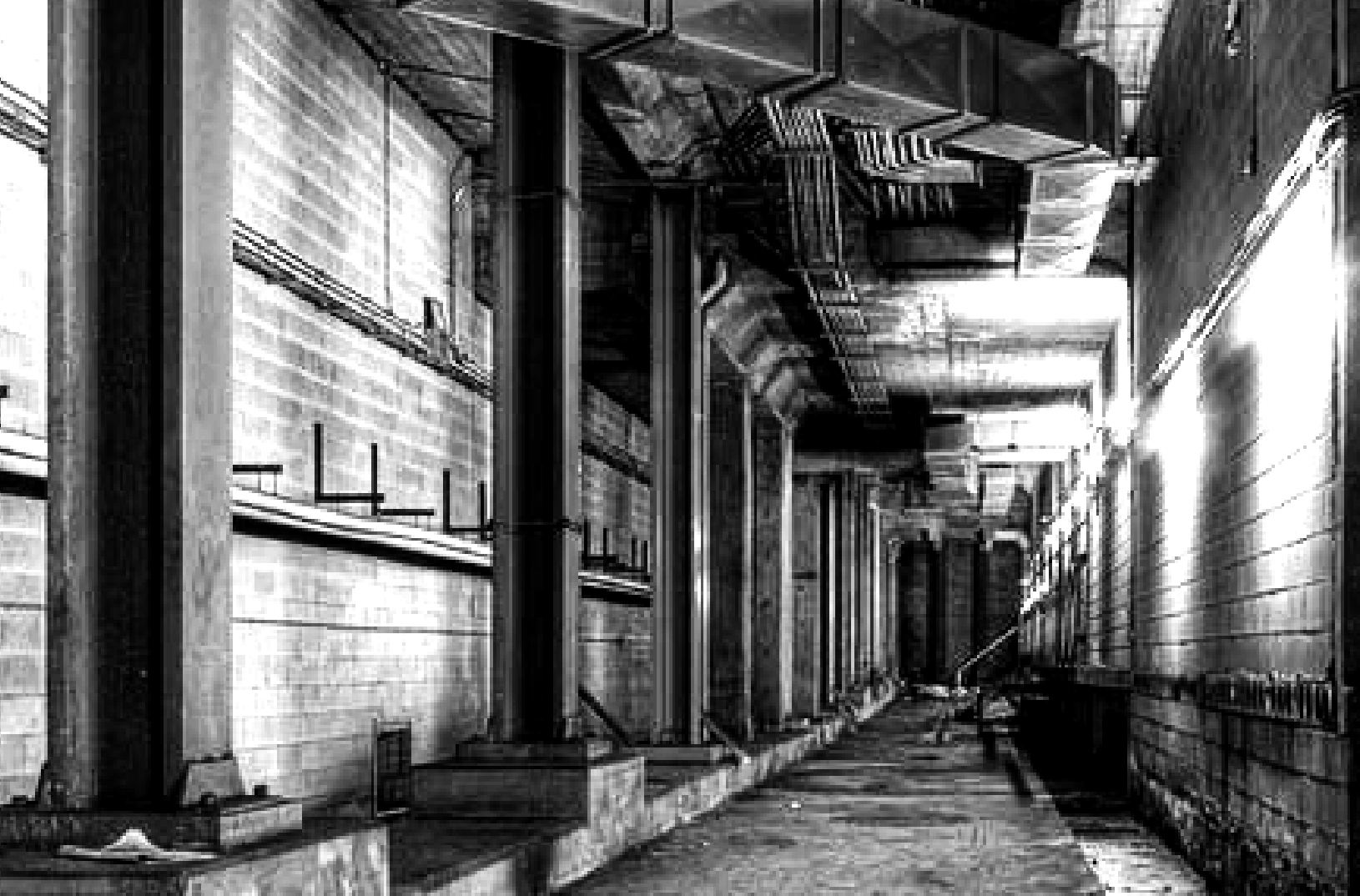

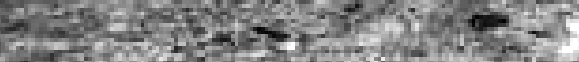
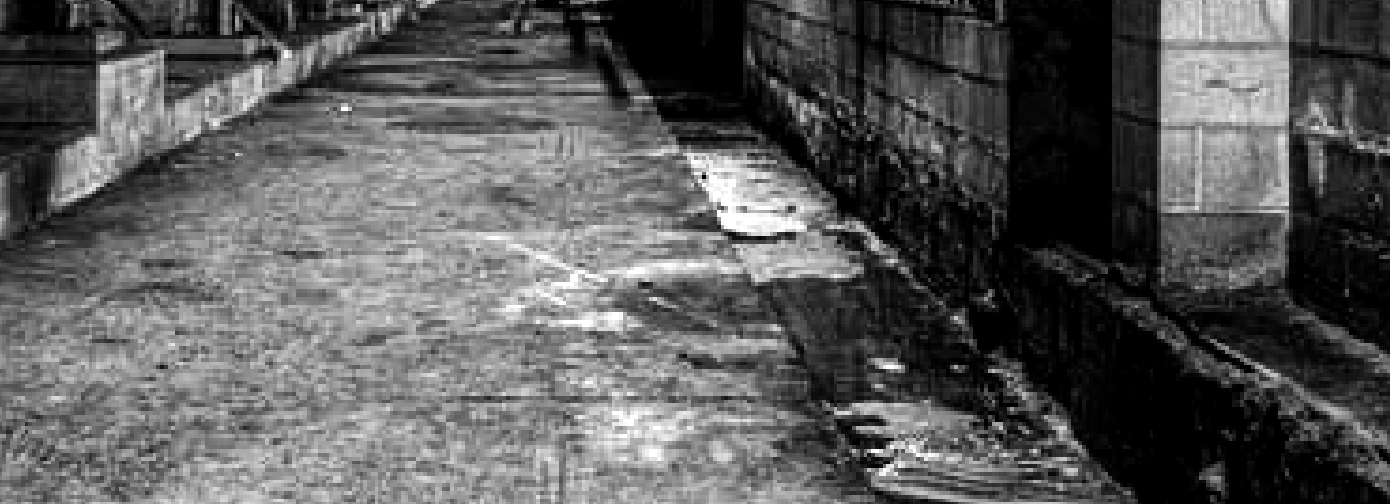


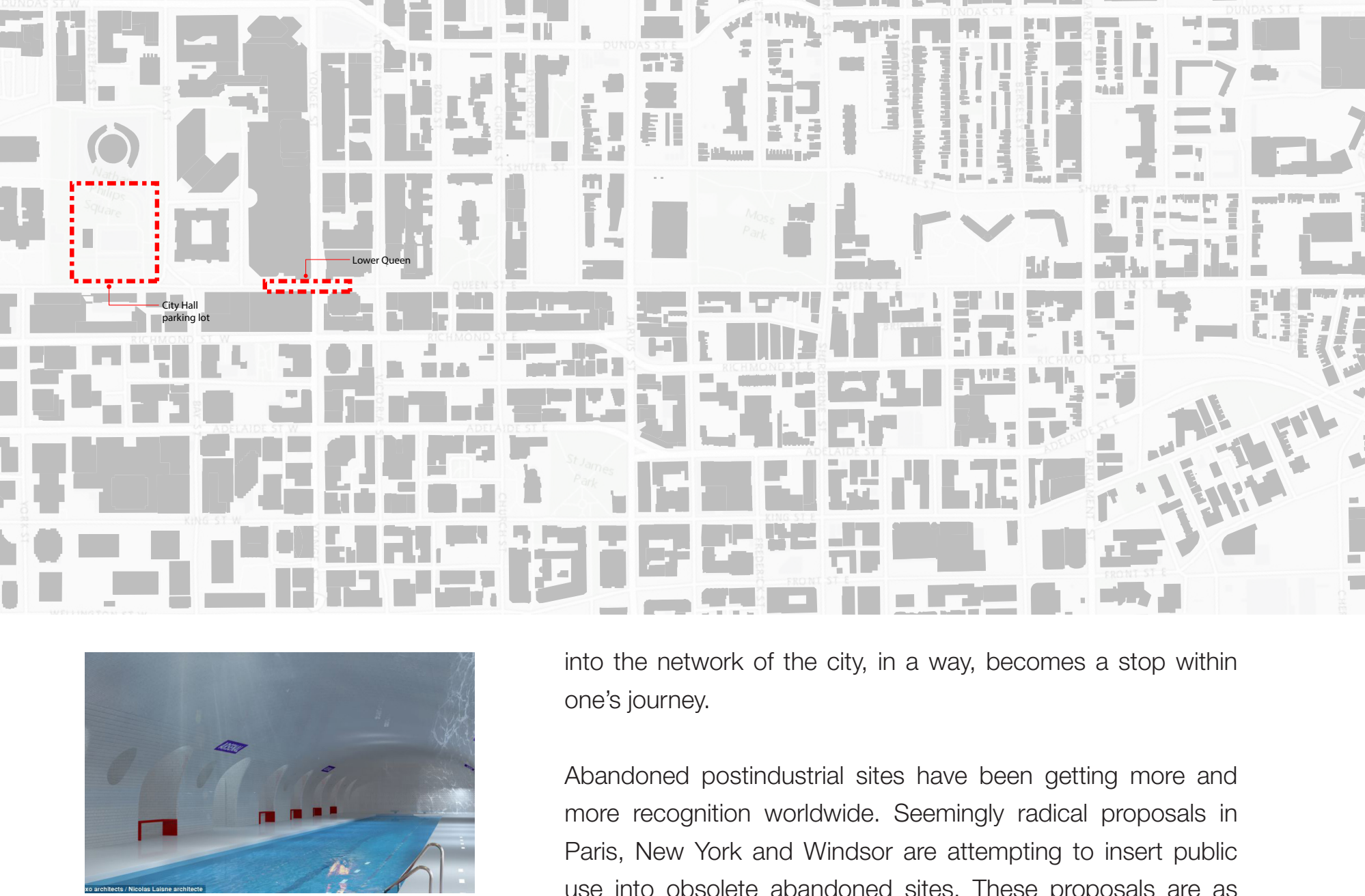

into the network of the city, in a way, becomes a stop within one's journey.

Abandoned postindustrial sites have been getting more and more recognition worldwide. Seemingly radical proposals in Paris, New York and Windsor are attempting to insert public use into obsolete abandoned sites. These proposals are as radical as underground parks with full grown trees to public pools, nightclubs, restaurants or even community centers. Technological innovation has made all of these proposals much less radical as solutions are found to almost any subterranean issue. Experiments in below grade green houses are currently underway and rely on highly complex systems of cross reflecting mirrors fiberoptics pipes. Coelux is an example of innovation in recreating sunlight in underground environments by calibrating LED fixtures to the same wavelengths as the sun. All of these, reducing the common reluctance of the below grade condition and giving tools to creating better below grade environments. Nolli's city plan for Rome was successful for its accurate reflection of the dialectical relationship of the solid and void relationship, the public and private spaces of its time (churches also included as publics space voids). The postindustrial city calls for an examination of the city not just in its 2D complexion but in its vertical sense. The Nolli plan of the postindustrial city 


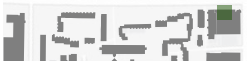
- >l" IIIr. HL -in

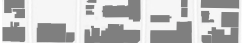

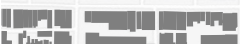

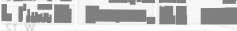

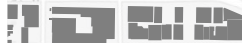

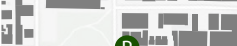
[n! $P$ TP P 세일

$1=-\frac{16}{16}$ $-\gamma^{-1}$ E -1]L I 1

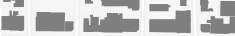
tring

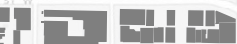

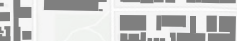
분 $=$ trient

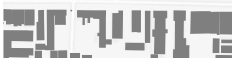

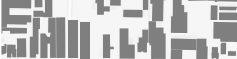

$1=-15-7 !$

$\frac{5}{4}$ EIfl.

- 1)

allition

$10=-12$ tinc

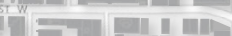

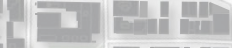

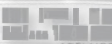

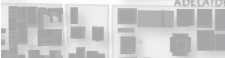
This -1

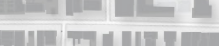

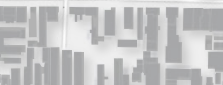

PJis $P$ ?

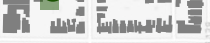
17 minm

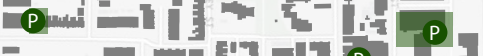
$=-1$ m

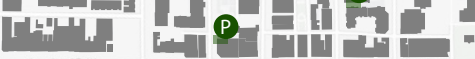
MT

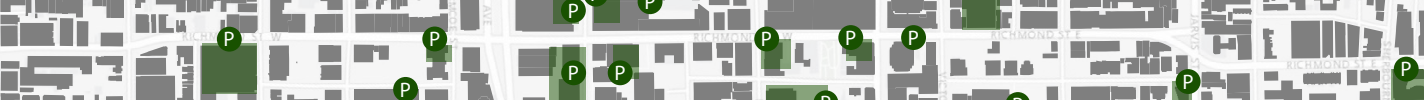

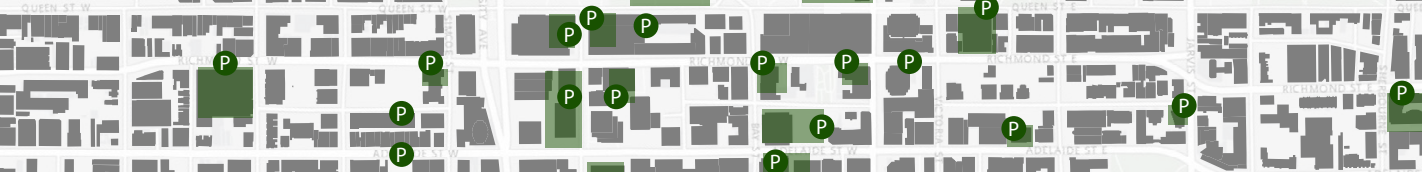
G

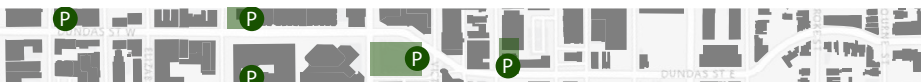
$P$ PP $\frac{P}{P}$ P

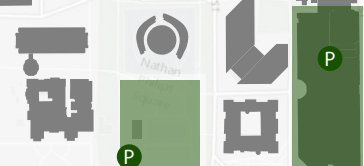
$B_{0} \mathrm{H}^{-3}$

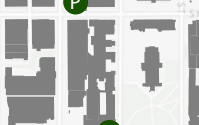

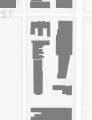
10

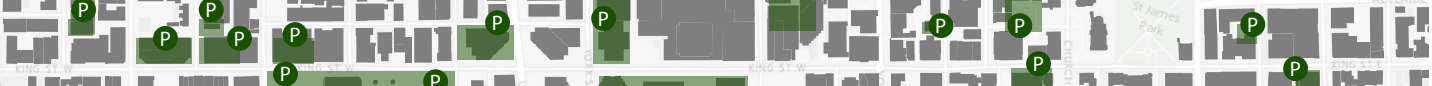

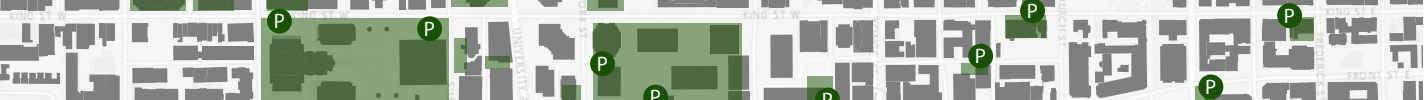
는

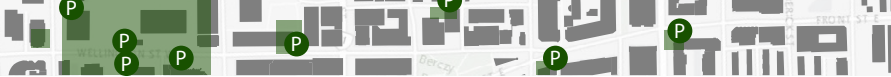

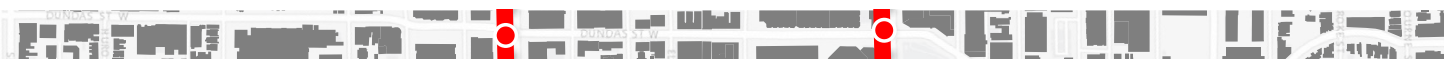

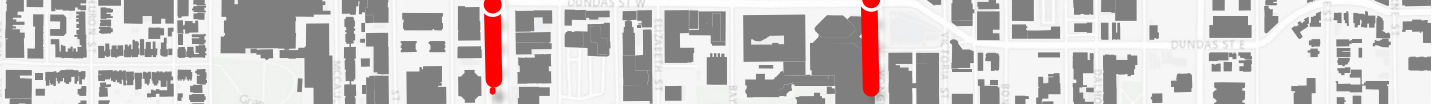
Sim minam

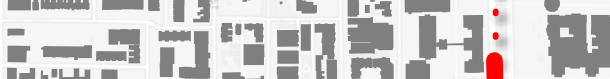
(O) 广מㄴ.".

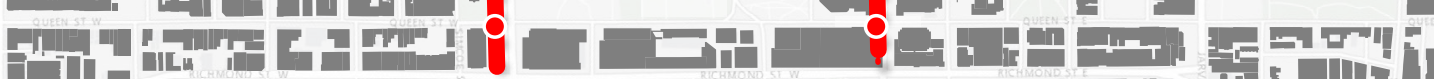

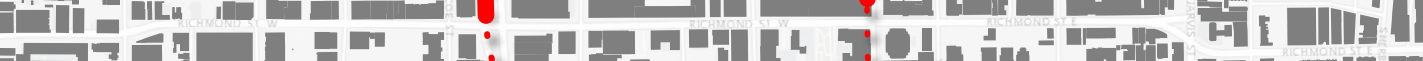
군

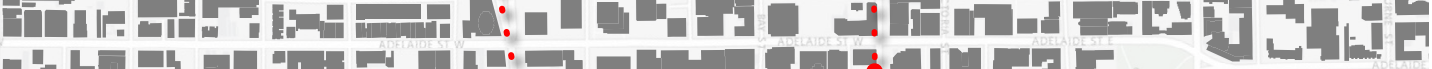

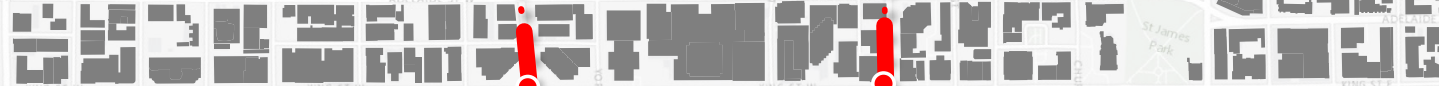

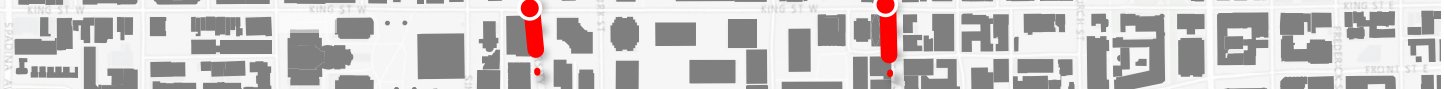

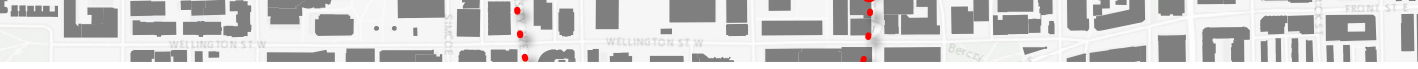

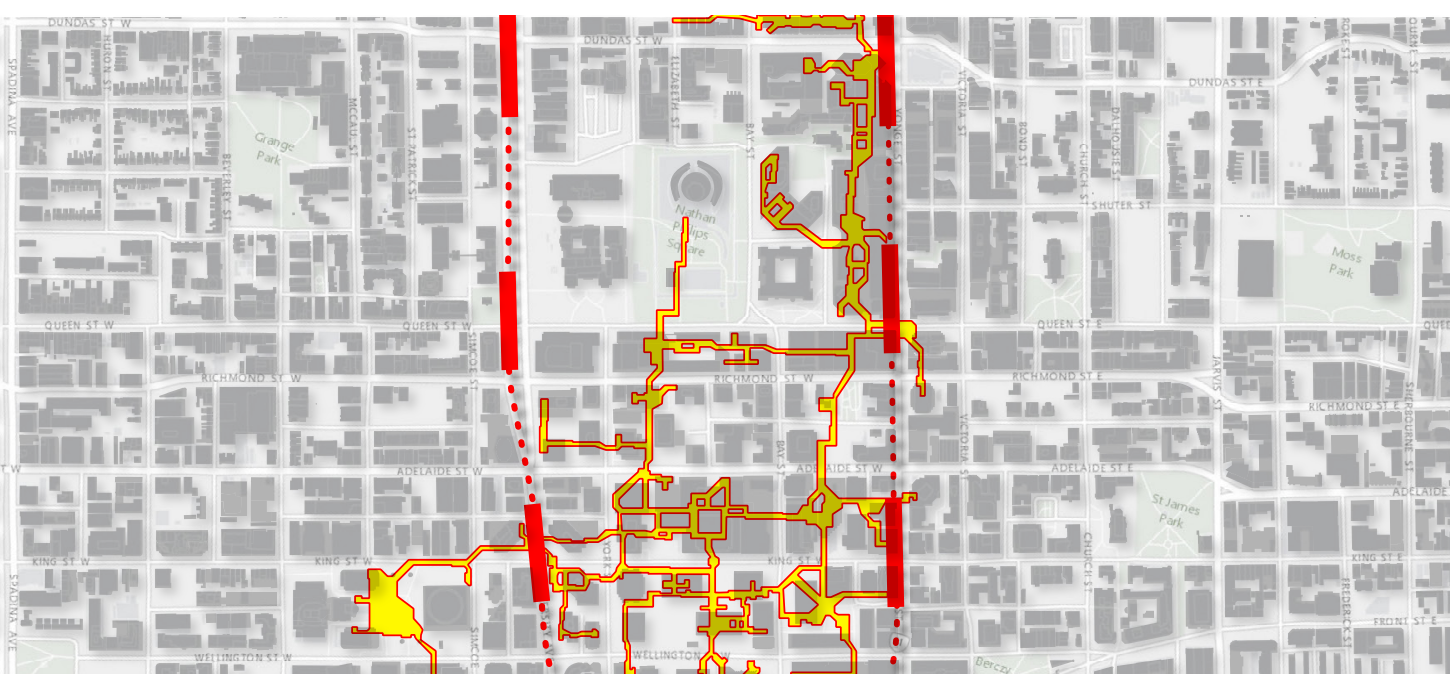




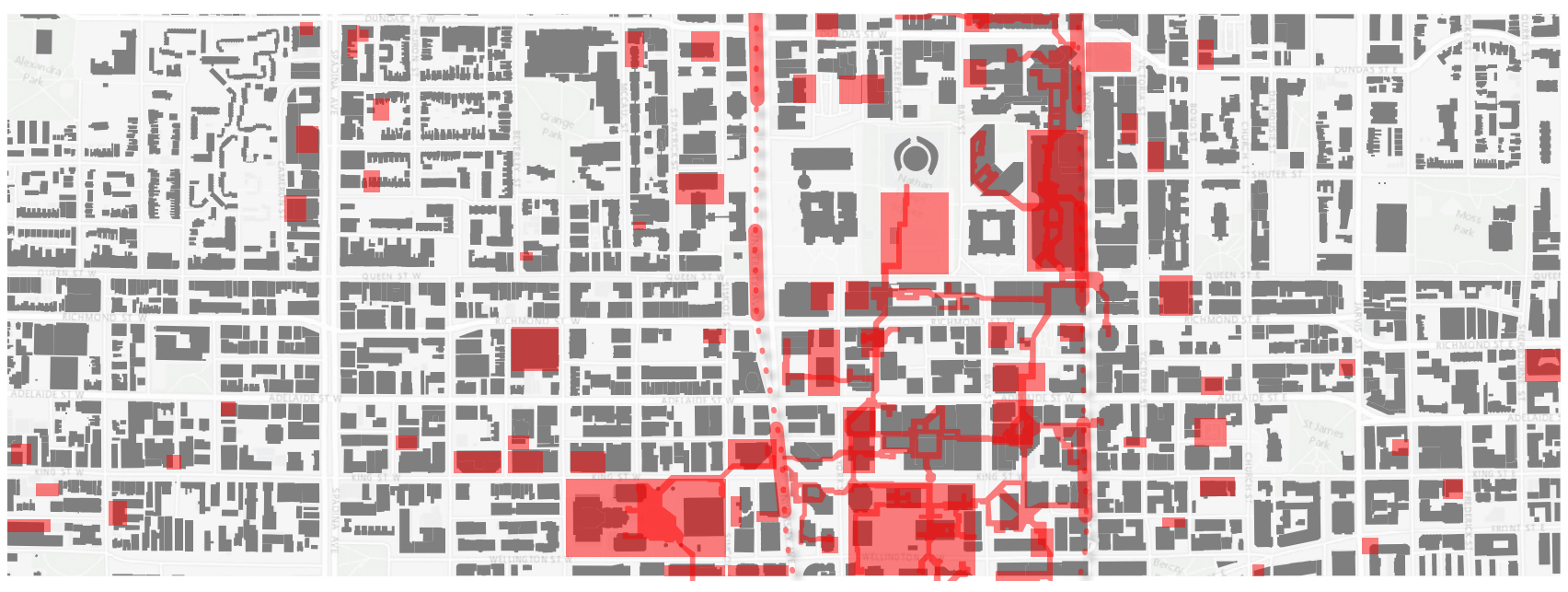

is a diverse one with a wide range of public void spaces which position themselves not only at ground plane but in the vertical sense of the city.

Figure 6.13 (top, opposite page): Below grade Parking survey in Toronto's downtown core with future speculation of many becoming obsolete.

Figure 6.14 (middle, opposite page): Toronto's TTC stations as post industrial sites potentially becoming partially obsolete

Figure 6.15 (bottom , opposite page): Toronto's PATH system and its connection with the subway system, creating am underground cavity network of its own

Figure 6.16 (top): Analysis of potential future post industrial underground voids within the downtown urban core as part of the city's below grade urban fabric 
110 | MOMENTS OF TRANSITION 


\section{FINAL DESIGN PROJECT: A THERMAE}

As discussed in Chapter 6, thermaes, which provide a transformative experience within the city, are important to enhancing urban life, especially in the busy, fast-paced $21 \mathrm{st}$ century. The thermae then becomes a source of spiritual, mental and physical rejuvenation, a place of solitude and relief. A person enters the thermae in one condition only to exit in a different state, then inserts himself back into the city transformed and rejuvenated. Holistically, it is architecture's role to do this - to inspire, give a sense of awe, to transform

Figure 71 (below): Queen St. elevation, looking north and looking at Eaton Centre on West and from street and BOM on the east.
The thermae to be proposed is to be integrated into the city's amenity network, relevant to contemporary society as a public amenity. In a way, this thermae, is a post-industrial illustration of how a subterranean void can become a solid part of the greater system of the city, providing an accessible spiritual, mental

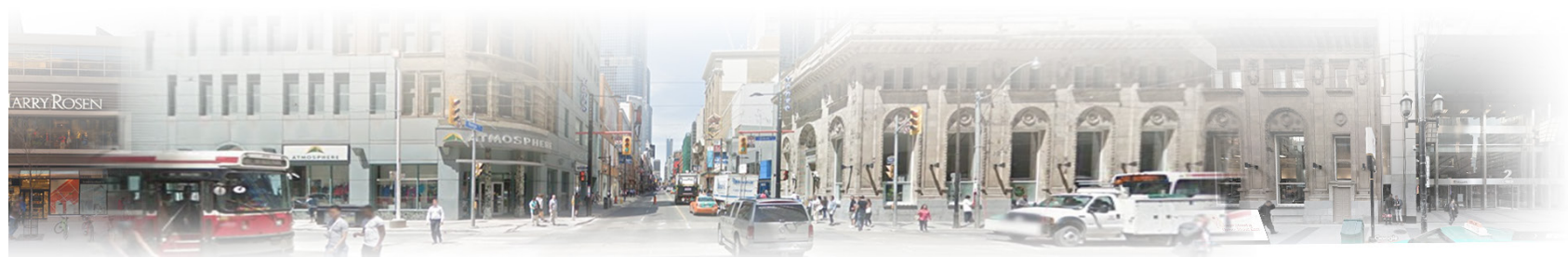


and physical experience. Nolli's 1748 voids have been given a renewed definition and are no longer looked upon only at their grade 2D condition.

The post-industrial condition calls for an examination of future abandoned voids sustaining a 'vertical' Nolli plan. Through a rigorous site selection process looking at many potential cavities to this below grade condition, I ultimately chose Lower Queen Station located at Yonge and Queen in downtown Toronto. The premise for this was one that consisted of this thermae as a case study within a network to be applied in other sites within the city. Lower Queen Station is one of the more complex sites surveyed and serves as an extreme case.

\subsection{Site existing conditions}

Located $16 \mathrm{~m}$ underground, the Lower Queen was planned as an east-west relief streetcar line to the Bloor line. Despite plans and initial construction, the project was halted due to speculation there was not enough need for it. As such, this eastwest line was never realized and remains to this day as a vacant unutilized space. The station was originally designed adjacent to the tunnel (today part of the PATH system) that now allows people to cross from the Eaton Centre to the former Simpson's department store (the Hudson's Bay store today).

Queen and Yonge is one of Toronto's major intersections, surrounded by historic buildings on three of its four sides. Its southwest corner was the old Simpson's department store (which, as previously stated, is now the Hudson's Bay). On the northwest corner used to be the Jamieson Building which is now expanded into the Eaton Centre; On the northeast corner is the 1912 bank building which was gutted inside but its façade still remains, and provides a public entrance to the subway as well as the Bank of Montreal and other offices. With research on transitions done both on an urban and architectural level, it seemed only natural to find a setting for an urban thermae. The intention was to find a site that could facilitate the growing

Figure 7.2 (top, opposite page): Site plan, illustrating TTC street entrances

Figure 7.3 (bottom left, opposite page): Queen platform level illustrating accessible entrances

Figure 7.4 (bottom right, opposite page): Queen platform level illustrating entry points from street 

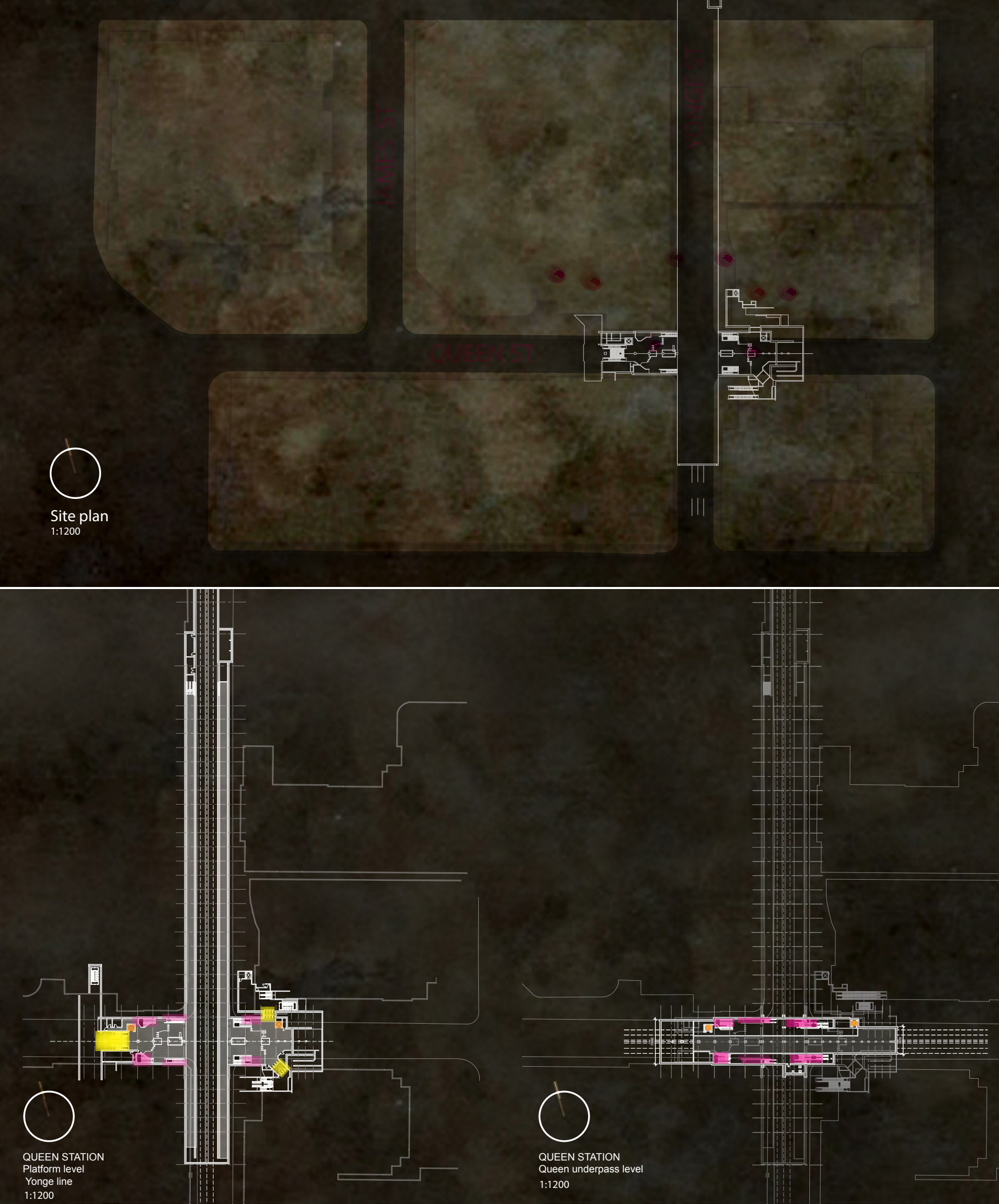

FINAL DESIGN PROJECT: A THERMAE 


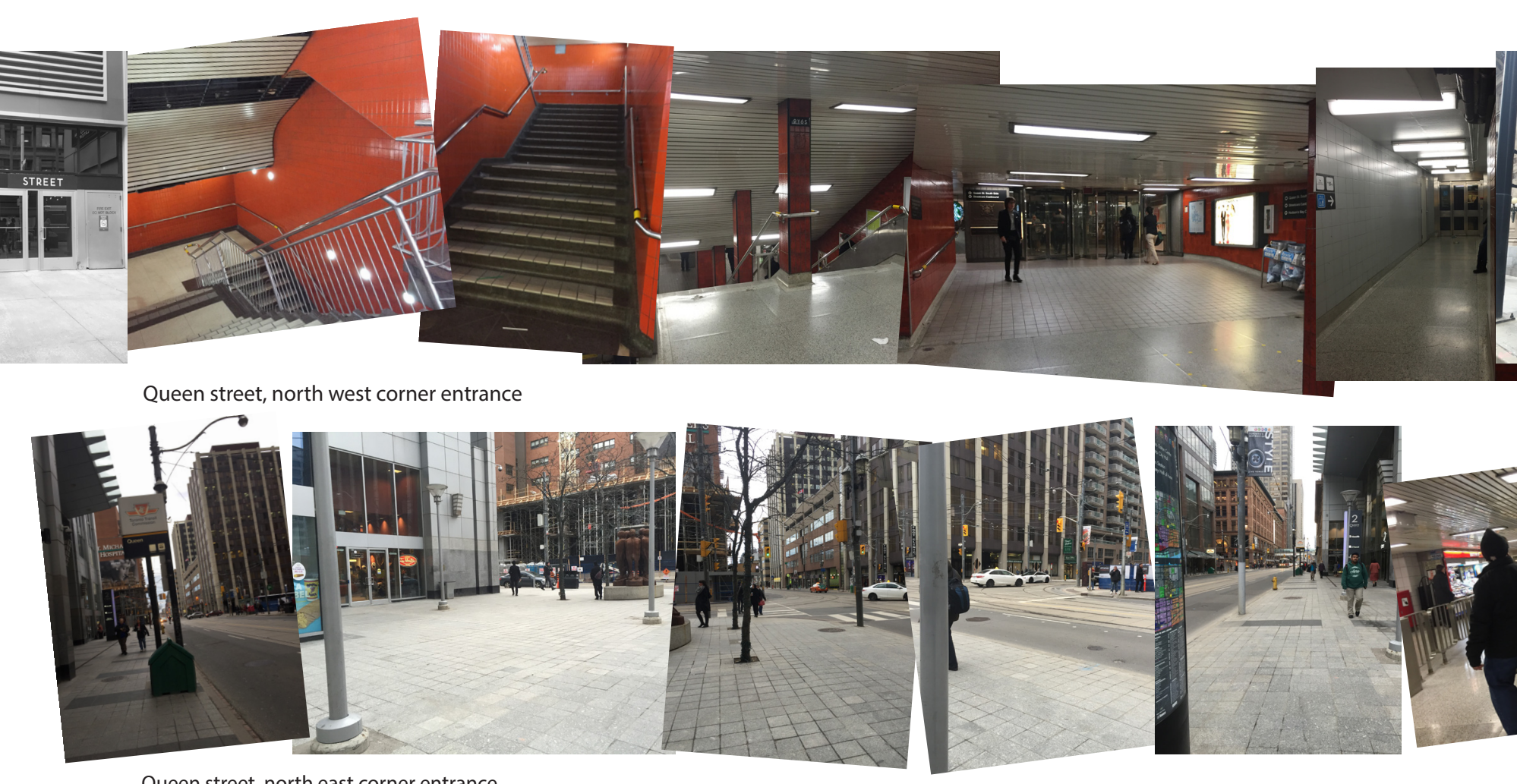

Queen street, north east corner entrance

need of urbanites for body cultivation, therefore to make it as accessible as possible. From the beginning, this project triggered great fascination with the underground and the possibility of incorporating spaces that were exposed and unexposed for possible transitions.

Prior to beginning design of the thermae, several parameters had to be established with respect to the site as it involved a

Figures 7.5: (top): Photo survey of entrance sequence to Queen street, north west corner entrance

Figure 7.6 (top middle): Photo survey of entrance sequence Queen street, north east corner entrance

West TTC
Entrance
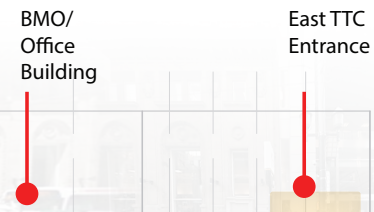

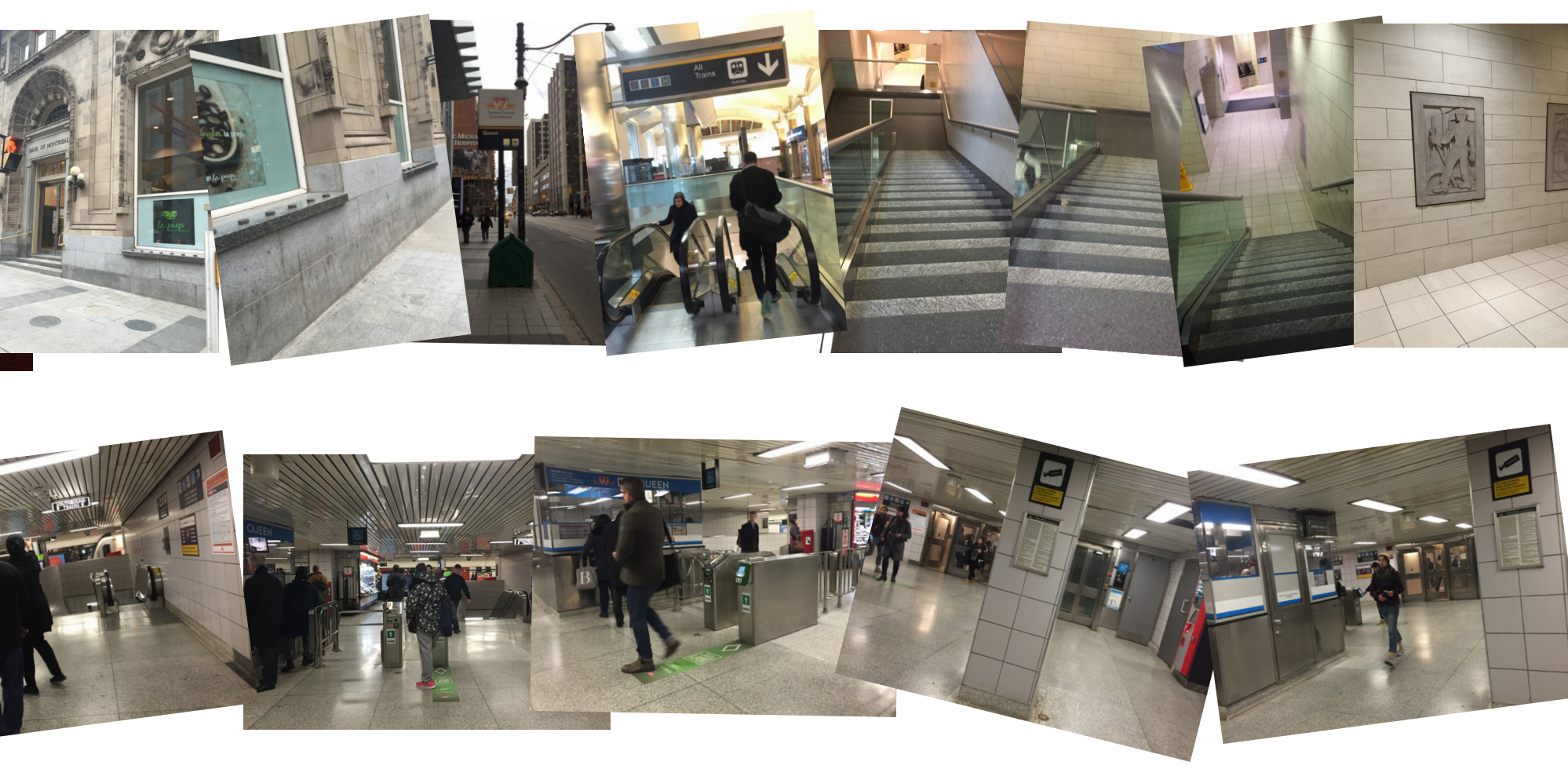

Figure 7.7 (below, opposite page): Site section, illustrating existing conditions.

Figure 7.8 (below):

Site section, illustrating proposed conditions. rather complex set-up. To fully understand the nature of Lower Queen, I requested a special tour in February 2016, which allowed me to see and experience it firsthand. As Lower Queen was meant to facilitate an east-west line from the Yonge line, access to it was designed directly from the station itself. Finding a separated entrance and exit was a goal I struggled with but ultimately I found a solution.

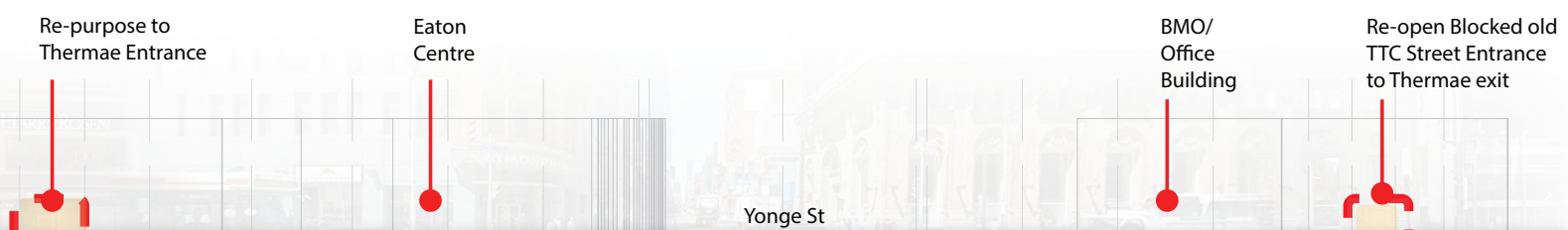




\subsection{Design Assumptions:}

Access Queen station is currently accessible via eight separate access points (see figure 7.2); seven active on all four corners - three on the northwest corner, two on the northeast corner and one on each of the south-east and south-west corners. The eighth entrance is left de-activated on the northeast corner of Queen and Yonge St (external street staircase which is now blocked). I intend to re-activate the northeast street access point and the northwest external entrance.

This thermae also relies on there being a separate ascend and descend down into it, therefore designing separate entrances and exits from the subway itself. In fact, the thermae will be disconnected from the subway infrastructure.

In doing this, I have proposed the following - the Queen subway station has a north and south platform which are separated by the trains. Having separated access points to each platform becomes accessible only by two options - going up to street level and crossing over or by going down one level to the Queen underpass to come up to the other side.

This underpass can be accessed in two ways - either through its public zone or by purchasing a TTC ticket and entering the stations zone. The public and paid tickets underpasses are completely separated from each other. I have chosen to repurpose the north public sets of access points as well as the
Figures 7.9 (below): Photo survey of the abandoned Lower Queen site conditions
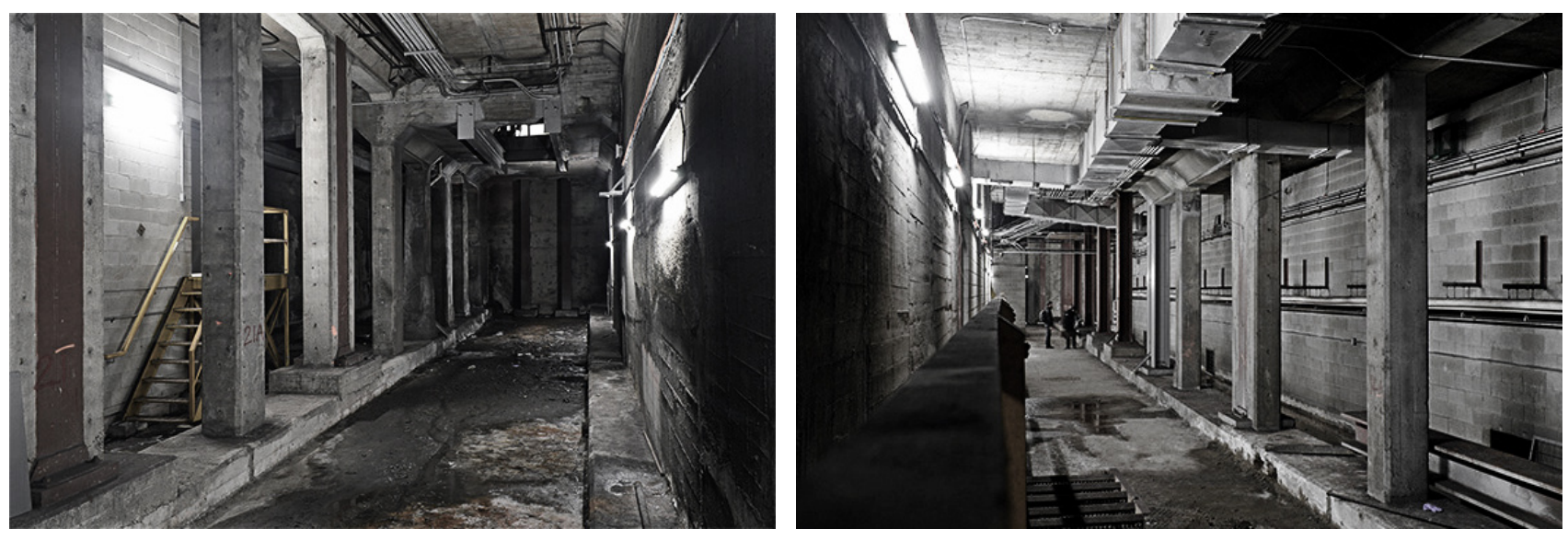

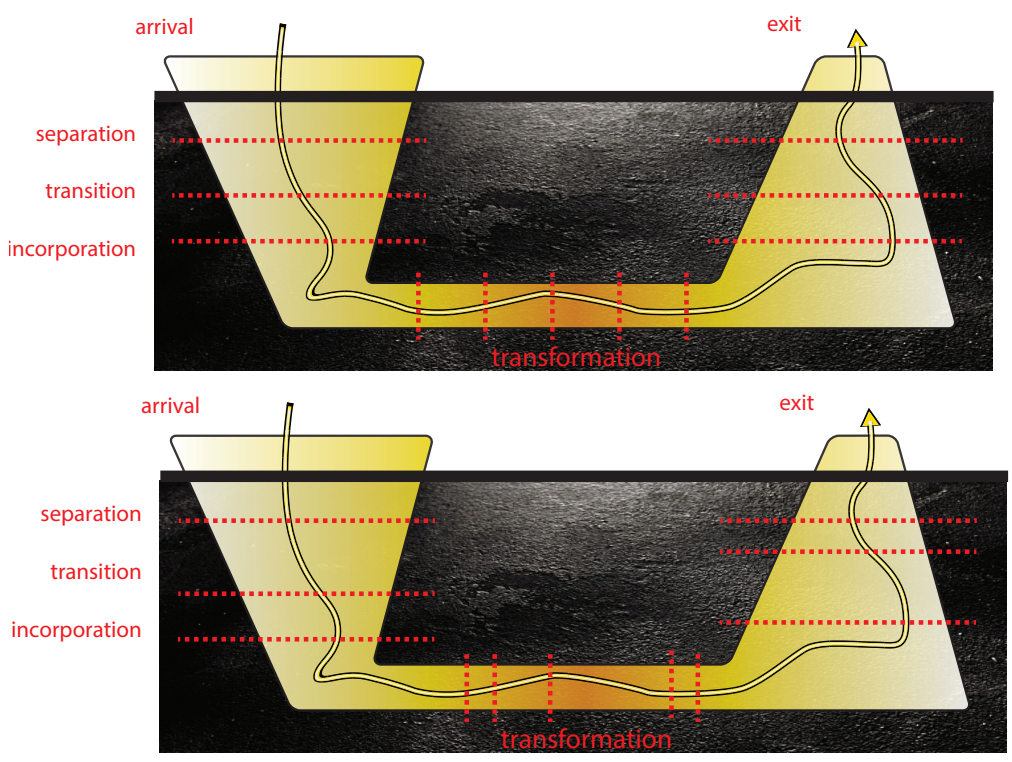

northern portion of the underpass for this thermae.

\subsection{Path to 'another place': strategies}

Figures 7.10 (top right): Separation, transition and incorporation as stages incorporated in the path to the underground. Exploring how variance in passage length has an effect on the overall experience.
Descent and ascend become primary design strategies for this project and crucial in providing one the experience of preparation, acknowledgement and understanding of an experience one is about to embark on or reversely its summation. A building, like a play, attempts to let its occupiers experience and be told a narrative to what it's about through movement within. Its different parts and their order help immerse one in a building's role and reason for being. Transitions in this case help extenuate and refine these as explored in previous chapters.
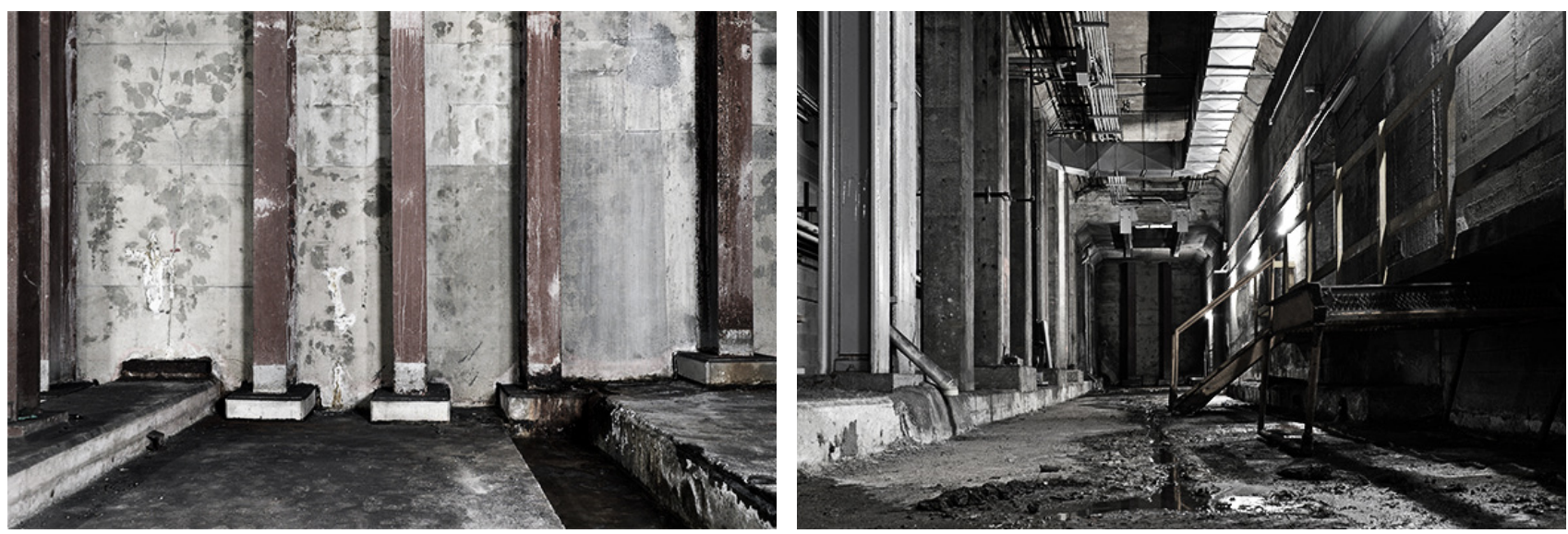

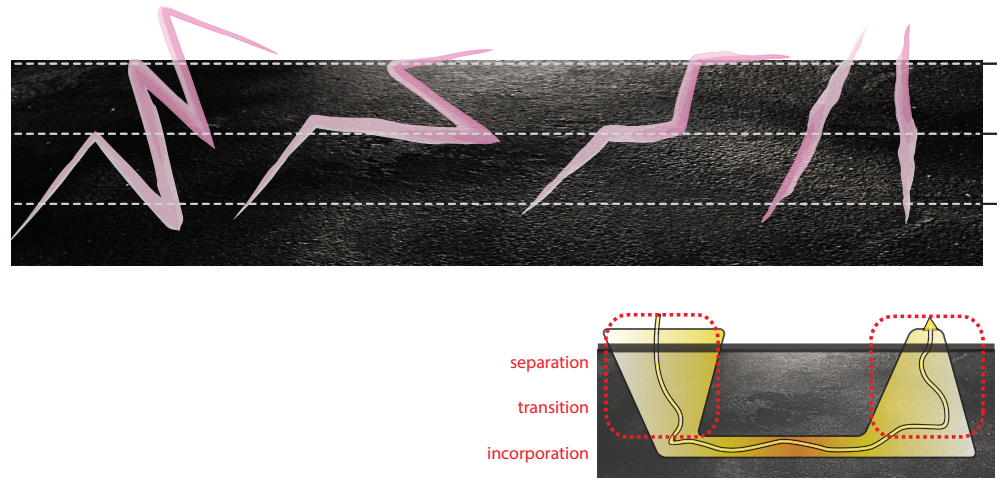

As explored in the precedent matrix, many times buildings and their architecture attempt to transfer one to 'another place', literally and metaphorically. Other buildings remain more straightforwards and their reason for being is not to get lost within, it might be functionality. I see this thermae as being much more of the former. This thermae's reason for being is to transport one from one's busy life to another place, a place of solitude and peace with oneself.

In attempting to develop appropriate strategies, I ultimately I found Van Gemp's theory of separation, transition, incorporation the most applicable in generating my own strategies. In doing this, I understood the great influence arrival and exit have in framing a building. The journey of pre-arrival to the thermae and the one coming from it became an exercise of its own for me and I attempted to develop appropriate strategies to deal with it. I tried to understand different possible stage lengths one could have before, within and exiting the thermae. I then examined how a change in length or consistency of sequence could directly influence the overall experience for a user. The first diagram (see figure 7.10) shows equal and consistent segments of transitions and spaces along the way as well as conceptual incorporation one goes through preparing for arrival into the site. Illustrating how consistent and alike transitions could translate in a monotone, anticipated and ordinary transitions - design wise, this could translate as typical staircases, no variance in dimensions, same height. The second diagram is meant to
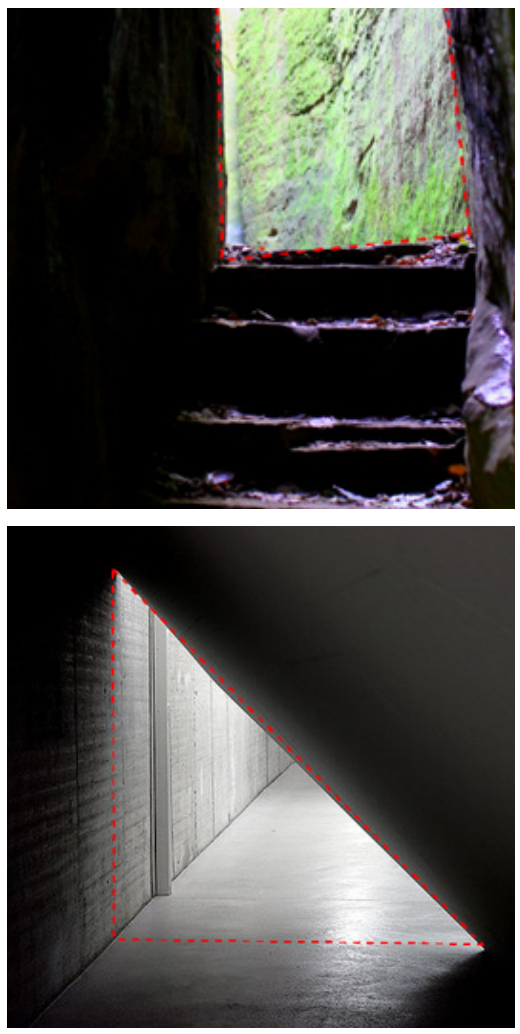

Figures 7.11 (top left): Variance in approaches in path to below.

Figures 7.12 (top): Framing a threshold. Transition from dark to light space, light is further enhanced by walking in the dark. 


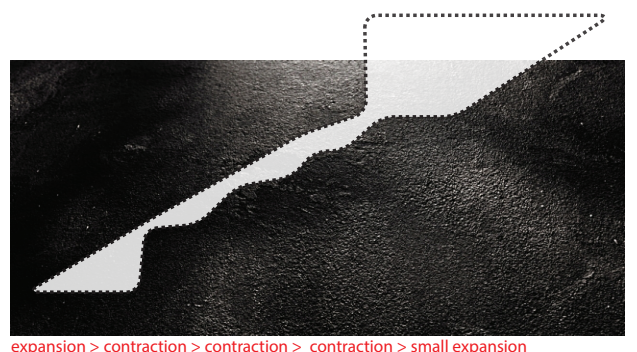

expansion $>$ contraction $>$ contraction $>$ contraction $>$ small expansion
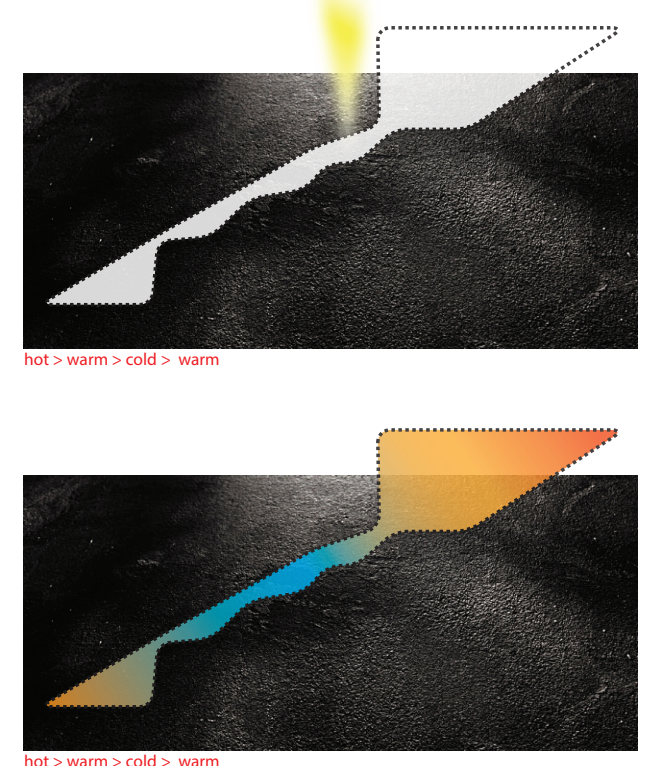

hot $>$ warm $>$ cold $>$ warm

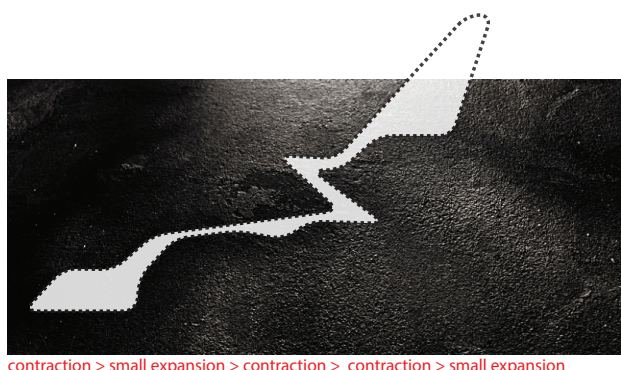

contraction > small expansion > contraction > contraction > small expansion

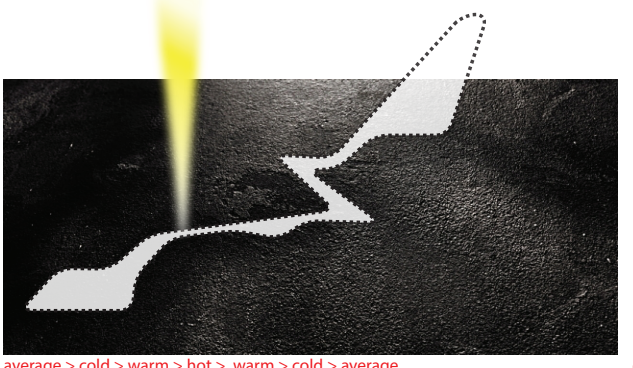

average $>$ cold $>$ warm $>$ hot $>$ warm $>$ cold $>$ average

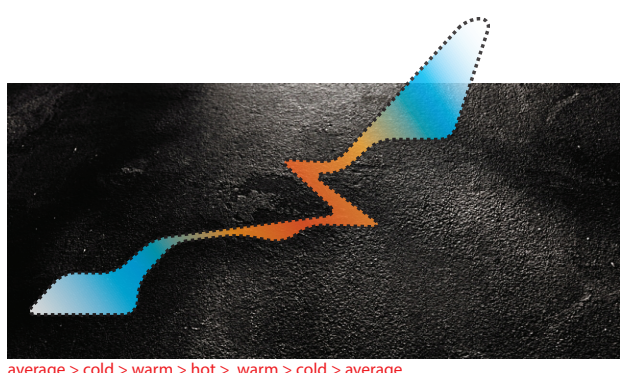

average $>$ cold $>$ warm $>$ hot $>$ warm $>$ cold $>$ average

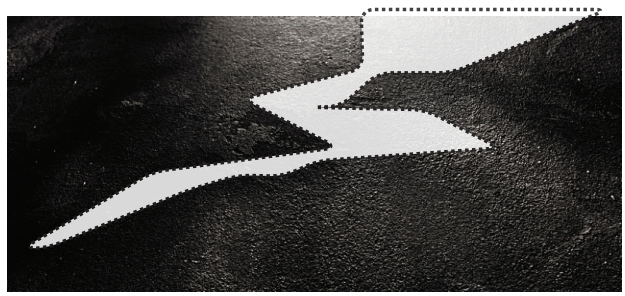

expansion > contraction > expansion > contraction > contraction

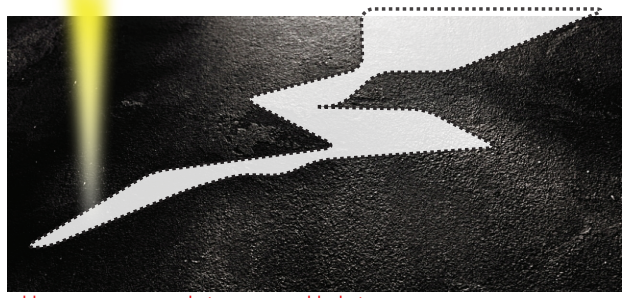

cold $>$ average $>$ warm $>$ hot $>$ warm $>$ cold $>$ hot

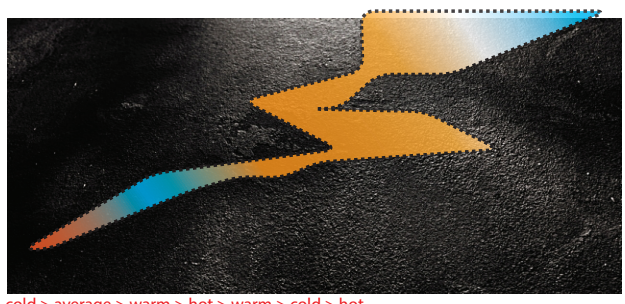

cold $>$ average $>$ warm $>$ hot $>$ warm $>$ cold $>$ hot
Figures 7.13 (top):

'The path to below' exploration through reward and denial strategies

(1) expansion and contraction of form

(2) gradients in a transition temperature material

(3) light aperture location can have a great effect on whole experience.

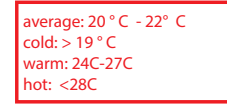

illustrate that an imbalanced interpretation of transitions/spaces could indicate more variance and less predictability for a user. These variances could potentially be a prolonged hallway, an exaggerated staircase, slanted walls, light to dark, etc.

\subsection{Design strategies}

The transition into the underground world can be abstracted into a mass being carved away from, being penetrated into. Transitions become crucial as they become signifiers of the level of detachment from the outside world until a full incorporation is achieved. Extenuating an overall experience, cognitively and physically, results in clever and intentional use of the very essence of an architect's primary tools. In this context, the descend 
down or ascend up can be straight up or down, comprised of a zigzag and at times go back to confuse one of one's bearings (see figure 7.11). There is no right or wrong answer in this, but different approaches that can be applied.

As discussed earlier in this thesis, and described so succinctly by Louis Kahn, "architecture is the thoughtful making of space" (Kahn). One of our greatest assets as future architects is the ability to inspire and directly influence people's lives through the way we manipulate space. Although we cannot control what they feel, we can surely do everything in our power to allow for this magic to happen and an implementation of the full design intent.

This thesis has enabled me to carefully examine transitional moments, a loose definition on one hand, but such a crucial one in choreographing the architecture of our lives. I believe that the way we perceive these moments is no different than the way a play narrates a story or a presentation will be presented. I believe that life is in a constant back and forth between reward and regression. It is the tension between the two that allows people to appreciate and enjoy the pleasures of life. Full appreciation will normally not occur without understanding and experiencing hardships. That is not to say that architecture should be hardship and pain before it exposes people to the true space. However, I believe that in order to inspire people, transitional moments must employ design strategies which have to do with reward in denial, constantly shifting from a pre-space to the space in subject and back again. Denial and anticipation allows for an evolutional kind of journey, on building anticipation, yet avoiding giving away all the information, allowing to build and trigger a familiar language. This by working directly on the temporality and permanence of a space. Specifically, for this thermae this could be diagrammatically and abstractly explored (see figure 7.13) in several ways -- formal expansion or contraction, temperatures differences, seen and unseen, materiality, aperture allowance and placement.

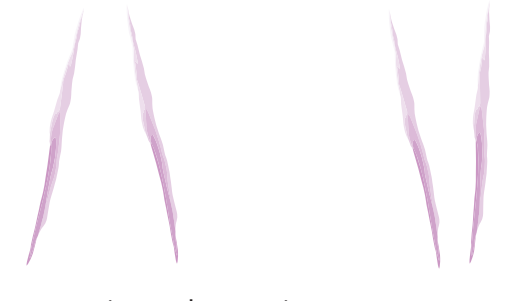

contraction and expansion
Figures 7.14 (top): Schematic sketch, contraction and expansion as a guiding design principle.

Figures 7.15 (top, opposite): Thermae Site plan, illustrating proposed arrival and exit locations as well as outline of lower queen station below grade.

Figures 7.16 (right, opposite): Design of arrival and exit sequence. Contraction at arrival and Expansion at exit. 


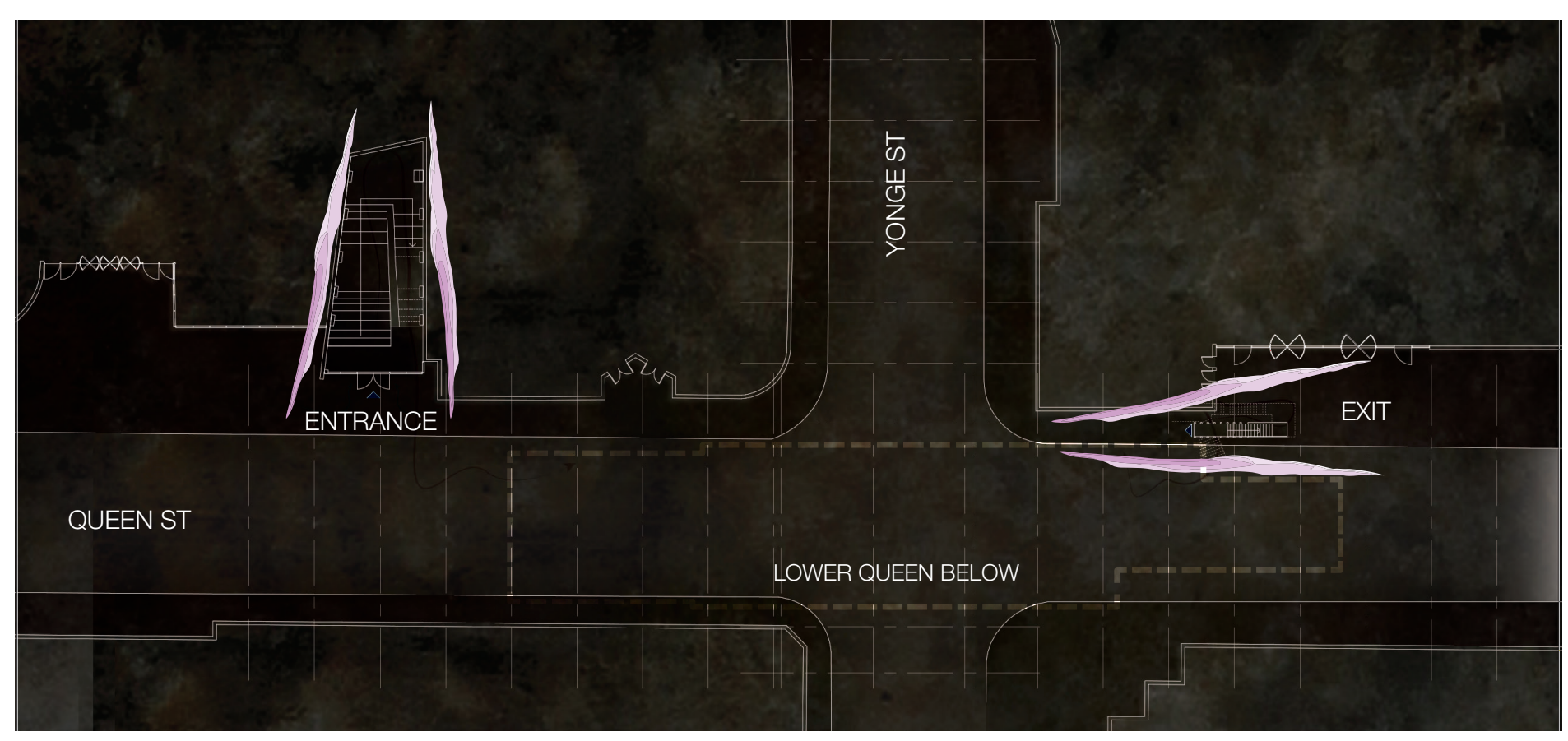

Site plan

1:600

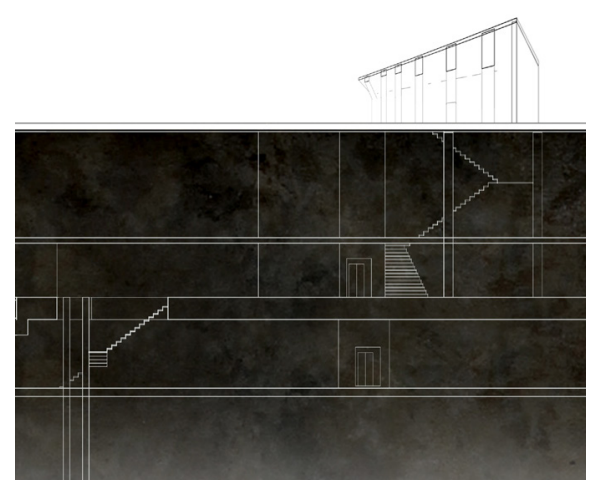

Exit sequence from north east corner Queen and Yonge

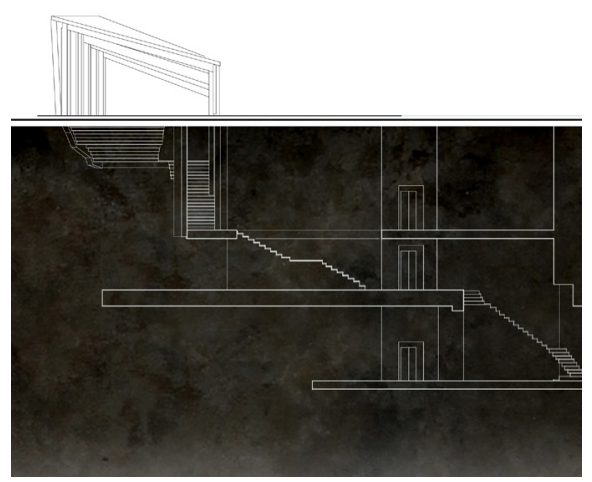

Arrival sequence from north west corner of Queen and Yonge

\subsection{Arrival and Exit}

To fully comprehend the complexity of the site, I felt it was crucial to address arrival and exit almost as a separate design component. In line with van Gennp's theory, designing the arrival and exit aspects in this site was an opportunity to create a clear-cut prologue and end-note to the journey. As the descend and ascend routes are stretched down and up several floors, the journey must avoid being monotone. It must excite, build anticipation and provide a preparation to the experience.

The journey down to the thermae begins with a loss of orientation and a constant feeling of decent downwards. At arrival descend and at exit ascend is constantly enhanced and exaggerated by a change in length or width of tread and rise. Bottleneck conditions along the way become ways of hinting of a change in direction, grade and elevation or temperature by change in materiality. The transitional space of arrival and exit to and from the thermae is formally non-linear in relation to its surrounded rather regulated and mundane subway station. This is to further contrast the break from it as a totally different experience. In general, arrival sequence and exiting sequence were centred on:

A. Loss of orientation (see figure 7.17 ) 

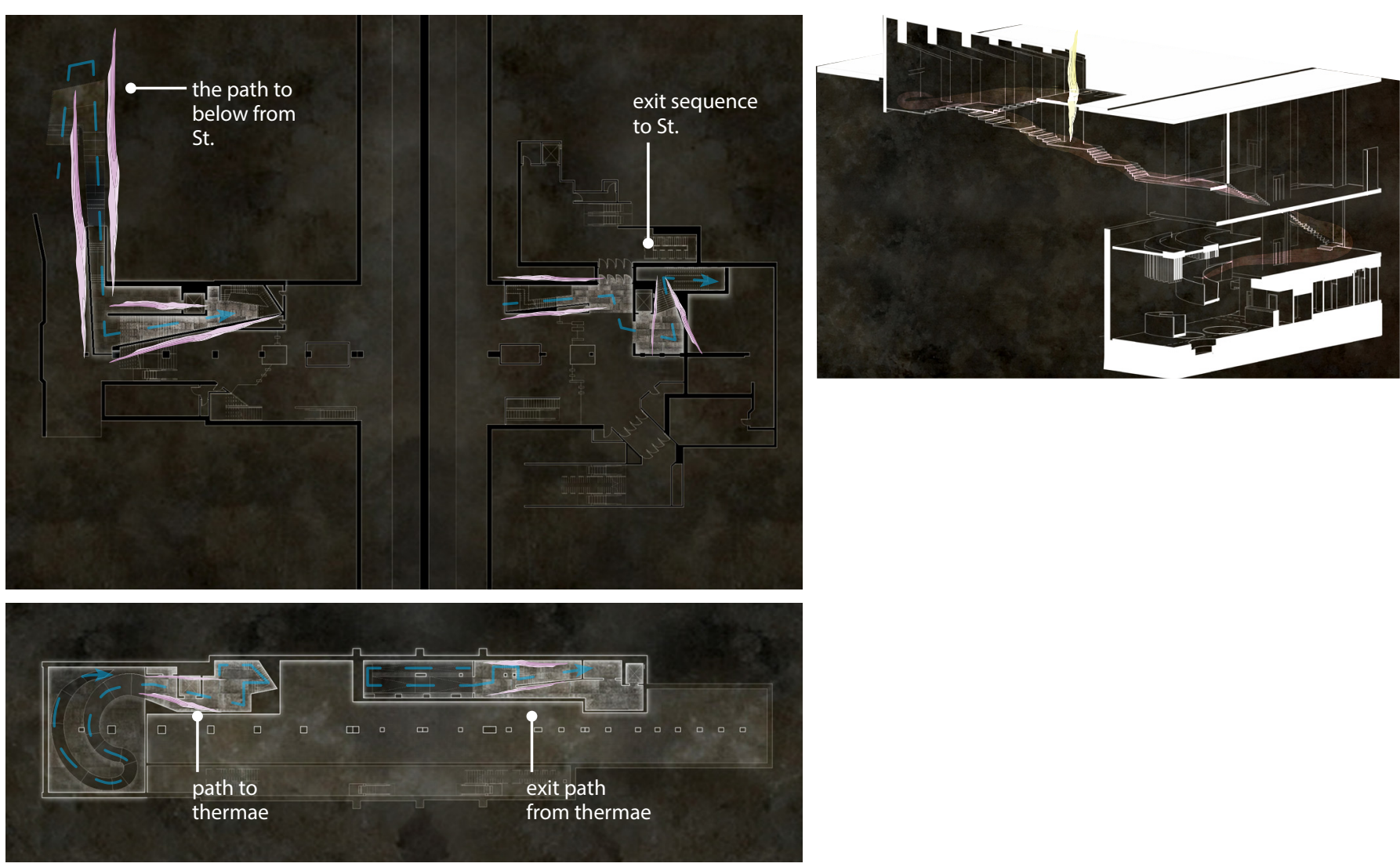

i. At arrival, providing a feeling of loss of orientation and enhancing the idea of entering another world and leaving the profane behind. This is achieved through a continuous change of direction and use of nonlinear elements culminating with the thermae's ramp completely erasing any trace of directions.

ii. Alternatively, at exit, user awareness is enhanced and feeling of loss of orientation is reduced. This is achieved by a more linear and rigid journey.

B. Formally (see figure 7.14-16).

i. Expansion and contraction are exaggerated as a means to achieving intimacy or a feeling of being part of a greater whole. At arrival, the feeling of contraction is constantly being reinterpreted through a change in height, proportion and bottleneck scenarios. The streetlevel threshold reacts formally accordingly and begins as an expanded form to a single height intimate space

Figures 7.17 (top, left): Arrival and exit illustration of sequence path at platform and underpass levels. Arrival with a focus on nonlinearity, contraction and loss of orientation and exit as being more linear and reinforcing expansion upwards. (plans at 1:800).

Figures 7.18 (top): Diagram of descend down into the thermae. 


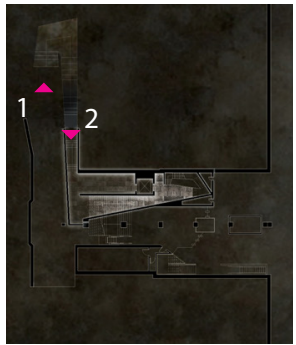

Figures 7.19 (right): Arrival sequence renderings.

(1) initial threshold descend down

(2) last ray of light before full incorporation

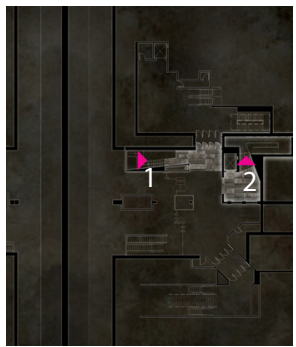

Figures 7.20 (right): Exit sequence renderings.

(1) ascend upwards

(2) ray of light before the actual incorporation with the external environment hunting of the culmination of the journey.
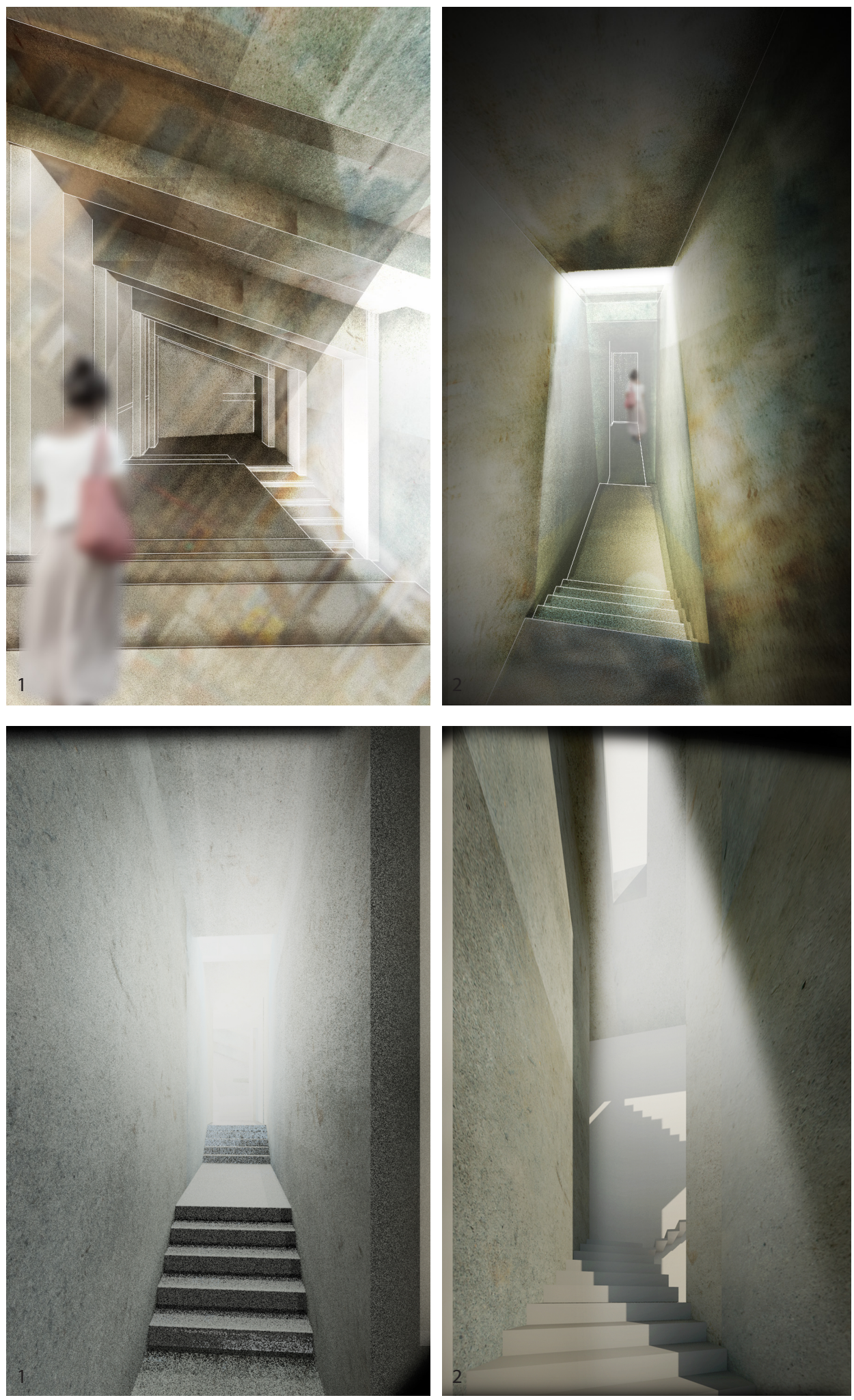

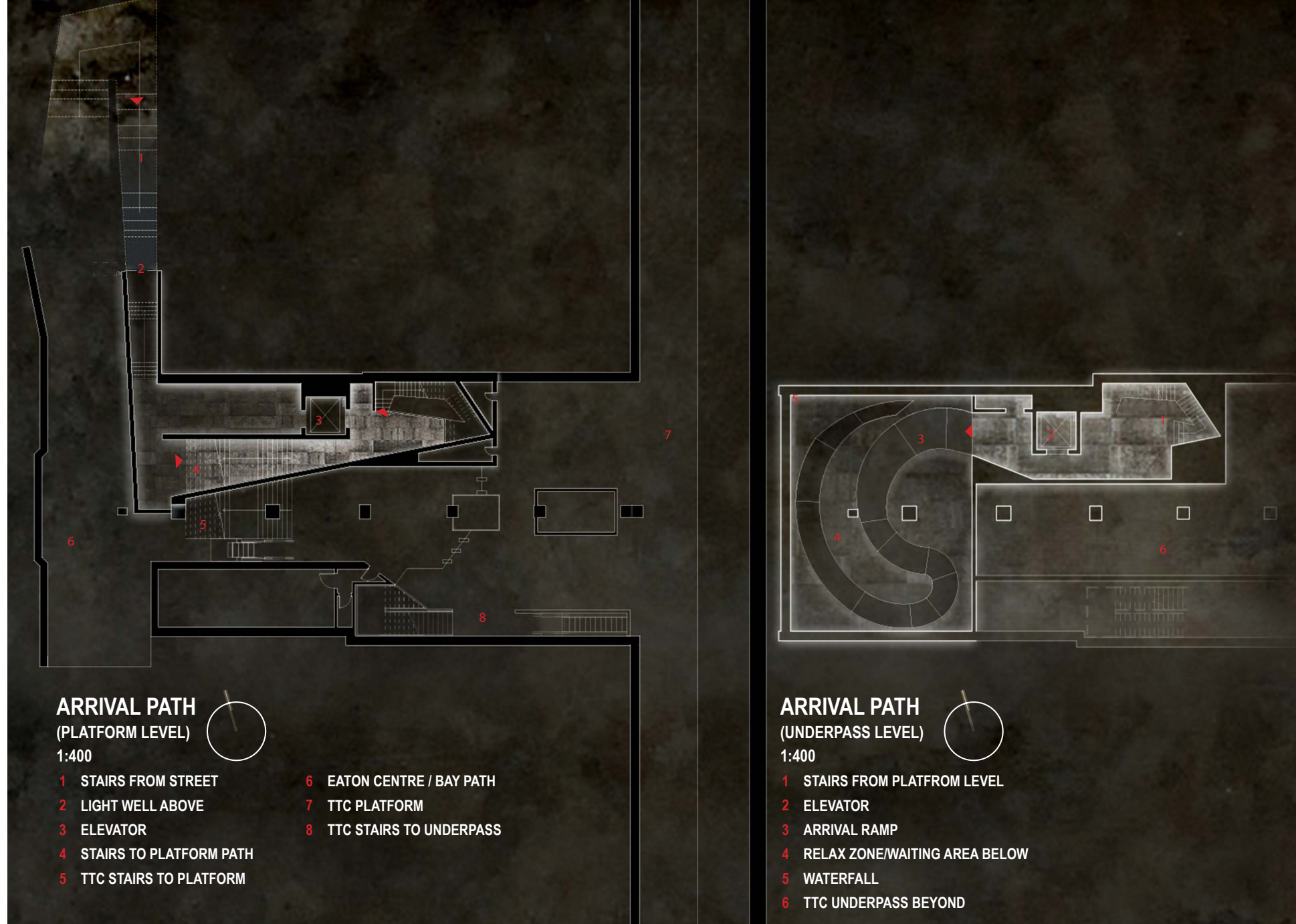

STAIRS FROM PLATFROM LEVEL

ELEVATOR

ARRIVAL RAMP

RELAX ZONE/WAITING AREA BELOW

WATERFALL

TTC UNDERPASS BEYOND

to mark the change.

ii. Expansion on the other hand is enhanced to begin to prepare one for the return to the outside world. Expansion is also reinforced as the formal threshold back to the street, as it begins from an intimate space and expands to denote the return to the city.

C. Light (see figure 7.19-20).

i. Being located several levels below grade, natural light is scarce. Therefore, I chose to make it symbolize an external connection to the city. Two light wells are strategically placed at beginning and end points of the journey. At the arrival entrance, a sequence light well is located at the first level change and is meant to signal the last orientation and ray of light before descend.

ii. Reversely at the exit sequence, light becomes crucial 


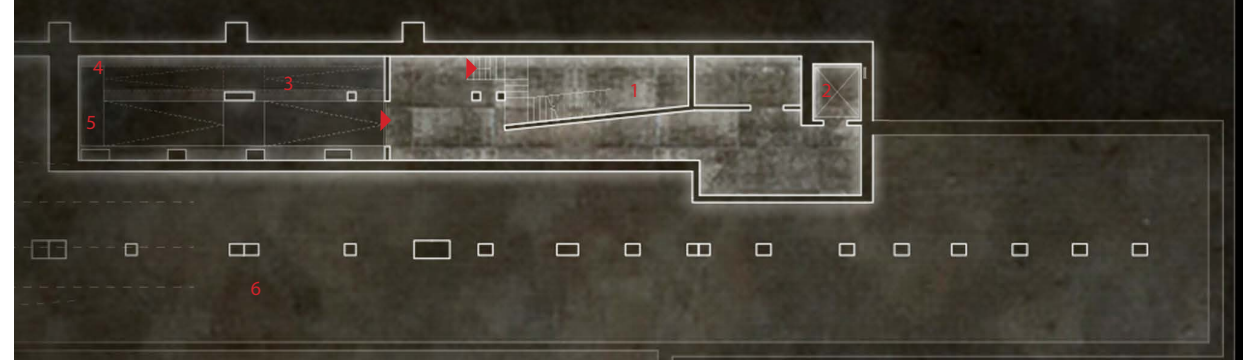

\section{EXIT PATH}

(UNDERPASS LEVEL)

1:400

STAIRS TO PLATFROM LEVEL

ELEVATOR

EXIT RAMP

REFLECTION PATH BELOW

WATERFALL

TTC UNDERPASS BEYOND

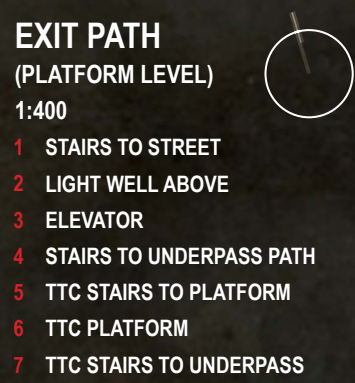

in providing the preparation to return to society. At exit sequence, a light well is again placed right before the final descend up, as a way of signaling and acknowledging the outside world is near and the end of this experience is here. D. Change in materiality and perception of lower temperature and warmth

i. At arrival, stress was made on choosing warmer materials enhancing the feeling of higher temperature as descend progresses into the thermae. Arrival sequence begins and ends with wood, starting as a connotation to warmth, despite the knowledge of going underground wood as a first impression and a final one.

ii. At exit, stress was put on using stone and concrete with thermal mass that renders a colder and less intimate feel in order to prepare for the final exit.
Figures 7.21 (top): Labeled plan of arrival to and exit path from the thermae. 


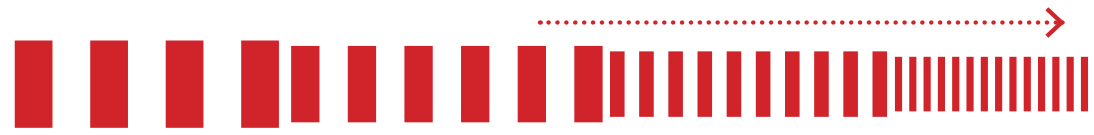

public

unrestricted $\hat{\vdots} \quad$ variation in level of

- individual experience and personal connectivity to mind body and soul personal restricted

\subsection{Thermae; A sequence}

Designed as a contemporary version of a revitalized ancient tradition, this thermae puts special significance on the rejuvenation qualities of water and offers hydro and halo therapy treatments. This in essence will become a water wellness thermae and will promote water as a prime and elevated vessel for transformation. This place will allow for both spiritual and physical renewal and transformation allowing purification and connection to oneself. A thermae becomes a place where one comes to physically and mentally detoxify. The act of removing layers of clothing is both literal and abstracted as skin layers are constantly being removed and then renewed through processes undergoing in this thermae. It acts as 'another place' - a place of solitude, a refuge and a place of detachment providing a pause from life. The aspect of removal from the outside world and connection and reflection to inner thoughts and soul is crucial to its success. As such, layers of design were centred on the creation of a sequence as ones creates his journey through the thermae's spaces going through spiritual, physical and mind transformations. Design principles were centred on promoting physical - healing, creating mental - awareness and soul cleansing - inspiration gained.

In truly reaching and engaging a synthesis I approached design in thinking of the programmatic elements required and how their assembly would reach the highest levels of body mind and soul experience. Design would be centered from a variation of in level of personal experience, beginning from the very arrival

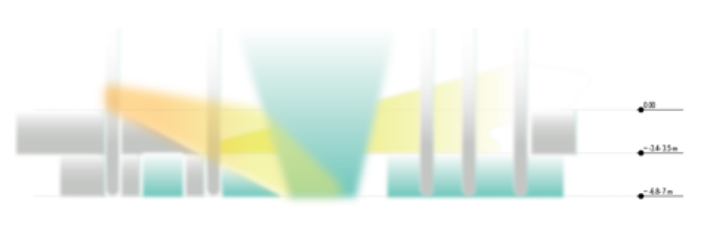
which is public and restricted and summing with the personal and restricted which would most likely be corp treatments (see figure 7.22).

Figures 7.22 (top): Guiding design concept gradient in intensity of personal experience

Figures 7.23 (above, middle): Initial schematic sketch of spatial relationships. 
detachment from

design objectives: loss of orientation descend down

'acknowledging the transition'

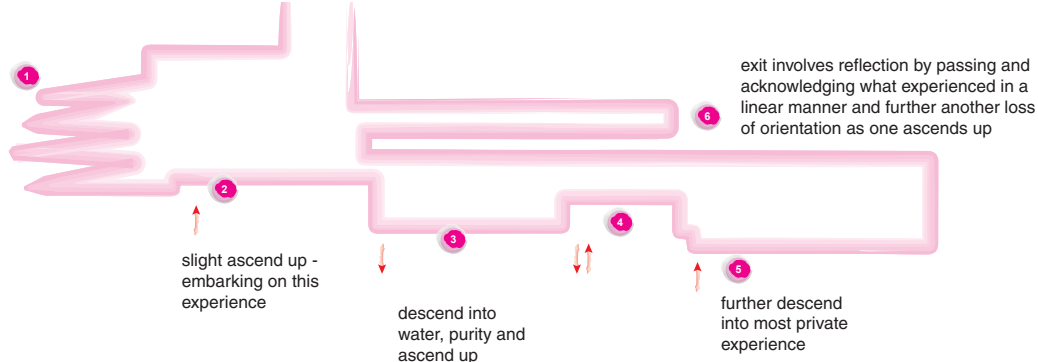

Similarly, to the design of the mikveh I began looking schematically at each program element required to the this thermae, linking spaces alike spaces in supporting the overall design concept strengthen transitions and understanding actual spatial requirements of each space. (see figure 7.23-7.25).
Figures 7.24 (top): Schematic illustration of journey through thermae.

Figures 7.25 (right): Spatial elements as a function of intensity of personal experience .

Figures 7.26 (below): Initial schematic section of spatial requirements and relationships.
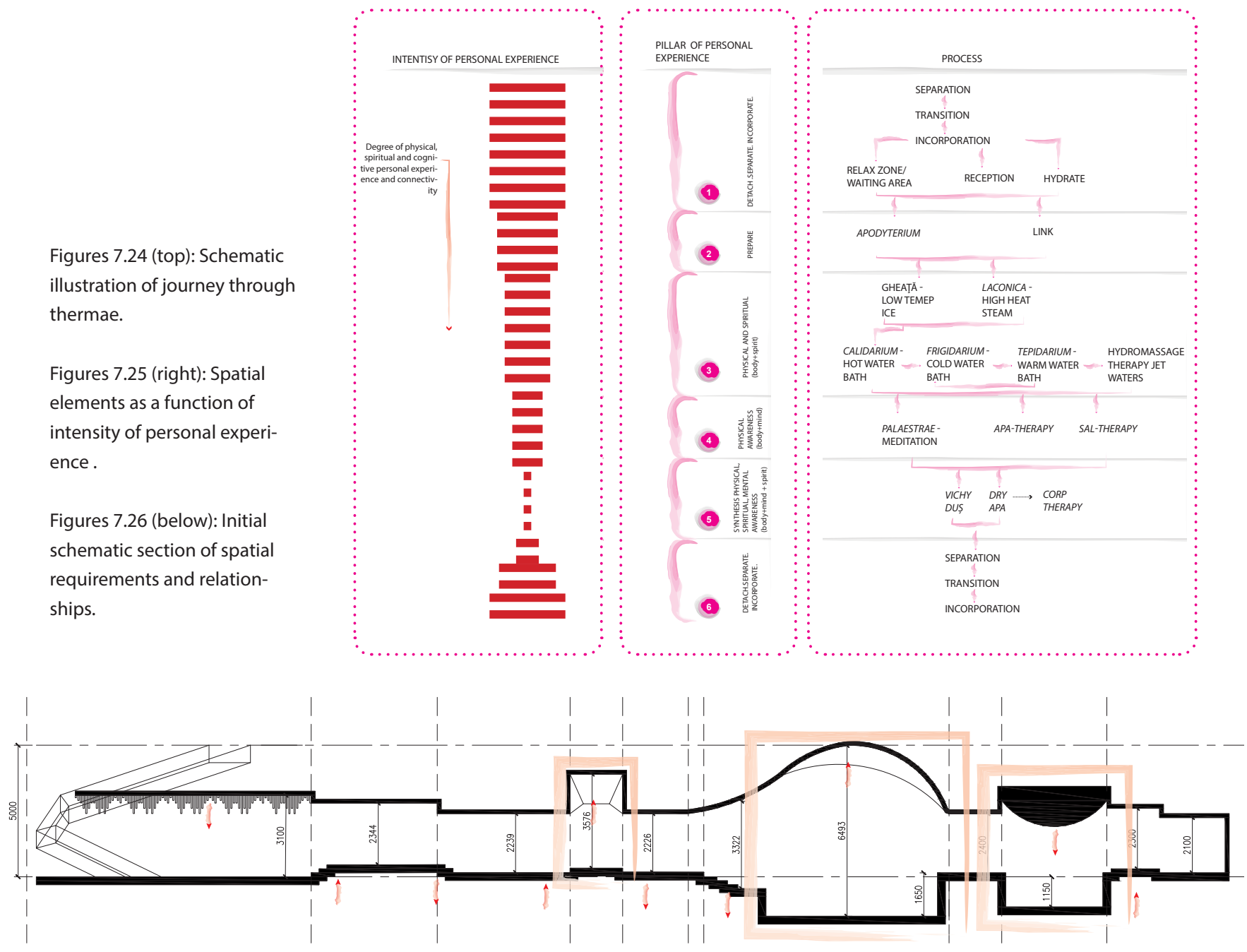
Programmatically, I wanted the Design of this thermae to be centred on attempting to convey an intentional sequence of space, one that would relate degree of personal connectivity levels. These would start at

1. detach. separate. Incorporate.

2. prepare

3. Physical and spiritual (body + soul)

Continue to

4. Physical awareness (body + mind)

And conclude with a

5. Synthesis of the physical, spiritual and mental (body mind and spirit)

6. detach. separate. Incorporate.

In line with the creation of a sequence through space, it was essential map out exact programa necessary in sustaining each stage which culminated with having to map out the preferred sequence one would go through in the thermae. To reach the outmost of each space I created a table

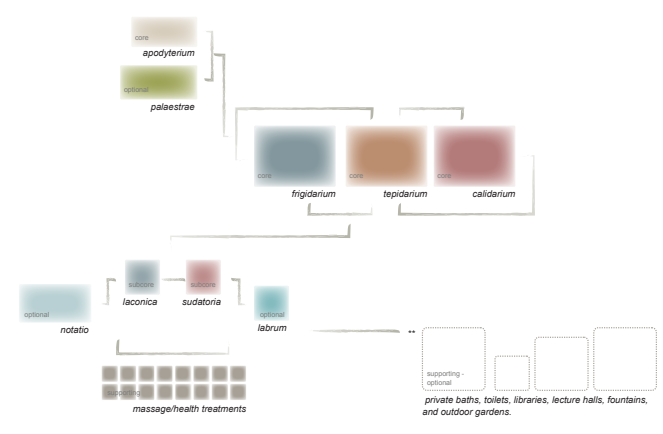

Figures 7.27 (top): Program elements relationships, based on Roman bath sequence of space.

Figures 7.28 (below): Layers of personal experience linked to program space, its meaning and archtiectural expresion.

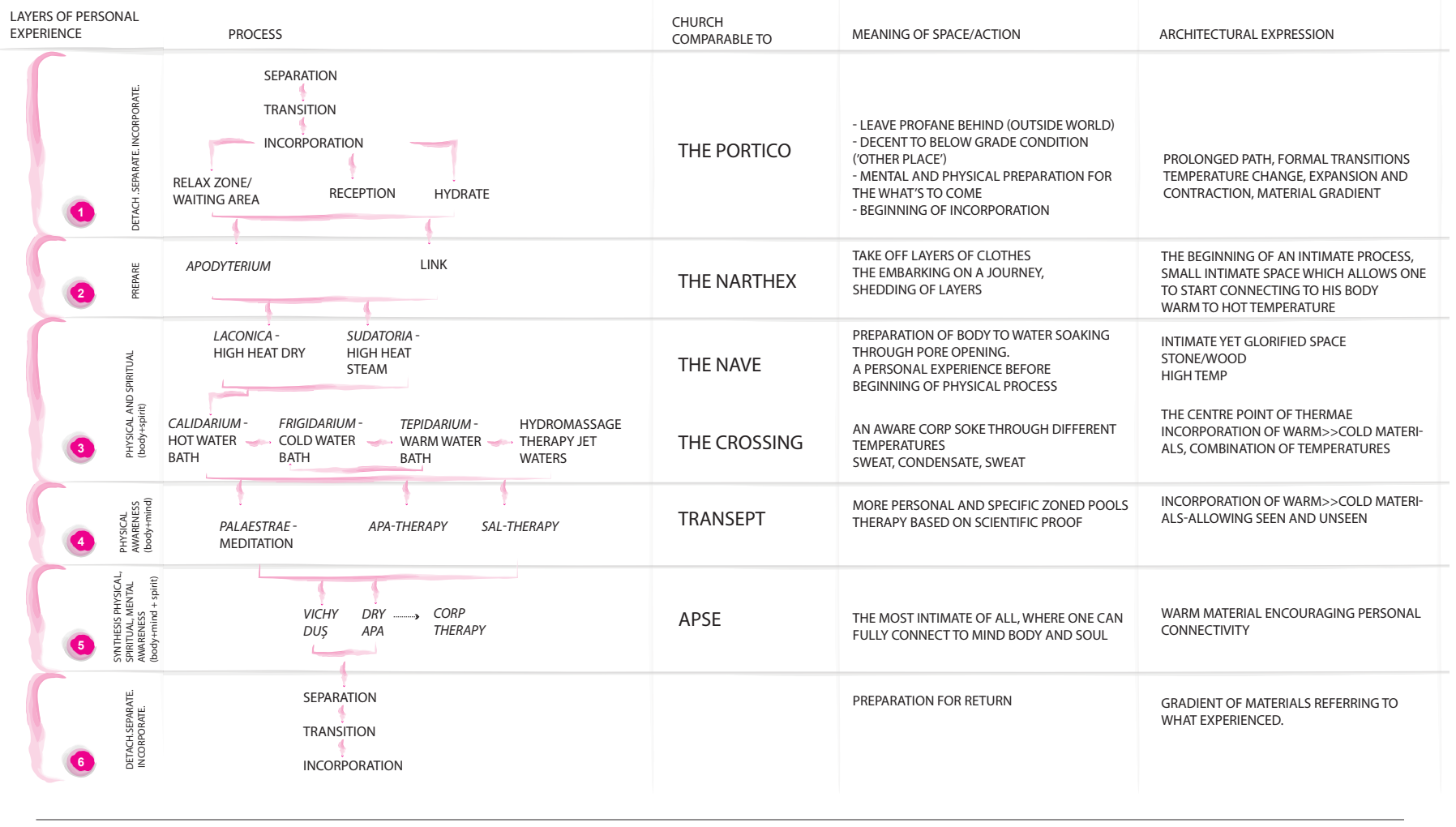


Figures 7.29 (below):

Labeled thermae plan. (see figure 7.26) assisting me in explaining the process one would have to go through crucial to sustaining the theme and wanted journey of the thermae. The tables become quite detailed and is sequential to the category before it as to referring to the degree of personal connectivity, a space's reason for being and architectural devices used to express each quality.

The intensity of collective vs personal experience varies as one progresses through the thermae to culimanate in a sole personal experience. Yet being a publicly accessible thermae, design was to accomoadate both levels of experiences. This translated in corridor widths suggesting levels of intimacy, amount of seating available and where and use how the porportions of a space. Typically, a narrower and lower space would indicate a more personal experience vs wider and taller spaces speaking of a collective whole. Arrival and exit spaces were intentionally exaggerated, both double height spaces allowing one to gage the knowledge and sight into the space he is leaving or arriving.
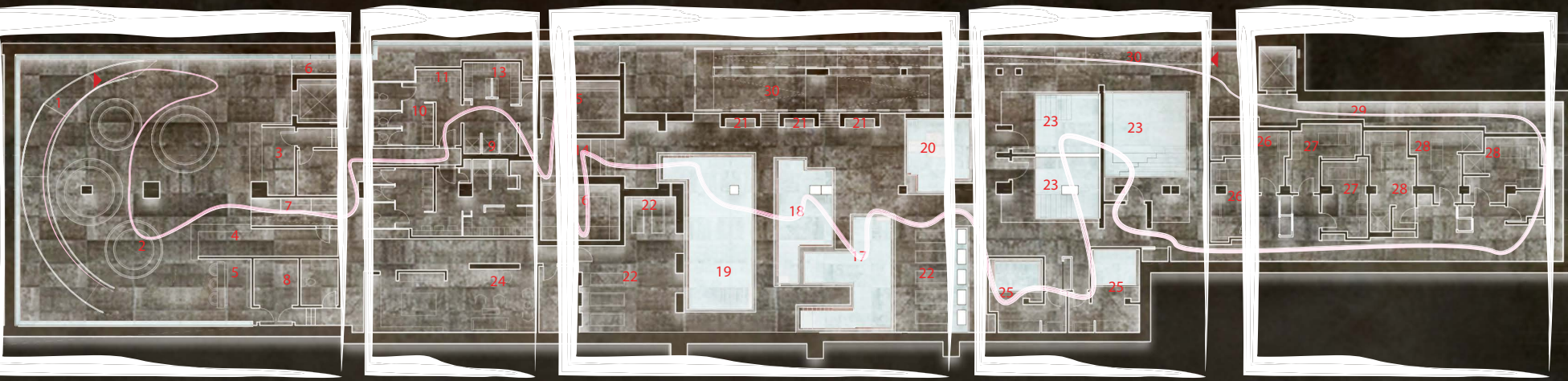

\section{THERMAE PLAN}

$1: 300$

DETACH.SEPARATE. INCORPORATE

ARRIVAL RAMP

RELAX ZONE/WAITING AREA

RECEPTION

ROBES

HYDRATE BAR SUDATORIA ROOM
PHYSICAL AWARENESS

23 APA-THERAPY POOLS

24 PALAESTRAE - MEDITATION SAL-THERAPY POOLS
SYNTHESIS

26 VICHY DUȘ

DRY APA

CORP THERAPY
DETACH.SEPARATE. INCORPORATE

REFLECTION PATH

EXIT RAMP
PREPARE

BY.PASS PATH

PATH TO APODYTERIUM

SERVICE PATH/WC

APODYTERIUM

WIC

PREP AREA

SHOWERS

BENCH+LOCKERS
PHYSICAL AND SPIRITUAL

14. TRANSITIONAL PATH

5 TEPID ROOM

CALIDARIUM

FRIGIDARIUM

9 TEPIDARIUM

0 THERAPY JET WATERS

1 CHEVETTE

REFLECT 

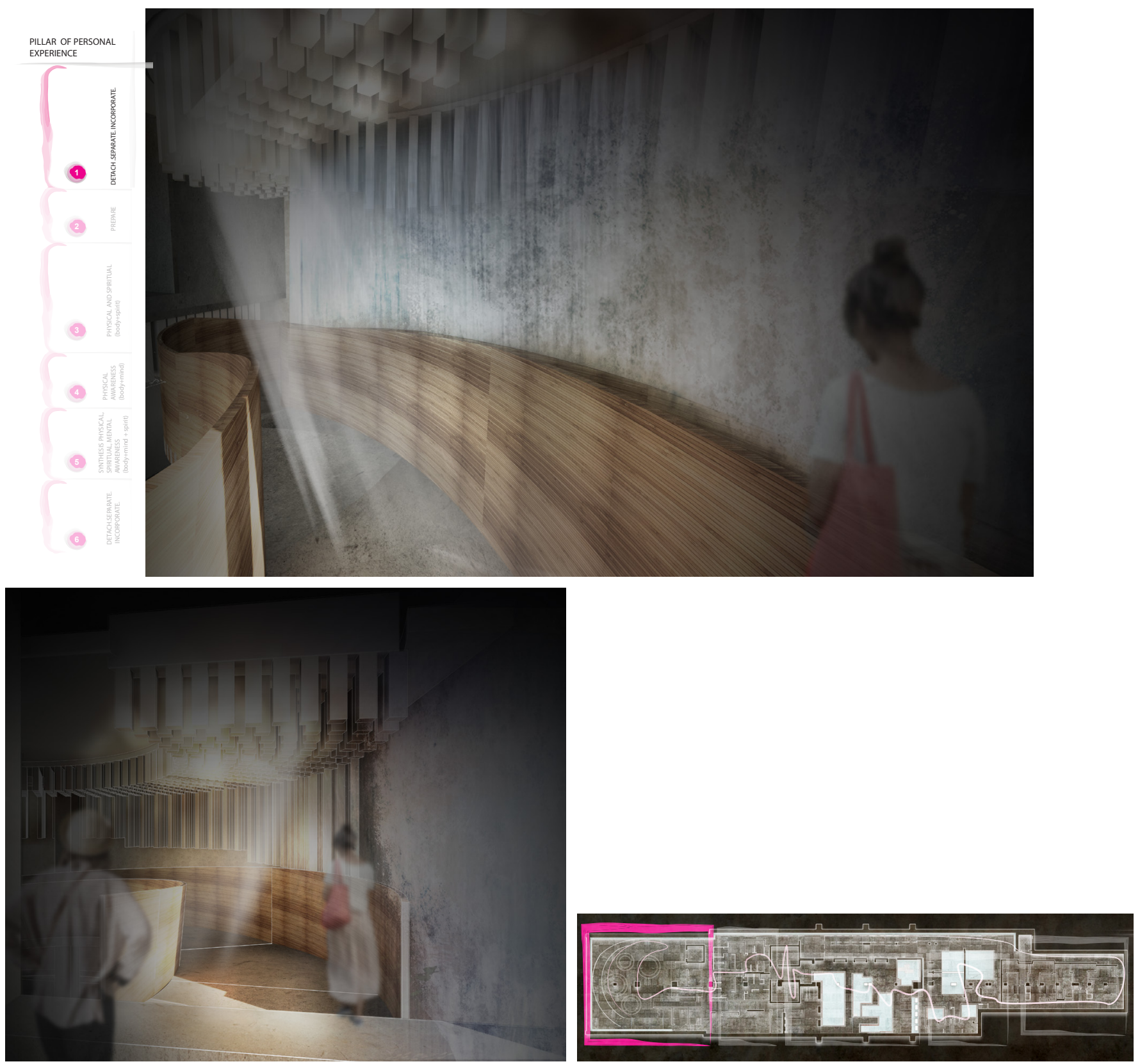

The experience in both spaces is the most public and unre-

Figures 7.30 (top): Renders of beginning of journey at arrival zone. stricted in the thermae.

Arrival zone (see figure 7.30) into the thermae requires the least levels of personal connectivity and is part of the detachment separation and incorporation process. Its importance (reason for being) is for its transitional role in facilitating the incorporation into the thermae, allowing for the outside world to be left behind and open oneself to another place and experience. Architec-

Figures 7.31 (opposite, top): Renders of the start of the journey, the transitional space leading up to the appadarium

Figures 7.32 (opposite, bottom): Renders of ice and steam room and the transition leading up to them. 

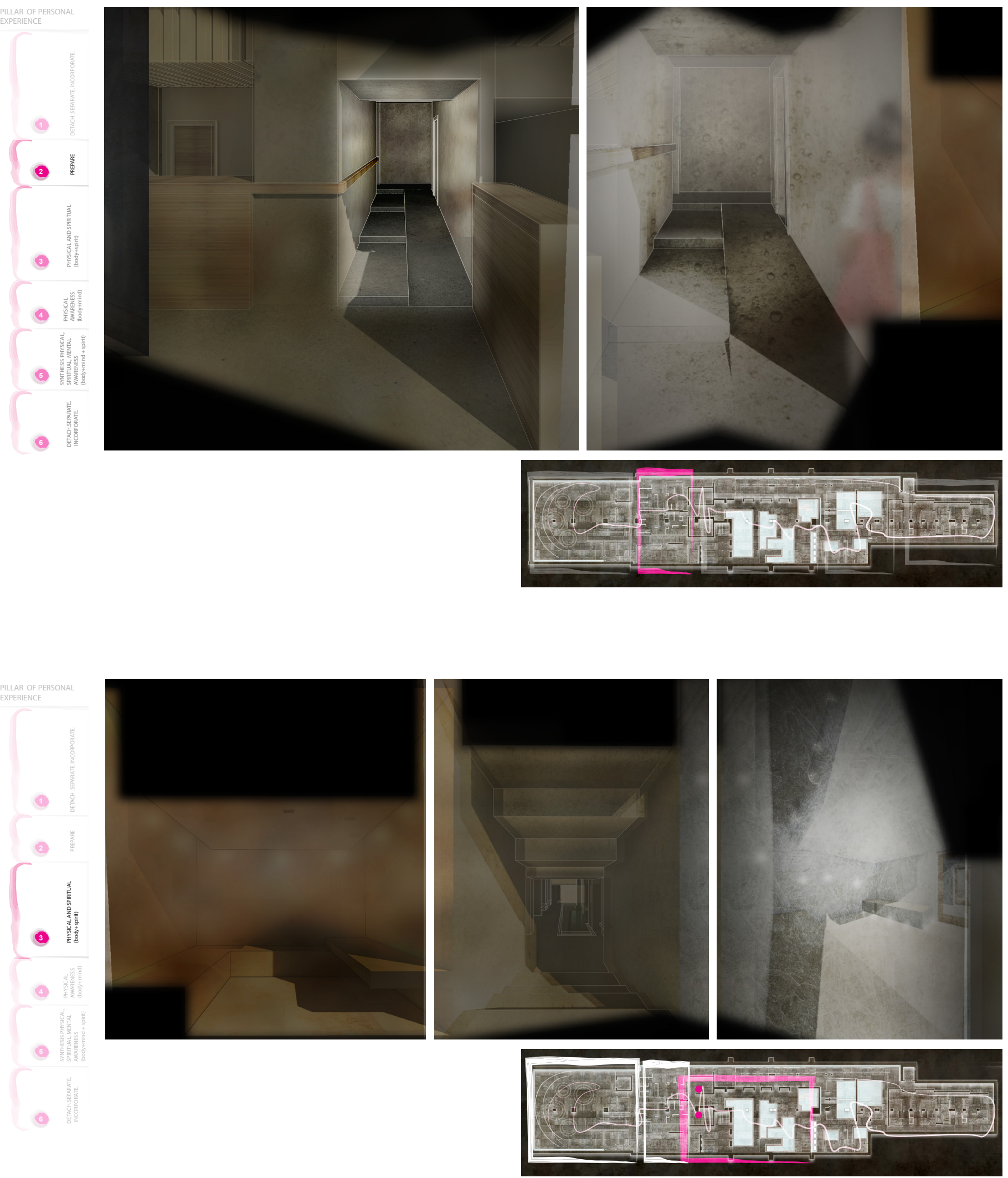

FINAL DESIGN PROJECT: A THERMAE | 131 


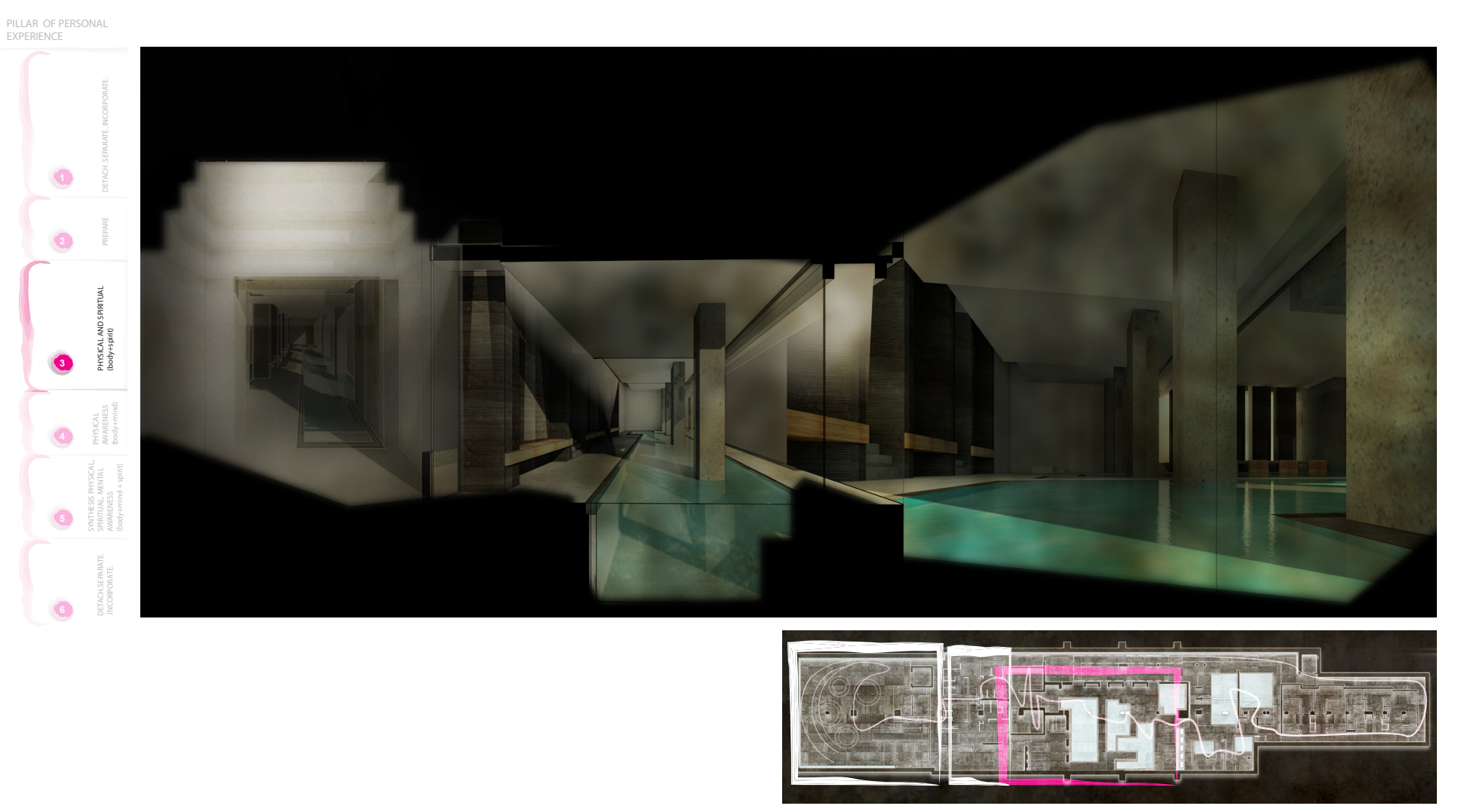

tural devices employed were the feeling of loss of orientation through a long and maze like descend allowing for a formal and acknowledgment of transition. Formerly expansion and contraction also helps in creating this illusion.

From the arrival zone one now embarks on the beginning of his experience (see figure 7.31). Through transcending him into a small intimate space where he ascends into the appadarium - the change room. Temperature of this space rises, and condensation begins one some of the walls to denote change in environment and prepare one to the change room. The change room is where one removes his clothes symbolically embarking on the start of slowly removing other layers of skin through water processes.

Leaving the change room marks the beginning of the physical and spiritual process prior to going into the waters. An ice and Figures 7.33 (top): steam room (see figure 7.32), are parallel to one another and offer an application of extreme low and hot temperature as a means to preparing the body to soaking in water, as it opens Render of waters and transition leaving extreme temperature rooms and framing view into the waters. 


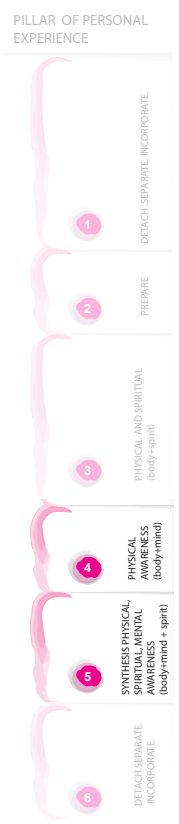

Figures 7.34 (top): Renders of hydrotherapy and corps rooms.

Figures 7.35 (right): Renders of pre exit transition and exit
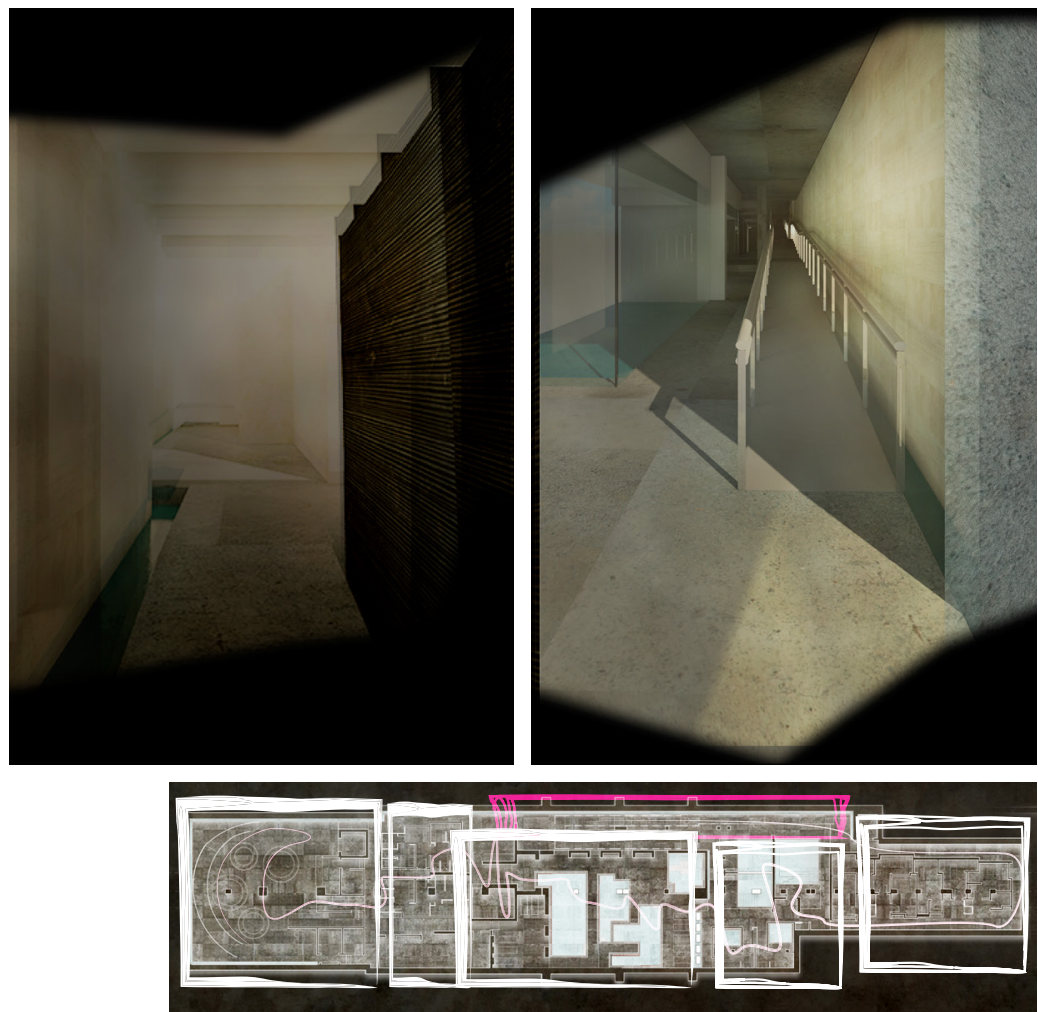

ramp. 

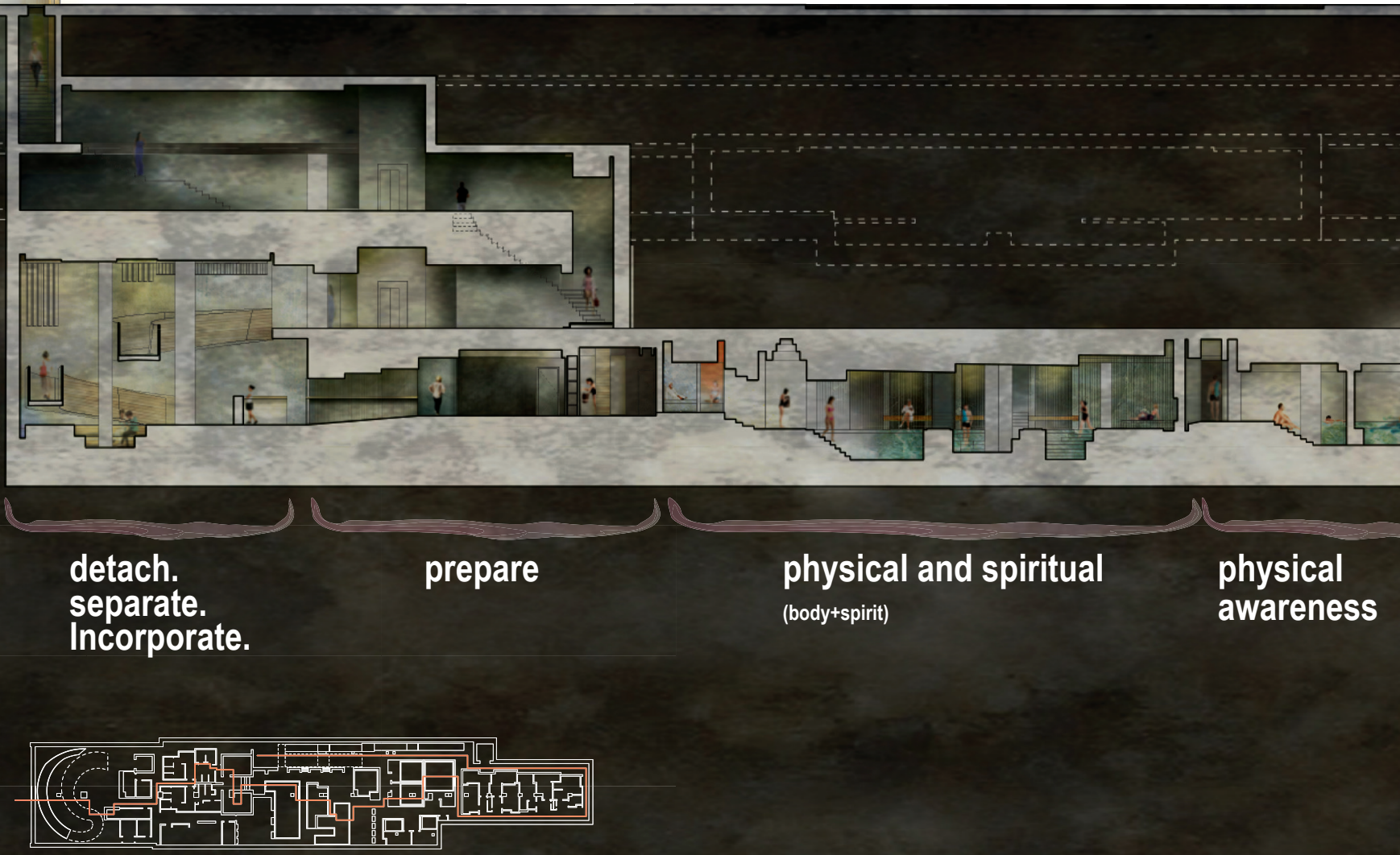

SPLIT SECTION

$1: 150$

pores and begins blood circulation. These rooms become sup-

porting spaces and a prologue to the waters.

As one concludes the extreme temperature rooms, view to the waters is being framed (see figure 7.33). But It is beyond a Light well. To get to the pools one has to descend into the light well marking a change in experience and connotation to divinity just before descending into warm temperature waters. One is then to go through cold and hot waters consecutively. Design of pools was done in a way that placed stairs and seating at strategic places to constantly be able to go from one to another.

In leaving the waters one has to ascend upwards from the space, where he is faced with hydrotherapy and halotherapy (see figure 7.34) which involve water physical therapy and salt 


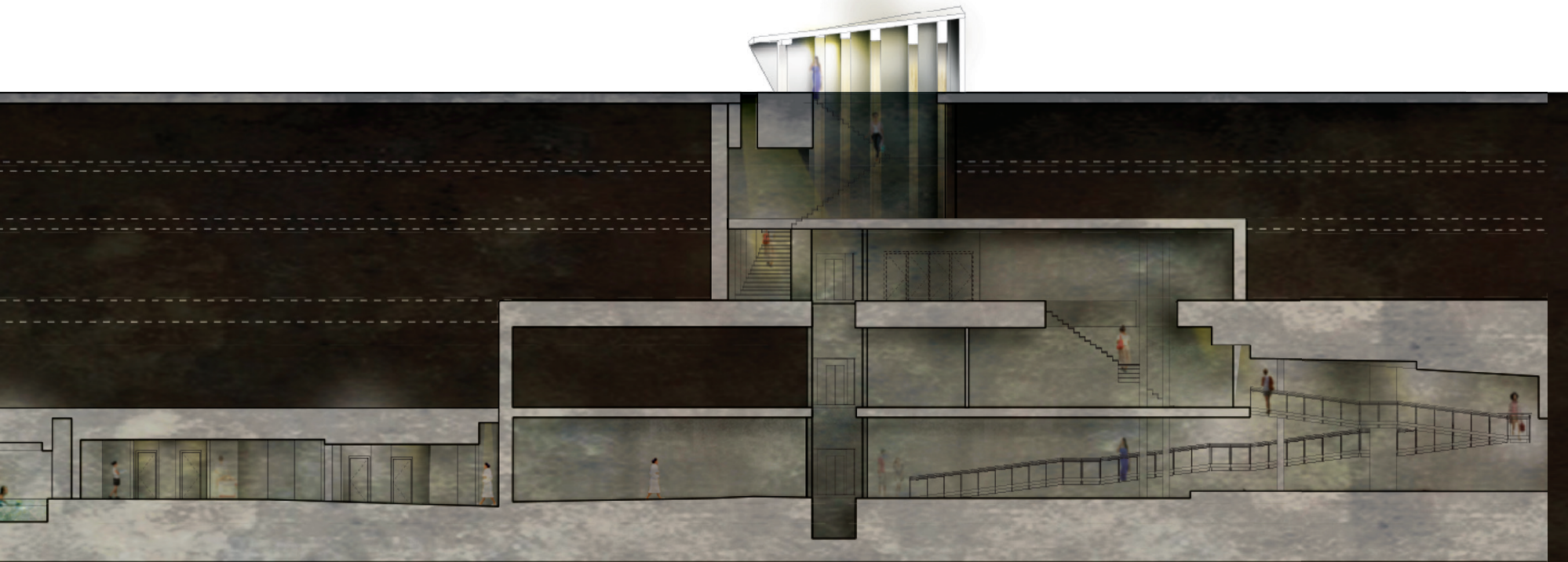

\section{synthesis physical, spiritual, mental} awareness

(body+mind + spirit)

\section{detach. separate. \\ Incorporate.}

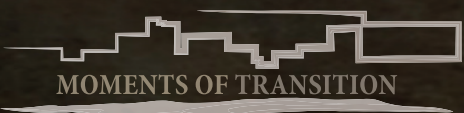

Figures 7.36 (top): Split section. floats. This point in the journey becomes a more personal one yet not totally in allowing views into within rooms. Architecturally space becomes less open than the waters area yet still maintains high ceilings and relatively wide corridors.

Approaching the most intimate of all spaces in the thermae are dry and wet corp treatments room (see figure 7.34). Transition between these rooms are meant to feel intimate and is guided by small nooks and niches along the ramped journey. The rooms are essentially wrapped by a corridor that descends and then ascends back up to connect back to the exit ramp

Finally, one is brought to the exit sequence (see figure 7.35), a double height space which exits by means of a linear ramp to the level above. The linearity of the ramp is meant to direct- 


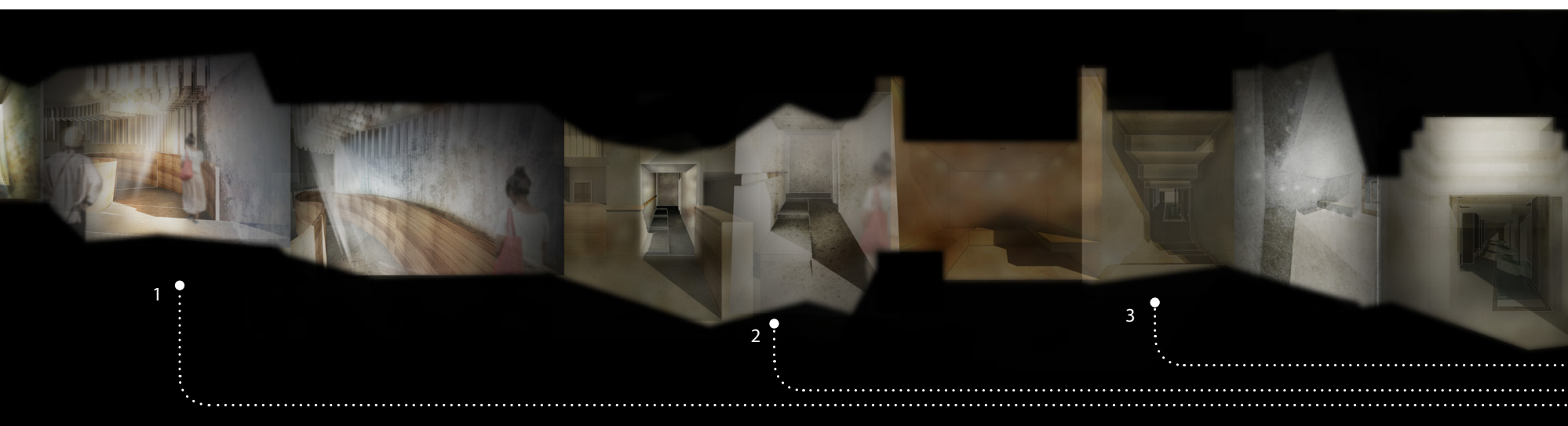

ly contrast the loss of directionality and geometry of the entry ramp in that it promotes the opposite - visibility and directionality. The exit ramp is intentionally designed to be reversed to journey direction of the thermae to allow one to look at the spaces as he ascends, reflect and acknoledge what was experienced.

This thermae is centred on transformation through water. Water, in its many states or temperatures became the premise for this thermaes. Contrast hydrotherapy, or literally contrasting between warm and cold temperatures sounds trivial today yet it was revolutionary for its time. The Romans pioneered what is today known as therapeutic contrasting which involves the immersion and continuous alternation between immersion in hot and cold waters. Scientific and psychological benefits are numerous, including reduced muscle aches, injury recovery, tension reduction, relief from strain-related injuries (Ingraham, 2015). The idea behind alternating between hot and cold is to gain the blood stabilizing effect of hot water and on the other hand gain from the effect of cold water on circulation directing freshly circulated blood into internal organs and body core. Interchanging water or room temperatures became a technique to greatly increase circulation, healing and regeneration (Ingraham, 2015).

Sequence through temperatures and water states started to become routes in creating the premise for this thermae. focused on contrast. Exploring contrast hydrotherapy involved looking at the structure of Roman baths and the process through its waters (see figure 7.27). And 


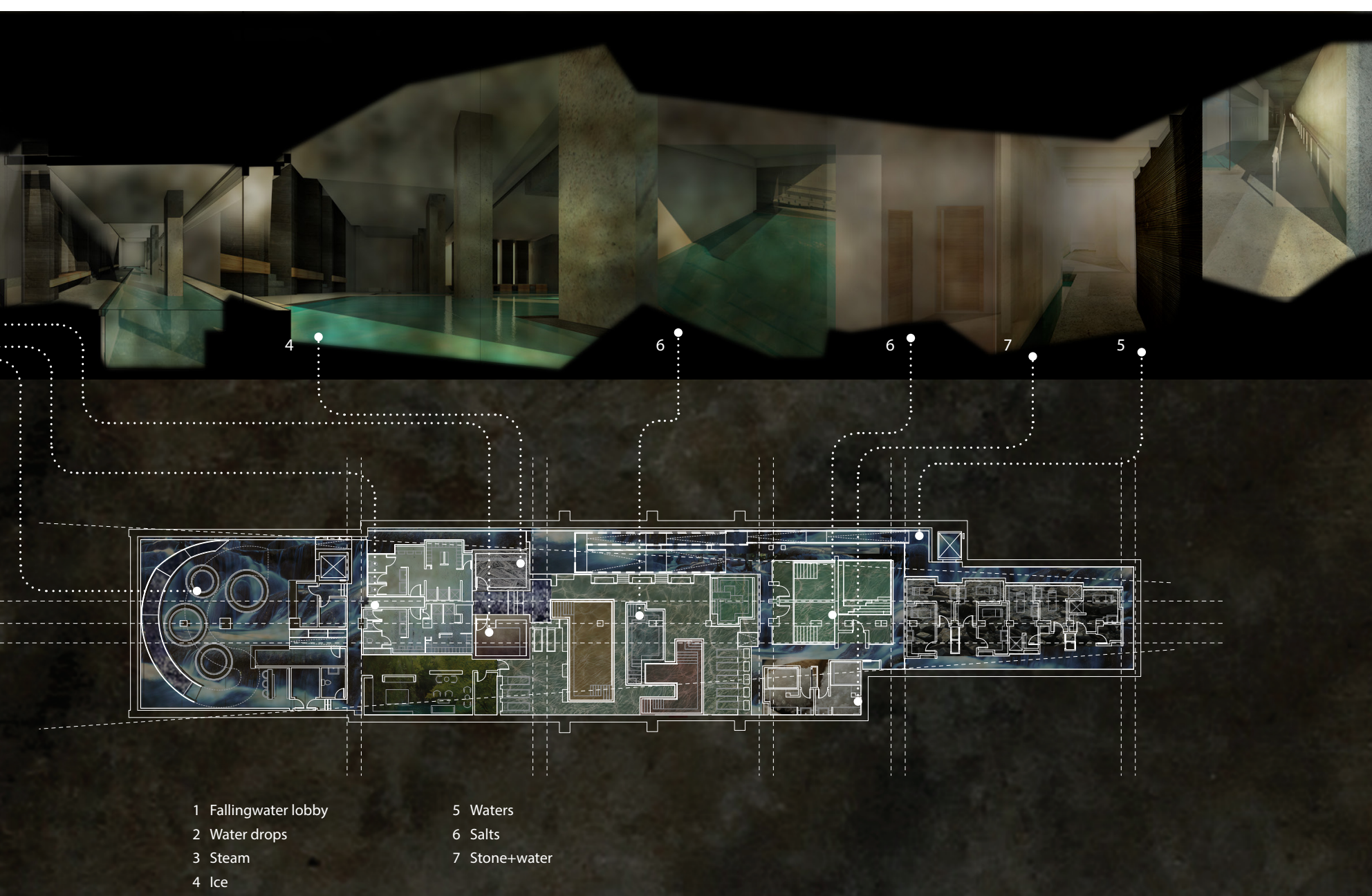

1 Fallingwater lobby

4 Ice
6 Salts
7 Stone+wate

$39^{\circ} \mathrm{C}$

$24^{\circ} \mathrm{C}$ 


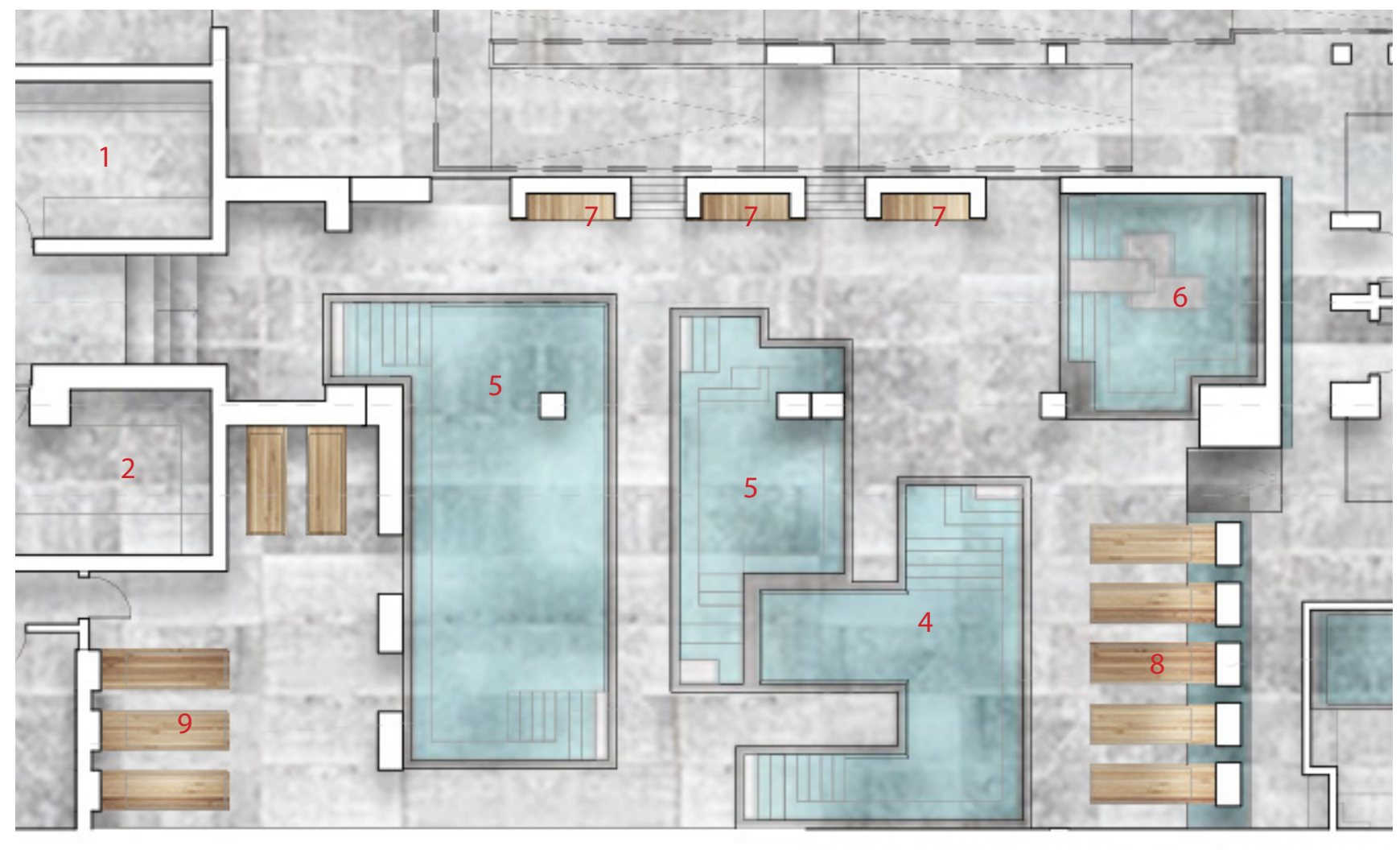

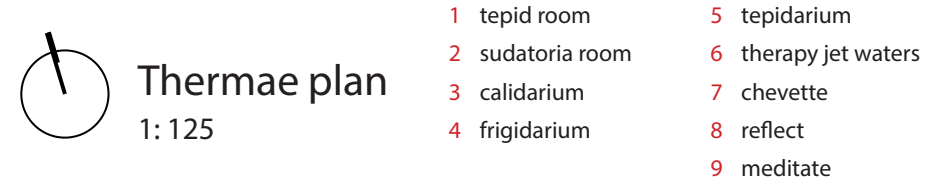

then attempting devise a similar analysis for what might be temperatures of associated rooms or water in this thermae (see figure 7.37). In a sense, creating an artificial environment which correlates to the natural world - for example, the waterfall lobby, echoing sounds of rainfall or waterfalls, rain drops for condensation as a natural process and one that happens. Contrast waters states as ice and steam are out in contrast to one another to produce the relationship between temperatures and effective in relaying the wanted sequence (see figure 7.37).

Water in its many states coupled with requirements of temperature and as such material were helpful guides in further exploring these spaces. As such arrival and exit

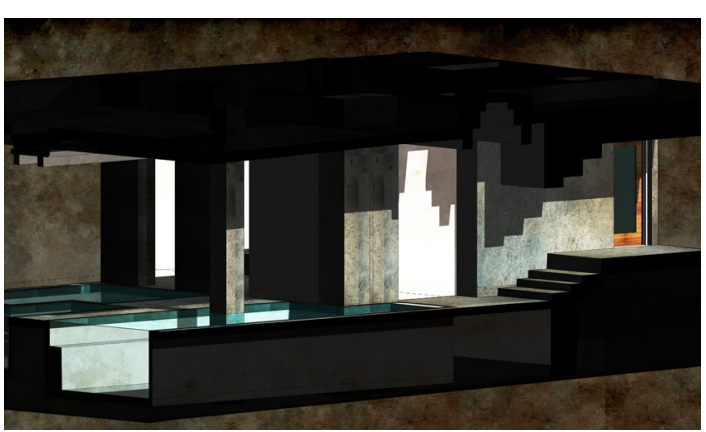

Figures 7.38 (top) Waters, plan

Figures 7.39 (middle) Into the waters, perspective

Figures 7.40 (opposite, top 3 images): Pool renders

Figures 7.41 (opposite, bottom): Section along waters 
paths were generally looked at as the wet ares, condensation and temperature gradient at path to change rooms as being able to intensify experience to it. Steam at and cool at 1-7 celsius temepratures at ice room.

In general the intention of materiality in the Thermae was a limited material palette of stone, textured stone, concrete and wood. This was strategically done to enhance sensations, and reduce distractions or to denote a change in program. For example - Wood was used to symbolize warmth at arrival ramp, wall edges or at waters at wall niches and beds. Textured stone to invoke vertical connection, used at elevator and separating walls.

Design for the waters employed similar characteristics of materiality and temperature strategies. Wood was used to symbolize warmth and intimacy at seating nooks, wall shelves or meditation beds. Textured stone was used on piers symbolizing verticality and a connection to above and a gray stone and concrete columns were used throughout to let these moments be emphasized (see figure 7.40). Transition into the waters is marked by light, change in elevation and formal expansion (see figure

Figures 7.42 (below): Cross section study of spatial relationships.

Figures 7.43 (next page): Experiential section. its largest space, it is where the true collective experience
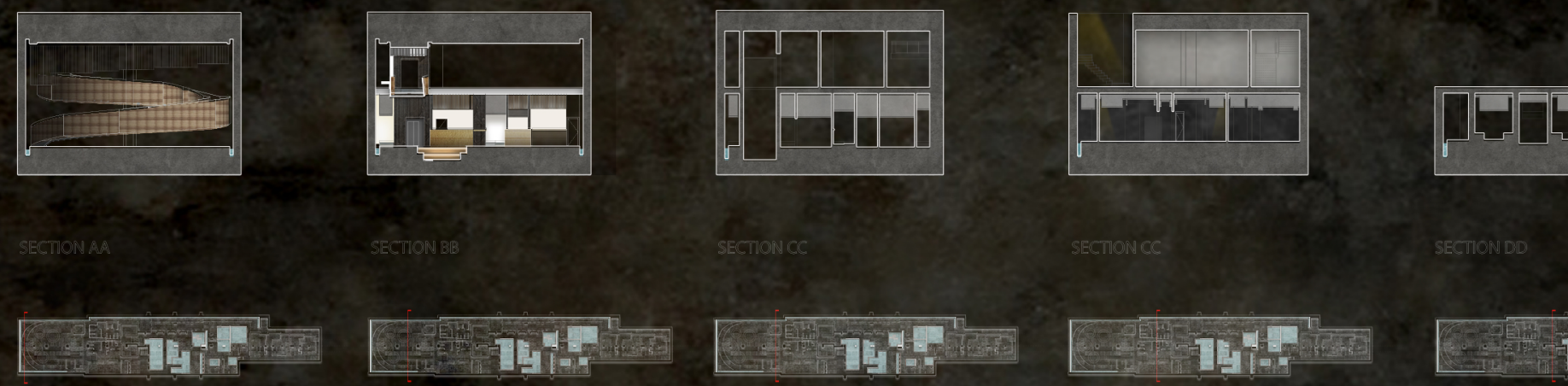


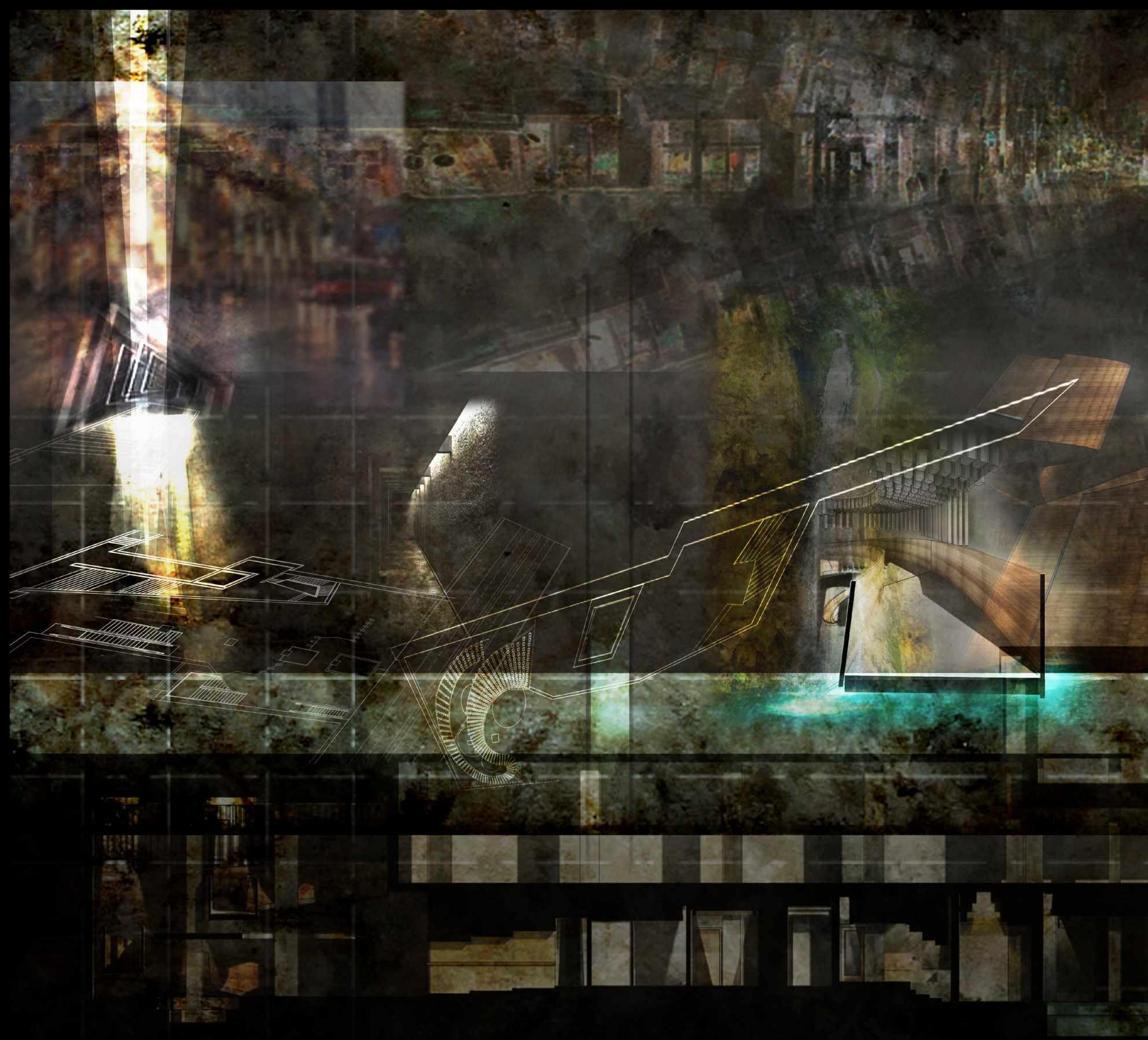




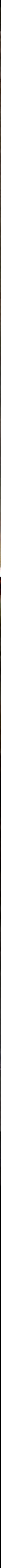


144 | MOMENTS OF TRANSITION 


\section{COCNCLUSION}

"the realm of conscious and unconscious speculation and questioning - the zone where things concrete and ideas are intermingled, taken apart and reassembled where memory, values, and intentions collide." Fred Koetter

The research and design methodology of this thesis was based on macro and micro design apprehensions with respect to enhancing transitional moments, both from an architectural and urban level. Both buildings and urban fabrics are primarily concerned with the creation of spaces and places for people to dwell, live their daily lives and be the backdrop to both individual and shared experiences. Their success is highly dependant on transitions and thresholds which intensify this shared or individual experience. Working from both a cognitive and physical reality, transitional spaces have the important role of affecting people as they go through them. This can be in the form of a literal obstruction in space from a mundane looking surrounding - to make one aware of the transition at hand. It can be by making someone take a longer route to experience something. It can be by connecting two spaces by their common denominator or by a sharp and literal transformation from one to the next. These conditions become an indispensable measure in the urban, and architectural built context. It is what makes an experience through space meaningful, moving and memorable. It amplifies meaning through the physical tension, contrast, scale and proportion and metaphysical elements.

This thesis has enabled my interests in architecture to grow and to truly understand basic and complex theory concepts. The theoretical framework of this thesis helped immensely in providing grounds for the design portion and to engage in design of transitional moments. Thermae was explored on the premise that it was a building that sustained meaningful transitions. Architecture relies on the artful making of these transitions, without them it would not be whole. Transitions that inspire, spuprise and move are everything, they can even become the subject work. 


\section{REFERENCES}

Abrams, P. (2001). Water in Religion. Retrieved from Water Policy International Ltd: http:// www.africanwater.org/religion.htm

Alene, D. (2013, July 13). The spa as a spiritual place. Retrieved March 04, 2016, from spirit-20130713 Los Angeles Times: http://articles.latimes.com/2013/jul/13/health/la-he-spa-

Alio, J. (2012). Europe's Oldest Mikveh. Retrieved from Best of Sicily Magazine: http://www. bestofsicily.com/mag/art421.htm

Mohenjo-Daro. Retrieved from http://project-history.blogspot.ca/2006/11/ancient-city-of-mohenjodaro.html

Ancient Bible History. (2013, September 29). Bath / Washing. Retrieved Janurary 17, 2016, from Ancient Bible History: http://ancientbiblehistory.com/1/category/bath $\% 20$ washingef8bc56c7b/1.html

Baptistery. (2015, November 10). http://www.religionfacts.com/baptistery. Retrieved February 02, 2016, from ReligionFacts.com.

Barrick, A. L., Rader, J., Hoeffer, B., \& D. Sloane, P. (2008). Bathing Without a Battle. New York : Springer Publishing Company.

Bartholomew, A. (2010). The Spiritual Life of Water: Its Power and Purpose. Park Street Press .

Baudrillard , J., \& Nouvel, J. (2002 ). The Singular Objects of Archtiecture. University of Minnesota Press.

BBC. (2014). Primary History: Indus Valley: Technology and Jobs. Retrieved March 02, 2016 , from http://www.bbc.co.uk/schools/primaryhistory/indus_valley/technology_and_jobs/

Berkowitz , B., \& Patterson , C. (2014, 0120$)$. The health hazards of sitting. The Washington Post. Retrieved from https://www.washingtonpost.com/apps/g/page/national/thehealth-hazards-of-sitting/750/.

Blaze Carlson, K. (2012, December 21). Organized religion on the decline? Growing number of Canadians 'spiritual but not religious. The National Post. Retrieved from http://news. nationalpost.com/holy-post/organized-religion-on-the-decline-growing-number-ofcanadians-spiritual-but-not-religious.

Body Blitz Spa. (2014). The Waters. Retrieved Janurary 10 , 2016 , from Body Blitz Spa: Health by water: https://bodyblitzspa.com/index.php/water-circuit

Boettger, T. (2014). Threshold Spaces: Transitions in Architecture. Analysis and Design Tools. Birkhäuser.

Bushak, L. (2015, December 11). A Brief History Of Bathing: The Importance Of Hygiene, From Ancient Rome's Sophisticated Showers To The Modern Day. (Medical Daily) Retrieved 02 11, 2016 , from http://www.medicaldaily.com/brief-history-bathingimportance-hygiene-ancient-romes-sophisticated-showers-modern-364826

Cameron, C. (1775). The Baths of the Romans with remeasure restoration drawings of Palladio. London.

Casey, E. (2013). The Fate of Place. University of California Press.

City Life Church. (2015). Water Baptism. Retrieved from City Life Church: https://www.citylife. church/baptism/. 
Cohen, N. (1999). Urban Conservation. Cambridge, Massachusetts, United States: The MIT Press.

Cullen, G. (1995). Concise Townscape. New York, NY: Routledge.

Dori Stories. (2007). Memorial to the Murdered Jews of Europe. Retrieved 2015, from http:// www.dori-stories.com/

Eisenman, P. (2005, 05 31). Memorial to the Murdered Jews of Europe, Berlin. Retrieved from Frontline: http://www.pbs.org/wgbh/pages/frontline/shows/germans/memorial/ eisenman.html

Fikret, Y. (1992). Bath and Bathing in Classical Antiquity. The MIT Press.

Fisher, S. (2015, 09 09). Philosophy of Architecture. Retrieved 11 16, 2015, from Stanford Encyclopedia of Philosophy: http://plato.stanford.edu/

Gray, M. (2016). Bath. Retrieved from Sacred Sites: https://sacredsites.com/europe/united_ kingdom/bath.html

Heidegger, M. (1971). Building. Dwelling. Thinking. Harper \& Row.

Heise, J. (2007, February 8). A Short History of Bathing before 1601. Retrieved from http:// gallowglass.org/jadwiga/herbs/baths.html

Ingraham, P. (2015, 11 04). Contrast Hydrotherapy. Retrieved 02 04, 2016, from Pain Science: https://www.painscience.com/articles/contrasting.php

Janus. (2015, 11 21). Crystalinks Metaphysics and Science Website. Retrieved from http://www .crystalinks.com/janus.html

Joedicke, J. (1985). Space and Form in Architecture. Karl Krämer Verlag.

Kahn, L. (1971). Transcribed from the documentary 'My Architect: A Son's Journey by Nathaniel Kahn'. Master class at Penn, 2003.

Kenoyer, M. (1996). "Great Bath" Mohenjo-Daro. (O. Khan, Editor) Retrieved from Harappa.com: https://www.harappa.com/slide/great-bath-mohenjo-daro-0

Koetter, F. (1980). Notes on the In Between. Harvard University Press.

Kroll, A. (2010, 11 25). AD Classics: Jewish Museum, Berlin / Daniel Libeskind. Retrieved 1121 , 2015, from ArchDaily: http://www.archdaily.com/91273/ad-classics-jewish-museumberlin-daniel-libeskind

Kroll, A. (2011, 02 11). AD Classics: Barcelona Pavilion / Mies van der Rohe. Retrieved 1004 , 2015, from ArchDaily: http://www.archdaily.com/109135/ad-classics-barcelonapavilion-mies-van-der-rohe

Kuehn , R. (1992). A Place for Baptism. Chicago: Archdiocese of Chicago.

Le Corbusier. (1999). Le Corbusier Talks with Students. Princeton Architectural Press.

Le Corbusier. (2014, 12 26). Le Corbusier, plans. Retrieved 11 14, 2015, from medienarchitektur: http://www.medienarchitektur.at/architekturtheorie/le_corbusier/2011_corbusier_links_de.shtml

Leach, N. (2006). Camouflage. The MIT Press.

Lefebvre, H. (1991). The Production of Space. Blackwell.

Leyden, K., Goldberg, A., \& Michelbach, P. (2011). Understanding the Pursuit of Happiness in Ten Major Cities. Urban Affairs Review, 861-888. 
Liminal. (2015). (Merriam-Webster, Producer) Retrieved 10 25, 2015, from Merriam-Webster Online: http://www.merriam-webster.com/dictionary/liminal

Liminality. (2009). OED Third Edition. (O. U. Press, Producer) Retrieved 11 17, 2015, from Oxford English Dictionary Online: http://www.oed.com/view/Entry/248158? redirectedFrom=liminality\#eid

Lynch, K. (1960). The Image of the City. Cambridge, Massacheses: The MIT Press .

Marc Antonio Architects. (2010, January 18 ). Natural Laws of Architecture - The Elevation. Retrieved November 5, 2015, from Marc Antonio Architects Blog : marcantonioarchitects.com/natural-laws-of-architecture-the-elevation/

Meiss, P. (1990). Elements of Architecture: from Form to Place. London, EN: Routledge.

Meslin, M. (2005). Encyclopedia of Religion. Retrieved from http://www.encyclopedia.com/article1G2-3424500306/baptism.html

myetymology. (2016). Thermae. Retrieved from http://www.myetymology.com/latin/thermae.html

Norberg-Schulz, C. (1980). Genius Loci: Towards a Phenomenology of Architecture. Rizzoli.

Oppenheimer, M. (2014, july 18). Examining the Growth of the 'Spiritual but Not Religious'. The New York Times. Retrieved from http://www.nytimes.com/2014/07/19/us/examiningthe-growth-of-the-spiritual-but-not-religious.html?_r=0

Oxford University Press. (2016, March). trans-, prefix. Retrieved Janurary 25, 2016, from OED Online: http://www.oed.com/view/Entry/204575?

Pallasmaa, J. (2012). The Eyes of Skin: Architecture and the Senses (Vol. Third Edition). Wiley.

Plantinga, A. (2007). Religion and Science. Stanford Encyclopedia of Philosophy, Spring 2014 Edition. Retrieved from http://plato.stanford.edu/entries/religion-science/

Pokhilko, A. (24, March 2004). The Meaning of Water in Christianity. Retrieved from http://www. orthodoxytoday.org/articles4/PokhiltoWater

Ponto, J. (2010, May 4). How Long is Now? Retrieved 11 15, 2015, from Jodie ponto Photo Blog: http://jodieponto.com/photoblog/2010/05/04/how-long-is-now/

Rabbi Hammer, Jill. (2015). Rising from the Ritual Bath. Retrieved 12 02, 2015, from Ritualwell Tradition and Innovation: http://www.ritualwell.org/ritual/rising-ritual-bath

Raymond Allchin, F. (2016, 03 01). Encyclopedia Britannica. Retrieved 03 17, 2016, from Bhārat; Bhāratavarsha; Republic of India : http://www.britannica.com/place/India/ Developments-in-the-Ganges-basin\#ref485020

Roman Baths, B. (2016). Roman Bathing Complex. Retrieved from http://www.romanbaths.co.uk/ roman-bathing-complex

Row, C., \& Koetter, F. (1984). Collage City. Cambridge, Massachusetts: The MIT Press.

Sadler, S. (1999). The Situationist City. Cambridge, Massachusetts: MIT Press .

Salat, S., Labbé, F., \& Nowacki, C. (2011). Les villes et les formes: Sur l'urbanisme durable. Paris: Hermann.

Sigfried, G. (1967). Space, Time and Architecture: The Growth of a New Tradition (5th ed., rev. and enl. ed.). Harvard University Press. 
Sion, B. (2015). Memorials in Berlin and Buenos Aires: Balancing Memory, Architecture, and Tourism. London, England: Lexington Books.

Sitte, C. (1889). City Planning According to Artistic Principles. London: Phaidon Press.

Slonim, R. (1996). Total Immersion: A Mikvah Anthology. J. Aronson. Retrieved from http://www. chabad.org/theJewishWoman/article_cdo/aid/1541/jewish/The-Mikvah.htm.

Smith, V. (2007). Clean, A History of Personal Hygiene and Purity. New York : OUP Oxford.

Space. (2015). (Merriam-Webster, Producer) Retrieved 10 25, 2015, from Merriam-Webster: http://www.merriam-webster.com/dictionary/space.

Stones of the Bible. (n.d.). Retrieved from http://www.s-studies.0catch.com/Stones/Stone\%20 Study\%204.htm

The Therme Vals / Peter Zumthor. (2009, 02 11). Retrieved from ArchDaily : http://www.archdaily. com/13358/the-therme-vals

Thermae. (2016). Retrieved from Myetymology Resources and Information: http://www. myetymology.com/latin/thermae.html

Thermal springs in Europe. (2016). Retrieved from https://thermalsprings.wordpress.com/ ancient-thermal-baths-and-spa/origin-of-spa/

Tice, J. ( 2005-2016, 10). The Nolli Map and Urban Theory . (U. o. Oregon, Producer) Retrieved 10 06, 2015, from The Nolli Map Website : http://nolli.uoregon.edu/urbanTheory.html

Trancik, R. (1986). Finding Lost Space. New York : Van Nostrand Reinhold Company.

"trans-, prefix.". (2016, March). (O. U. Press, Producer) Retrieved Janurary 25, 2016, from Oxfor English Dictionary Online: http://www.oed.com/view/Entry/204575?

Tschumi , B. (1981). Manhattan Transcripts. London, EN: Academy Editions.

UNESCO. (2006). Water and World Views: Water, religions and beliefs. Retrieved from World Water Day 2006: Water and Culture: http://webworld.unesco.org/water/ wwd2006/world_views/water_religions_beliefs.shtml

Upinder, S. (2008). A History of Ancient and Early Medieval India: From the Stone Age to the 12th Century. India: Pearson Education.

Van Gennep, A. (1961). The Rites of PAssage. University of Chicago Press.

Van Tubergen, A., \& van der Linden, S. (2001). A brief history of spa therapy. The Eular Journal Annals of the Rheumatic Diseases. Retrieved from http://ard.bmj.com/ content/61/3/273.full\#R2

Venturi, R. (2002). Complexity and Contradiction in Architecture. New York, New York: The Museum of Modern Art.

Vitruvius Pollio, M. (2009 ). Ten Books on Architecture: de Architectura. London .

W. Turner, V. (1967). The Forest of Symbols: Aspects of Ndembu Ritual. Ithaca, N.Y.: Cornell University Press.

Zumthor, P. (2003). Atmospheres: Arcthiectural Environments | Surrounding Objects. Basel: Birkhauser.

Zumthor, P. (2010). Thinking Architecture (Vol. Third Edition ). Basel, Switzerland: Birkhauser. 


\section{APPENDIX A}

\section{The Thermae: case studies - Baths of Caracalla}

Occupying an area of roughly 120,000 sq m, the Baths of Caracalla were the 2nd largest and best preserved thermae in Rome. Built between 212 and 219 A.D., the Baths of Caracalla were estimated to be able to seat 1,600 bathers at one time. Despite its large size, in plan the Caracalla baths display fluidity and simplification in their arrangement. The plan is centralized by the crossing of two main axes, a short north-south governed by the notatio, frigidarium, caldarium $(C, F, N)$ crossed by the long east-west axis where the palestrae (B) are located on either side of the short axes (see Figure 10.1)

There baths can be accessed through four main entrances from the north. Two entrances bring one into a hall which serves as a primary entrance orienting people and framing wanted views into the complex. This entrance hall is adjacent to the $\mathrm{N}$-natation on either side and to the apodyterium - which was perceived as a twostory room. Interestingly, the entrance hall provided views into $\mathrm{N}$ yet did not allow direct access which was screened off by colonnades. The other two entrances go into a triple height reception space which is a barrel-vaulted vestibule (d) separated by columns framing views into the palestra and adjacent spaces. The grandiose mass of this bathing complex required many circulation preparation rooms which allowed for further hierarchy division (see Figure 10.1). Some of these halls (like hall $\mathrm{m}$ ) were two stories high and utilized controlled lighting from the ceiling. The Caldarium (hot water pool) had a monumental circular diameter of $35 \mathrm{~m}$ and projected from the regulated plan. Being the hottest room, it was located on the southwest side of the complex and protruded in order take full advantage of the sun. roofed by a concrete dome, similar to the Pantheon dome but with series of arched windows, the thick walls of the Caldarium were relieved by niches surrounding the pools and providing moments that were smaller in scale for bathers within the room. One of the niches on the north-south axes also provided vision and access into the tepidarium. The central niche 

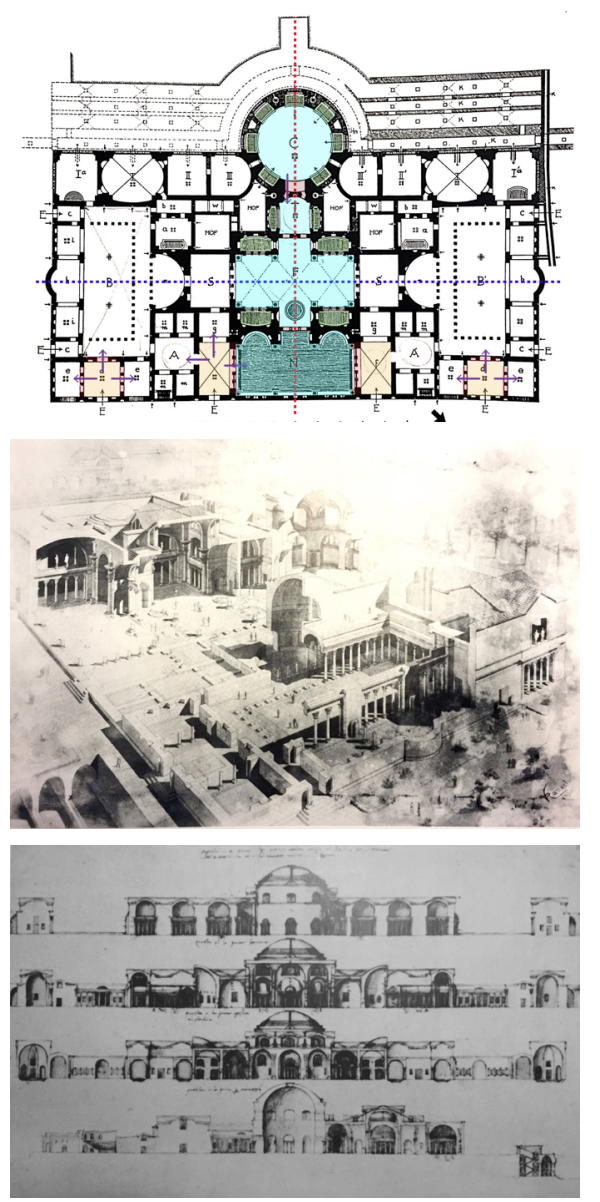

Figure 10.1 (top): Baths of Caracalla, restored perspective, sections and facades. then opens up again into the frigidarium through two columns suggesting wanted movement into this space. (Fikret, 1992, pp. 146-162).

There baths can be accessed through four main entrances from the north. Two entrances bring one into a hall which serves as a primary entrance orienting people and framing wanted views into the complex. This entrance hall is adjacent to the $\mathrm{N}$-natation on either side and to the apodyterium - which was perceived as a twostory room. Interestingly, the entrance hall provided views into $\mathrm{N}$ yet did not allow direct access which was screened off by colonnades. The other two entrances go into a triple height reception space which is a barrel-vaulted vestibule (d) separated by columns framing views into the palestra and adjacent spaces. The grandiose mass of this bathing complex required many circulation preparation rooms which allowed for further hierarchy division (see Figure 10.1). Some of these halls (like hall $\mathrm{m}$ ) were two stories high and utilized controlled lighting from the ceiling. The Caldarium (hot water pool) had a monumental circular diameter of $35 \mathrm{~m}$ and projected from the regulated plan. Being the hottest room, it was located on the southwest side of the complex and protruded in order take full advantage of the sun. roofed by a concrete dome, similar to the Pantheon dome but with series of arched windows, the thick walls of the Caldarium were relieved by niches surrounding the pools and providing moments that were smaller in scale for bathers within the room. One of the niches on the north-south axes also provided vision and access into the tepidarium. The central niche then opens up again into the frigidarium through two columns suggesting wanted movement into this space. (Fikret, 1992, pp. 146-162).

\section{The Thermae: case studies - Old Baths of Pompeii}

The Pompeii Old Baths represents the asymmetrical category of the Roman baths types. The asymmetrical layout usually represented smaller bathing establishments which spread around cities. This asymmetrical type was an early way of planning baths, and usually involved baths arranged in a row 
barrel vaulted halls adjacent to a colonnade exercise court/ This is what is often referred to as the Pompeian type. The earliest example dates back to circa 2nd century A.D. and is known as the Stabian Baths in Pompeii. Later, this layout was also used in houses or villas which had baths (Fikret, 1992, p. 3).

Pompeii offers a glimpse into early examples of a mediumsize bath house combined with the palaestrae known as the exercise room. All bath houses in Pompeii were fully integrated into the city blocks, and bordered with other programs like shops. This early bath house created a clear separation of zones between the two functions - the baths and the exercise room. The palaestrae zone included the exercise room, a party room and supporting rooms. The bathing zone included a series of independent vaulted, parallel, rectangular rooms as well as their service spaces (see Figure 10.2). There was also a Laconicum - sweat room incorporated within these and differentiated in shape from the baths rooms, as it was usually a small circular-domed chamber. The Stabian baths were also known for adding a destrictarium - a room for people to scrape off all oils and sweat (see Figure 10.2). The main entrances were usually from the exercise room, although there was a secondary entrance leading from the street to the baths. Baths were divided between men and women with the heating amenities separating the two. A secondary service corridor ran behind the bathing block separating it from the street.

The Stabian baths were an important departure point in bath planning as they represented a logical and functional sequence of usage in a straight sequence representing the actual usage. This arrangement, known as the single axis row type in bath planning, was extremely useful in the preservation of heat (as one moved from cold to hot) and efficient in its organization. Water supply, drainage and heating facilities were also extremely well thought through in the planning, and were located in a single corridor between the women's and men's' bathing facilities. Barrel-vaulted rooms often utilized the ends of the rooms for
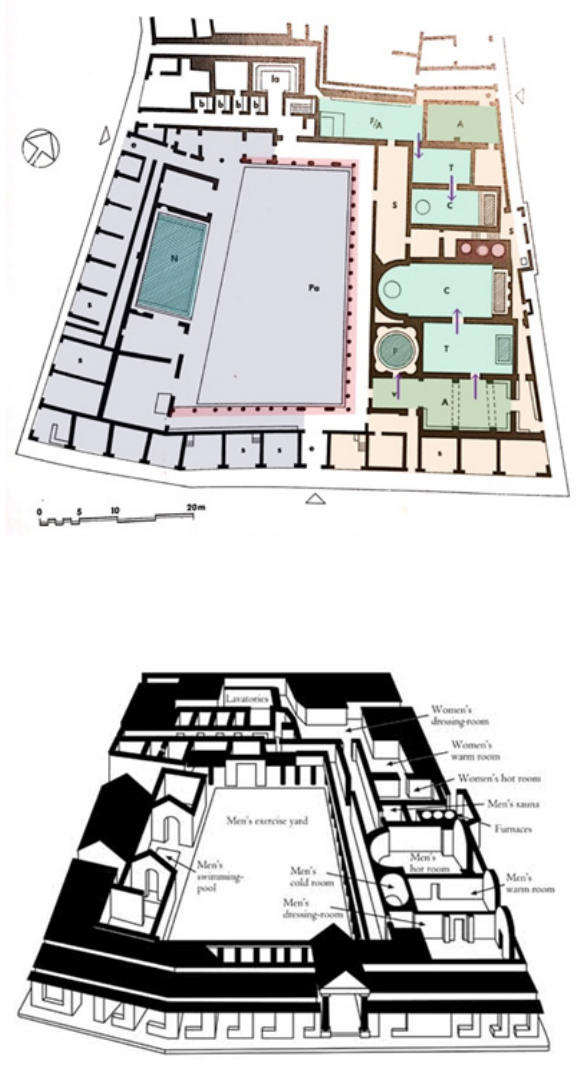

Figure 10.2 (top): Stabian Baths, Pompeii overlay spatial analysis

Figure 10.3 (middle): Typical Roman bath house layout 
niches or aps for sitting or for bringing in controlled indirect daylight.

Aquae Sulis, located in the city of Bath, in what is present-day England, was a prominent example of the Roman bathing culture and stands as an example for the benefits of thermo-mineral bathing. Curative bathing, and the importance of thermal baths and its therapeutic qualities, were proved by ancient literature and epigraphical sources (Fikret, 1992, p. 92). Thermal baths are different than the artificially heated ones due to their relative isolation outside of major towns and ease of access.

Curative bathing is highly influenced by the natural source it is supplied by - by the quality of the water, natural heat, mineral content, electricity and radioactivity. In addition to its previously stated religious associations, water was proven to cure problems connected to the liver, kidneys and digestive tract. Thermal water was believed to be especially effective against muscular pains, rheumatism and arthritis (Fikret, 1992, p. 93). Vitrivius devoted a whole chapter to the properties of water in his Book Eight, and according to him, "Every hot spring has healing properties because it has been boiled with foreign substances, and thus acquires a new useful quality. For example, sulphur springs cure pains in the sinews, by warming up and burning out the corrupt tumours of the body by their heat. Aluminous springs, used in the treatment of the limbs when enfeebled by paralysis or the stroke of any such malady, introduce warmth through the open pores, counteracting the chill by the opposite effect of their heat, and thus equably restoring the limbs to their former condition. Asphaltic springs, taken as purges, cure internal maladies." (Vitruvius Pollio, 2009 , pp. , book VIII)

At its peak, Aquae Sulis was one of the most popular curative centres. Strong linkage to the worshipping the Celtic god Sul is associated to this site, reinforcing water's connection and role to spirituality and religion. While thermal waters were first used for their curative powers during the Iron Age (circa 1200 B.C.), 
architectural development by the Romans took place around 1st century A.D. Aquae Sulis was supplied water by the adjacent hot mineral spring which was at a constant temperature of 49 degrees $\mathrm{C}$ and by regular water sources through pipes. The water was declared sacred soon after its discovery, where the ya shrined to the Sulis, a goddess of water. The Romans later identified Sulis with the goddess Minerva as a healing deity. The natural springs were much more than a source of hot water to the Romans who considered them a sacred place where assistance and communication with the deities and mortals could take place (Gray, 2016).

While the Bath complex went through many changes over time, its planning principles are organized through a simple arrangement which has remained constant to this day. Its planning was revolved around an east-west axis where two artificially heated zones were located on either side of the 'Great Bath' (see Figure 10.4). The 'Great Bath' was the thermal water bath getting is the thermal water bath getting its water from the water from the spring located in its northwest. The 'Great Bath', $8.9 \times 9 \mathrm{~m}$ and 1.56 deep, was given the most importance and prominence of all other programs in the complex. Access into the baths was by way of four steep steps entirely surrounding the pool. It was its own 'great' hall centralized and allowing access to all other secondary areas within the complex. This was a spacious hall, which encouraged lounging in one of the rectangular and semicircular niches along its walls. There were two thermal water supplied baths -- the central 'Great Bath' maintained at $45 \mathrm{C}$ and the 'Lucas Bath' directly east of the Great Bath and feeding from it at a cooler runoff temperature. The 'Great Bath' hall was almost reminiscent of a basilica in its two rows of square piers supported looking like an arcade. Later these columns carried a barrel vault over the pool, which represented the nave, allowing controlled lighting through its roof. (Fikret, 1992, p. 119)

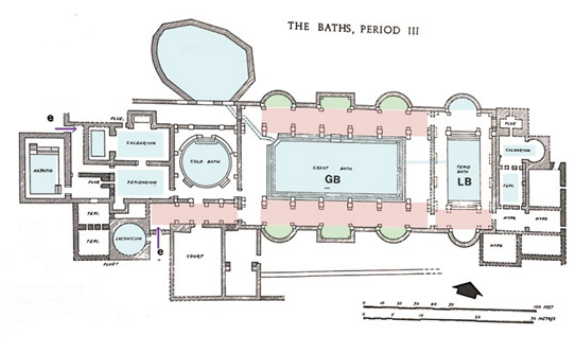

As a bathing facility, Aquae Sulis allowed visitors a variety

Figure 10.4 (top): Thermal Baths, Aquae Sulis, Bath, overlay spatial analysis 

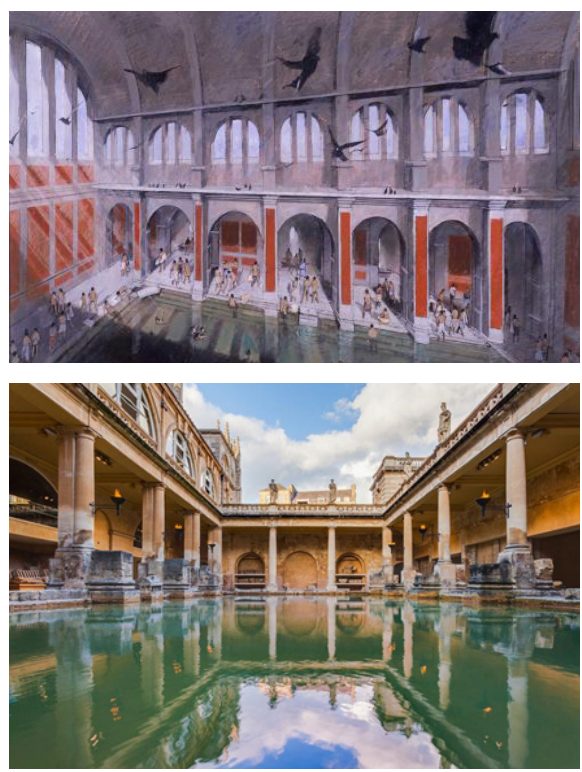

Figure 10.5: Image of what bathing could have been like in the Great Bath Hall in early years and what it looks like today of bathing choices. Entrance was from the southwest and northwest, giving the visitor the choice of either going directly to the 'Great Bath' or starting from the smaller pools that were artificially heated. People could also combine two modes of bathing, regular and thermal, in any order they wanted or as their doctor recommended. It was also likely that there were two individual treatment rooms to the west of the Laconicum (Fikret, 1992, p. 119).

With the decline and fall of the Roman Empire in the 5th century and the beginning of the Dark Ages and Byzantine period, Christianity started taking on a much more centralized role. The Catholic Church adopted a more opinionated position on bathing. It rejected Roman values yet was careful about totally rejecting bathing. Devil-like and pagan associations were being made with bathing. The church was highly opposed to the luxury and obsession with the body and soul that bathing evoked. It preached in favour of modesty, frugality and self-denial. The only way the church would accept bating was if luxury and pleasure were removed and bathing would remain solely a functional, hygienic and medicinal activity. Despite this, beliefs about bathing remained fragmented. Other developments, such as invasions, wars and internal events, led to a further decline of the Greco Roman World, resulting in abandoned water supplied from cities, towns destroyed and bath houses repurposed. By 700. A.D., bath houses still existed, despite disapproval from the Catholic Church and remained the social centres that they once were. Some bathhouses gained a reputation for being similar to brothels, where people engaged in sexual acts.

Interestingly, the Black Plague during the 14th century (13401350 A.D.), changed popular European views of bathhouses. Hygiene as a scientific and medical response was not proven and bathing up until this point was done mostly for bodily, religious or spiritual connectivity. Doctors believed that pores opened by the heat of the water would allow more illness to enter their body, and were under the impression that complete 
filth and dirt could block disease. Coupled with this, the Christian Church's views began to be more widely accepted, as bath house were increasingly depicted as places of sin. From then on, the practice of bathing practically disappeared and so did the existence of public bath houses.

People actually believed that having dirt all over their bodies could prevent disease. This view was also backed by the church's disapproval of pubic bathhouse which they regarded as places of sin where nudity could lead to sexual acts. From this point on, bathing as a communal act became rarer as people bathed privately according to their wealth level, if at all. The importance of bathing and hygiene as a measure of better health and serving medical purposes only began to reappear in the 18th century along with the age of enlightenment. The idea of water as a therapeutic and hygienic component also began during this time and the term hydrotherapy was conceived to describe therapies based on the use of water. "Hydropathy stressed the benefits of cold water both for drinking and for bodily applications, and the benefits of personal habits for prevention and healing" (Barrick, Rader, Hoeffer, \& D. Sloane, 2008, pp. 11-14). Different health conditions were being recognized and appropriate baths were recommended. In the mid-19th century, cleanliness was increasingly seen as part of cultural ideals associated with good health and gentility. Soap, plumbing and the manufacturing of bath tubs became a huge business and municipal water systems were being constructed. New commercial bathhouses began offering middle and upper classes different types of bath options.

The ancient Greeks were the pioneers of what we would now consider the modern shower. The idea of the mechanical shower as we know it today was first invented in England in 1767. After understanding the importance of hygiene and the medical value of bathing as a means for sanitation and preventing disease, the first public modern baths opened in England in 1829. In fact, from this point in history on, the importance and stress over 

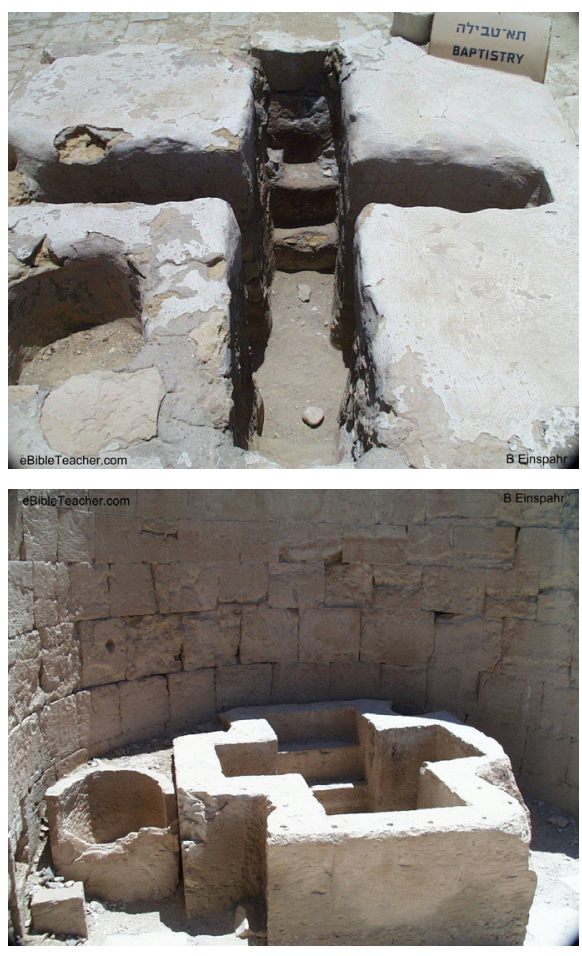

Figure 10.6: Cross-shaped fonts in early Christian baptisteries located in Avdat, and Mamshit/Mampsis personal hygiene as a means to achieving purity and cleansing entered society norms. While bathing today is an act that is done privately, bathing and hygiene have retained their social status symbolizing a transformation from dirt to purity. The importance of bathing as a transformative activity has retained its importance till this day. The modern-day spa attempted in a way to replace the old Roman bathing house or Turkish baths as the centre of social and public life.

\section{APPENDIX B}

\section{Immersion in religion; Christianity}

Baptism originates from the Greek work baptein, meaning plunge, to immerse or to wash. During the Homeric (1200 B.C.) period and on, the term literally referred to a rite of immersion in water (Meslin, 2005). Water is central to religious life in almost all Christian churches and sects and is described as being involved in initiation rituals. Symbolizing life, cleansing or purification, it has particular importance in the Old Testament and also later in the New Testament. Alexander Pokhilko describes the meaning of water as both significant and symbolic in Christianity by means of the following quotes from the Old and New Testament,

\footnotetext{
"Water was created on the first day (Genesis 1:2, 6-8). The Spirit of God was hovering over the face of the waters (Genesis 1:2). The earth was founded upon the waters (Genesis 1:6-7, 9-10). God commanded the water to bring out an abundance of living souls (Genesis 1:20-21). God is compared with the rain (Hosea 6:3). Water brings life (cf. Exodus 15:23-35; 17:2-7; Psalms 1:3; 22:2; 41:2; 64:10; 77:20; Isaiah 35:6-7; 58:11) and joy (Psalm 45:5). It is a powerful purifying element and can destroy evil and enemies as in the stories of the Flood and the flight of Israel from Egypt (Genesis 3:115; Exodus 14:1-15:21)" (Pokhilko, 24)
}

From the very beginning in the Old Testament, Christians are taught to believe that water is a mystical powerful force which is connected to God in some way. It is supposed to have ways of cleansing sins, inner and outer defilement, and regenerate the human body. Water is also described as having a mysterious connection to the Holy Spirit, perhaps as a symbol of giving life or a form of rebirth. Most streams of Christianity use water for 
initiation rituals. Baptism, originated in the symbolism of Moses leading the Israelites from slavery in Egypt through the Red Sea, and of course from Jesus's baptism by John the Baptist in the Jordan River. After Jesus's resurrection, he commanded his disciples to baptise in the name of the Father, Son, and Holy Spirit (Matthew 28:19-20). So Baptism became a symbol of Christ's burial and resurrection.

Baptism, a sacrament of admission and public deceleration has slight differences between Christian dominations. Yet the overall consensus is that it stands as a symbol of proximity of God, a liberation from the domination of a sin, the profane that separates us from God (Abrams, 2001)

רาר

The symbolic value of water is important for cleansing the profane and dirt away. Anywhere water will enter or touch will be as if it was directly filled by God, just as man needs water to survive physically, he needs it to survive spiritually. One's entrance into the water during baptism identifies one with Christ's death on the cross, his burial in the tomb, and his resurrection from the dead. "... Christ died for our sins according to the Scriptures, that he was buried, that he was raised on the third day according to the Scriptures." (Corinthians 15:3-4) (City Life Church, 2015).

The early form of baptism among the earliest Christians involved either immersion, referring to a total submersion in water, or a partial one, which involved kneeling in water while water is being poured over one's upper body. Other forms involve affusion or aspersion. Affusion refers to pouring water on one's forehead three times and aspersion refers to only the sprinkling of water on the head (Abrams, 2001). Earliest forms of baptism involved immersion in fonts and were designed for full immersion. Later versions included smaller fonts using the non immersion methods, Affusion or Aspersoin using fonts that were essentially holders of a basin of water. These fonts were usually placed near or at the entrance to the church's nave as a token of reminder of baptism.
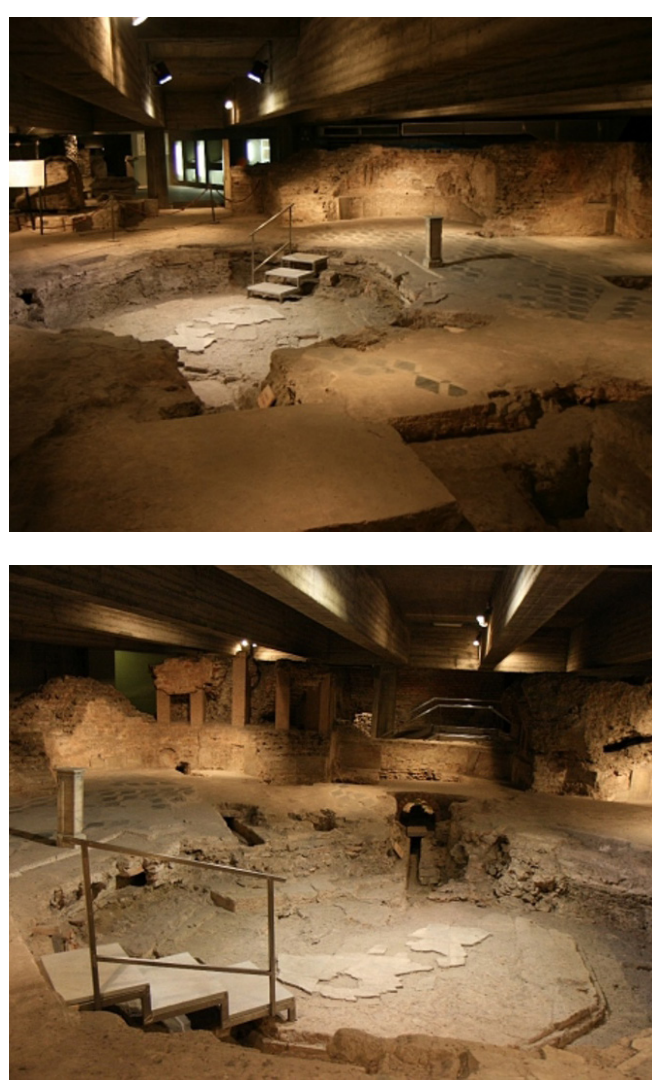

Figure 10.7 : 4th century A.D. Battistero Paleocristian, early Christian baptistery which was located under Milan's Duomo. Octagonal baptismal font was surrounded with radiating apses, and traces of the canals that used to feed it with water 
To administrate the process of Baptism, Christians use Baptisteries which were small chapels or portions of the church where baptism would take place, usually located next to the entrance of the church. Historically, Baptisteries first started to appear when adult baptism was practiced and immersion was a rule. Evidence of the first ones dates back to around 4th century A.D. Architecturally, as a building type, Baptisteries usually had a circular or polygon shape (rectangular forms were relatively rare). An octagon was usually utilized due to the number 8's symbolism in Christianity representing eternity and rebirth. It also symbolized the day Christ rose from the dead after seven days of the world's creation (Baptistery, 2015).

Ahighly intimate hierarchy of space was utilizedinvolving recessed surrounding walls supported with columns and culminating with a domed roof. Baptisteries were planned directly upon the centrality of the baptismal font. The font usually incorporated three steps (for the holy trinity) to its floor and early designs were often as cross-shaped. This font could essentially be a manmade tank, pool or a natural body of water (river or lake) where the entire body is immersed, dunked, submerged under water to symbolize the death of sin, of profane and rejuvenation into purity. Immersion in water is repeated depending on each sect of Christianity of tradition. For example, the Eastern Orthodox Church practices full triple immersion. (Baptistery, 2015)

\section{Judaism}

Water is central to Jewish law and ritual life as it restores or maintains ritual purity. Some perceive much of water's reference in the Torah as direct symbolism to his presence. Judaism incorporated two main ablution rituals, tevilah referring to full body immersion done in 'living water' (sea, a river, a spring or in a mikveh), and netilat yadayim referring to washing the hands. Whenever mentioned in the bible, it symbolizes flow, lovingkindness, intimacy, transformation, nurturance, abundance and prosperity or even referring to God as water. The Great 
Flood story in Genesis 6-8, acts as a reminder of the power of water, both physically and spiritually in acting as both a giver of life and its destroyer. The Great Flood was sent by God and destroyed humanity only letting Noah, his family and a pair of each type of animal to survive in an ark. This story emphasized the importance of morality and ethics in the eyes of Gods and how water has the ability to wash away all sins in the world and start anew, similar to Christianity in which the death and resurrection of Christ erased all, allowing nothing in between man and God. Another reference showing how powerful water is, and as an instrument of both reward and punishment used by God is the crossing of the Red Sea and its parting by Moses as a miraculous event to allow the Israelites to escape from the Egyptian army that was chasing them. Here God blessed the Israelites and let them cross, giving them life through water, and punished the Egyptians by letting them drown in the sea (Rabbi Hammer, Jill, 2015) (Alio, 2012)

Originally a priestly practice in ancient times, hand washing continues to this day by non-priests as part of the democratization of this Jewish ritual that started in the Second Temple Period. Hand washing is an act that is done on a daily basis, several times while saying a blessing during the act. It involves a laver which holds the water and assists in pouring water over each hand. This was believed to be the vessel that priests used during the Temple of Solomon in Jerusalem. This act is done with a blessing and a laver when one wakes up in the morning, and before eating bread. The act of hand washing is also customary (but not a ritual) before prayer, when leaving a washroom, when leaving a cemetery, before meal, after touching intimate parts of the body or cutting nails. This act, seemingly mundane and normal, is meant to ingrain the importance of spiritual purity and preparation needed before performing certain acts as normative as they may be, like eating. The symbolism of washing one's hand is meant to add structure, preparation and, in a way, celebration and importance to these acts. In this context, water is seen as the purifying medium to prepare one for this act 
(Rabbi Hammer, Jill, 2015).

Mikveh literally means the gathering of waters and they symbolically refer to the waters of rebirth. These waters date back to ancient Jewish traditions and relate to concepts of taharah purity and tumah impurity. The mikveh was used for temple worship in biblical times - to differ one from being sacred as opposed to profane. The act of ritual purity was done to enable approaching the temple while pure and to be sure profanity was not on you when approaching the temple, and to get rid of any impurity by illness, seminal emission, contact with a corpse, menstruation or childbirth. The mikveh and immersion in its waters are thought to remove the tumah impurity condition and make one pure. Today, the mikveh is used primarily by women after their menstruation cycle (a woman in a state of menstrual "impurity" is called niddah), giving birth or before marriage, by Jewish men to achieve ritual purity, and as part of conversion to Judaism. In the post-temple destruction, purity rituals became more lenient and anyone can approach a synagogue or a Torah even if he/she is ritually impure (Rabbi Hammer, Jill, 2015). Interestingly, building a mikveh takes precedence, according to Jewish law, over building a synagogue. Further, a Torah scroll or a synagogue can be sold to raise money to build one. A group of Jews living in proximity to one another cannot gain a community status if they do not have a mikveh. This shows just how important purity is in Jewish life, as private or communal prayer can be done in virtually any location but mikveh is "the touchstone of Jewish life and the portal to a Jewish future". Mikveh is rooted in and relies on spiritual purity, and relates to a concept that is highly regarded in Jewish life, separation and distinction and they bless God who "separates between the holy and the mundane, between light and darkness, between Israel and the nations, between the seventh day and six days of labor..." Judaism relies highly on the separation and segregation between holy and mundane for concentration (Slonim, 1996).

Figure 10.8: Ortigia, Sicily "In many ways, the mikveh is the threshold separating the unholy from the holy, but it is even 
more. Simply put, immersion in a mikveh signals a change in status - more correctly, an elevation in status. Its unparalleled function lies in its power of transformation, its ability to effect metamorphosis... The individual who descends into the mikveh as a gentile emerges from beneath its waters as a Jew" (Slonim, 1996).

According to Judaism, when the earth was created, at first there was water. It is this extraordinary compound which is a primary source of life and energy that is mirrored spiritually in Judaism as having powers of purification, and rejuvenation.

The mikveh also evokes both the symbols of life and death, more specifically the womb and grave. When people are immersed in the mikveh, they are rendered powerless. They temporarily give up control. They are divested of their autonomy. It's as if the person is demonstrating a desire or willingness to be at one with the source of life and to be united with God. The act of immersion in the mikveh takes on almost an element of rebirth or an embrace of a higher form of existence. As such, its use in the conversion process can be better understood, especially as Jewish tradition sees immersion as offering a gateway to purity connected to the creation of humanity.

Other uses of the mikveh waters involve purifying and immersing new utensils before they are used by a Jew. Interestingly, waters are used in the context of death, where water is poured in a specific manner over the entire body of a deceased before he/ she is buried and his/her soul rise up to heaven. "The mikveh personifies both the womb and the grave; the portals to life and afterlife". (Slonim, 1996)

Architecturally, the Jewish tradition prescribes numerous and complex rules in the construction of a mikveh in order to achieve the power of its purity and holiness. Essentially, any natural body of water - oceans, rivers, wells and spring-fed lakes "are mikvehs in their most primal form". They constitute the waters of a divine source, before earth took its shape. Mikvehs fall under the understanding that many of these natural water sources are inaccessible or hard to reach on a regular basis and
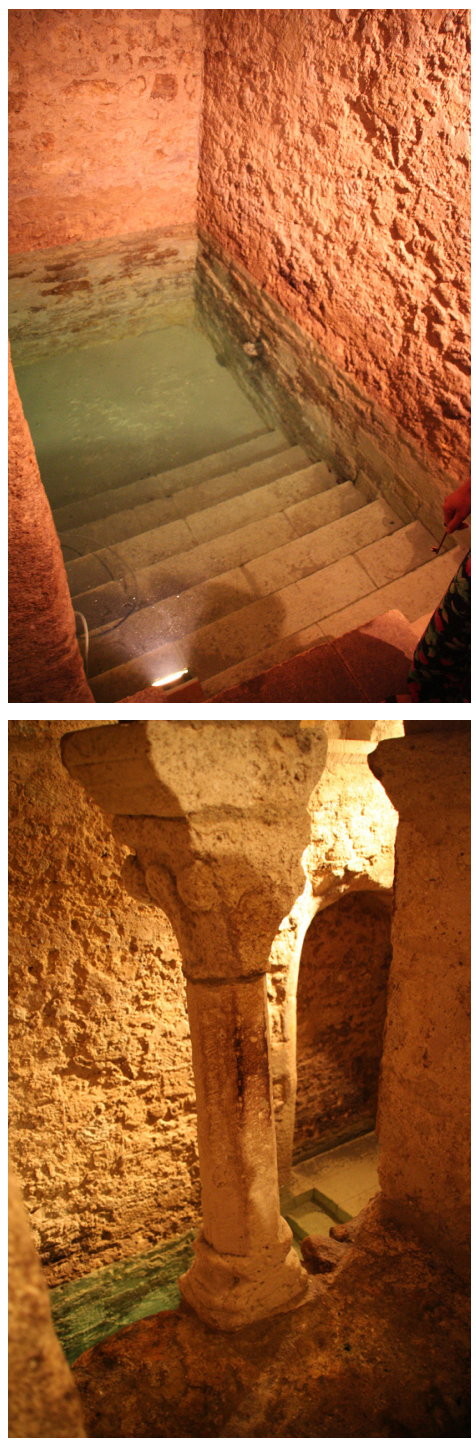

Figure 10.9 (top): Underground mikve connected to water cistern. 
offer little privacy. A mikveh must have a concentration of water that involves at least 200 gallons of rainwater in accordance with strict regulations. Most mikvehs are comprised of several pools which are refilled regularly with tap water and have a free flow of waters between the rain water and tap. The mikveh must be built into the ground and as a purposeful and central part of the building. This is to distinguish it from being an afterthought that is added on in the form of a bathtub or Jacuzzi. The mikveh waters are accessed by syairs and are usually chest-high (roughly 1.1-1.3m) and kept at comfortable to warm temperatures. The mikve never stood as a substitute for a bath or a shower. In fact, Jewish law "stipulates that one must be scrupulously clean before immersing". In facilitating this, mikvehs usually have preparation areas, baths and showers and other cleaning aids as preparation for immersion in the mikveh. Mikvehs in large communities have as many 20-30 preparation areas and two to four immersion pools. (Slonim, 1996) 